\title{
THE NEXT GENERATION ROUTER SYSTEM COOLING DESIGN
}

\author{
A thesis \\ Presented to \\ the Faculty of California Polytechnic State University \\ San Luis Obispo \\ In Partial Fulfillment \\ of the Requirements for the Degree \\ Master of Science in Mechanical Engineering
}

By

Garrett Andrew Glover

2009 
(C) 2009

\section{Garrett Andrew Glover}

\section{ALL RIGHTS RESERVED}




\section{THESIS COMMITTEE}

TITLE: The Next Generation Router System Cooling Design

AUTHOR: Garrett Andrew Glover

DATE SUBMITTED: November 2009

Dr. Jesse Maddren

Committee Chair

Dr. Chris Pascual

Committee Member

Dr. Kim Shollenberger

Committee Member 


\section{ABSTRACT \\ The Next Generation Router System Cooling Design \\ Garrett A. Glover}

Advancements in the networking and routing industry have created higher power electronic systems which dissipate large amounts of heat while cooling technology for these electronic systems has remained relatively unchanged. This report illustrates the development and testing of a hybrid liquid-air cooling system prototype implemented on Cisco's 7609s router. Water was the working fluid through cold plates removing heat from line card components. The water was cooled by a compact liquid-air heat exchanger and circulated by two pumps. The testing results show that junction temperatures were maintained well below the $105^{\circ} \mathrm{C}$ limit for ambient conditions around $30^{\circ} \mathrm{C}$ at sea level. The estimated junction temperatures for Cisco's standard ambient conditions of $50^{\circ} \mathrm{C}$ at 6,000 feet and $40^{\circ} \mathrm{C}$ at 10,000 feet were $104^{\circ} \mathrm{C}$ and $96^{\circ} \mathrm{C}$ respectively. Adjustments to the test data for Cisco's two standard ambient conditions with expected device characteristics suggested the hybrid liquid-air cooling design could meet the projected heat load. 


\section{ACKNOWLEDGEMENTS}

I would like to extend my gratitude to Dr. Maddren and Dr. Pascual for their time and guidance throughout my research. The knowledge I gained and the success I achieved in my research could not have been possible without their continuous support. I would also like to thank Cisco's technical leads, Herman Chu and Joe Russo, for contributing their time and expertise. The following students assisted in the manufacturing and assembly of the prototype: Tres Clemens, William (Rusty) Browning, Brian Wares, Cody Norman. 


\section{Table of Contents}

Table of Tables ..........................................................................................

Table of Figures ...................................................................................

\section{Chapter 1}

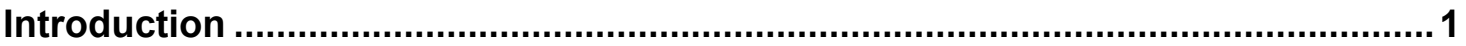

\section{Chapter 2}

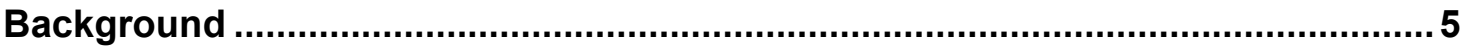

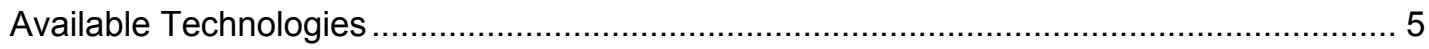

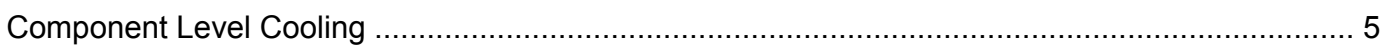

Board and System Level Cooling......................................................................................... 11

Available Technology Summary …………………................................................................ 12

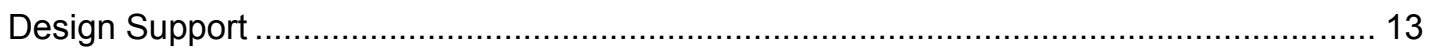

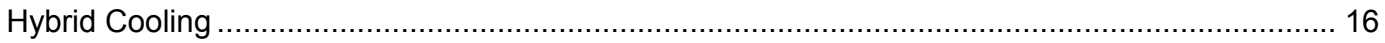

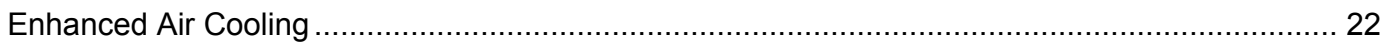

\section{Chapter 3}

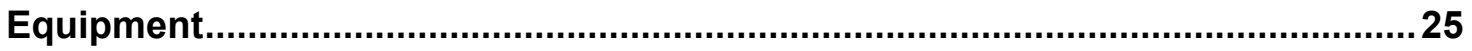

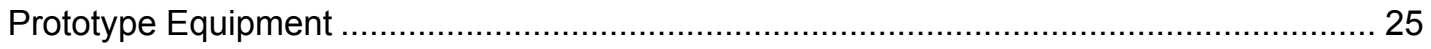

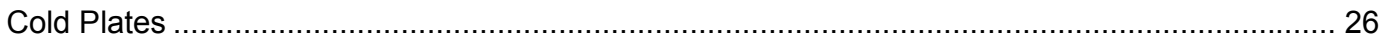

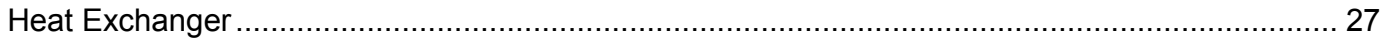

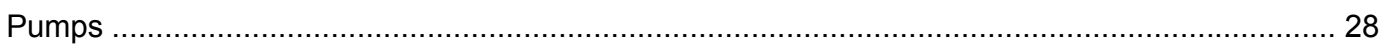

Tubing

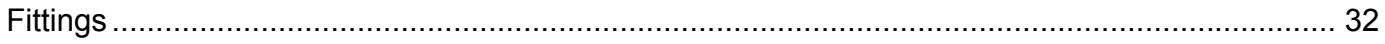

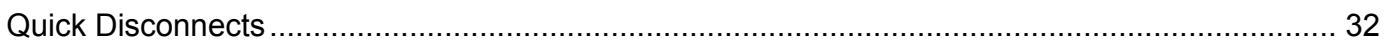

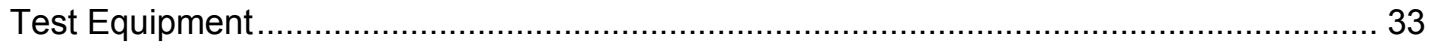

Blower 


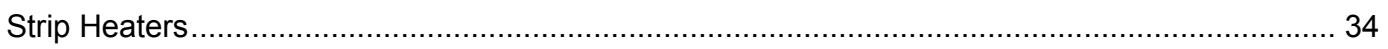

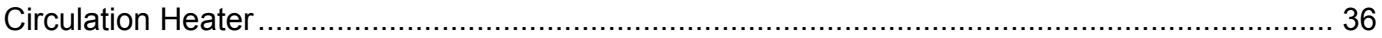

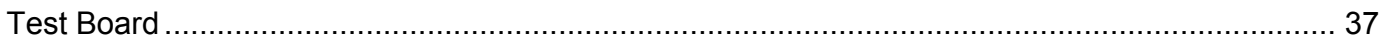

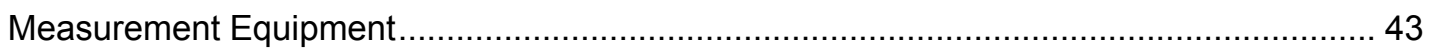

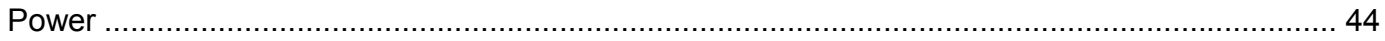

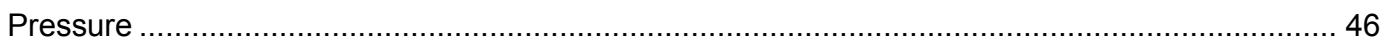

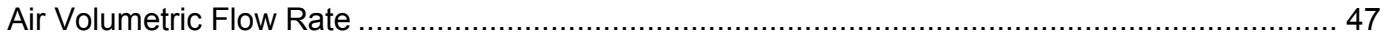

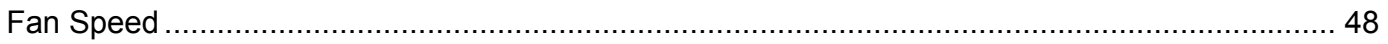

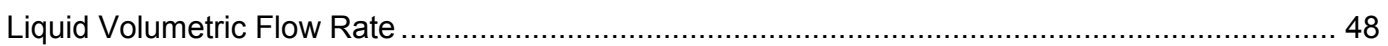

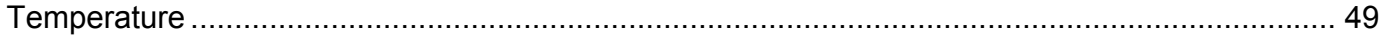

\section{Chapter 4}

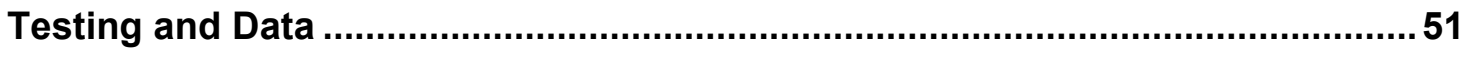

Testing

\section{Chapter 5}

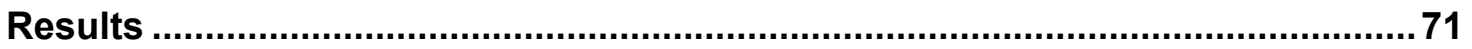

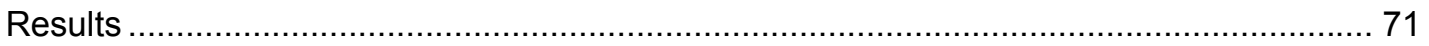

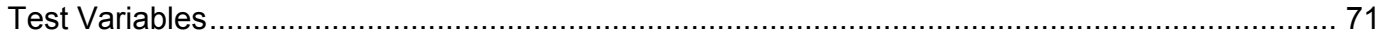

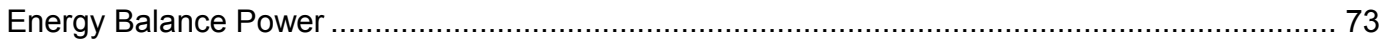

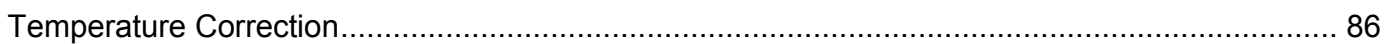

\section{Chapter 6}

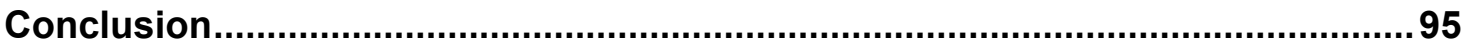




\section{Appendix A}

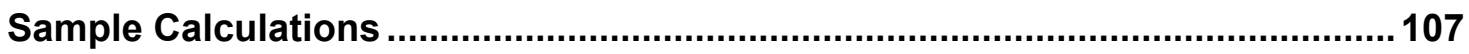

Heat Exchanger Water Power Sample Calculation ................................................... 108

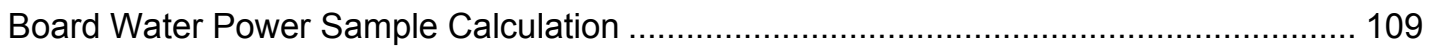

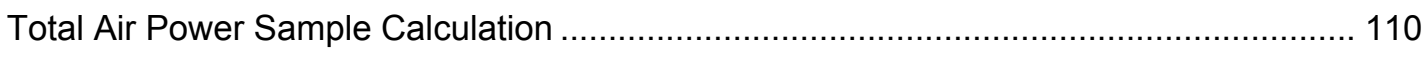

Board Air Power Sample Calculation..................................................................... 112

Board Electrical Power Sample Calculation ............................................................. 114

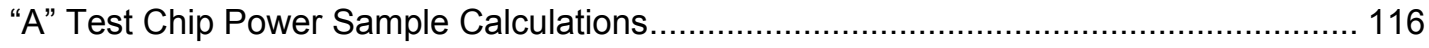

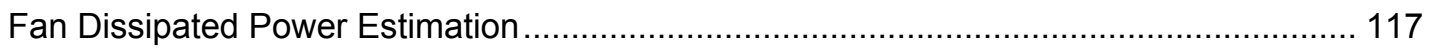

Heat Exchanger Performance Sample Calculations ….............................................. 120

Corrected Fluid Temperature Sample Calculations.................................................... 122

Corrected Junction Temperature Sample Calculations ................................................ 125

Laminar Flow Element Mass and Flow Rate Sample Calculations ................................ 127

\section{Appendix B}

Test Board Specifications

\section{Appendix C}

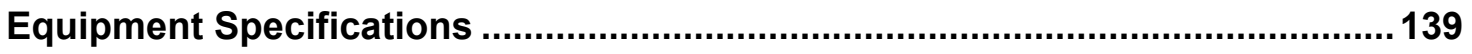

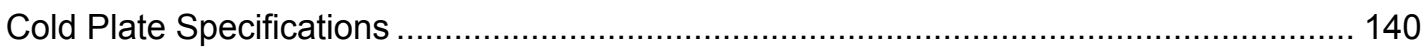

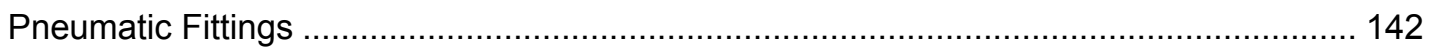

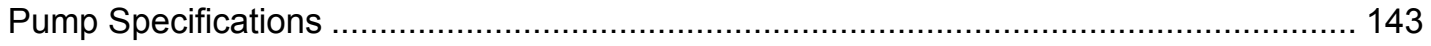

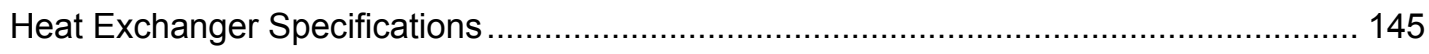

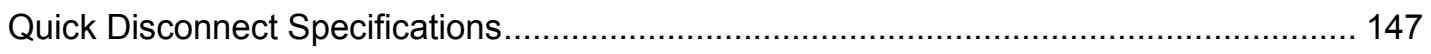

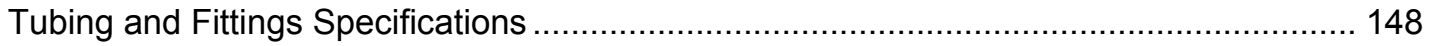

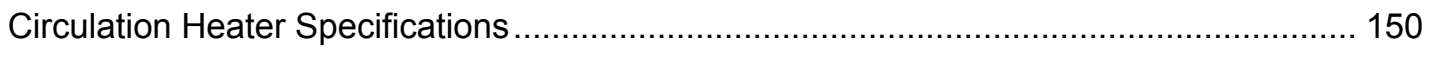

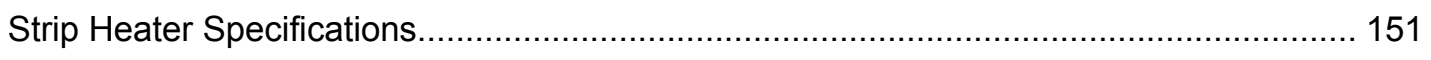




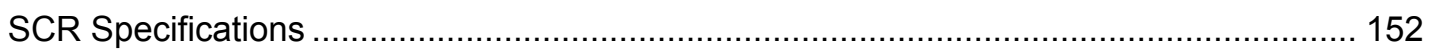

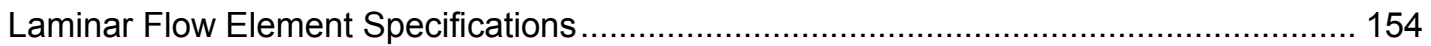

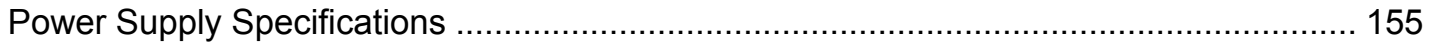

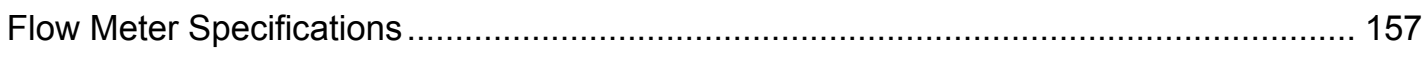

\section{Appendix D}

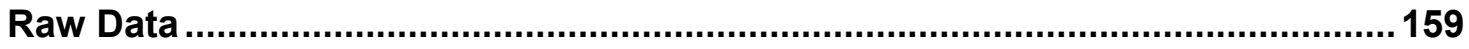




\section{Table of Tables}

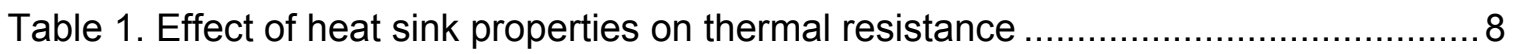

Table 2. Results from Flotherm simulation............................................................ 21

Table 3. Piping diameter and head losses for various liquid velocities ....................... 22

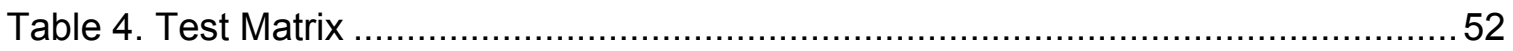

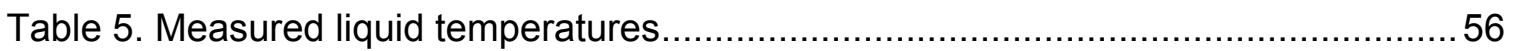

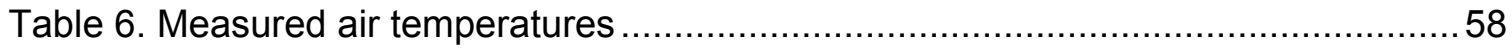

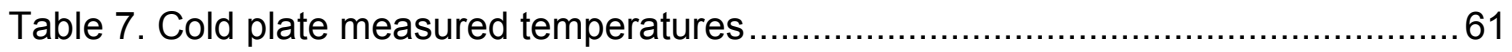

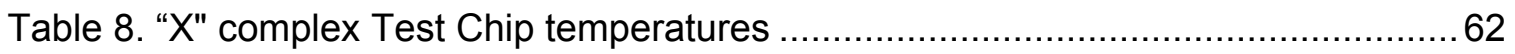

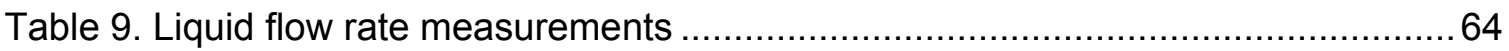

Table 10. Measured pressure drops through router

chassis with corresponding flow rates and fan speeds ............................66

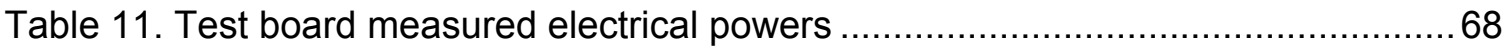

Table 12. System electrical power measurements .................................................. 70

Table 13. Test variables values with junction and cold plate temperatures ...................72

Table 14. Calculated energies transferred to water and air through the system............73

Table 15. Electrical power, including estimated fan power, comparison to air energy balance ........................................ 82

Table 16. Fan power percentage of total system power ............................................ 84

Table 17. System power from pre-heat exchanger air and heat exchanger water compared to total power supplied to system

Table 18. Board power from board pre-heat exchanger air and board water compared to total power supplied to Test Board.......................86

Table 19. Thermal resistance values with case and average water temperatures .........88 
Table 20. Powers and corrected heat exchanger

effectiveness with new water temperatures

Table 21. Adjusted baseline (Test 1) temperatures to Cisco ambient requirements ......91

Table 22. Corrected "A" case and junction temperatures

for Cisco ambient conditions and true product design criteria 92

Table 23. Calculated board electrical power and uncertainty from measured 115

Table 24: Summary of the fan power, efficiencies and air temperature rise for all conducted tests 119

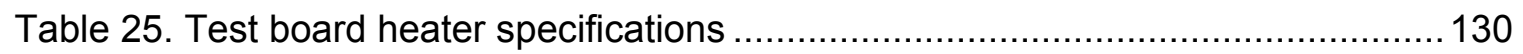

Table 26. Heater groups with measured resistances and calculated powers 131

Table 27. Data acquisition thermocouple temperature readings during testing with calculated properties for system water and air 160

Table 28. Circulation heater power measurements for various PWM input control currents 161

Table 29. Test Chip cold plate thermocouple preliminary test data 162

Table 30. Test Chip temperature sensor preliminary data. 163 


\section{Table of Figures}

Figure 1. Cross-section of typical module

denoting internal and external cooling regions........................................... 6

Figure 2. Simplified cross-sectional view of cold plate ............................................ 16

Figure 3. Percentage of heat transferred to

liquid as a function of average liquid temperature...................................... 17

Figure 4. Schematic of liquid cooling system ……………................................... 19

Figure 5. Simplified schematic of rack with air cooling path.......................................20

Figure 6. Junction temperature as a function of approach velocity

at different mean inlet temperatures (fin pitch equal to $1.25 \mathrm{~mm}$ )..................23

Figure 7. External and internal isometric views of cold plates ………………….......26

Figure 8. Lytron ES0714G liquid-to-air aluminum oil cooler heat exchanger .................28

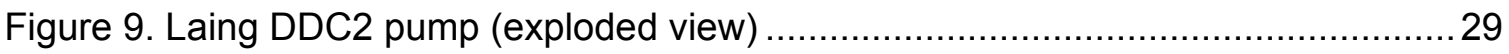

Figure 10. Laing DDC2 pump (isometric view) ……….............................................. 30

Figure 11. Back of chassis exposed showing tubing, pumps, and heat exchangers ......31

Figure 12. Nylon single-barbed connectors used with tubing ……................................32

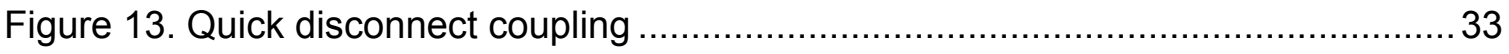

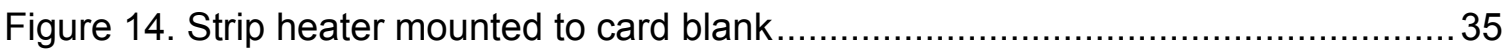

Figure 15. Card blank (with strip heater) inserted into rack ..............................................36

Figure 16. Watlow circulation heater similar to the one used in experiment ....................3

Figure 17. Mock mainboard with heater and aluminum blocks ......................................4 40

Figure 18. Mock Main Board assembled with cold plates and piping …........................41

Figure 19. Mock Daughter Cards with heaters and aluminum blocks ............................ 41

Figure 20. Mock Daughter Cards assembled with cold plate ....................................... 42

Figure 21. Mock mainboard (left) and daughter cards (right) .................................... 42 
Figure 22. Laboratory layout with all test and measurement equipment

Figure 23. Power terminal block panel and front

plane of chassis with attached air intake fitting.....

Figure 24. Chassis mounted manometer with thermocouple

connector terminal and laminar flow element shown in the background.

Figure 25. Laminar flow element with manometer used to measure the air volumetric flow rate through the chassis 48

Figure 26. Liquid flow meters, reservoir, and circulation heater. 49

Figure 27. Liquid closed loop diagram showing temperature probe, flow meter and valve locations .55

Figure 28. Chassis layout showing air flow path and thermocouple locations. 57

Figure 29. Baseboard 1 cold plate showing the location of the thermocouple on top at the outlet

Figure 30. Underside of cold plate showing heater attachment and thermocouple locations 59

Figure 31. Test board layout showing the cold plate thermocouple locations and numbering scheme.

Figure 32. "X" complex Test Chip temperature sensor layout with a picture showing the "A" Test Chip and "B" Test Chip

Figure 33. Pressure tap locations of LFE and router chassis 65

Figure 34. Pressure tap locations on ride side of router chassis 65

Figure 35. Electrical supply terminals used to power heaters on the Test Board 67

Figure 36. Strip heaters and circulation heater electrical supply terminals 69

Figure 37. Overall energy percentage transferred to medium for different system level (bottom x-axis) and board level (top x-axis) air flow rates 77 
Figure 38. Overall energy percentage transferred to medium for different system level (bottom x-axis) and board level (top x-axis) liquid flow rates ... 78

Figure 39. "A" test chip junction temperature as a function of fan duty cycle and percentage of liquid flow rate 79

Figure 40. Influence of power transferred to water on nomalized Test Chip junction temperature. 80

Figure 41. Thermal resistance stack up for chip-to-cold plate liquid performance. 87

Figure 42: Fan nominal power based on operating duty cycle. 118

Figure 43. "X" complex Test Chip layout with measured resistances and expected powers .134

Figure 44. Mainboard heater, block, and thermocouple layout ............................... 135

Figure 45. Daughter cards heater, block, and thermocouple layouts......................... 136

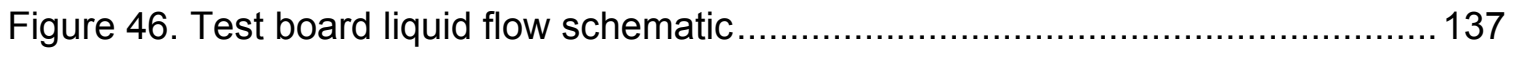

Figure 47. Pneumatic fittings used on cold plates............................................ 142

Figure 48. Circulation heater power for different PWM control currents ..................... 161 


\section{Chapter 1}

\section{Introduction}

Imagine being able to have a real-time video conference with ten people from all different parts of the world with just the push of a button. This video conference has high definition quality for both video and audio. On top of it is a fully interactive display allowing all attendees to view and share their documents as if they were all using the same computer. This technology is actually available. But it requires huge bandwidths and large router systems to handle the networking traffic. Consequently the processors and chips within these router systems generate large amounts of power which inevitably get converted into dissipated heat. The temperature of the router components need to be maintained within a desirable range to guarantee reliable operation. Thus it becomes vital to have a cooling system capable of managing those levels of power.

Cisco Systems delivers networking solutions to small and medium businesses as well as large enterprises. They have to continually enhance their solutions, (real-time video conferencing, for example) to maintain their competitive advantage. As a result, the performance of their router systems needs to be enhanced in order to, increase the heat dissipation levels. The existing cooling systems are unfortunately nearing their limit, given system and environmental constraints. 
The purpose of this thesis is to develop the next generation router system cooling design. The power levels associated with this study are far lower than those of real-time video conferencing router systems previously mentioned. But, the demonstrated methods and concepts in this document do have the potential to be utilized on such router systems. The Infinity 7609s router is the subject of this research. The chassis and line card configurations represented in the design of the new cooling system were capable of handling 33\% projected power increase.

The current Infinity 7609s routers utilize heat sinks coupled with forced air to maintain component temperatures within acceptable ranges for reliable operation. Air cooling is the preferred method because of its low cost, high reliability and serviceability. The projected heat dissipation levels for future models, however, may exceed the capabilities of air cooling using current designs. Lower heat transfer rates, due to low thermal conductivity, are associated with air. The effective cooling rate using air can be enhanced by increasing the surface area of the heat sinks, but this requires more space, and space is limited in the large router systems. Line cards are mounted in a 19" rack and the line card slot pitch is only 1.8". Alternatively, increasing air velocity can enhance the cooling rate, but this requires more fan power and consequently increasing system noise levels. The electrical power requirements for the router air cooling system are already a significant percentage of the overall system requirements. The noise levels are nearing the OSHA limit of $90 \mathrm{dbA}$ for persons without hearing protection (Maddren \& Pascual, 2005).

Many technologies exist which enhance the cooling of electronic devices. These include passive devices such as highly conductive interface materials, heat spreaders, and heat sinks, to 
list a few. Passive devices have no moving parts and thus are typically inexpensive and highly reliable. Active devices such as fans and pumps are typically used to overcome friction and increase cooling fluid velocities for increased cooling. Designing with redundancy can reduce the issue of low reliability associated with these devices. The transport properties of liquids allow higher heat transfer rates than air, but liquid cooled systems generally are more complex, expensive, and less reliable (Maddren \& Pascual, 2005).

The cooling system design has the following constraints: heat rejection capable of maintaining component temperatures within desirable limits, fits within available space, meets reliability requirements with minimal time for repair, satisfies customer's requirements and concerns, meets environmental requirements such as noise and safety, and low cost. These constraints have guided current cooling designs and will continue to influence future designs (Maddren \& Pascual, 2005).

Research was conducted to identify available technologies for cooling router systems. With the guidance of Cisco personnel the cooling system's constraints and objectives were identified. Two board level cooling designs, enhanced air and conduction cold plate, were considered potential solutions. The thermal capabilities of those designs were analyzed using FloTherm, a CFD program used by Cisco. The FloTherm results helped justify the decision to construct a liquid-hybrid cooling system utilizing cold plate conduction. Also, it was more feasible to implement the liquid-hybrid design compared to the enhanced air solution. A mock test board was fabricated with kapton heaters and aluminum blocks to represent the generated power and component layout for one line card. This was placed in the modified hybrid chassis 
and tests were performed to determine the effectiveness of the cooling system. The test results were also compared to the mathematical FloTherm model to confirm its accuracy. The mathematical model and prototype will aid in next generation router system cooling designs.

The success of this study is dependent on a few criteria. First, experimental data and trends corresponding closely to the FloTherm model must be obtained. This will establish a baseline for proper constraints needed for correct modeling in the future. Next, it is expected that this prototype will be used for future tests so it must be fully functional and capable of generating the heat loads of this study and future studies. Finally, the design of this prototype will be the stepping stone for the next generation router system cooling design. Therefore, the design needs to maintain acceptable temperatures for the projected heat load both on the system and board level.

There are many cooling options available which can tolerate the expected heat load. Each has a specific function and varying effects on the different levels of cooling: component, board, and system. Emerging technologies are under development and being researched which pose as potential solutions, though they may not currently be available. Most plausible solutions were reviewed and their expected impacts on the current Cisco router blade were analyzed. This information is discussed in the next section. 


\section{Chapter 2}

\section{Background}

The technology associated with electronic cooling has been evolving due to the rapid performance boost in electronic systems. New concepts and techniques for cooling are continually being researched by universities and industry. Some are commercially available and others have yet to be applied. This chapter will first discuss applicable cooling technologies for Cisco's router systems. Second, it will give supporting details for the development of the liquidair hybrid cooling prototype.

\section{$\underline{\text { Available Technologies }}$}

Electronic cooling can be separated into three categories: component level, board level, and system level (rack or facility). Each has a specific cooling method but the goal of each category is to reject heat allowing the electronic components to operate at a desirable temperature.

\section{Component Level Cooling}

Components have an internal and external means of module cooling. The internal module depends on conduction as its principal mode of heat transfer. Thus, the thermal resistance is dependent on physical construction and material properties. Some heat is transferred to the printed circuit board (PCB), through the chip connections, while the rest goes to the case. Heat 
from the case is dissipated through conduction, convection, or radiation to the surroundings which is external to the module. Figure 1 shows the internal and external regions of the module.

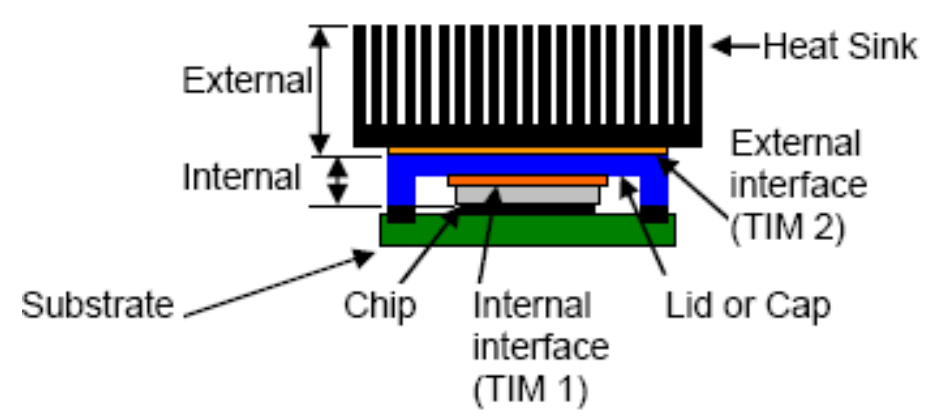

Figure 1. Cross-section of typical module denoting internal and external cooling regions

\section{$\underline{\text { Internal Module }}$}

Some internal module cooling technologies applicable to Cisco's routers are heat spreaders, lids, and use of heat pipes in heat spreaders. Heat spreaders are used to help alleviate large thermal gradients on dies by distributing the heat and causing a more uniform heat flux. Heat pipes in the base of heat spreaders can dramatically enhance the performance of heat spreaders. Lids are used on some components as a form of heat spreader, as well as a mating surface for a heat sink.

Heat spreaders are made from materials with high thermal conductivities and are bonded to their components. This allows the heat spreaders to manage the asymmetric power distribution of the components. Using materials with higher thermal conductivities can reduce thermal resistance. Wei and Suzuki (2005) analyzed the change in spreader material from aluminum $(180 \mathrm{~W} / \mathrm{m}-\mathrm{K})$ to copper $(400 \mathrm{~W} / \mathrm{m}-\mathrm{K})$ and noticed a $31 \%$ reduction in thermal resistance. 
Integration of heat pipes in the base of heat spreaders help reduce the spreaders' thermal resistance, though with a boiling fluid. The spreader is hollowed out and filled with a wick and a liquid, usually water. The heat pipes require more space in the heat spreader increasing the overall dimensions, primarily height. This can become a problem when space is limited, like on a router blade.

A lid can eliminate the addition of a heat spreader and acts as a mounting surface for a heat sink. Both lid thickness and material thermal conductivity have an influence on the lid's thermal resistance. $\mathrm{Xu}$, et al. (2004) observed minimal reduction in thermal resistances between differences in lid thermal conductivities and thicknesses. A lidless component condition was also investigated by $\mathrm{Xu}$, et al. (2004). The conclusion was the performance gain of the lidless package diminished as the lid thickness and thermal conductivity increased. The use of a lid then comes down to the user's preference and Cisco router components currently incorporate the heat spreader as part of the extruded heat sink.

\section{$\underline{\text { External Module }}$}

The more conventional forms of electronic cooling are external to the module and utilize forced air coupled with heat sinks. Heat sinks have fins extending from the base, creating a larger surface area. This method increases the surface area to volume ratio in order to increase convective heat transfer to the working fluid, which in this case is air. The thermal performance of heat sinks is a function of: base thickness, base area, fin thickness, fin height, fin spacing, and thermal conductivity of the material. Current designs have been increasing the quantity of fins 
while diminishing the spacing. Also, combination of materials has been applied to heat sinks. For instance, instead of having a heat sink made entirely of aluminum (150 - $200 \mathrm{~W} / \mathrm{m}-\mathrm{K})$ the base can be made of copper ( $350-390 \mathrm{~W} / \mathrm{m}-\mathrm{K})$ while the fins are aluminum. This increases the thermal conductivity of the heat sink, enhancing the thermal performance. The areas considered for heat sink modification used to increase the heat transfer capabilities are: increased die size, increased base thermal conductivity, and increased heat sink volume. This is an issue for Cisco because there is a strict height constraint for the router blades, making it impossible to increase the heat sink height, though the footprint could be increased. Table 1 was created by Sauciuc, et al. (2005) to compare various heat sink alterations and their impact on thermal resistance. It can be seen that increasing the size of the heat sink and thermal conductivity are some of the most influential alterations used to reduce thermal resistance (Pascual, 2005).

Table 1. Effect of heat sink properties on thermal resistance

\begin{tabular}{|l|c|}
\hline \multicolumn{1}{|c|}{ Parameter } & $\begin{array}{c}\text { Thermal Resistance } \\
\text { Reduction (K/W) }\end{array}$ \\
\hline Increasing the Die Size (from 10 to $30 \mathrm{~mm}$ ) & 0.080 \\
\hline Increase the Base Conductivity (from 180 to W/m-K) & 0.059 \\
\hline Increase the Fin Gap (from 0.9 to $1.6 \mathrm{~mm}$ ) & 0.036 \\
\hline Increase the Fin Height (from 40 to $80 \mathrm{~mm}$ ) & 0.026 \\
\hline Increase the Velocity between Fins (from 3 to $6 \mathrm{~m} / \mathrm{s}$ ) & 0.016 \\
\hline Increase Base Thickness (from 4 to $10 \mathrm{~mm}$ ) & 0.016 \\
\hline Increase Fin Conductivity (from 180 to $390 \mathrm{~W} / \mathrm{m}-\mathrm{K}$ ) & 0.015 \\
\hline
\end{tabular}

In order to increase volume and surface area the heat sink needs to be longer or wider. Often in low profile servers, heat sink width is constrained as well as the height, allowing only the heat sink to increase in length or reduce fin spacing. The negative effect of these options is 
increased air flow resistance. Chan and Wei (2005) investigated the effect of increased heat sink length on thermal resistance. Their results showed negligible influence on thermal resistance as a function of length. The increased length air flow resistance decreased the flow rate enough to counter-act the benefits of increasing the surface area.

An optimization on heat sink design based on the Entropy Generation Minimization Method developed by Bejan was performed by Xu, et al. (2004). The optimization described the entropy minimum to be a function of the quantity of fins on the heat sink and the individual heat sink fan power. It was noticed that the thermal resistance did not decrease substantially with an increase of fins until the fan power was greater than $0.5 \mathrm{~W}$. Thus, when the fan power went from $0.1 \mathrm{~W}$ to $1.0 \mathrm{~W}$ the thermal resistance was reduced by $0.1 \mathrm{~K} / \mathrm{W}$ or $20 \%$. There was a negligible decrease in thermal resistance when the fan went from $1.0 \mathrm{~W}$ to $1.5 \mathrm{~W}$ suggesting the heat sink performance will not increase further with increased air flow.

The thermal performance of a module is not just affected by the heat sink capabilities, but also the method for attachment of heat sink to module. This is important because ideally all the heat from the module case should be transferred to the heat sink. If the heat sink is not properly attached, there is an increase in thermal resistance causing poor heat transfer. It becomes vital to use a thermal interface material (TIM) between the mating surfaces. Xu's, et al. (2004) numerical model varied the thermal conductivity of a TIM used between the heat sink base and component case from 2 to $20 \mathrm{~W} / \mathrm{m}-\mathrm{K}$. The overall thermal resistance of the package was reduced by $22 \%, 0.1 \mathrm{~K} / \mathrm{W}$, when the thermal conductivity was changed from 2 to $7 \mathrm{~W} / \mathrm{m}-\mathrm{K}$. The thermal resistance only decreased an additional $9 \%, 0.03 \mathrm{~K} / \mathrm{W}$, when the thermal conductivity went from 
7 to $20 \mathrm{~W} / \mathrm{m}-\mathrm{K}$. A TIM can be improved through use of mechanical clamping, i.e. screws or clamps, of the heat sink to the module. Phase change materials are also available to help reduce thermal resistance at the heat sink-to-module interface.

Alternative solutions to air cooling have been considered, especially with the progress in electronic design and packaging. One type of solution uses water-cooled cold plates to remove the heat. Water has a higher thermal conductivity allowing it to have a significant decrease in thermal resistance when compared to air. Sauciuc, et al. (2005) stated the current priority in research is to develop a single phase cooling system. A microchannel cooling design is one of the cooling concepts being researched. This concept will be able to provide very low thermal resistances while maintaining small outside dimensions. The microchannels range in size from tens to hundreds of microns in width and are typically oriented in a parallel scheme. The same concept of increasing the surface area to volume ratio used in heat sink design is being applied to the microchannel design. These micochannels increase the surface area exposed to the cooling liquid resulting in enhanced heat transfer, especially in the laminar flow regime where the heat transfer coefficient is inversely proportional to the hydrodynamic diameter (Pascual, 2005).

There are some great advantages associated with the microchannel design though Chan and Wei (2005) stated that components-off-the-shelf (COTS) for liquid cooling do not exist for microprocessor standards. Also, liquid cooling requires: cold plates, pumps, heat exchangers, fans, tubing, fittings, and liquid; while only heat sinks and fans are needed for air cooling. Other concerning issues with liquid cooling are cost, availability components, and long term 
component reliability. In addition, there is a standard for fans and blowers to provide five years or greater of continuous operation which pumps of liquid cooling would have to meet.

Finally, a more advanced look into liquid cooling is two-phase liquid cooling and immersion cooling. These technologies utilize the heat transfer benefits of higher thermal conductivity and lower thermal resistance associated with boiling. The thermal performance would be higher than single phase liquid cooling and air cooling. Unfortunately, these two technologies are still in the research phase and need to be developed more before being applied.

\section{Board and System Level Cooling}

Board and System level cooling is comprised of four fundamental systems: air-cooling, hybrid-cooling, liquid-cooling, and refrigeration-cooling. Air cooling consists of transferring heat from electronic modules to air by means of fans and heat sinks. Hybrid cooling uses air-toliquid cooled heat exchangers to cool air to a lower temperature before it passes over the array of electronics. Liquid cooling uses liquid cooled cold plates to remove heat from the electronic components while cooling the liquid with a liquid-to-liquid heat exchanger. Refrigeration cooling uses the liquid cold plates as well as a device to refrigerate the liquid before it enters the cold plate, allowing for larger heat transfer rates.

\section{Air and Hybrid Cooling}

The most basic and utilized cooling system, air-cooling, can be separated into serial and parallel forced flow systems. Serial flow encompasses the same air passing over successive rows of components or boards. As a result, each row is cooled by air that has been preheated by the 
previous row. This can generate a large temperature rise in the air as is passes through the machine. In parallel flow, all the components or boards experience the same inlet temperature air. The downside is the need for increased volumetric flow rates. In order to keep the higher flow rates associated with serial flow while having similar thermal managing capabilities as parallel flow, a hybrid cooling system can be used. The high temperature air at the end of the system is passed over a liquid cooled heat exchanger, extracting the heat and providing cooler air. This utilizes the advantages of indirect liquid cooling at the component level while maintaining the system level advantages of air.

\section{$\underline{\text { Liquid and Refrigeration Cooling }}$}

Expanding on the use of liquids, liquid cooling enhances the heat transfer rates by using high heat transfer coefficient liquids, such as water, to remove heat from the components as well as the system. A coolant distribution unit (CDU) is used to control and distribute system cooling liquid to the boards. The system heat load is transferred to the secondary loop via a liquid-toliquid heat exchanger in the CDU. This technology has great potential, but there are virtually no COTS available for liquid cooling. This relates back to the issue of cost, availability of COTS, and long term reliability. There is some development of this technology, but most related information is proprietary. Refrigeration cooling is available but requires more space, higher cost, and is primarily used for specialty computing systems.

\section{Available Technology Summary}

Due to constraints imposed on Cisco router blades, there are few options available for enhanced air cooling. There is the hope of providing individual fans and ducting to higher power 
components, but there is a need for increased space. Embedding heat pipes into the base of heat spreaders can provide acceptable heat transfer, though size constraints will also play a major role in thermal limits. It is expected that enhanced air cooling could provide enough cooling for this next generation router, but it probably will not be able to tolerate any future router designs here after.

In the case where the heat dissipation rates are too high for air cooling, hybrid and liquid cooling could be respectable solutions. The technology may not be available in industry now, but there are major developments underway. Industry understands the necessity of this technology for future progress in electronic performance. Higher heat transfer rates and cooling capabilities will always be the main goals in sight. With this emerging technology it looks as if hybrid or liquid cooling will be the simplest and most cost efficient way to implement in order to reach the next level of goals. Eventually, components, board layouts, and system layouts will in need to be redesigned to handle larger performance enhancements.

\section{Design Support}

Preliminary analyses were performed on both hybrid-cooling and enhanced air-cooling to help determine which design to focus on for the development of the prototype. Computational fluid dynamics modeling, using FloTherm, was conducted for the liquid cooling at the board level. The system level analyses were modeled with applicable heat transfer equations in Engineering Equation Solver (EES). Refer to Maddren (2006) for further details on these preliminary analyses. 
Cisco's Infinity 7609s router was modified with the new cooling system. The current system is a 9-vertical slot, half-rack router dissipating approximately $6.6 \mathrm{~kW}$ (730 W per card). The higher power components are expected to double, thus increasing the total board power close to $1000 \mathrm{~W}$. Currently there are two "X" complexes and two "Y" complexes which are composed of the higher power components. All the complexes were represented by an "X" complex with roughly double the power $(160 \mathrm{~W})$. The "A" chip and "B" chip, part of the "X" complex, powers doubled to $90 \mathrm{~W}$ and $46 \mathrm{~W}$ respectively. "A", "B", and "C" (6.3 W) chips are all attached to the same air cooled heat sink in the current design. The remaining power of the complex is generated by " $\mathrm{D}$ " (17.7 W). The analyses focused on cooling " $\mathrm{A}$ ", " $\mathrm{B}$ ", and "C". These devices were all attached to the same cold plate in the liquid cooling scheme, and the same heat sink in the air cooling scheme.

The future higher power components currently have not been designed so the component level thermal resistances are unknown. For the increased power devices, "A" and "B", the junction to board thermal resistance was assumed unchanged at $1.35 \mathrm{~K} / \mathrm{W}$ while the junction to case resistance was decreased from $0.38 \mathrm{~K} / \mathrm{W}$ to $0.20 \mathrm{~K} / \mathrm{W}$. Further decreases in the junction to case thermal resistances would be beneficial in terms of reducing the maximum device junction temperature. Constraints of the design are outlined on the next page. 


\section{Constraints:}

- Must conform to existing physical dimensions (board pitch, system geometry, etc.)

- Reasonable limits must be maintained so that the cost of ownership is not excessive in comparison to existing system. The cost of ownership includes the following recurring and non-recurring costs:

o Component and manufacturing cost (non-recurring)

o First cost of facility (non-recurring)

o Operation and maintenance (recurring)

- Reliability, Availability, and Serviceability

o The mean time between failures (MTBF) should not exceed current baseline

o No more than ten (10) minutes downtime per year (99.999\% operational)

o The mean time to repair (MTTR) should not exceed current baseline

o Should be serviceable by normal technician with standard tools

o System components must be hot swappable, maximum of two (2) minutes to perform operation

o Cooling system should have built-in redundancy whenever possible

- Cooling system materials must have availability and manufacturability

- Cooling system power consumption should not increase more than the heat dissipation rate (less than a factor of two)

- Noise must meet NEBS requirement of $65 \mathrm{dbA}$ for normal operations and OSHA requirement of $90 \mathrm{dbA}$ maximum

- Cooling system requirements must be satisfied by current data center facility capabilities (Pascual, 2005) 


\section{Hybrid Cooling}

The model developed in FloTherm was used to determine the heat transfer characteristics at the board level. The board level characteristics were then applied to the entire system enabling proper component sizing, i.e. heat exchanger, pump, piping, etc. In the model each complex had a cold plate attached to its "A", "B", and "C" chips to help remove their generated heat. The cold plates were sized using approximately the same dimensions as the existing air cooled heat sinks. The cold plate foot print was $100 \mathrm{~mm}$ by $200 \mathrm{~mm}$ with a height of $7 \mathrm{~mm}$. The cooling channels ran the length of the cold plate and were $3.5 \mathrm{~mm}$ square. The cold plates were made of aluminum. Figure 2 shows a simple cross-sectional view of the cold plate.

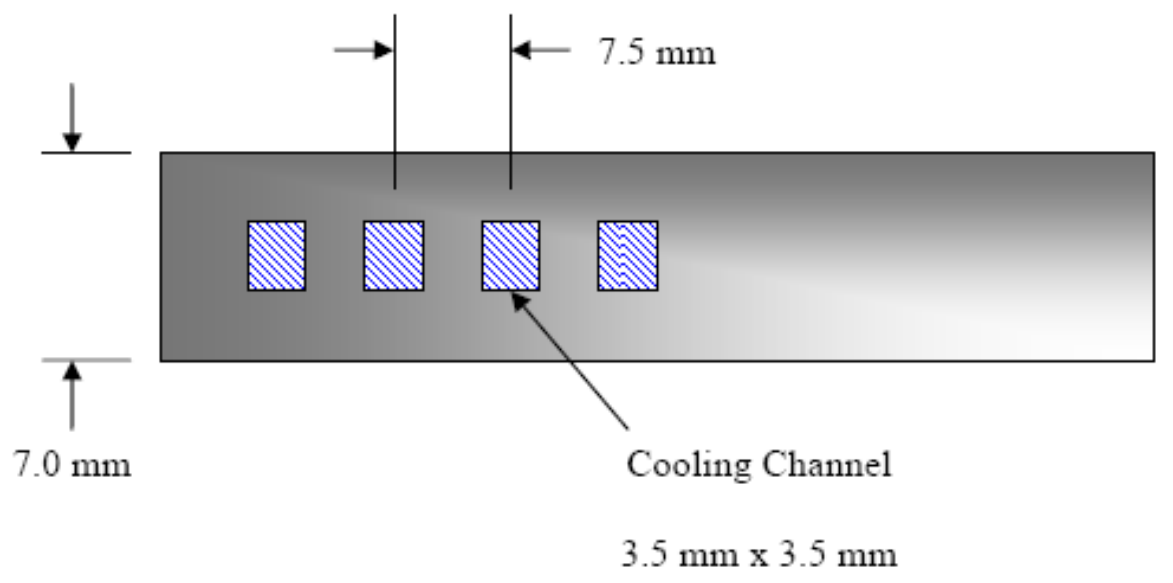

Figure 2. Simplified cross-sectional view of cold plate

The FloTherm modeling was needed to determine how much of the complex's heat dissipation was transferred to the air, and how much was transferred to the liquid. In addition, the FloTherm modeling was used to determine the device junction temperatures. The "A" chip junction temperature in the four complexes was of main concern. The " $\mathrm{B}$ " and " $\mathrm{C}$ " chips had lower powers causing their junction temperatures to be lower than "A"; thus were less of a 
concern. The FloTherm model showed a maximum junction temperature below $105^{\circ} \mathrm{C}$ could be achieved with an average liquid temperature less than approximately $72.5^{\circ} \mathrm{C}$.

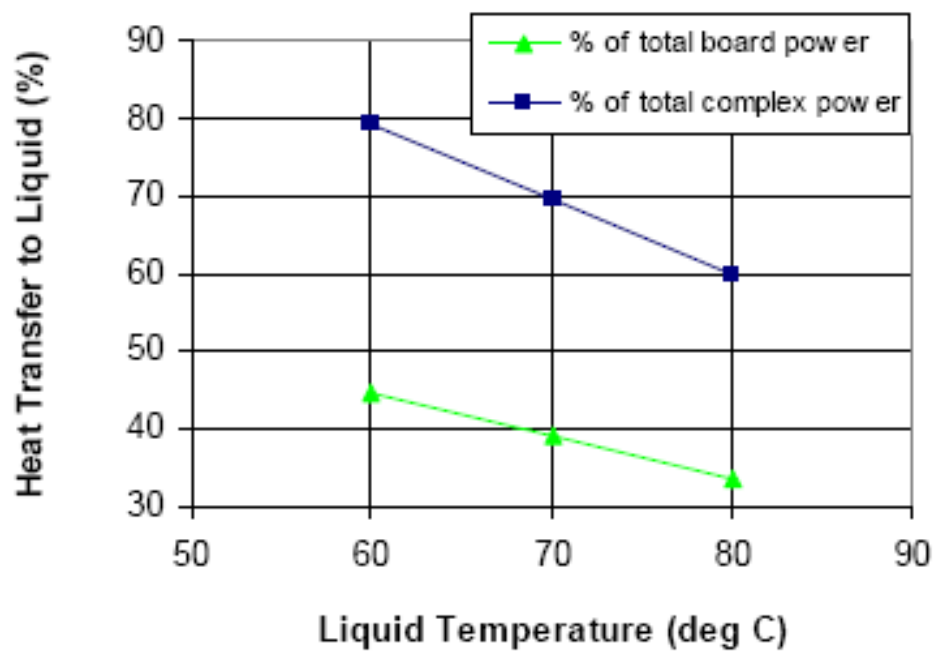

Figure 3. Percentage of heat transferred to liquid as a function of average liquid temperature

Figure 3 shows the percentage of heat dissipated to the liquid with respect to the total heat dissipated by the board $(1010 \mathrm{~W})$ and the heat dissipated by the devices attached to the cold plates $(569 \mathrm{~W})$. At a liquid temperature of $60^{\circ} \mathrm{C}, 79.3 \%$ of the heat dissipated by the devices attached to the cold plates was transferred to the liquid. This value decreases to $59.7 \%$ when the liquid temperature is increased to $80^{\circ} \mathrm{C}$ (Maddren, 2006).

In order to determine the mass flow rate of the liquid, an energy balance was needed. There was an assumed temperature difference of $10^{\circ} \mathrm{C}$ between the liquid inlet and outlet of the cold plate. Equation [ 1 ] yields: 


$$
q=\dot{m} c_{p}\left(T_{m, i}-T_{m, o}\right)
$$

where $(q)$ is the heat transferred to the liquid, $(\dot{m})$ is the mass flow rate of the liquid, $\left(c_{p}\right)$ is the specific heat and $\left(T_{m, i}\right)$ and $\left(T_{m, o}\right)$ are the mean inlet and outlet temperatures, respectively. The calculated mass flow rate was approximately $0.024 \mathrm{~kg} / \mathrm{s}$ and the velocity was $0.027 \mathrm{~m} / \mathrm{s}$. This flow is laminar and fully developed with a $\operatorname{Re}_{D}=229$ and $\left(\frac{x_{f d, h}}{D_{H}}\right)_{\text {lam }} \approx 11.45$. The Nusselt number for fully developed laminar flow in a square cross section channel is a constant value of $N u_{D}=2.98$ (Incropera $\&$ Dewitt, 2002). These values were based on the assumptions: (1) that $70 \%$ of the heat from the devices attached to the cold plate is transferred to the liquid (2) that there are 10 parallel-single pass channels in the cold plate, and (3) the channel dimensions are those shown in Figure 2.

The liquid cooling of the rack was modeled in Engineering Equation Solver (EES). The liquid cooling schematic along with liquid state points is shown in Figure 4. Energy balances were applied to the cold plates and liquid heat exchanger. The effectiveness-NTU method was applied to calculate the overall performance of the heat exchanger (Incropera \& Dewitt, 2002), assuming a cross flow configuration with both fluids unmixed. The overall heat transfer coefficient (U-value) was determined for a plate-fin surface with louvered fins (Kays \& London, 1984). 


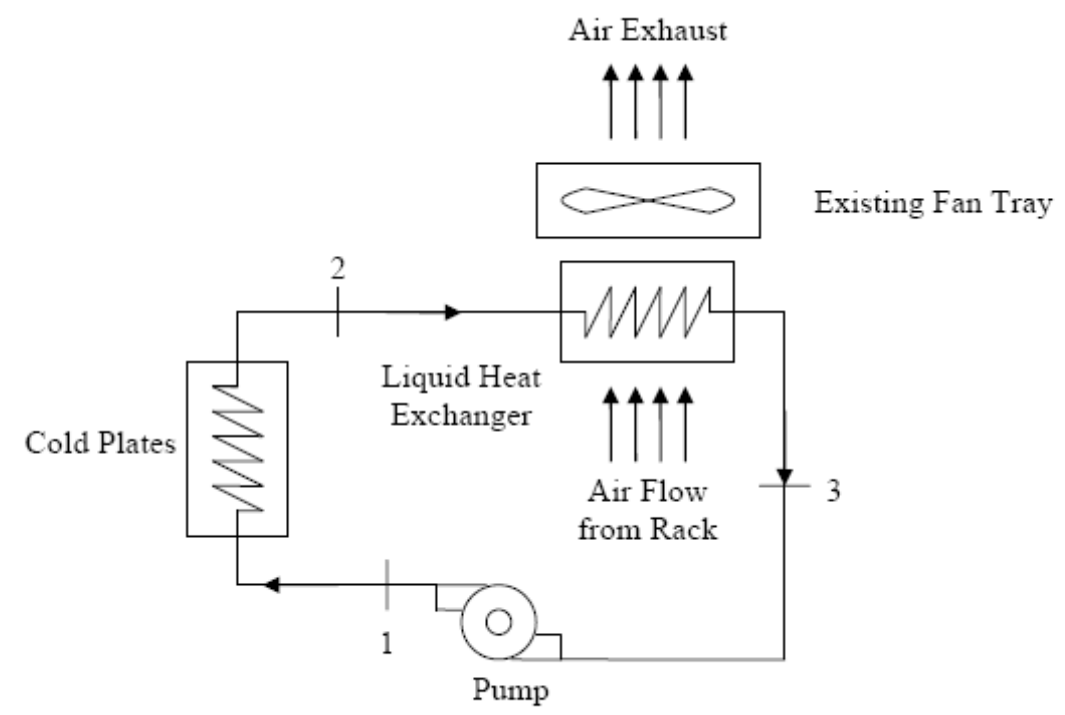

Figure 4. Schematic of liquid cooling system

Figure 5 shows the air cooling path through the rack. The model assumed the inlet air to be $40^{\circ} \mathrm{C}$ at an elevation of $10,000 \mathrm{ft}$. The total air flow through the cabinet was assumed to be $0.514 \mathrm{~m}^{3} / \mathrm{s}(1089 \mathrm{cfm}), 0.057 \mathrm{~m}^{3} / \mathrm{s}(121 \mathrm{cfm})$ per card, and the total heat dissipated by the electronic components on the boards was approximately nine times the board power (1.01 kW) or $9.1 \mathrm{~kW}$.

The " $A$ " junction temperature was a function of the average liquid temperature and it was determined previously that if the liquid temperature exceeded approximately $72.5^{\circ} \mathrm{C}$, the junction temperature would exceed $105^{\circ} \mathrm{C}$. Energy balances were applied to the air in order to calculate the temperature increase of the air across the cards and through the liquid heat exchanger. 


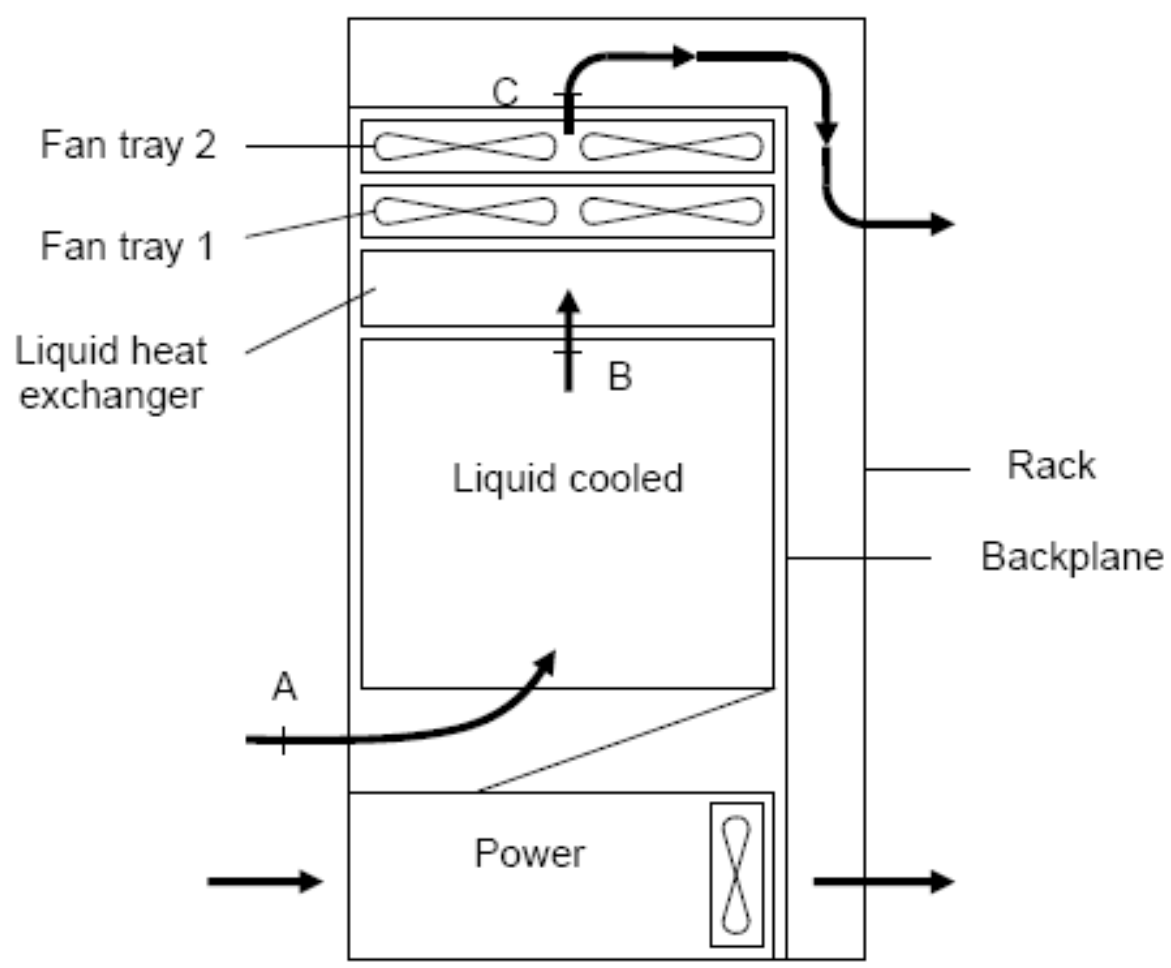

Figure 5. Simplified schematic of rack with air cooling path

Table 2 shows some of the results from the system simulation assuming a $10^{\circ} \mathrm{C}$ temperature increase of the liquid through the cold plate and a UA value for the heat exchanger of $500 \mathrm{~W} / \mathrm{K}$. The system simulation results, with the assumed values, produced an average liquid temperature of $68.8^{\circ} \mathrm{C}$, which was lower than the needed maximum average temperature for reliable device operation. The heat rate to the liquid per card is $400.1 \mathrm{~W}$, which results in a total system liquid flow rate of $5.30 \mathrm{lpm}$ (1.40 gpm) (Maddren 2006).

The UA value is directly related to heat exchanger size or volume. It was calculated that the UA value needed to be above $300 \mathrm{~W} / \mathrm{K}$ in order to achieve water temperatures below the $72.5^{\circ} \mathrm{C}$ limit. With the cross-sectional area being equal to the flow area of the fan trays, the 
minimum depth or thickness of the heat exchanger was calculated $3.81 \mathrm{~cm}(1.5 \mathrm{in})$ to $5.08 \mathrm{~cm}$ (2.0 in) for the given constraints. The overall heat transfer coefficient, $\mathrm{U}\left(\mathrm{W} / \mathrm{m}^{2}-\mathrm{K}\right)$, was calculated assuming nominal values for the flow rates and temperatures of the fluids.

Table 2. Results from Flotherm simulation

\begin{tabular}{|l|c|c|}
\hline Heat dissipated per card (given) & 1010 & $\mathrm{~W}$ \\
\hline UA value (assumed) & 500 & $\mathrm{~W} / \mathrm{K}$ \\
\hline Air flow rate per card (assumed) & $\begin{array}{c}0.514 \\
(1089)\end{array}$ & $\begin{array}{c}\mathrm{m}^{3} / \mathrm{s} \\
\text { (cfm) }\end{array}$ \\
\hline Inlet air, $\mathrm{T}_{\mathrm{A}}$ (given) & 40.0 & ${ }^{\circ} \mathrm{C}$ \\
\hline Intermediate air, $\mathrm{T}_{\mathrm{B}}$ & 55.1 & ${ }^{\circ} \mathrm{C}$ \\
\hline Exhaust air, $\mathrm{T}_{\mathrm{C}}$ & 65.4 & ${ }^{\circ} \mathrm{C}$ \\
\hline Inlet liquid (to cold plate), $\mathrm{T}_{1}$ & 63.8 & ${ }^{\circ} \mathrm{C}$ \\
\hline Outlet liquid (to cold plate), $\mathrm{T}_{2}$ & 73.8 & ${ }^{\circ} \mathrm{C}$ \\
\hline Average liquid temperature & 68.8 & ${ }^{\circ} \mathrm{C}$ \\
\hline Liquid flow rate & 5.30 & $\mathrm{Ipm}$ \\
\hline Card heat rate to air (per card) & 609.9 & $\mathrm{~W}$ \\
\hline Single card heat rate to liquid & 402.1 & $\mathrm{~W}$ \\
\hline HX effectiveness & 0.56 & - \\
\hline
\end{tabular}

The piping material, layout, and sizing were not selected prior to these preliminary calculations. Head losses and required pumping powers, however, were calculated for various pipe sizes and fluid velocities. A typical velocity associated with small piping or tubing is in between $0.609-0.914 \mathrm{~m} / \mathrm{s}(2.0-3.0 \mathrm{ft} / \mathrm{s})$. Table 3 shows the corresponding losses for inside tubing diameters and fluid velocities. Larger diameters are desired because of lower head losses. Pump motor requirements are on the order of 10's of watts and two pumps are needed for redundancy. The line card plumbing will have quick disconnects to the system piping. This allows for the 
cards to be removable and prevent any water leakage during operation. All piping was expected to fit between the backplane and the rear of the cabinet.

Table 3. Piping diameter and head losses for various liquid velocities

\begin{tabular}{|c|c|c|c|c|c|c|c|}
\hline \multicolumn{2}{|c|}{ Velocity } & \multicolumn{2}{c|}{$\mathbf{D}_{\text {card }}$} & \multicolumn{2}{c|}{$\mathbf{D}_{\text {main }}$} & \multicolumn{2}{c|}{ Head Loss } \\
\hline $\mathbf{m} / \mathbf{s}$ & (ft/s) & $\mathbf{~ m m}$ & (in) & $\mathbf{m m}$ & (in) & $\mathbf{m}$ & (ft) \\
\hline \hline 0.30 & $(1.0)$ & 6.4 & $(0.252)$ & 19.2 & $(0.756)$ & 3.05 & $(10.0)$ \\
\hline 0.61 & $(2.0)$ & 4.5 & $(0.178)$ & 13.6 & $(0.535)$ & 3.20 & $(10.5)$ \\
\hline 0.91 & $(3.0)$ & 3.7 & $(0.146)$ & 11.1 & $(0.437)$ & 3.44 & $(11.3)$ \\
\hline 1.22 & $(4.0)$ & 3.2 & $(0.126)$ & 9.6 & $(0.378)$ & 3.78 & $(12.4)$ \\
\hline 1.52 & $(5.0)$ & 2.9 & $(0.113)$ & 8.6 & $(0.338)$ & 4.27 & $(14.0)$ \\
\hline
\end{tabular}

The hybrid cooling system design will work for the given constraints. The addition of heat exchangers, pumps, cold plates, and piping are required for this design. Due to the heat exchanger sizing, the router chassis will have to increase by $3.81 \mathrm{~cm}(1.5 \mathrm{in})$ to $5.08 \mathrm{~cm}$ ( $2.0 \mathrm{in})$. No other alterations to the router's exterior dimensions will be required for this design. The location of the pumps and their mounting should not interfere with any of the router's internal structure.

\section{Enhanced Air Cooling}

The same setup used in hybrid cooling was also used in enhanced air cooling; "A", "B", and "C" were all attached to the same heat sink. Analyses were performed on areas including heat sink materials, fin pitch, and heat transfer coefficients, to name a few. These were used to determine the feasibility of using air cooling for the projected power increase. 
The heat sink material, fin pitch, fin thickness, base thickness, and air velocity were analyzed. These variables were adjusted to obtain better heat transfer characteristics. Figure 6 shows the "A" junction temperature as a function of the approach velocity at different mean inlet temperatures for a fin pitch of $1.25 \mathrm{~mm}$. There are a few data points below the $105^{\circ} \mathrm{C}$ junction temperature limit, showing the feasibility of enhanced air cooling.

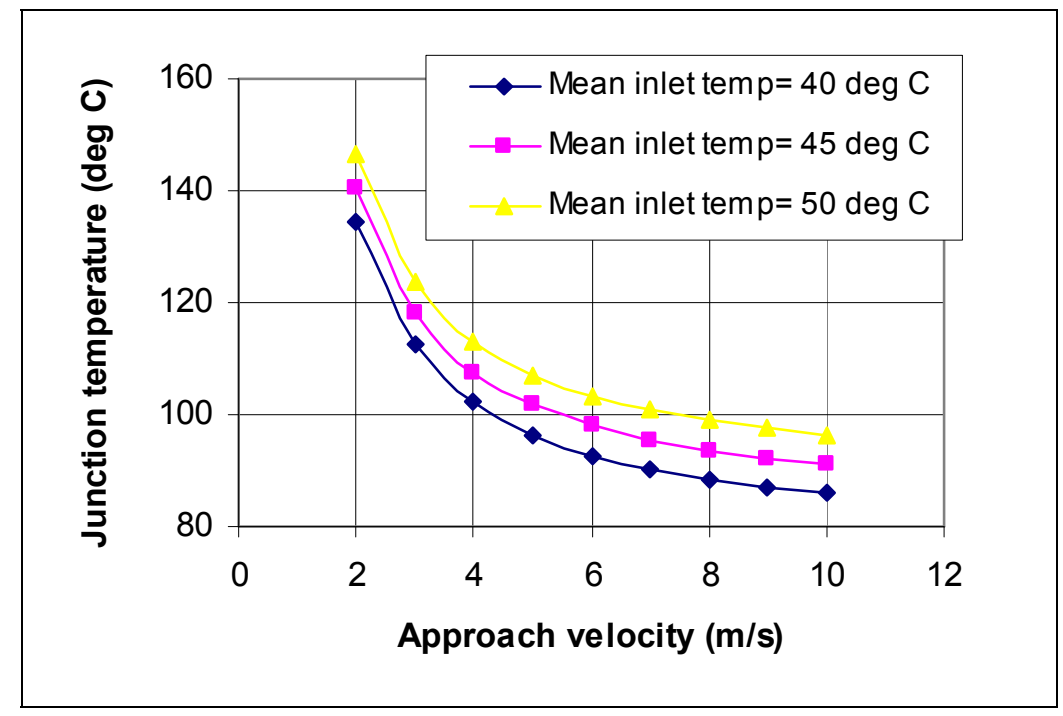

Figure 6. Junction temperature as a function of approach velocity at different mean inlet temperatures (fin pitch equal to $1.25 \mathrm{~mm}$ )

The result of these analyses showed the possibility of an enhanced air cooling scheme. With the correct air velocity, heat sink fin pitch, and heat sink thermal conductivity the "A" junction temperature can be maintained below the $105^{\circ} \mathrm{C}$ limit. The fin pitch will have to decrease requiring a higher air velocity to overcome the associated increased pressure drop across the heat sink. Ducted air to the complexes' heat sinks is needed to achieve the higher velocities without increasing the system volumetric flow rate. There will be an increase in the 
overall pressure drop across the board, but it should only have a small effect on the total system air flow.

It is important to give the greatest possible volumetric flow rate to these heat sinks in order to maintain optimum operating conditions. The heat sink's performance can significantly decrease with flow rates that are too low. This is primarily due to air heating up as it passes through the heat sink and the high power densities. If there is not enough air taking away the heat, then the components will heat up beyond their operating temperature limit. Some of the components/heat sinks may have to be moved or redesigned in order to receive the maximum volumetric flow rate.

Conclusions from Maddren (2006) and discussions with Cisco’s technical leads, found that enhanced air cooling would not meet the expectations for future Cisco products. Cisco's technical leads found it more beneficial to pursue the hybrid liquid-air cooling system due to the possible board layout modifications and limits of enhanced air cooling. It was also found to be more manageable to produce a working hybrid cooling system prototype as opposed to an enhanced air cooling system.

These preliminary design analyses set the foundation for the production of the hybrid cooling system prototype implemented on the Infinity 7609 s router system. The equipment used was selected based on the hybrid preliminary design. All equipment associated with the prototype is described in the next section. 


\section{Chapter 3}

\section{Equipment}

The preliminary design analysis for the hybrid cooling system guided the construction of the prototype and testing equipment. A fully functional prototype was assembled allowing board

and system level measurements to be acquired during testing. The prototype is a first iteration in the router system alternative cooling design. Its goal was to show if the design can handle the projected heat load and help identify additional alternative cooling design complications. All the equipment associated with the router cooling system was enclosed in the router chassis, while all other equipment necessary for testing was kept outside to prevent additional flow obstructions. The equipment specifications, selection, and design are explained in this section. Most of the equipment was selected based on availability, cost, and implementation. The idea behind this was the constraint of having the equipment easily available, reasonably serviceable, and cost efficient. This provides a more realistic approach to the feasibility of this system being able to perform properly under the specified constraints.

\section{Prototype Equipment}

As mentioned previously, all the prototype equipment needed for the router system cooling design was fully enclosed in the router chassis with the addition of $6.35 \mathrm{~cm}$ (2.5 in) in height. This increase in height was necessary to enclose the two heat exchangers needed for the design. Cold plates were constructed to remove heat from the higher power components of the 
complexes. Two pumps were mounted in the back of the chassis, down near the power supplies, and connected in parallel. Tubing and fittings provided water connections to the cold plates, heat exchangers, and pumps. Quick disconnects allowed the card to be removed without having to drain the entire system.

\section{$\underline{\text { Cold Plates }}$}

Four cold plates were manufactured and attached to heater blocks on a mock test board representing the projected power increase. These cold plates had dimensions of $136.5 \mathrm{~mm}$ by $95.3 \mathrm{~mm}$ by $7.00 \mathrm{~mm}$. These dimensions were designed to closely match those of the current heat sinks attached to the four complexes' higher power components. The cold plates were made from aluminum blocks. These blocks were cut to the desired external dimensions mentioned above, then drilled. After drilling the inlet, outlet, and parallel channels weld plugs were used to seal the channels. The inlet and outlet orifices were tapped to specification. Figure 7 shows the internal and external structures of the cold plates.

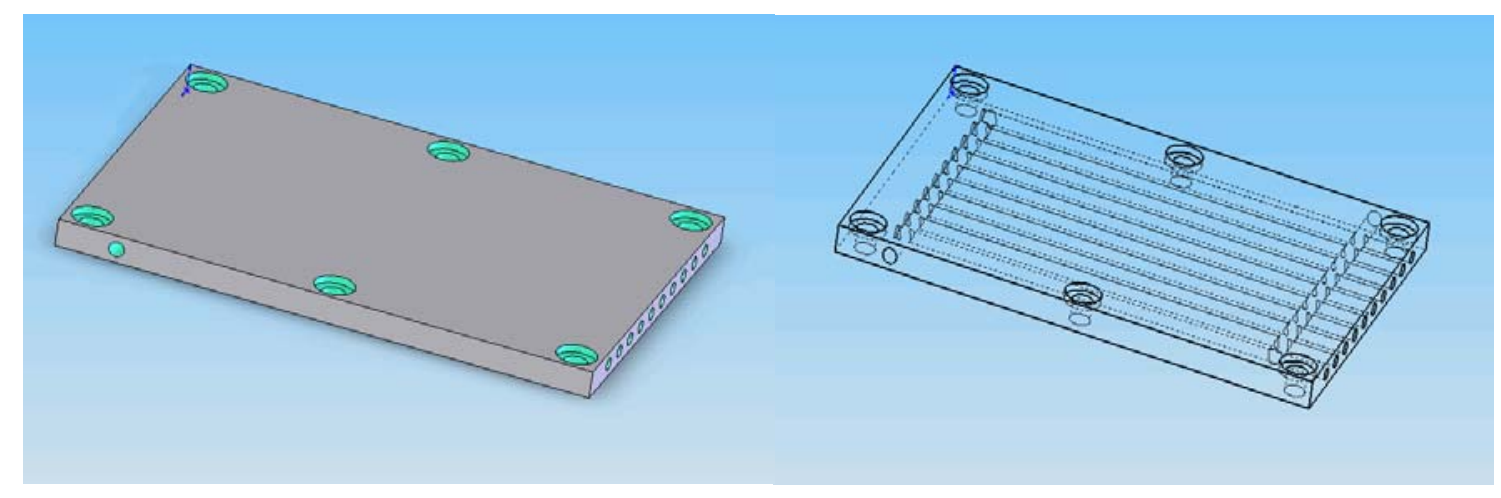

Figure 7. External and internal isometric views of cold plates 
The cold plates have six holes evenly spaced around the perimeter to accommodate the screws needed to attach to the card. The hole-pattern was slightly smaller than the current heat sinks, which helps prevent PCB warping when the cold plate is clamped or screwed down. PCB warping can cause uneven contact between the devices, or in this case heater blocks, and cold plate increasing the thermal resistance. These holes were counter-bored allowing the screw heads to be lower profile. Bellville disc washers were used with each of the six screws to help the cold plate provide a uniform force of $62.1 \mathrm{kPa}(9 \mathrm{psi})$ to the two heater blocks underneath. This force was needed to use the phase change material between the heater blocks and the cold plate. Threaded stainless steel pneumatic fittings with o-rings were used at the inlet and outlet orifices of the cold plates. There were two different inlet and outlet orientations of the cold plates which mirrored one another: top-left bottom-right, bottom-left top-right. This allowed for shorter, balanced piping on the board. Further cold plate specifications are listed in Appendix C.

\section{Heat Exchanger}

Two Lytron ES0714G heat exchangers were used to cool the heated liquid. It was difficult to find a single "off-the-shelf" heat exchanger with a frontal area equivalent to the fan trays and with a relatively short depth. The two Lytron heat exchangers provided an equivalent fan tray frontal area when placed next to one another and fit comfortably inside the chassis. The depths of the heat exchangers were $7.77 \mathrm{~cm}$ (3.06 in) which required the overall height of the router chassis to increase by $6.35 \mathrm{~cm}$ (2.5 in). This height increase also provided the chassis with the same size exit air plenum as the current chassis configuration. 
The heat exchangers were liquid-to-air aluminum oil coolers; though for this prototype the liquid was water. They have a fluid volume of $508 \mathrm{ml}\left(31 \mathrm{in}^{3}\right)$ and can tolerate temperatures up to $200^{\circ} \mathrm{C}$. The flat tube fluid channels and efficient header manifold result in a low pressure drop so smaller, less expensive pumps could be used. Figure 8 is a picture of the heat exchanger with a fan plate. The fan plates were removed before the heat exchangers were mounted in the chassis. The heat exchanger specifications are in Appendix C.

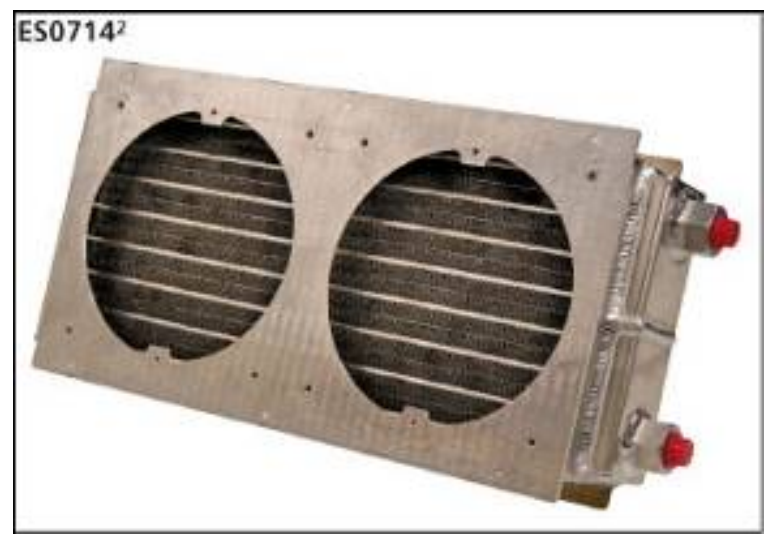

Figure 8. Lytron ES0714G liquid-to-air aluminum oil cooler heat exchanger

\section{Pumps}

Two Laing DDC2 12-volt pumps were installed in parallel, both capable of providing the desired $5.30 \mathrm{lpm}(1.40 \mathrm{gpm})$ liquid flow rate. These pumps are used in mass produced watercooled workstations. They have an expected service life of over 50,000 hours. The only moving part is the spherically shaped rotor which is seated on an ultra hard, wear resistant ceramic ball. The bearing is self-aligning and lubricated by the medium. The rotor is always magnetically held in its designated position. All parts in contact with the medium are also corrosion resistant. Figure 9 shows the exploded view of the pump. 


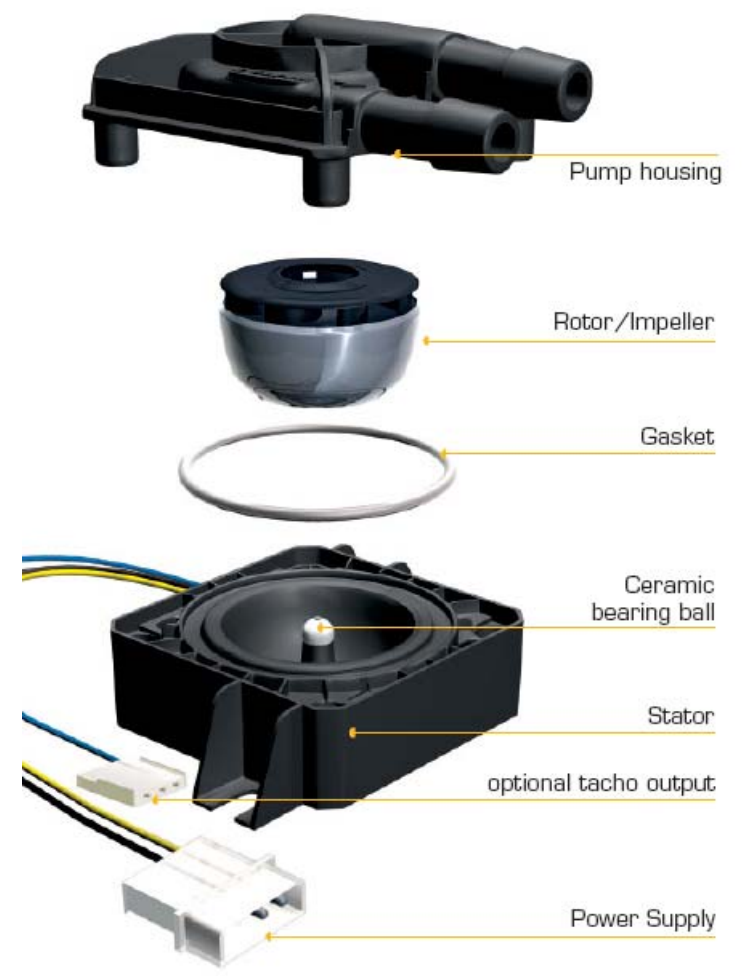

Figure 9. Laing DDC2 pump (exploded view)

These pumps have a power consumption of 18 watts, which is insignificant compared to the power consumed by the current fans and rack power. The dimensions for the pumps are $86.4 \mathrm{~mm} \times 87.9 \mathrm{~mm} \times 38.1 \mathrm{~mm}$ (3.40 in $\mathrm{x} 3.46$ in $\times 1.50$ in). The pumps can tolerate temperatures reaching $60^{\circ} \mathrm{C}\left(140^{\circ} \mathrm{F}\right)$. Figure 10 shows the assembled isometric view of the pump. 


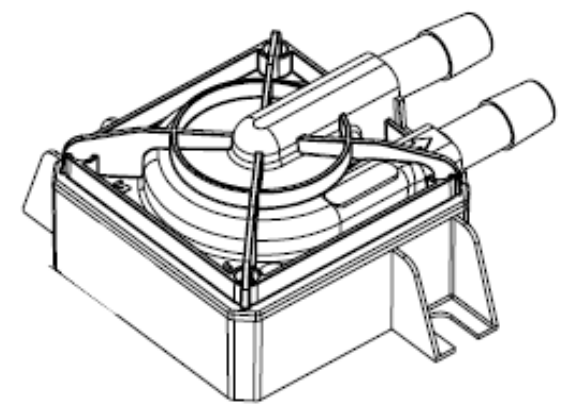

Figure 10. Laing DDC2 pump (isometric view)

Figure 11 (on the next page) shows the location of the pumps inside the chassis. Check valves were also used at the pump outlet to help regulate flow. Pump specifications are listed in Appendix C.

\section{Tubing}

The tubing was made from clear PVC. This tubing is used in food and beverage applications. It has a non-absorbing surface which resists bacterial growth. This helps prevent bacterial fouling in the lines. The tubing is flexible allowing for easier assembly. It ranges in sizes from an inside diameter of $12.7 \mathrm{~mm}(0.500 \mathrm{in})$ to the smallest of $3.2 \mathrm{~mm}(0.125 \mathrm{in})$. The smallest tubing was used only at the board level, while the majority of the system tubing was $12.7 \mathrm{~mm}$.

There was limited space on the board and the piping needed to fit inside without altering the components' layout. The tubing size on the board was selected to minimize board air flow obstruction and accommodate piping around other devices. The temperature rating for the tubing is $74^{\circ} \mathrm{C}\left(175^{\circ} \mathrm{F}\right)$. Due to the tubing material softening at higher temperatures, barbed fittings 
were used with tubing clamps. This helped ensure leak protection even when introduced to temperatures exceeding the rated value.

Figure 11 shows the tubing in the rear of the chassis and the location of the pumps and heat exchangers. Tubing is seen exiting the chassis, which was needed to introduce test equipment into the system. Tubing specifications are listed in Appendix C.

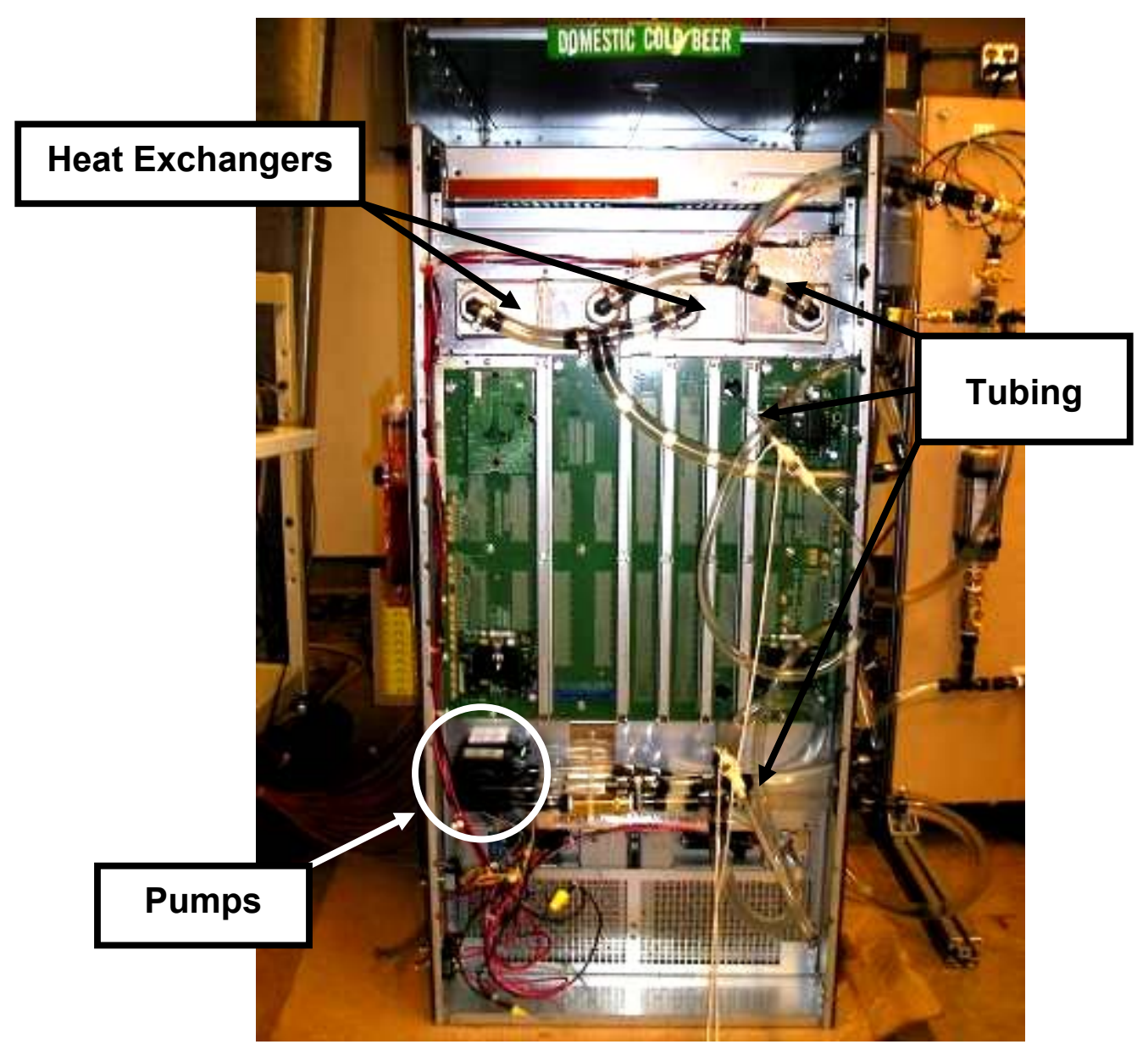

Figure 11. Back of chassis exposed showing tubing, pumps, and heat exchangers 


\section{Fittings}

The fittings used with the tubing were barbed nylon connectors. They were single barbed which helped minimize leaks because it had a smoother sealing surface than multi-bared connectors. The fittings have the same temperature rating as the tubing, $74^{\circ} \mathrm{C}\left(175^{\circ} \mathrm{F}\right)$. Tubing clamps were used with the fittings previously mentioned. The fittings can be seen in Figure 11 as the black connectors between tubing. Figure 12 shows some of the common tube-to-tube fittings. The fitting specifications are listed in Appendix C.

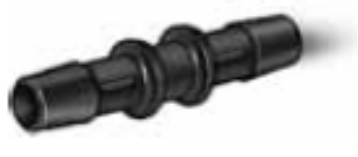

Couplings

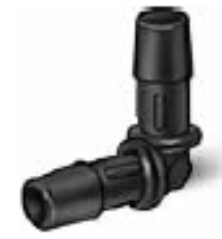

$90^{\circ}$ Elbows

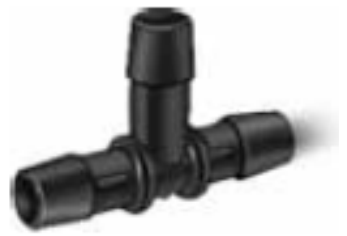

Tees

Figure 12. Nylon single-barbed connectors used with tubing

\section{$\underline{\text { Quick Disconnects }}$}

Quick disconnects were used to connect the board cold plates to the rest of the liquid system. The purpose of these couplings was to satisfy the constraint for the cards to be 'hot' swappable. The quick disconnects allow for frequent leak-free connections and disconnections. When the plug was inserted into the socket a latch was engaged in a groove on the plug, locking the assembly and permitting $360^{\circ}$ swiveling so tubing did not twist or kink. The temperature rating for these particular quick disconnects is $71^{\circ} \mathrm{C}\left(160^{\circ} \mathrm{F}\right)$. 


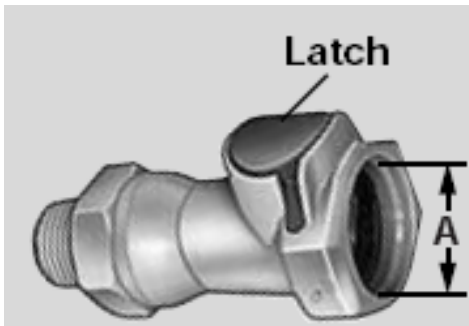

Socket

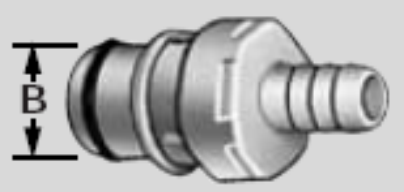

Plug

Figure 13. Quick disconnect coupling

Figure 13 shows an example of the socket and plug of the quick disconnect. The quick disconnects will be mounted to the backplane of the rack in the customer product, but they were not mounted for the prototype. Difficulties in mounting accounted for their loose attachment. Further quick disconnect details are described in Appendix C.

\section{$\underline{\text { Test Equipment }}$}

Additional equipment was needed for testing the board and system level heat transfer characteristics. This test equipment provided additional heat to the air (strip heaters), water (circulation heater), and card (test board), as well as a controlled air flow (blower). This test equipment is crucial for properly representing the future heat dissipation by the router system. Thus, their selection was based on the projected power increase for the card which was applied to the entire rack of 9-cards. The expected system power percentages to air and water found in the preliminary analyses were also used to size the equipment. Ultimately, the strip heaters and circulation heater would generate the proper air and water powers representing the remaining 8 cards not inserted into the rack. The test board represents one individual card for both air and 
water heat transfer. All this equipment represented the projected power increase for the entire router system.

\section{Blower}

A blower was used to force air through a laminar flow element, which was used to measure volumetric flow rates. It is then guided to the chassis through a special fitting and ducting. A damper was placed at the beginning of the ducting to control the air flow going through the chassis. The chassis inlet pressure would be calculated based off the laminar flow element volumetric flow rate. The damper would be used to adjust the flow rate to obtain the proper cabinet inlet pressure.

\section{Strip Heaters}

Strip heaters were used to heat up the remaining air which did not pass through the test board. From the preliminary analyses results shown previously in Table 2, approximately $610 \mathrm{~W}$ from a single card gets transferred to the air. This means the strip heaters need to be able to supply a total approximate power of $5 \mathrm{~kW}$ to accurately represent the total heat dissipation to air for 8 -cards. The test board accounts for the $9^{\text {th }}$ card. These strip heaters generate heat by electrical resistance and their rate for $832 \mathrm{~W}$, supplied by a $208 \mathrm{~V}_{\text {ac }}$ power source. The power supplied to the strip heaters was further controlled with an SCR power controller for electrical resistance heaters. The SCR controller smoothly proportioned electric power to the resistance heaters based on the control signal. This allowed better manipulation of the test environment. 
The strip heaters were mounted in the center of card-blanks. These card blanks had perforated metal sheets attached at the bottom creating an air flow pressure drop similar to that experienced by a card full of components. This helped create a more accurate representation of the system's heat dissipation to the air. Each strip heater spanned roughly the entire length of the card blank and was slightly thinner than the card pitch. This allowed for uniform heating to the air passing through, representing the average air temperature increase across 8-cards. Figure 14 shows a strip heater mounted to a card blank and Figure 15 shows the card blank being inserted into the rack. Specifications on the strip heaters and SCR controllers are shown in Appendix C.

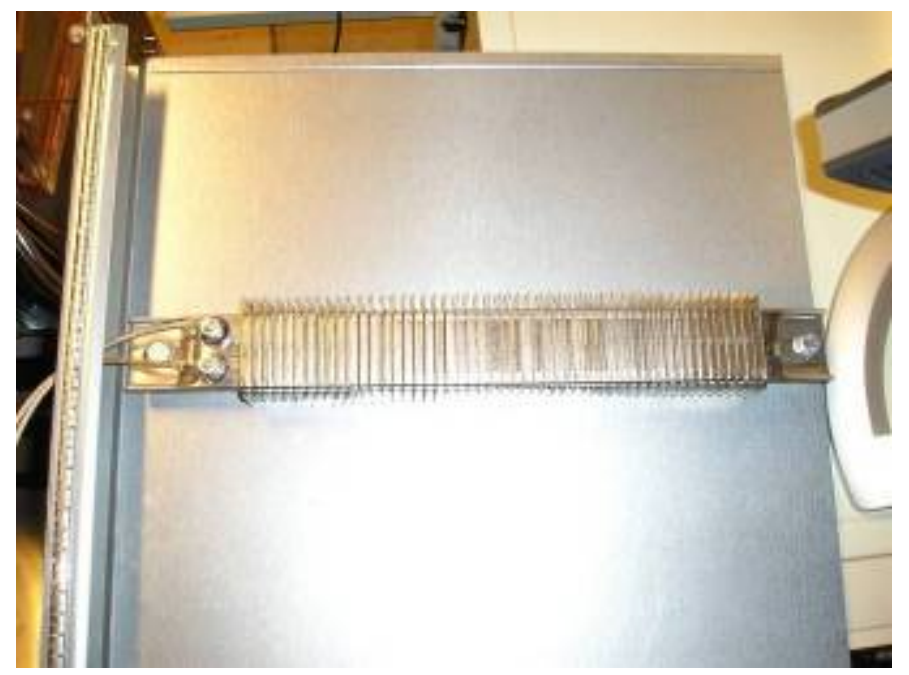

Figure 14. Strip heater mounted to card blank 


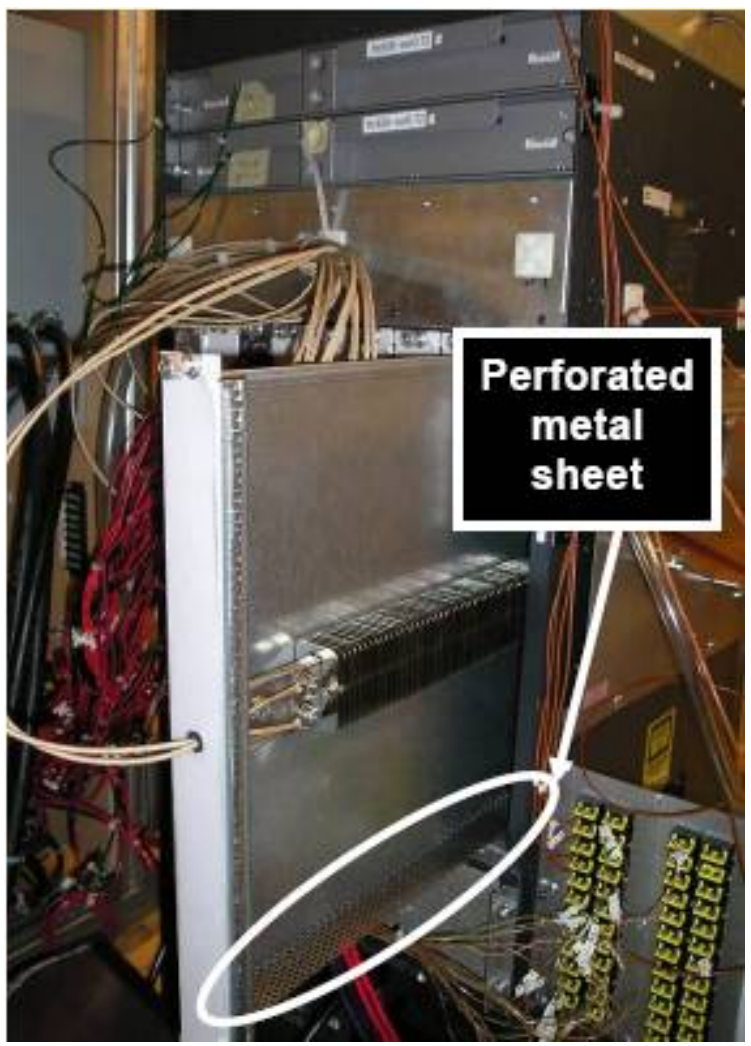

Figure 15. Card blank (with strip heater) inserted into rack

\section{$\underline{\text { Circulation Heater }}$}

A Watlow CBEB23J10-20 circulation heater was used as a way of heating the remaining system water which was not passing through the cold plates. From the results in Table 2, about $400 \mathrm{~W}$ is supplied to the water from the cold plates on a single card. Thus the total amount of power dissipated to the water for the remaining 8-cards would be approximately $3.2 \mathrm{~kW}$. This circulation heater has a rated power of $3.7 \mathrm{~kW}$ supplied by a $208 \mathrm{~V}_{\text {ac }}$ power source. The power supplied to the circulation heater was controlled in the same manner as the strip heaters; by an SCR power controller. The SCR controller adjusted the circulation heater outlet water temperature to match that of the test board water outlet temperature. Thus a better simulating environment was created allowing for realistic system characteristics. The circulation heater was 
connected to the liquid system from outside of the chassis. Figure 16 shows a Watlow circulation heater similar to the one used. Circulation heater specifications are listed in Appendix C.

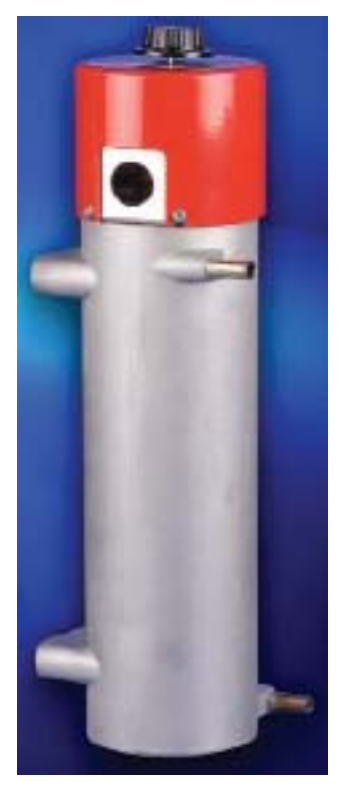

Figure 16. Watlow circulation heater similar to the one used in experiment

\section{$\underline{\text { Test Board }}$}

In order to simulate the heat dissipation generated by a card a mock test board was built. The test board had the same component powers and layout as one of Cisco's card designs. Every component on the card was sized, positioned, and power rated. This information was extracted from a FloTherm model provided by Cisco. Given this information, kapton heaters were selected to best represent individual and clusters of components. These kapton heaters were attached to PCB boards representing the mainboard and daughter cards. Some of the components had significant heights, so aluminum blocks were created and the kapton heaters were placed on the under sides of the blocks. This simulated the distributed heat across the entire device case. Individual heat sinks were placed on top of heater blocks representing the card components with 
individual heat sinks. Components such as connectors and capacitors did not generate heat, but their physical dimensions had an influence on the air flow through the card. These components were represented by solid aluminum blocks and placed in their respective locations.

The two "X" and two "Y" complexes on the real card were each simulated by an "X" complex on the test board. This representation of the card complexes matched the preliminary design simulation model mentioned earlier in Chapter 2. Each " $X$ " complex was represented by both an "A" and "B" heater block attached to its cold plate. These heater blocks had the same dimensions as the respective device and also had high power mica heaters adhered to their underside. Alumina thermal adhesive was used to attach the mica heaters to the aluminum blocks. The mica heaters were used instead of the kapton heaters because the watt density needed for those particular devices was above the kapton limits.

A "X" complex Test Chip was used to represent the last complex in the air stream on the mainboard. The " $\mathrm{X}$ " complex Test Chip had temperature sensitive resistors located throughout the chip, allowing accurate measurements of the junction temperature. The location of the " $\mathrm{X}$ " complex Test Chip at the end of the test board air stream was chosen based on the air temperature being higher at the end of the stream. Since the temperature would be the highest at that location there would be less heat transfer to the air and the devices would have the highest junction temperatures on the test board.

The " $\mathrm{A}$ " heater block was expected to generate close to $90 \mathrm{~W}$ while the " $\mathrm{B}$ " heater block would generate $46 \mathrm{~W}$. The total power attached to the cold plates was approximately $136 \mathrm{~W}$. 
The "C" heaters were not attached to the cold plates, as described in the preliminary design analysis, due to the complexity of height differences between components. Based on the voltage supplied to the groups of kapton heaters and their measured resistances, the total test board power was expected to be approximately $1040 \mathrm{~W}$. There were several different voltages used to provide the power rated for the heaters. Therefore heaters were grouped together based on the nominal voltage needed to provide their respective powers.

Thermocouples also accompanied the heaters and cold plates. The thermocouples were placed on cold plates, heater blocks, the PCB, and an "A" mica heater. These thermocouples were used to measure the temperatures across the test board. A thermocouple was placed in the center of the underside of each cold plate. Another thermocouple was placed on top of the cold plate at the water outlet location. These were used to determine the thermal characteristics of the cold plates.

The daughter cards were placed face down over the Main Board, creating space limitations and the stacking of many components on top of one another. There clearance was less than $1 \mathrm{~mm}$ between components when the test board was fully assembled. A complex on one of the daughter cards had a cold plate connected in parallel with the remaining three cold plates on the Main Board. This required meticulous assembly of the test board, ensuring leak-free connections. 


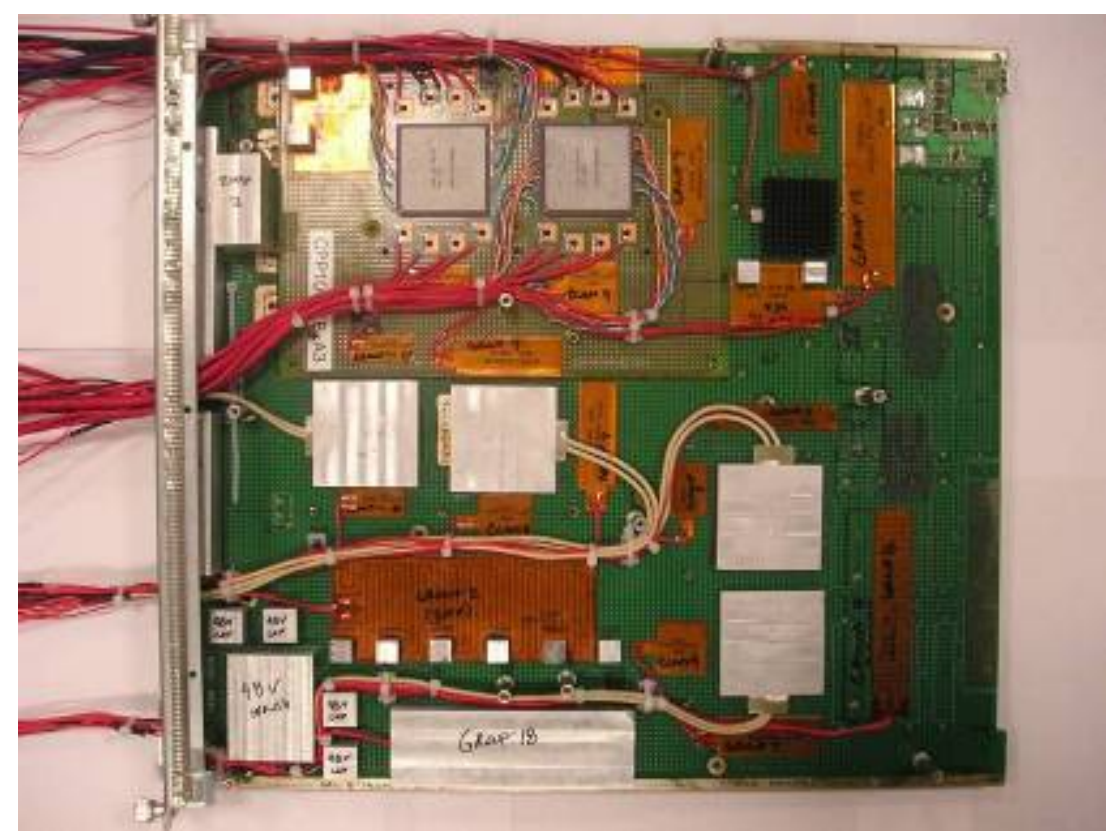

Figure 17. Mock mainboard with heater and aluminum blocks

Figure 17 shows the heaters and aluminum blocks attached to the mock mainboard with all wires exiting its front plane. The wires were bundled together and guided out of the mock test board in a manner meant to minimize air flow obstruction. The wires actually obstructed the air flow across the mock test board more than would be obstructed on the real card. This implies the real card would be expected to have slightly better thermal characteristics than the mock test board.

Figure 18 shows the mock mainboard assembled with cold plates. This further demonstrates space limitations. Figure 19 and Figure 20 show the daughter cards with and without the cold plate attached, respectively. One of the large aluminum blocks was replaced by a smaller wood block to accommodate the cold plate plumbing connections in the full assembly. Figure 20 shows the wooden block installed on the Test Board assembly. 


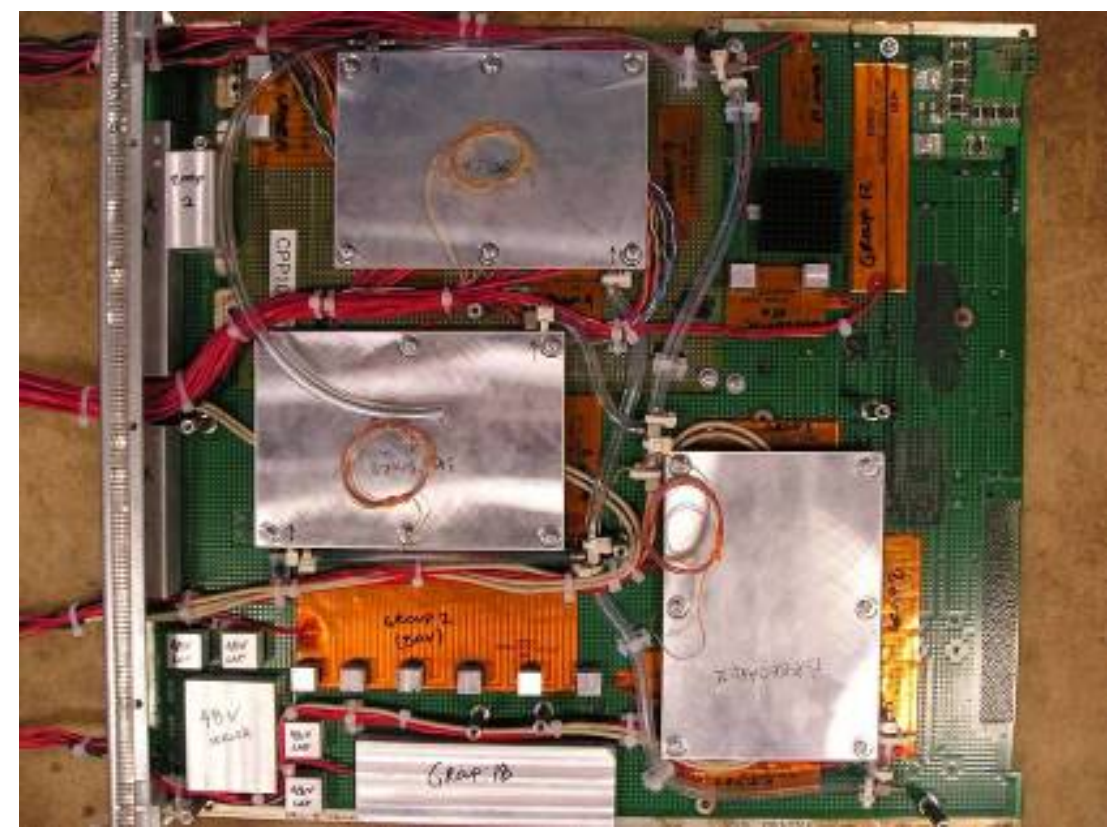

Figure 18. Mock Main Board assembled with cold plates and piping

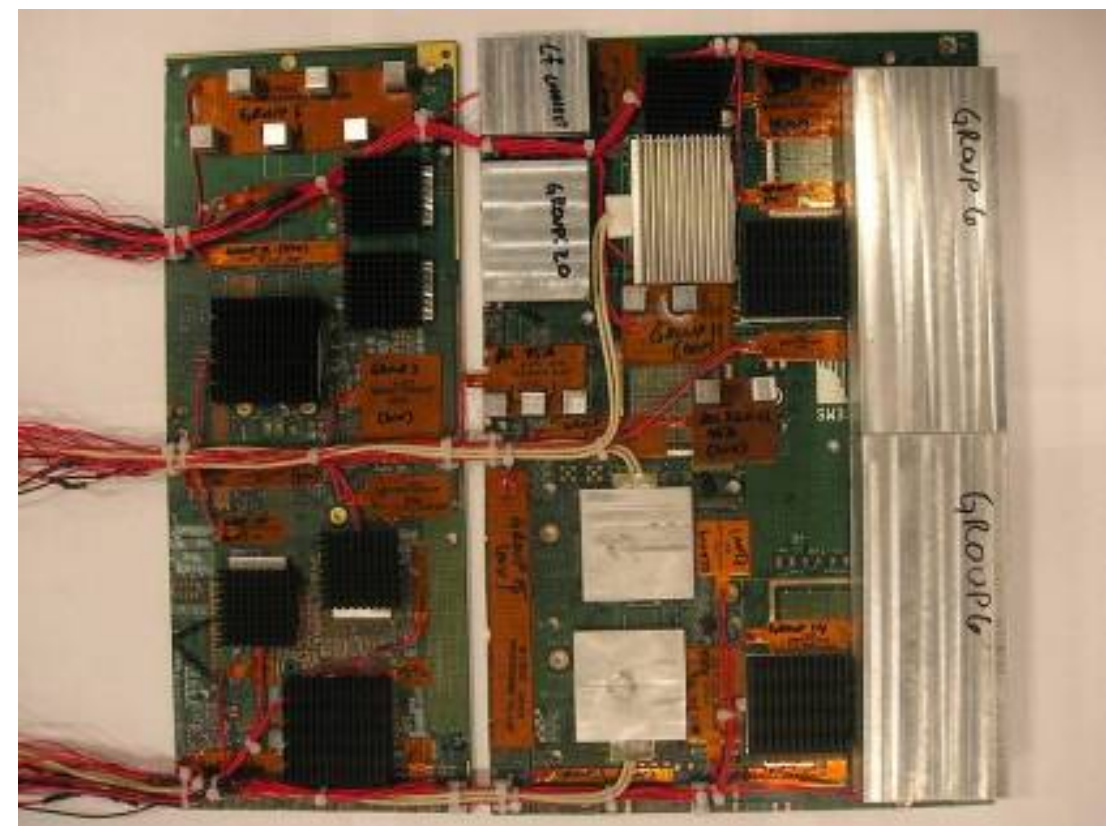

Figure 19. Mock Daughter Cards with heaters and aluminum blocks 


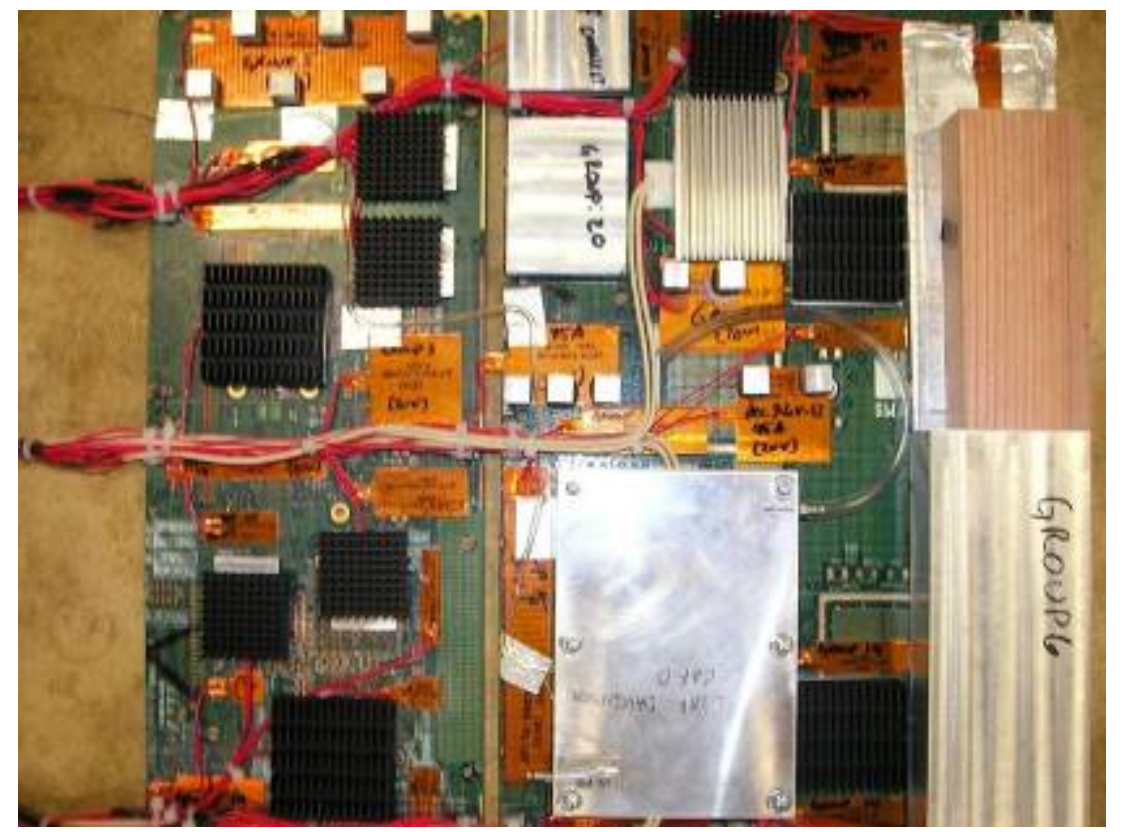

Figure 20. Mock Daughter Cards assembled with cold plate

Figure 21 shows the full test board assembly with the daughter cards flipped face down on top of the mainboard with all the wires exiting in the same direction.

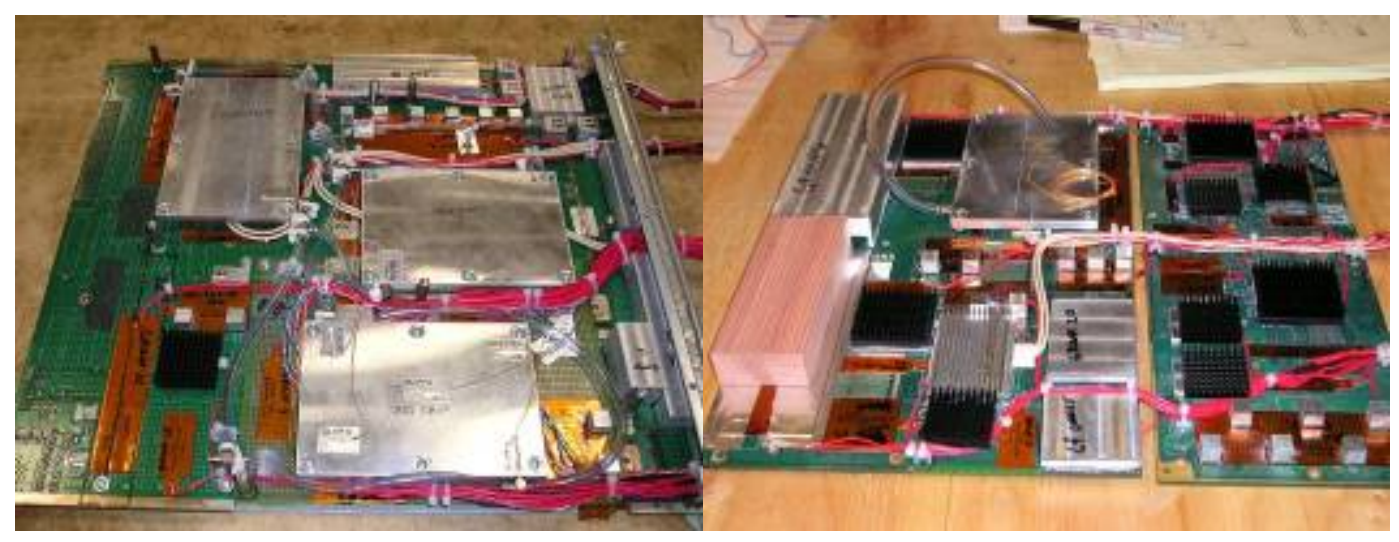

Figure 21. Mock mainboard (left) and daughter cards (right) 
All the test board schematics and specifications are listed in Appendix B. These include: heater specifications and locations, liquid flow mapping, thermocouple locations, and test chip layout.

The prototype equipment simulated the behavior of the design under the expected heat load. The remaining equipment needed for this prototype allowed for measurements to be collected during operation.

\section{Measurement Equipment}

The measurements needed during testing were electrical power, differential and gauge pressures, air and liquid volumetric flow rates, fan speeds, and temperatures. These measurements allowed the design capability analysis to be performed. There were many devices used to acquire measurements during testing, such as manometers, volt meters, and thermocouples to name a few. Every measuring device had an error or uncertainty associated with the reading. These uncertainties influenced the accuracy of the measurements as well as the calculations using this data. Equipment selection was focused on minimal measurement uncertainties, use or implementation, and availability. Some equipment was from the Mechanical Engineering Department and the rest was purchased. Figure 22 shows the laboratory set up with all the test and measurement equipment. 


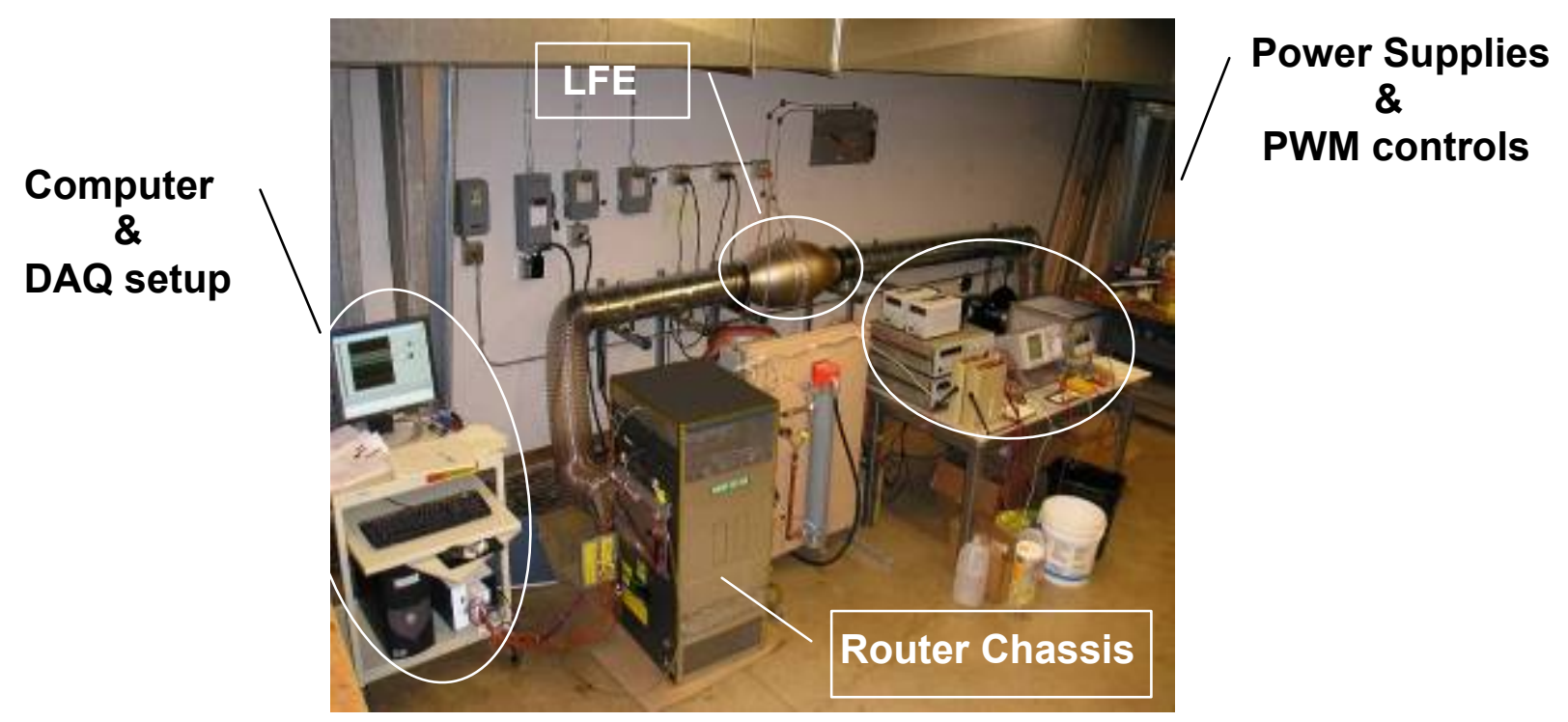

Figure 22. Laboratory layout with all test and measurement equipment

\section{$\underline{\text { Power }}$}

Power to the test board heaters, not including the "A" test chip, was supplied by two HP 6012b DC power supplies. The "A" test chip was supplied by two smaller GPS-Series (Digital) DC power supplies. Both sets of power supplies could be adjusted to obtain various power outputs. Figure 23 shows the terminal block panel was used to supply power to the test board, strip heaters, and circulation heater along with the front plane of the chassis. The outputs from the HP power supplies were connected to main terminal blocks which distributed the power to other terminal blocks through power resistors. The power resistors were used to reduce the supply voltage to various terminal blocks since not all the heaters were operated at the same supply voltage. 


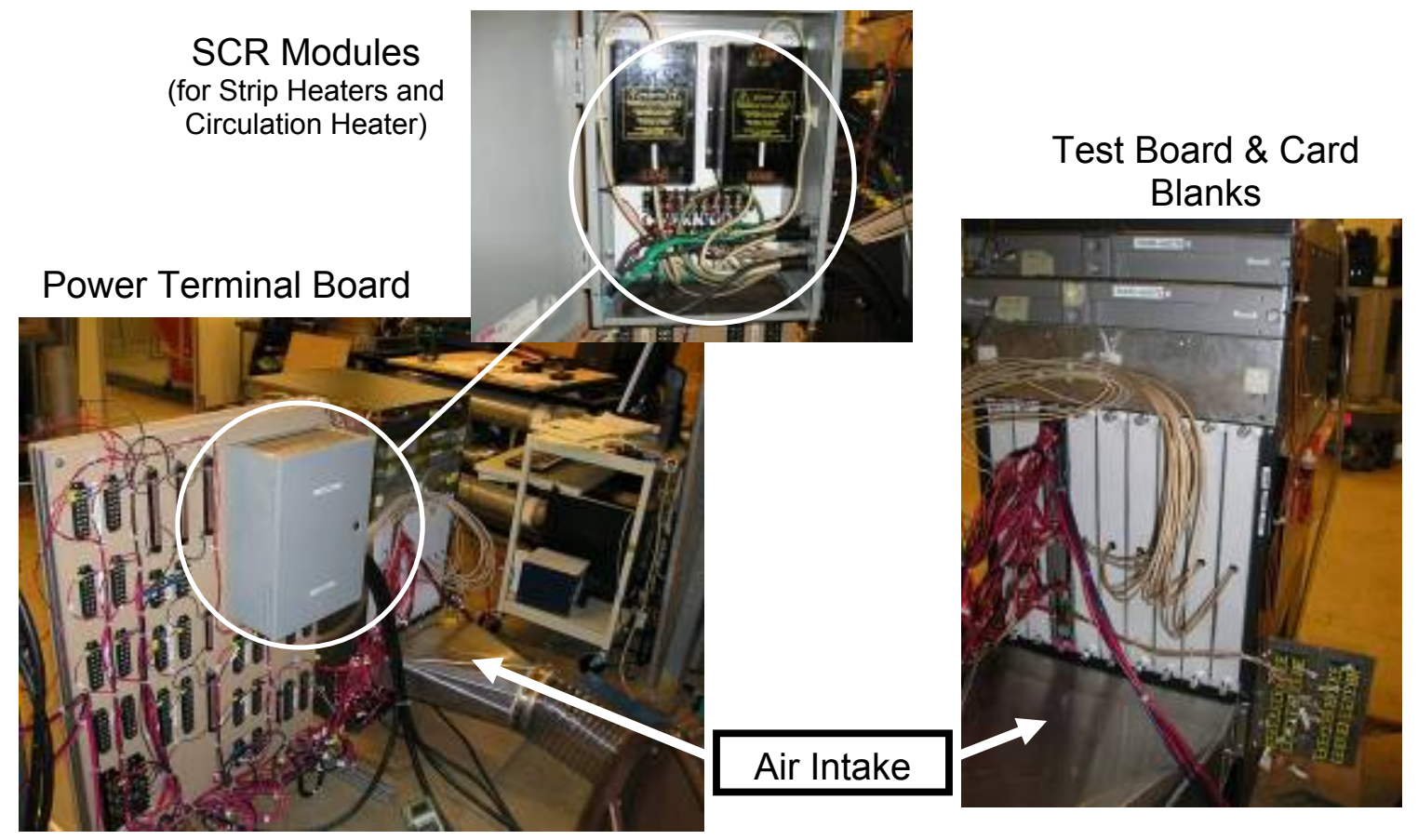

Figure 23. Power terminal block panel and front plane of chassis with attached air intake fitting

The SCR controllers for the strip heaters and circulation heater were directly plugged into $208 \mathrm{~V}_{\text {ac }}$ single phase circuit breakers. Two simple electrical circuits with potentiometers were used to adjust the control current (mA) to the SCR controllers. The control currents were measured with two digital multi-meters, allowing continuous control during testing. The control current measurements paired with proper scaling helped determine the power supplied to the strip heaters and circulation heater.

Power was measured for the strip heaters, circulation heater, the " $\mathrm{A}$ " and " $\mathrm{B}$ " test chips of the "X" complex Test Chip, and the heaters on the test board. A digital multi-meter and a clamp-meter were used to determine the voltages and currents being supplied to the heater groups on the test board, including the " $\mathrm{A}$ " and "B" test chips. The digital multi-meter and 
clamp-meter were also used to determine the voltages and currents which were supplied to the strip heaters and circulation heater. Because their powers were regulated by SCR controllers, the voltages and currents fluctuated over different ranges and at different frequencies depending on the input signal. Steady measurements were only obtained at full power and the other measurements were visually averaged. All measurements taken with the digital multi-meter and clamp-meter were used for a couple of reasons. First, to double check the mock test board total power. And second, to see individual heater group powers such as, "A" and "B" heaters and "X" complex Test Chip heaters ("A" test chip and "B" test chip).

The uncertainty associated with the clamp-meter was $\pm 5 \%$ reading $+2.5 \mathrm{~A}$. The uncertainty associated with the digital multi-meters was $\pm 0.05 \mathrm{~V}$. The uncertainty associated with the GPS-Series (Digital) power supplies was $\pm 5 \%$ reading +2 digits for both voltage and current. The measurement uncertainties will be further discussed in the Results section and Appendix A.

\section{Pressure}

Pressure measurements were acquired to help determine the air volumetric flow rate along with determining various gauge pressures throughout the cabinet. These measurements were obtained from inclined manometers filled with water. The uncertainty with these manometers was $\pm 2.5 \mathrm{~Pa}\left( \pm 0.01 \mathrm{inH}_{2} \mathrm{O}\right)$. Figure 24 shows the manometer used to measure the cabinet air pressures along with the thermocouple connecter block. 


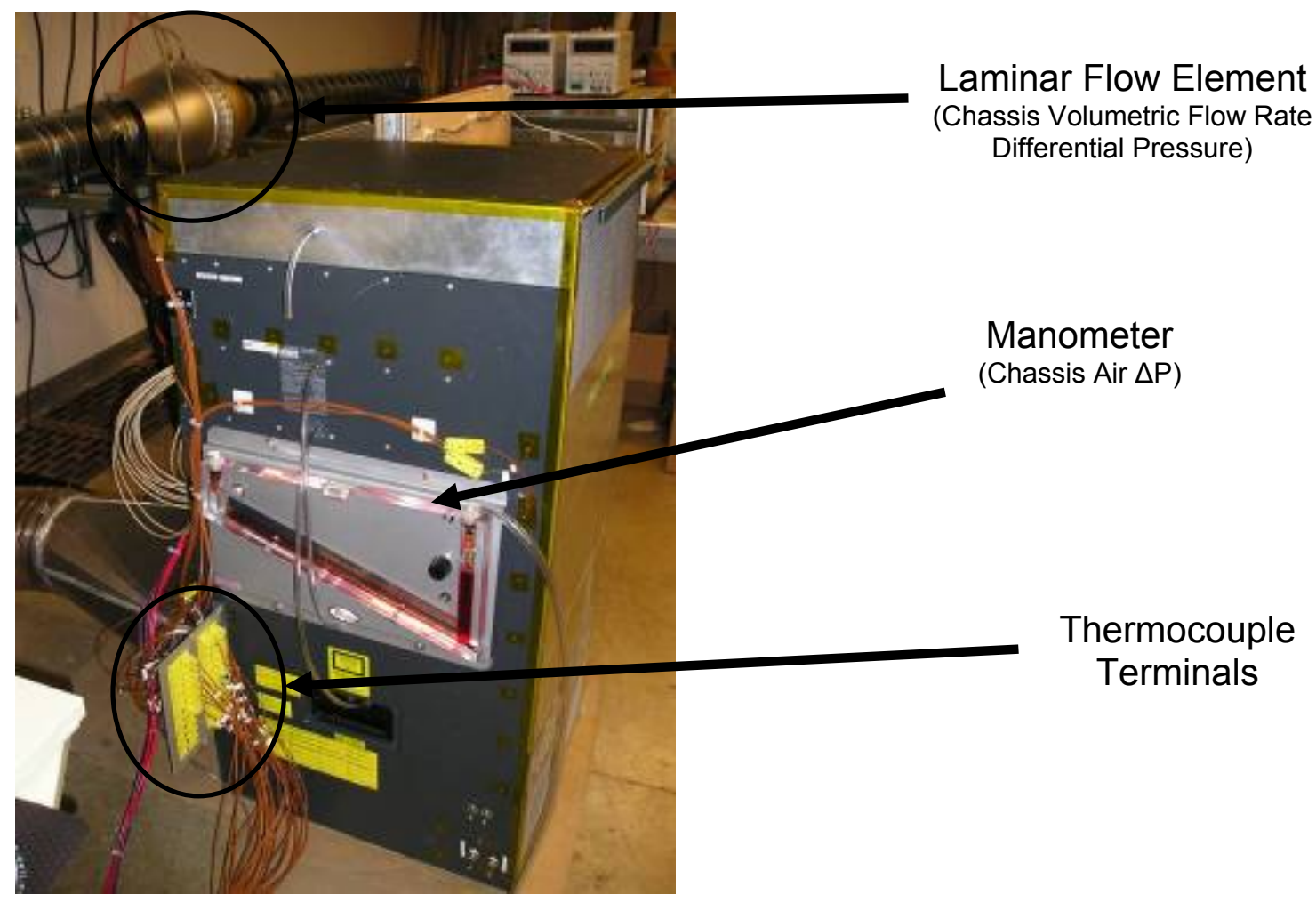

Figure 24. Chassis mounted manometer with thermocouple connector terminal and laminar flow element shown in the background

\section{Air Volumetric Flow Rate}

A laminar flow element was used to determine the volumetric flow rate of air going through the cabinet. This device has many small channels which air passes through in the laminar flow regime. The differential pressure between the inlet and outlet is measured using a manometer. This differential pressure is then converted to volumetric flow using the calibration curve given by the manufacturer. There was a specified length of straight pipe/ducting needed before and after the laminar flow element in order to create the correct flow regime. The error associated with the laminar flow element was $\pm 0.86 \%$ per $0.472 \mathrm{~m}^{3} / \mathrm{s}(1000 \mathrm{cfm})$. Figure 25 shows what the laminar flow element looks like in the system. 


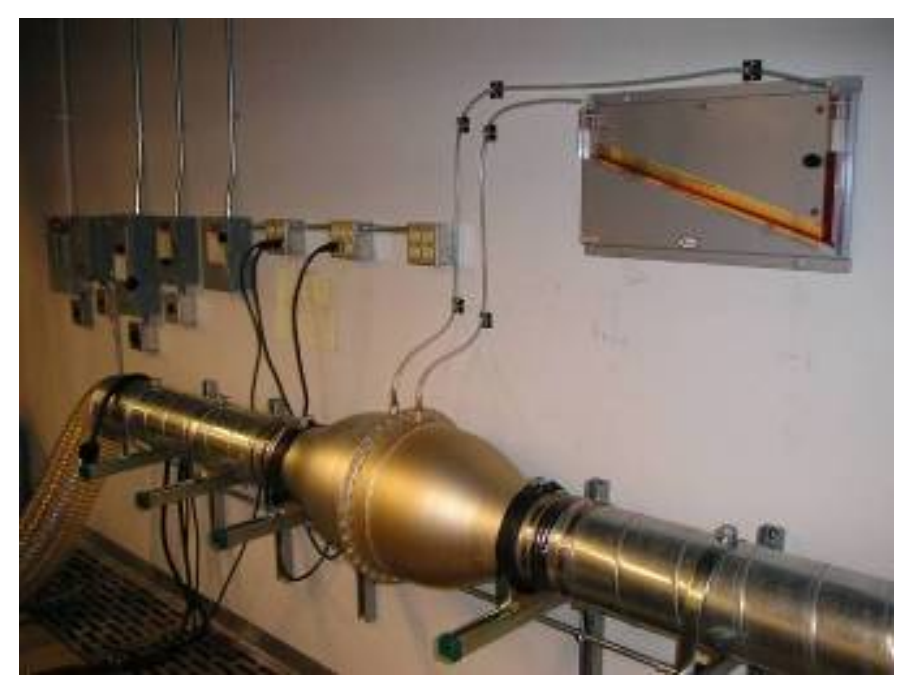

Figure 25. Laminar flow element with manometer used to measure the air volumetric flow rate through the chassis

\section{Fan Speed}

When the routers are placed in data centers the air volumetric flow rate through the cabinet cannot be measured. Instead, tachometer outputs from the fans are used along with performance curves to estimate the air volumetric flow rate. One fan tachometer output was used during testing. The wire output was placed in a simple circuit, outlined by the fan manufacturer, to get a pulse reading on an oscilloscope. The frequency of the pulses was used to determine the fan speed in revolutions per minute.

\section{Liquid Volumetric Flow Rate}

The liquid volumetric flow rates were measured using rotameters. The mock test board flow rates and circulation heater flow rates were measured with separate flow meters. The test board had lower flow rates requiring a smaller scaled flow meter and visa versa for the circulation heater flow. By adding the two flow rates, the total system liquid volumetric flow rate 
was determined. The uncertainties for the higher and lower flow rate rotameters are $\pm 2 \%$ full scale of $18.9 \mathrm{lpm}(5.0 \mathrm{gpm})$ and $7.6 \mathrm{lpm}(2.0 \mathrm{gpm})$ respectively. Figure 26 shows the locations of the mounted flow meters along with the reservoir used to fill the system and accommodate volume increases due to thermal expansion.

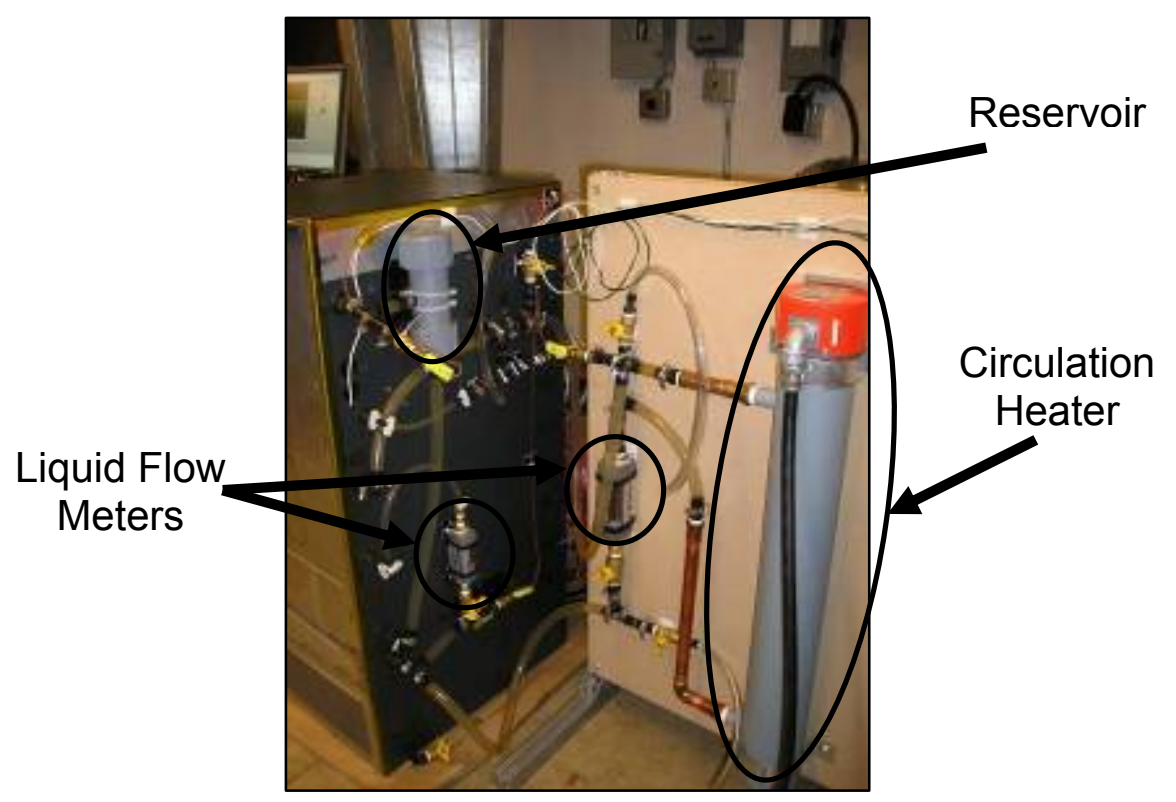

Figure 26. Liquid flow meters, reservoir, and circulation heater

\section{$\underline{\text { Temperature }}$}

The temperatures of the water, air, and test board components were measured with thermocouples. These thermocouples were grounded K-type with an uncertainty of $\pm 1.0^{\circ} \mathrm{C}$. The temperatures of the "A" and "B" test chips were measured from internal temperature sensitive resistors. Calibration curves were used with the measured resistances to determine the " $\mathrm{A}$ " test chip and "B" test chip junction temperatures. All the thermocouples and resistors were connected 
to a data acquisition system which continuously acquired measurements using a program called LabVIEW.

The prototype and measurement equipment were continuously checked during testing to ensure proper operation. The air flow damper was adjusted multiple times in order to obtain the correct cabinet air inlet conditions. The circulation heater power needed to be regulated so the outlet water temperature matched the test board outlet water temperature. The equipment dictated how the tests would be performed and influenced the accuracy of the results. 


\section{Chapter 4}

\section{Testing and Data}

This section presents the collected data and provides a brief explanation of how the tests were executed.

\section{$\underline{\text { Testing }}$}

There were a total of nine separate tests performed on hybrid-liquid cooling design. These tests varied fan speed (air flow rate), liquid flow rate, and power supplied to the "X" complex Test Chip. The results from these tests outline the system limits for the hybrid liquid cooling design.

\section{$\underline{\text { Tests }}$}

The first test performed in the series was the baseline test. This test operated the system at $100 \%$ of its expected performance. The baseline test was used as a reference for analyzing the other test data and characterizing the system design. The remaining tests varied fan speed and liquid flow rates to identify system operating conditions which would cause the junction temperature of the " $\mathrm{A}$ " test chip to approach, but not exceed, its $105^{\circ} \mathrm{C}$ limit. The last two tests operated the system beyond its expected power conditions; increasing the " $\mathrm{X}$ " complex Test Chip power above the projected power of $142 \mathrm{~W}$. Table 4 shows the test matrix with the variable adjustments during each test. 
All the tests were performed at sea level with an ambient air temperature that ranged from $29^{\circ} \mathrm{C}$ to $33^{\circ} \mathrm{C}$. This range was contributed to the laboratory temperature increasing during test operation because of the router's heated exhaust air. The operating conditions outlined for the design were $40^{\circ} \mathrm{C}$ ambient air at $10,000 \mathrm{ft}$ elevation and $50^{\circ} \mathrm{C}$ at $6,000 \mathrm{ft}$ elevation. Laboratory conditions could not meet these requirements, so the test data was adjusted to represent the system operating under the stated conditions.

Table 4. Test Matrix

\begin{tabular}{|c|c|c|c|c|}
\hline Test & \multicolumn{4}{|c|}{ Test Variables } \\
\hline & $\begin{array}{c}\text { Test Board } \\
\text { Power }\end{array}$ & $\begin{array}{c}\text { Fan } \\
\text { Speed }\end{array}$ & $\begin{array}{c}\text { Liquid Flow } \\
\text { Rate }\end{array}$ & $\begin{array}{c}\text { Test Chip } \\
\text { Power }\end{array}$ \\
\hline $\mathbf{1}$ & $100 \%$ & $100 \%$ & $100 \%$ & $100 \%$ \\
\hline $\mathbf{2}$ & $100 \%$ & $75 \%$ & $100 \%$ & $100 \%$ \\
\hline $\mathbf{3}$ & $100 \%$ & $50 \%$ & $100 \%$ & $100 \%$ \\
\hline $\mathbf{4}$ & $100 \%$ & $25 \%$ & $100 \%$ & $100 \%$ \\
\hline $\mathbf{5}$ & $100 \%$ & $100 \%$ & $75 \%$ & $100 \%$ \\
\hline $\mathbf{6}$ & $100 \%$ & $100 \%$ & $50 \%$ & $100 \%$ \\
\hline $\mathbf{7}$ & $100 \%$ & $75 \%$ & $75 \%$ & $100 \%$ \\
\hline $\mathbf{8}$ & $100 \%$ & $100 \%$ & $100 \%$ & $130 \%$ \\
\hline $\mathbf{9}$ & $100 \%$ & $75 \%$ & $100 \%$ & $130 \%$ \\
\hline
\end{tabular}

\section{Testing Procedure}

The test procedure used for is outlined on the next page. Under normal operating conditions the chassis would be placed in an open room at atmospheric pressure, but for this testing air was ducted to the cabinet inlet to accurately measure the air volumetric flow rate. With the air being ducted to the cabinet inlet, air flow adjustments were needed to simulate the chassis in normal operating conditions. For example, when exposed to an open room there is a pressure lower than atmospheric pressure at the cabinet inlet because air flows into the chassis. The lower pressure at the cabinet inlet is influenced by air velocity which is correlated to the 
volumetric flow rate. With the volumetric flow rate and cabinet inlet frontal area, the expected cabinet inlet pressure was calculated using Bernoulli's equation or

$$
\Delta P=\frac{1}{2} \rho v^{2}
$$

where $(\Delta P)$ is the pressure drop between the cabinet inlet and atmospheric pressures, $(\rho)$ is air density assuming air as an ideal gas, and (v) is air velocity.

The ducted air flow was adjusted in order to produce pressures at the cabinet inlet matching the calculated pressures from Equation [2 ]. Also, the circulation heater power was regulated so its outlet water temperature matched the test board outlet water temperature. The following procedure explains the start up, system checks, and general measurements collected during one test. Further explanations on measurements are in the next section titled "Data".

\section{Test Procedure:}

1. Run LabVIEW and verify all thermocouples are working properly

2. Turn on blower, pumps, and fans

3. Measure laminar flow element differential pressure and enter reading into an Excel file which calculates the expected cabinet inlet pressure, based on the volumetric flow rate and cabinet inlet cross-sectional area, using Equation [2 ] (See Appendix A for a sample calculation)

4. Check cabinet inlet pressure and compare to value in Excel calculation 
5. Adjust damper until cabinet inlet pressure corresponds closely with Excel calculation $\left[ \pm 12.5 \mathrm{~Pa}\left( \pm 0.05 \mathrm{inH}_{2} \mathrm{O}\right)\right]$

6. Turn on breaker boxes to strip heaters and circulation heater

7. Adjust supply circuit potentiometers to provide desired power outputs (dependent on test being performed) to strip heaters and circulation heater

8. Turn on all power supplies to the Test Board and adjust voltages to desired ratings

9. Check flow meters and adjust valves as needed to obtain a higher flow rate at Flow Meter 1 which is approximately $8 \mathrm{x}$ greater than the flow rate at Flow Meter 2 (the lower flow rate should be close to $1 / 9^{\text {th }}$ of the total flow rate)

10. Adjust circulation heater potentiometer until circulation heater outlet temperature matches the test board water outlet temperature.

11. Wait a few minutes for system to reach steady state ( $\sim 20$ minutes)

12. Record temperatures using LabVIEW, cabinet pressures, laminar flow element differential pressure, electrical powers (voltages and currents), fan speed (frequency on oscilloscope)

13. Adjust test variables and repeat steps 3 through 12

Continuous watch on all readings was needed to ensure the system did not deviate from the desired set point. When the laboratory ambient temperature increased the LFE differential pressure changed, requiring adjustments to the ducted air. Also, as the water temperatures 
increased the liquid flow rates would change. Often several iterations of the test procedure would be conducted in order to get the system to reach steady state.

\section{Data}

All collected data is presented in this section. The data consists of four major categories: temperature, flow rate, pressure, and electrical power.

\section{$\underline{\text { Temperature }}$}

The closed loop liquid temperature was measured at four points. These points can be seen in Figure 27 showing the liquid closed loop.

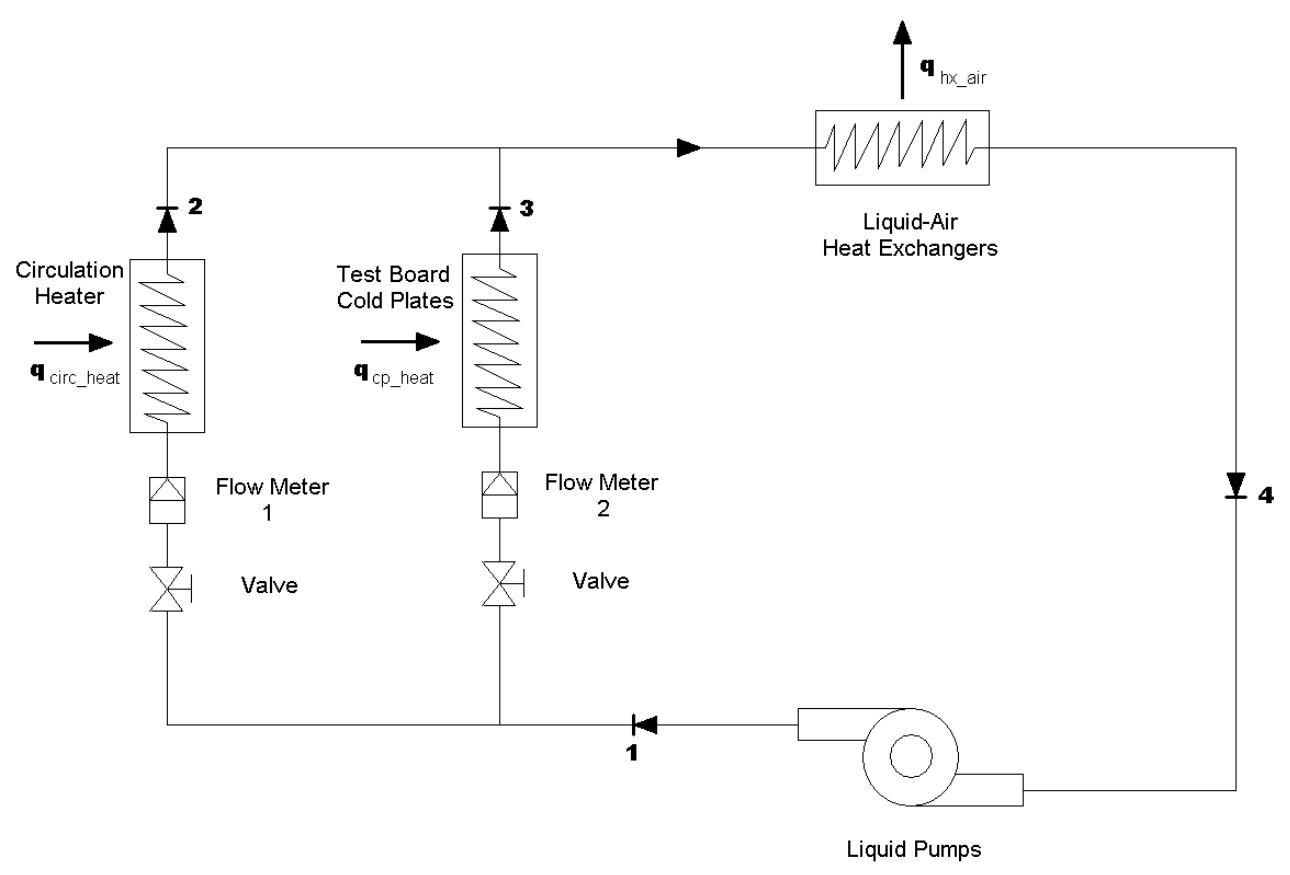

Figure 27. Liquid closed loop diagram showing temperature probe, flow meter and valve locations 
The temperature at Point 1 was of the liquid before it passed through the circulation heater and Test Board cold plates, thus giving the initial state of the liquid. The liquid temperature increased as it passed through the Test Board cold plates and circulation heater. The temperature at Point 4 was of the liquid after it passed through the liquid-air heat exchanger and was cooled. The temperatures at Point 1 and Point 4 were the same temperature because the energy transferred by the liquid pumps was negligible. Table 5 shows all the measured liquid temperatures for the nine tests.

Table 5. Measured liquid temperatures

\begin{tabular}{|c|c|c|c|c|}
\hline \multirow{2}{*}{ Test } & \multicolumn{4}{|c|}{ Liquid Temperature ( $\left.{ }^{\circ} \mathbf{C}\right)$} \\
\cline { 2 - 5 } & Point 1 & Point 2 & Point 3 & Point 4 \\
\hline $\mathbf{1}$ & 42 & 52 & 53 & 42 \\
\hline $\mathbf{2}$ & 45 & 58 & 57 & 45 \\
\hline $\mathbf{3}$ & 48 & 60 & 61 & 49 \\
\hline $\mathbf{4}$ & 57 & 72 & 70 & 57 \\
\hline $\mathbf{5}$ & 44 & 58 & 57 & 44 \\
\hline $\mathbf{6}$ & 44 & 61 & 62 & 44 \\
\hline $\mathbf{7}$ & 46 & 60 & 60 & 46 \\
\hline $\mathbf{8}$ & 44 & 57 & 56 & 44 \\
\hline $\mathbf{9}$ & 45 & 57 & 57 & 45 \\
\hline
\end{tabular}

The temperature of the air passing through the chassis was measured at eight different points; the locations of these thermocouples are shown in Figure 28 and the measured temperatures are in Table 6 . The air temperature was first measured before it entered the chassis at Point 1. Point 2 was in the middle of the Test Board, which was located in slot 3 on the chassis. Point 3 was near the top of the Test Board which was the end of the air stream passing through the Test Board. At the bottom face of heat exchanger 1 (HX1) and heat exchanger 2 (HX2) were Points 4 and 5, respectively. Point 6 and Point 7 captured the air temperature as the 
air exited HX1 and HX2, respectively. Finally after the air passed through the fans, the exhaust air temperature was measured at Point 8 . Point 5 temperatures were significantly higher than Point 4 suggesting the thermocouple at Point 5 was in contact with the metal on HX2 or the metal one of the blank strip heater line cards. Point 6 and Point 7 temperatures were higher than the exhaust air at Point 8 . This suggests the air temperatures were more representative of localized temperatures as opposed to average air temperatures at the respective locations. The exhaust air temperature should be the highest temperature of all the thermocouple locations.

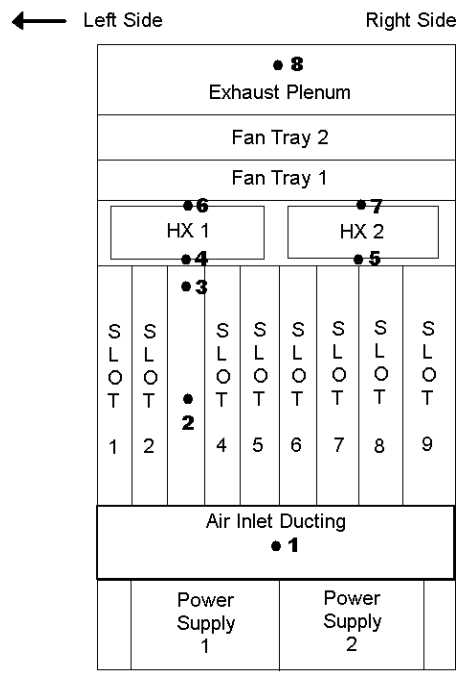

Front View

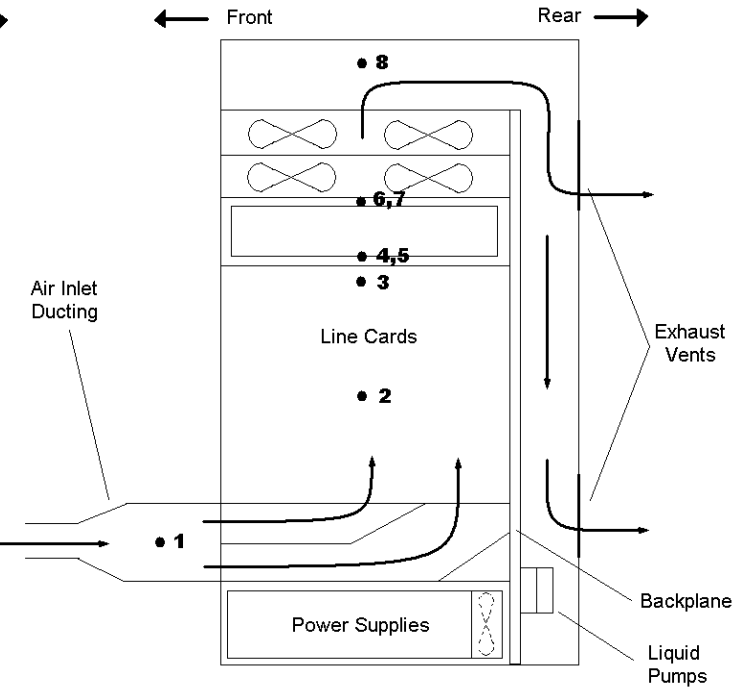

Right Side View

Figure 28. Chassis layout showing air flow path and thermocouple locations 
Table 6. Measured air temperatures

\begin{tabular}{|c|c|c|c|c|c|c|c|c|}
\hline \multirow{2}{*}{ Test } & \multicolumn{7}{|c|}{ Air Temperatures ( $\left.{ }^{\circ} \mathbf{C}\right)$} \\
\cline { 2 - 9 } & Point 1 & Point 2 & Point 3 & Point 4 & Point 5 & Point 6 & Point 7 & Point 8 \\
\hline $\mathbf{1}$ & 29 & 36 & 37 & 41 & 49 & 46 & 57 & 43 \\
\hline $\mathbf{2}$ & 30 & 39 & 39 & 44 & 53 & 50 & 61 & 47 \\
\hline $\mathbf{3}$ & 30 & 41 & 42 & 47 & 57 & 55 & 70 & 51 \\
\hline $\mathbf{4}$ & 33 & 45 & 51 & 56 & 68 & 65 & 88 & 60 \\
\hline $\mathbf{5}$ & 32 & 40 & 40 & 45 & 53 & 49 & 61 & 46 \\
\hline $\mathbf{6}$ & 32 & 41 & 41 & 46 & 53 & 50 & 61 & 46 \\
\hline $\mathbf{7}$ & 33 & 42 & 43 & 47 & 55 & 52 & 65 & 49 \\
\hline $\mathbf{8}$ & 30 & 40 & 36 & 42 & 52 & 49 & 59 & 46 \\
\hline $\mathbf{9}$ & 30 & 39 & 36 & 43 & 53 & 50 & 61 & 47 \\
\hline
\end{tabular}

The Test Board had four cold plates removing heat from the " $\mathrm{A}$ " and " $\mathrm{B}$ " chips they covered. The cold plates had one thermocouple located in the middle of their underside, or bottom, and one on top at the liquid outlet. Figure 29 shows the placement of the thermocouple on top of the cold plate at the outlet. Figure 30 shows the thermocouple location on the underside of the cold plate. The "X" complex Test Chip cold plate had more attached thermocouples than the other three cold plates. The extra thermocouples were used to understand the temperature profile across the entire cold plate during preliminary testing as a way to identify any concerning issues with the cold plate design and attachment. The preliminary testing data showed no concerning issues which concluded the need to record only the top-outlet and underside-middle thermocouple temperatures as was done by the other three cold plates. The preliminary testing data can be viewed in Appendix D. 


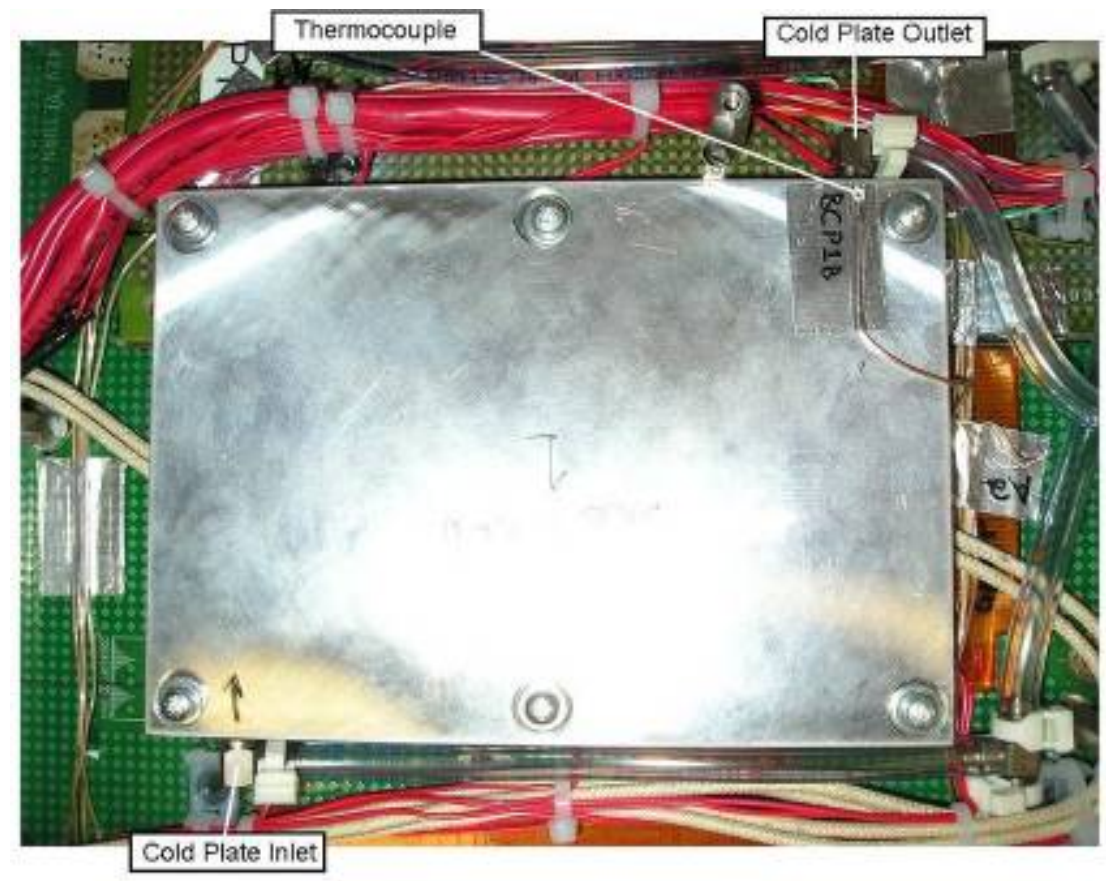

Figure 29. Baseboard 1 cold plate showing the location of the thermocouple on top at the outlet

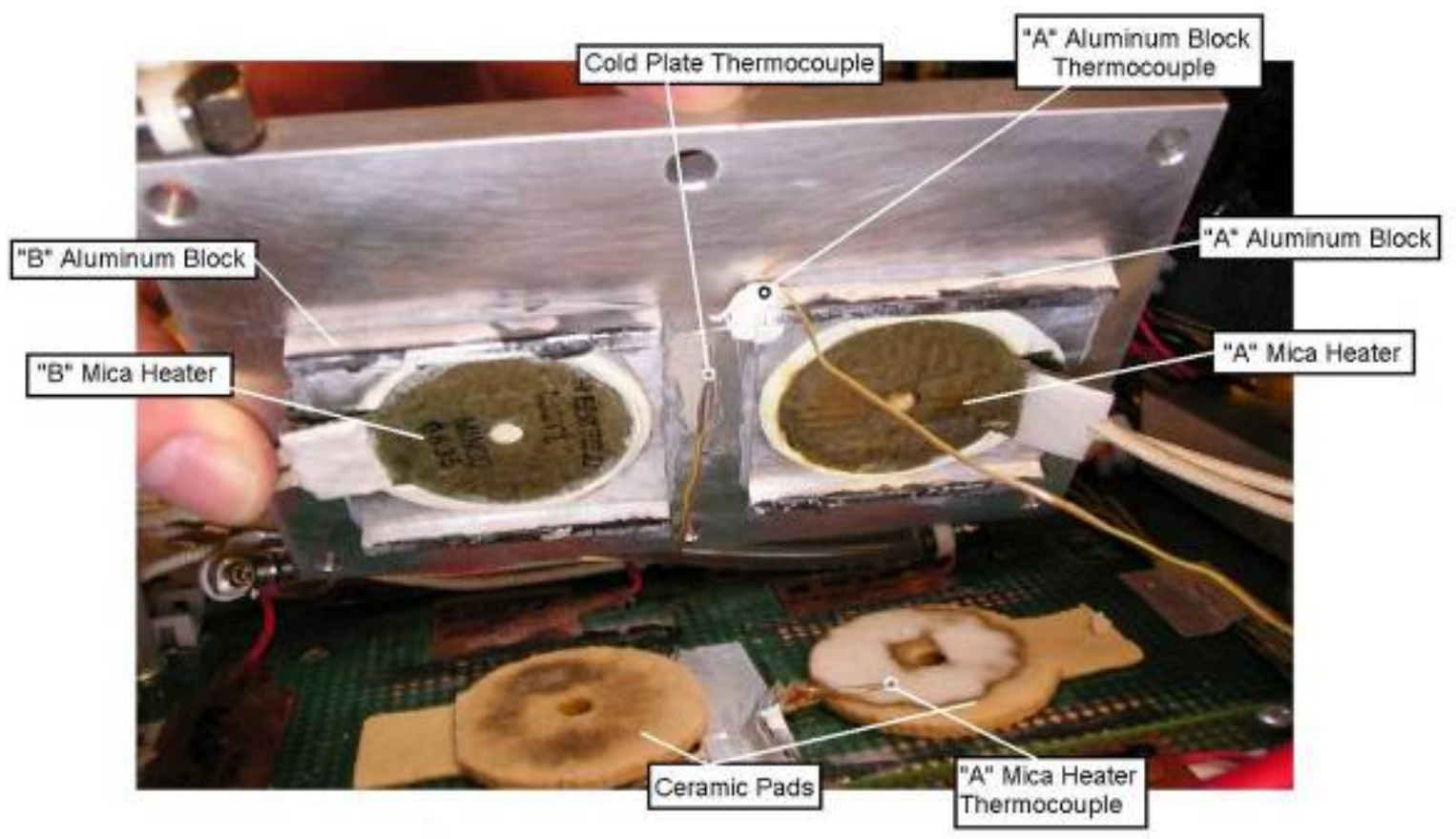

Figure 30. Underside of cold plate showing heater attachment and thermocouple locations 
Figure 31 shows the thermocouple (sensor) locations and numbering scheme used for the Test Board cold plates. The "X" complex Test Chip cold plate had six thermocouples labeled, but only two were used for gathering data during the nine tests, \#18 (center bottom) and \#19 (top outlet). The measured cold plate temperatures are in Table 7. It would be expected to have higher temperatures at the top-outlet because the liquid has been heated by the chips attached to the cold plate, but there were instances where the underside-middle temperatures were higher. The Test Chip and Baseboard 2 cold plates showed this characteristic during all the tests. This could be contributed to localized heating from the two chips where the thermocouple was placed. Also, the Daughter Card and Baseboard 1 cold plates showed a higher underside-middle temperature for several tests, but not all, when compared to the top-outlet sensor. For example Sensor \#8 showed higher temperatures for Test 1 and Test 2, then in Test 3 and Test 4 Sensor \#9 had the higher temperature. This characteristic is not desirable and may be contributed to the attachment method of the thermocouple to the cold plates. 


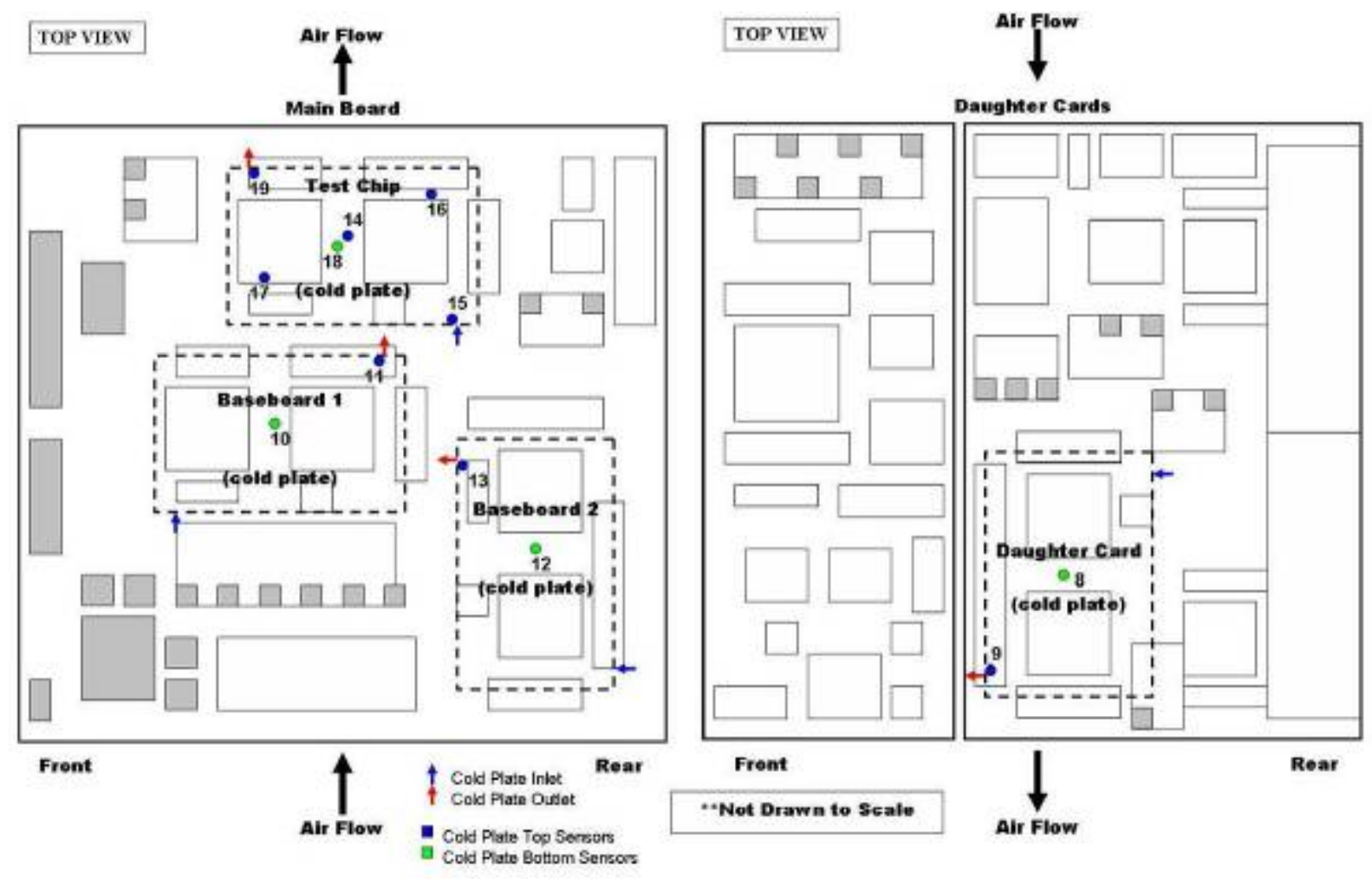

Figure 31. Test board layout showing the cold plate thermocouple

locations and numbering scheme

Table 7. Cold plate measured temperatures

\begin{tabular}{|c|c|c|c|c|c|c|c|c|}
\hline \multirow{3}{*}{ Test } & \multicolumn{8}{|c|}{ Cold Plate Temperature $\left.\mathbf{~}^{\circ} \mathbf{C}\right)$} \\
\cline { 2 - 9 } & $\begin{array}{c}\text { Sensor } \\
\mathbf{\# 8}\end{array}$ & $\begin{array}{c}\text { Sensor } \\
\mathbf{\# 9}\end{array}$ & $\begin{array}{c}\text { Sensor } \\
\mathbf{\# 1 0}\end{array}$ & $\begin{array}{c}\text { Sensor } \\
\mathbf{\# 1 1}\end{array}$ & $\begin{array}{c}\text { Sensor } \\
\mathbf{\# 1 2}\end{array}$ & $\begin{array}{c}\text { Sensor } \\
\mathbf{\# 1 3}\end{array}$ & $\begin{array}{c}\text { Sensor } \\
\mathbf{\# 1 8}\end{array}$ & $\begin{array}{c}\text { Sensor } \\
\mathbf{\# 1 9}\end{array}$ \\
\hline $\mathbf{1}$ & 70 & 64 & 58 & 58 & 48 & 54 & 61 & 57 \\
\hline $\mathbf{2}$ & 73 & 68 & 59 & 59 & 51 & 58 & 64 & 60 \\
\hline $\mathbf{3}$ & 69 & 71 & 67 & 65 & 54 & 62 & 65 & 63 \\
\hline $\mathbf{4}$ & 74 & 78 & 80 & 76 & 64 & 73 & 75 & 73 \\
\hline $\mathbf{5}$ & 74 & 68 & 61 & 61 & 51 & 58 & 62 & 60 \\
\hline $\mathbf{6}$ & 74 & 72 & 63 & 67 & 60 & 64 & 68 & 65 \\
\hline $\mathbf{7}$ & 77 & 71 & 68 & 64 & 54 & 61 & 63 & 62 \\
\hline $\mathbf{8}$ & 62 & 65 & 60 & 59 & 54 & 57 & 63 & 61 \\
\hline $\mathbf{9}$ & 64 & 66 & 61 & 60 & 55 & 58 & 64 & 62 \\
\hline
\end{tabular}


The "X" complex Test Chip was specially designed and fabricated to thermally represent the real "A" and "B" chips. The "A" Test Chip and "B" Test Chip, of the "X" complex Test Chip, each had eight temperature sensors which gave the temperature reading of the test chips' junction temperatures. The "A" Test Chip and "B" Test Chip were each tested to determine which four sensors registered the hottest temperatures, on each test chip, while the Test Board was fully powered. The hottest eight sensors, four on each test chip, were used during the actual testing. Figure 32 shows the sensor locations in a diagram with a picture of the " $\mathrm{X}$ " complex Test Chip for reference. The temperature readings from the experiments are in Table 8 . The junction temperature for the "A" Test Chip reached its limit of $105^{\circ} \mathrm{C}$ only on Test $\# 4$ when the PWM duty cycle for the fans was reduced to $25 \%$.

Table 8. "X" complex Test Chip temperatures

\begin{tabular}{|c|c|c|c|c|c|c|c|c|}
\hline \multirow{2}{*}{ Test } & \multicolumn{7}{|c|}{ Test Chip Temperatures $\left({ }^{\circ} \mathbf{C}\right)$} \\
\cline { 2 - 9 } & $\mathbf{B 1}$ & $\mathbf{B 2}$ & $\mathbf{B 3}$ & $\mathbf{B 6}$ & $\mathbf{A 2}$ & $\mathbf{A 4 , a}$ & $\mathbf{A 6}$ & A7 \\
\hline $\mathbf{1}$ & 66 & 67 & 66 & 66 & 91 & 85 & 91 & 90 \\
\hline $\mathbf{2}$ & 69 & 70 & 70 & 69 & 94 & 88 & 94 & 93 \\
\hline $\mathbf{3}$ & 70 & 71 & 71 & 70 & 95 & 89 & 95 & 94 \\
\hline $\mathbf{4}$ & 81 & 82 & 81 & 81 & 105 & 99 & 105 & 102 \\
\hline $\mathbf{5}$ & 67 & 68 & 68 & 68 & 93 & 86 & 93 & 92 \\
\hline $\mathbf{6}$ & 73 & 74 & 73 & 73 & 99 & 92 & 99 & 97 \\
\hline $\mathbf{7}$ & 68 & 69 & 69 & 68 & 93 & 87 & 93 & 92 \\
\hline $\mathbf{8}$ & 70 & 71 & 70 & 70 & 102 & 94 & 102 & 101 \\
\hline $\mathbf{9}$ & 71 & 72 & 71 & 71 & 104 & 95 & 104 & 102 \\
\hline
\end{tabular}




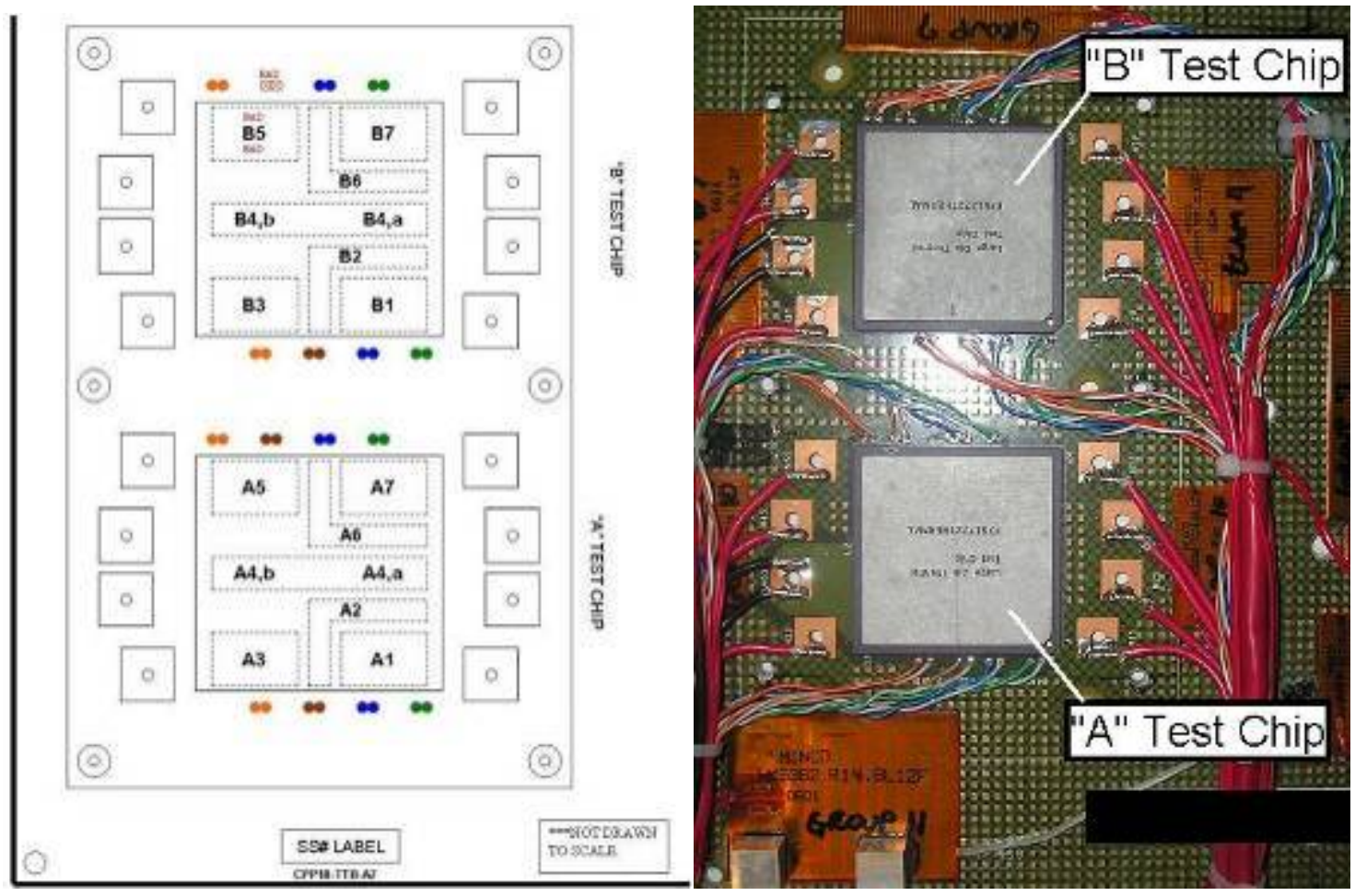

Figure 32. "X" complex Test Chip temperature sensor layout with a picture showing the "A" Test Chip and "B" Test Chip

\section{Flow Rate}

The liquid flow rates were measured with two flow meters located after the pumps and before the circulation heater and Test Board. Refer back to Figure 27 for the flow meter locations inside the liquid closed loop. Below in Table 9 are the recorded liquid flow rate measurements for all nine tests.

The air flow rates were calculated based on the measured differential pressure across the LFE. The measured LEF differential pressures and calculated air volumetric flow rates are presented in Table 10 in the next section titled "Pressure". 
Table 9. Liquid flow rate measurements

\begin{tabular}{|c|c|c|c|c|c|c|}
\hline \multirow{3}{*}{ Test } & \multicolumn{6}{|c|}{ Liquid Flow Rate \& Fan Speed } \\
\cline { 2 - 7 } & Flow Meter 1 & \multicolumn{2}{|c|}{ Flow Meter 2 } & \multicolumn{2}{|c|}{ Total Flow Rate } \\
\cline { 2 - 7 } & Ipm & $\mathbf{( g p m )}$ & Ipm & $\mathbf{( g p m )}$ & Ipm & (gpm) \\
\hline \hline $\mathbf{1}$ & 3.75 & $(0.99)$ & 0.40 & $(0.106)$ & 4.15 & $(1.10)$ \\
\hline $\mathbf{2}$ & 3.75 & $(0.99)$ & 0.40 & $(0.106)$ & 4.15 & $(1.10)$ \\
\hline $\mathbf{3}$ & 3.75 & $(0.99)$ & 0.41 & $(0.108)$ & 4.16 & $(1.10)$ \\
\hline $\mathbf{4}$ & 3.48 & $(0.92)$ & 0.35 & $(0.092)$ & 3.83 & $(1.01)$ \\
\hline $\mathbf{5}$ & 2.76 & $(0.73)$ & 0.35 & $(0.092)$ & 3.11 & $(0.82)$ \\
\hline $\mathbf{6}$ & 1.85 & $(0.49)$ & 0.22 & $(0.059)$ & 2.08 & $(0.55)$ \\
\hline $\mathbf{7}$ & 2.76 & $(0.73)$ & 0.34 & $(0.090)$ & 3.10 & $(0.82)$ \\
\hline $\mathbf{8}$ & 3.71 & $(0.98)$ & 0.45 & $(0.119)$ & 4.16 & $(1.10)$ \\
\hline $\mathbf{9}$ & 3.75 & $(0.99)$ & 0.46 & $(0.121)$ & 4.21 & $(1.11)$ \\
\hline
\end{tabular}

\section{Pressure}

The pressure drop at various locations throughout the router chassis were measured along with the LFE differential pressure. Figure 33 and Figure 34 show the locations of the pressure taps on the LFE and router chassis. All the pressure drops throughout the chassis were compared to the laboratory atmospheric pressure. Tap location \#1 was at the cabinet inlet and was used to determine the proper air flow into the chassis. Tap location \#2 was at the end of the line cards right before the heat exchangers. Tap location \#3 was after the heat exchangers and when compared to tap location \#2 determined the increased system pressure loss due to the addition of the heat exchangers. Tap location \#4 was after the fans in the exhaust plenum of the chassis. The measured pressure drop data is in Table 10. The LFE measured differential pressure along with the calculated air volumetric flow rates are also presented in Table 10. 


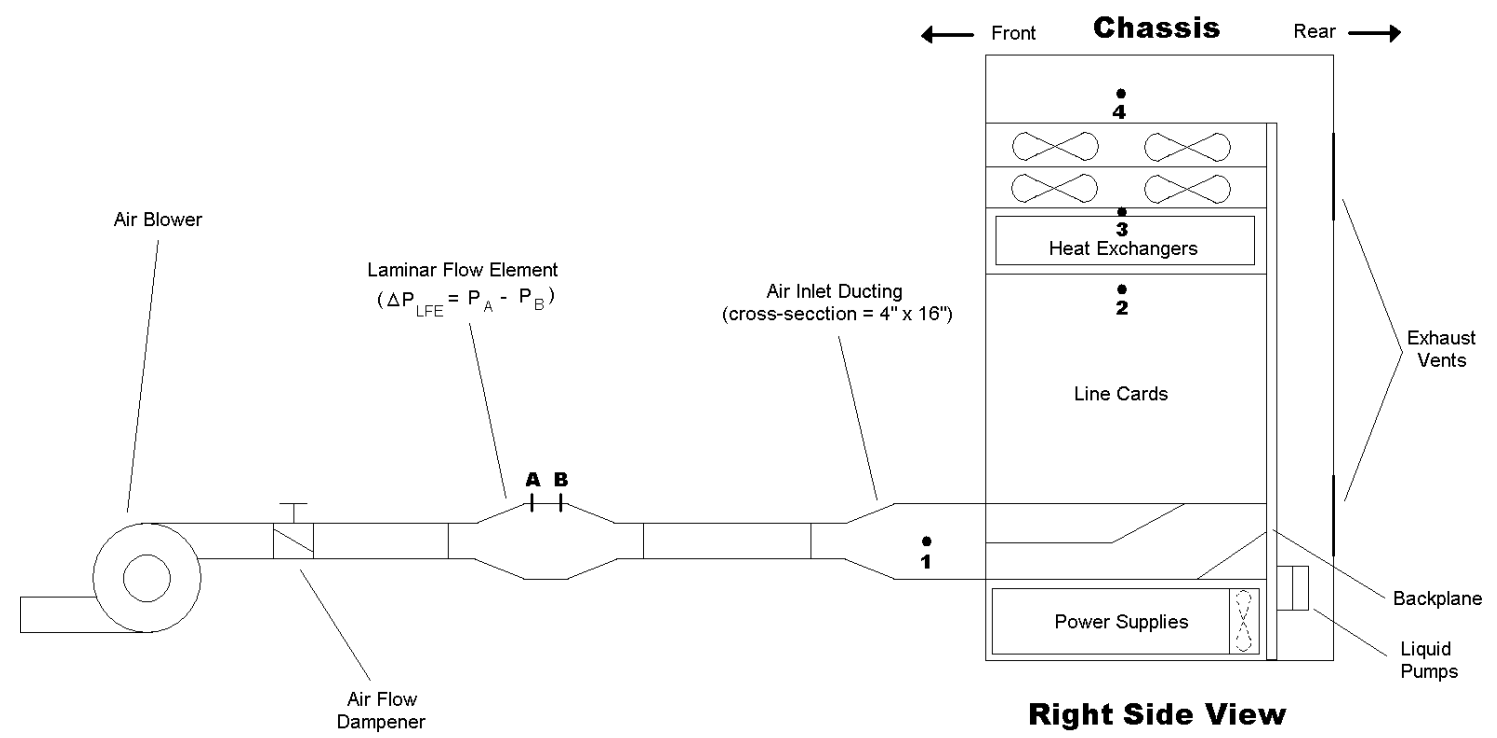

Figure 33. Pressure tap locations of LFE and router chassis

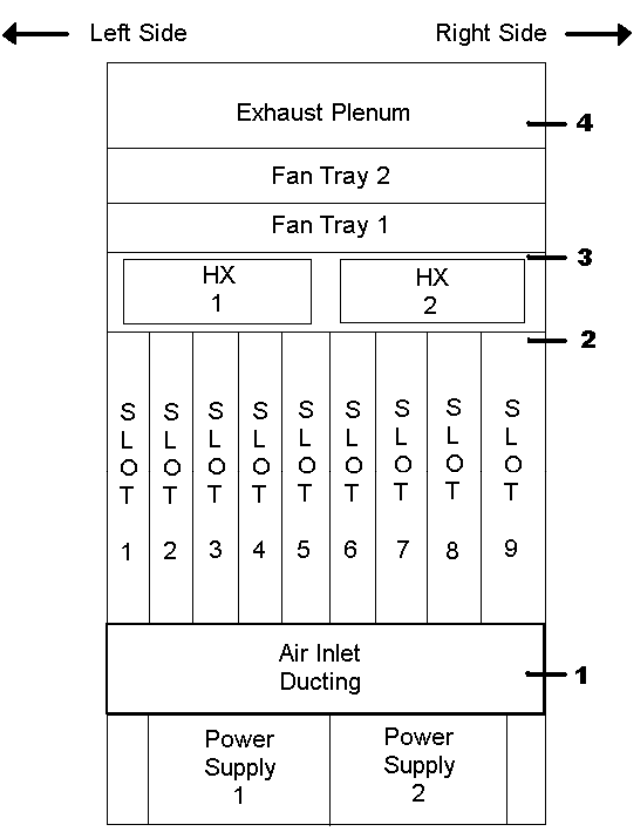

Front View

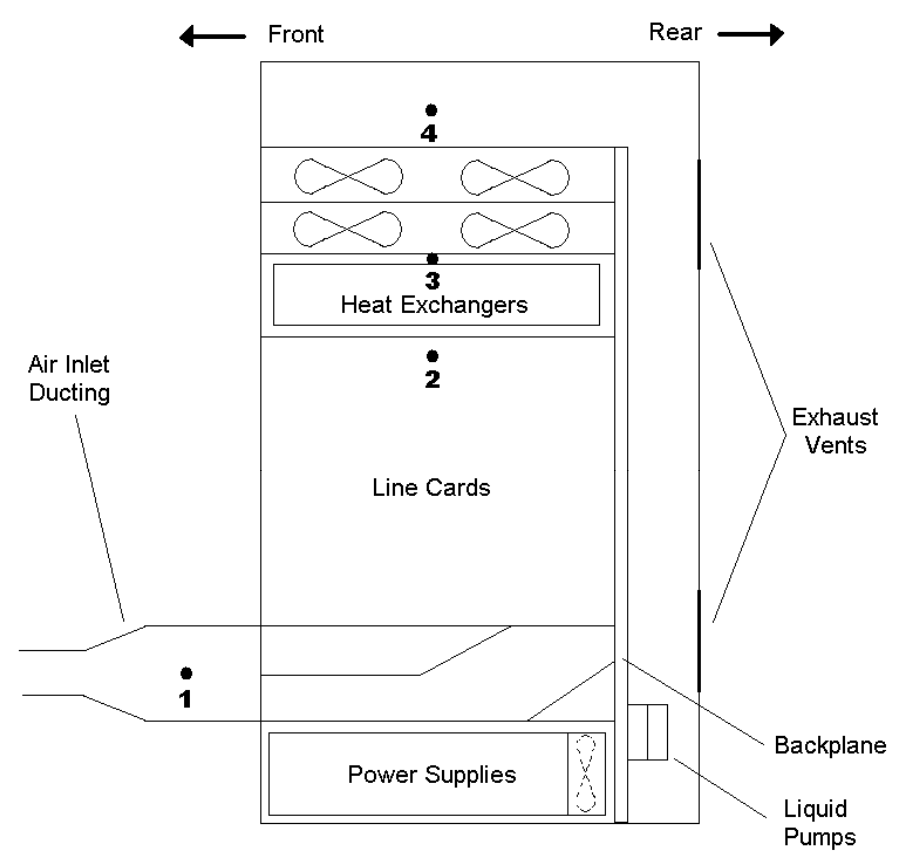

Right Side View

Figure 34. Pressure tap locations on ride side of router chassis 
Table 10. Measured pressure drops through router chassis with

corresponding flow rates and fan speeds

\begin{tabular}{|c|c|c|c|c|c|c|c|c|c|c|c|c|c|c|}
\hline \multirow{3}{*}{ Test } & \multicolumn{10}{|c|}{ Differential Pressure (inH2O) } & \multirow{2}{*}{\multicolumn{2}{|c|}{$\begin{array}{c}\text { LFE Vol. Flow } \\
\text { Rate }\end{array}$}} & \multirow{3}{*}{\begin{tabular}{|c|}
$\begin{array}{c}\text { Fan } \\
\text { Speed }\end{array}$ \\
$\mathrm{Hz}$ \\
\end{tabular}} & \multirow{3}{*}{\begin{tabular}{|c|}
$\begin{array}{c}\text { Fan } \\
\text { Speed }\end{array}$ \\
RPM
\end{tabular}} \\
\hline & \multicolumn{2}{|c|}{$\triangle \mathrm{PLFE}$} & \multicolumn{2}{|c|}{$\Delta \mathrm{P} 1$} & \multicolumn{2}{|c|}{$\Delta \mathrm{P2}$} & \multicolumn{2}{|c|}{$\Delta \mathrm{P3}$} & \multicolumn{2}{|c|}{$\Delta \mathrm{P} 4$} & & & & \\
\hline & $\mathrm{Pa}$ & $\left(\mathrm{inH}_{2} \mathrm{O}\right)$ & $\mathbf{P a}$ & $\left(\mathrm{inH}_{2} \mathrm{O}\right)$ & $\mathbf{P a}$ & $\left(\mathrm{inH}_{2} \mathrm{O}\right)$ & $\mathrm{Pa}$ & $\left(\mathrm{inH}_{2} \mathrm{O}\right)$ & $\mathrm{Pa}$ & $\left(\mathrm{inH}_{2} \mathrm{O}\right)$ & $\mathrm{m}^{3} / \mathrm{s}$ & (CFM) & & \\
\hline 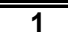 & 919 & (3.69) & -77 & $(-0.31)$ & $\begin{array}{ll}-142 \\
\end{array}$ & $(-0.57)$ & -281 & (-1.13) & 232 & (0.93) & 0.508 & (1077) & 242 & $\overline{7260}$ \\
\hline 2 & 872 & $(3.50)$ & -70 & \begin{tabular}{|l}
$(-0.28)$ \\
\end{tabular} & -127 & $(-0.51)$ & -234 & $(-0.94)$ & 187 & $(0.75)$ & 0.482 & (1022) & 221 & 6630 \\
\hline 3 & 692 & $(2.78)$ & -40 & $(-0.16)$ & -80 & \begin{tabular}{|l|}
$(-0.32)$ \\
\end{tabular} & -169 & $(-0.68)$ & 125 & $(0.50)$ & 0.384 & (813) & 180 & 5400 \\
\hline 4 & 518 & $(2.08)$ & -25 & $(-0.10)$ & -50 & $(-0.20)$ & -107 & $(-0.43)$ & 72 & $(0.29)$ & 0.287 & $(609)$ & 139 & 4170 \\
\hline 5 & 947 & $(3.80)$ & -95 & \begin{tabular}{|l}
$(-0.38)$ \\
\end{tabular} & -159 & \begin{tabular}{|l|}
$(-0.64)$ \\
\end{tabular} & -299 & $(-1.20)$ & 222 & $(0.89)$ & 0.523 & (1108) & 240 & 7200 \\
\hline 6 & 947 & $(3.80)$ & -97 & $(-0.39)$ & -164 & \begin{tabular}{|l|}
$(-0.66)$ \\
\end{tabular} & -299 & $(-1.20)$ & 217 & $(0.87)$ & 0.523 & (1108) & 240 & 7200 \\
\hline 7 & 892 & (3.58) & -77 & $(-0.31)$ & -130 & $(-0.52)$ & -254 & $(-1.02)$ & 187 & $(0.75)$ & 0.493 & (1045) & 219 & 6570 \\
\hline 8 & 942 & $(3.78)$ & -95 & $(-0.38)$ & -157 & $(-0.63)$ & -296 & $(-1.19)$ & 219 & $(0.88)$ & 0.520 & (1103) & 241 & 7230 \\
\hline 9 & 892 & (3.58) & -80 & $(-0.32)$ & -135 & $(-0.54)$ & -264 & $(-1.06)$ & 202 & $(0.81)$ & 0.493 & (1045) & 233 & 6990 \\
\hline
\end{tabular}

$\triangle \mathrm{P \#}=$ Tap\# - Atm.

$\triangle \mathrm{PLFE}=$ Tap A - Tap B

\section{Electrical Power}

The Test Board and overall system electrical powers were measured throughout all nine tests. This required measuring the voltage and current for each of the supplying terminals used in the test setup. Figure 35 identifies each supply terminal with their specified voltage. Also, the wire loops used to measure the currents are label at the bottom of Figure 35. Each terminal was given a number which corresponds to the measured data in Table 11. The data in Table 11 shows the voltage, wire loop current, and the calculated power from those two measurements. The measurements were collected by a multi-meter and a clamp-meter. The total board power was calculated by summing terminal powers \#2 through \#12. . 


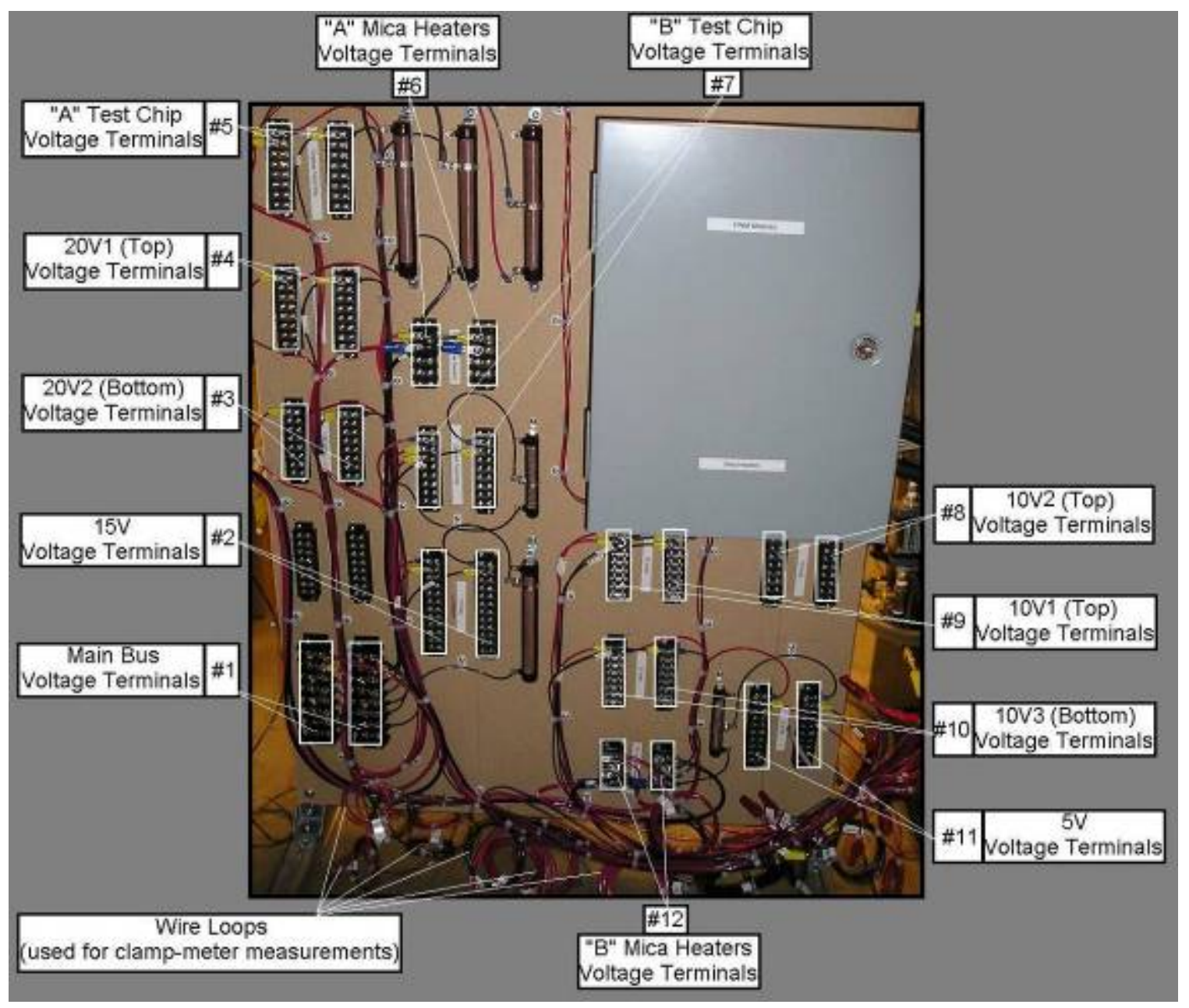

Figure 35. Electrical supply terminals used to power heaters on the Test Board 
Table 11. Test board measured electrical powers

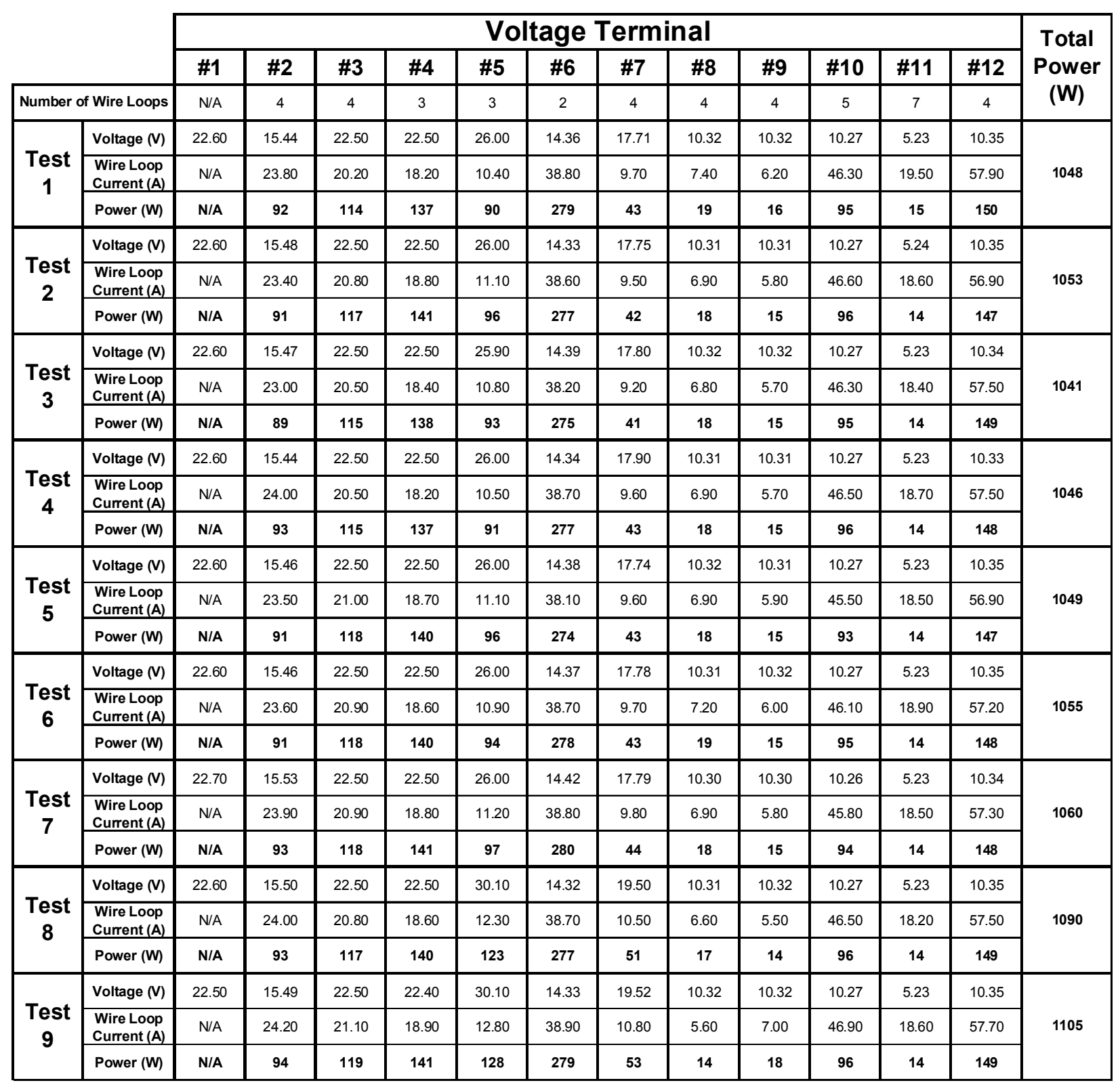

In addition to the Test Board electrical power, the voltage and current being supplied to the strip heaters and circulation heater were measured. The strip heaters and circulation heater were each powered by a PWM module. The strip heaters were powered at $100 \%$ duty cycle, which made measuring simple because the voltage and current did not fluctuate at the supply 
terminals. The circulation heater power was adjusted to provide a liquid temperature matching the test board liquid temperature, which was never at $100 \%$ duty cycle. Thus, the circulation heater had fluctuating voltages and currents. The circulation heater power was calculated using the control current to the PWM circuit along with a power trend line fitted to average power data measured from the circulation heater for its entire operating range. This trend line can be seen in Appendix D. The PWM modules and supply terminals for the strip heaters and circulation heater are shown in Figure 36. Table 12 shows the power readings from the four power supplies used to power the Test Board in addition to the PWM module power readings. The two small $30 \mathrm{~V}$ power supplies only provided power to the "A" Test Chip. These power supplies have a higher accuracy for their readings than the multi-meter and clamp-meter used for the test board electrical measurements. These power supply readings were used for calculating the power to the "A" Test Chip.

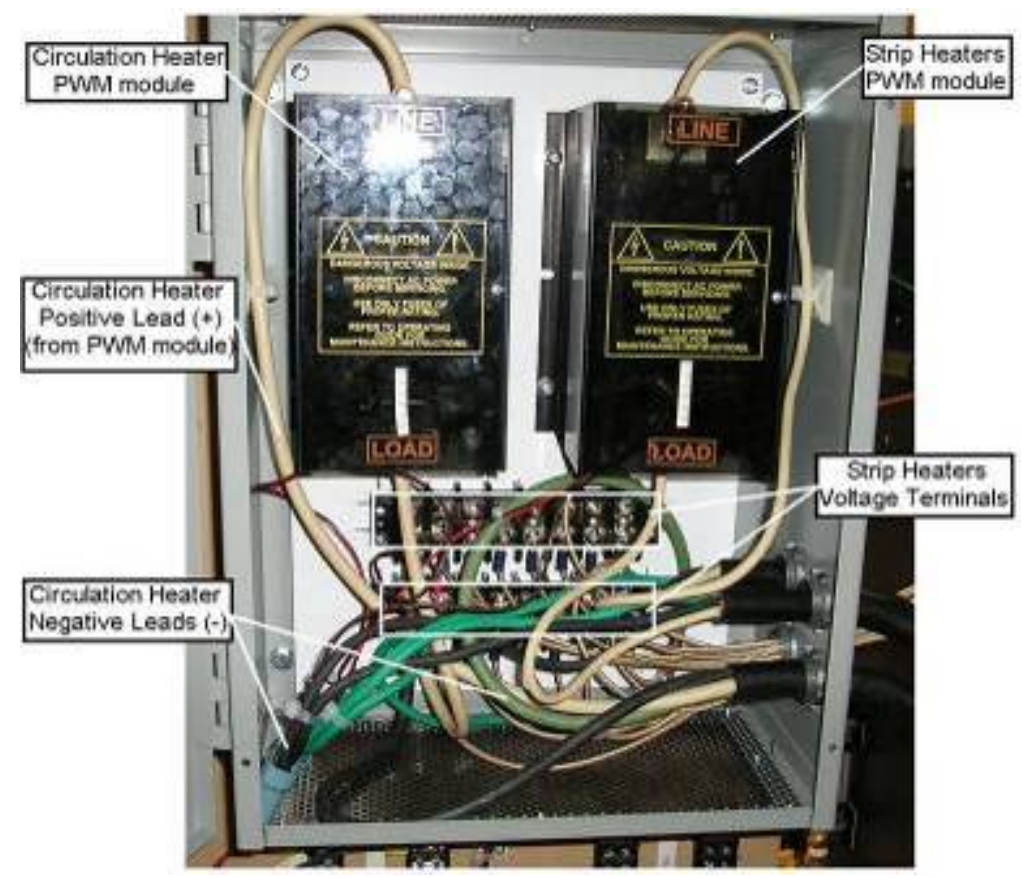

Figure 36. Strip heaters and circulation heater electrical supply terminals 
Table 12. System electrical power measurements

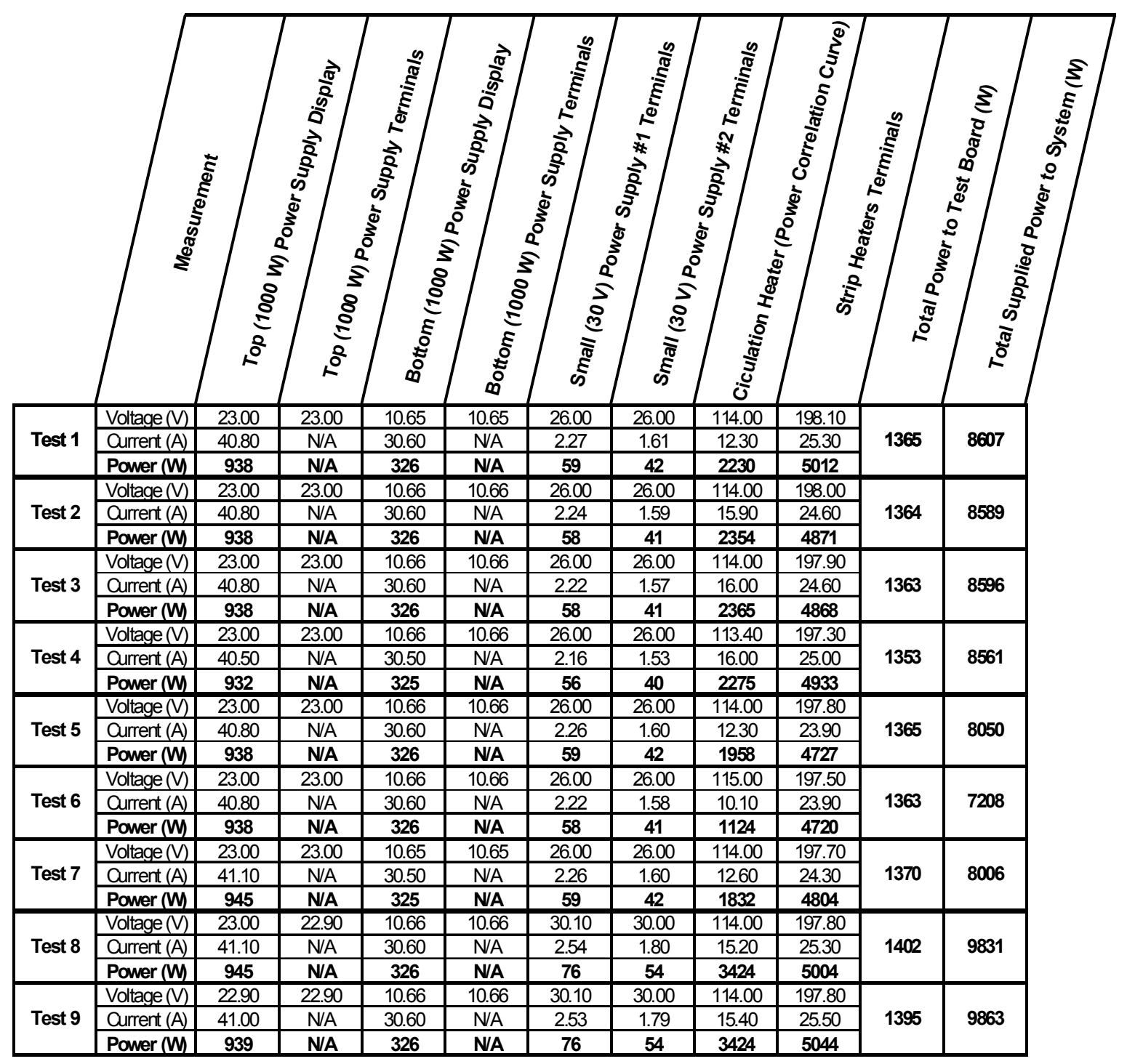




\section{Chapter 5}

\section{$\underline{\text { Results }}$}

This section presents the results from the collected data presented in Chapter 5. There is discussion on the test variables and their uncertainties, calculated energy balance powers, and corrected temperatures for the two Cisco ambient conditions: $50^{\circ} \mathrm{C}$ at $6,000 \mathrm{ft}$. and $40^{\circ} \mathrm{C}$ at $10,000 \mathrm{ft}$. Brief explanations of the performed calculations are provided in this section, but for detailed sample calculations refer to Appendix A.

\section{$\underline{\text { Results }}$}

The data shown in the previous section were used to further analyze the thermal performance of the hybrid cooling design. Energy balance and temperature correction calculations were performed to characterize the system for the two ambient conditions set by Cisco: $50^{\circ} \mathrm{C}$ at $6,000 \mathrm{ft}$ and $40^{\circ} \mathrm{C}$ at $10,000 \mathrm{ft}$. The junction temperature of the " $\mathrm{A}$ " Test Chip was one of the main focuses during testing because the true product " $\mathrm{A}$ " chip has a high heat flux and a maximum temperature rating of $105^{\circ} \mathrm{C}$. The data is presented by relating other temperatures and powers to the "A" Test Chip maximum junction temperature.

\section{$\underline{\text { Test Variables }}$}

Table 13 shows the different variable values, with their uncertainty, during each test along with the corresponding "A" Test Chip maximum junction and cold plate temperatures. The 
cold plate temperature corresponds to sensor \#18 in Figure 31 and Table 7. The Test Board power was calculated from the data in Table 11 and Table 12. The total power in Table 11 does not match the Test Board power in Table 13 because Table 13 used the more accurate power measurement from the small $30 \mathrm{~V}$ power supplies used to power the "A" Test Chip. Table 11 calculated the total power with all the measurements from the multi-meter and clamp-meter; the "B" Test Chip power was measured this way. Refer to Appendix A for electrical power sample calculations used for Table 13.

Table 13. Test variables values with junction and cold plate temperatures

\begin{tabular}{|c|c|c|c|c|c|c|c|c|c|c|c|}
\hline \multirow{4}{*}{ Test } & \multicolumn{9}{|c|}{ Test Variables } & \multirow{4}{*}{\begin{tabular}{|c|}
$\begin{array}{c}\text { Test Chip } \\
\text { Cold } \\
\text { Plate } \\
\text { Temp }\end{array}$ \\
${ }^{\circ} \mathrm{C}$ \\
\end{tabular}} & \multirow{4}{*}{$\begin{array}{c}\text { "A" } \\
\text { Junction } \\
\text { Max. } \\
\text { Temp. } \\
{ }^{\circ} \mathrm{C}\end{array}$} \\
\hline & \multirow{3}{*}{$\begin{array}{c}\text { Test Board } \\
\text { Power }\end{array}$} & \multirow{2}{*}{\multicolumn{2}{|c|}{ Liquid Flow Rate }} & \multicolumn{3}{|c|}{ Air Flow } & \multicolumn{3}{|c|}{ Test Chip Power } & & \\
\hline & & & & \multirow{2}{*}{$\begin{array}{c}\begin{array}{c}\text { Fan } \\
\text { Speed }\end{array} \\
\text { rpm }\end{array}$} & \multicolumn{2}{|c|}{ Flow Rate } & \multirow{2}{*}{$\begin{array}{l}\text { "A" } \\
\mathbf{W}\end{array}$} & \multirow{2}{*}{$\begin{array}{c}\text { "B" } \\
\text { W }\end{array}$} & \multirow{2}{*}{$\begin{array}{c}\text { Total } \\
\mathbf{W}\end{array}$} & & \\
\hline & & Ipm & (gpm) & & $\mathrm{m}^{3} / \mathrm{s}$ & (cfm) & & & & & \\
\hline$\overline{c 1}$ & $\overline{c 1060 \pm 54}$ & $40.15 \pm 0.57$ & $\left.\begin{array}{lll}(1.1 & \pm 0.15\end{array}\right)$ & $7260 \pm 60$ & $0.508 \pm 0.015$ & $(1077 \pm 31)$ & $=101 \pm 6.0$ & $43 \pm 13$ & 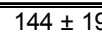 & $61 \pm 1.0$ & $91 \pm 1.0$ \\
\hline 2 & $1060 \pm 54$ & $4.15 \pm 0.57$ & $(1.1 \pm 0.15)$ & $630 \pm 60$ & $0.482 \pm 0.014$ & $(1022 \pm 30)$ & $100 \pm 6.0$ & $42 \pm 13$ & $42 \pm 19$ & \pm 1.0 & $94 \pm 1.0$ \\
\hline 3 & $1050 \pm 54$ & $4.16 \pm 0.57$ & $(1.1 \pm 0.15)$ & $5400 \pm 60$ & $0.384 \pm 0.014$ & $(813 \pm 30)$ & $99 \pm 5.9$ & $41 \pm 13$ & $40 \pm 19$ & $5 \pm 1.0$ & $95 \pm 1.0$ \\
\hline 4 & & $3.83 \pm 0.61$ & $\left(\begin{array}{ll}1.0 & \pm 0.16\end{array}\right)$ & $4170 \pm 60$ & $0.287 \pm 0.014$ & $9 \pm 30)$ & $96 \pm 5.8$ & $43 \pm 13$ & & \pm 1.0 & $105 \pm 1.0$ \\
\hline 5 & & & $(0.82 \pm 0$ & $7200 \pm 60$ & 0.5 & & 100 & $43 \pm 13$ & & & $93 \pm 1.0$ \\
\hline 6 & & 2 & $(0.55 \pm 0$ & $7200 \pm 60$ & 0.523 & & 5.9 & $43 \pm 13$ & & & $99 \pm 1.0$ \\
\hline 7 & 54 & 3.10 & $(0.82 \pm 0.14)$ & $6570 \pm 60$ & 0.493 & 31) & 100 & $44 \pm 13$ & 19 & 1.0 & $93 \pm 1.0$ \\
\hline 8 & $\overline{0 \pm 54}$ & $4.16 \pm 0.57$ & $\left(\begin{array}{ll}1.1 & \pm 0.15)\end{array}\right.$ & $7230 \pm 60$ & $0.520 \pm 0.015$ & (11 & $131 \pm 7.7$ & $51 \pm 15$ & 18 & 1.0 & $102 \pm 1.0$ \\
\hline 9 & $1110 \pm 54$ & $4.21 \pm 0.53$ & $(1.1 \pm 0.14)$ & $6990 \pm 60$ & $0.493 \pm 0.015$ & $(1045 \pm 31)$ & $130 \pm 7.6$ & $53 \pm 15$ & $183 \pm 22$ & $64 \pm 1.0$ & $104 \pm 1.0$ \\
\hline
\end{tabular}

The uncertainties associated with the variables in the testing were all relatively low except for two variables. The "B" Test Chip power measurement had the largest uncertainty with a range from $28 \%-32 \%$. This was contributed to the low accuracy of the clamp-meter and the small resolution of the measured current supplied to the "B" Test Chip; a lower measured current, with the clamp meter, had a greater uncertainty. The liquid flow rate had the second largest uncertainty ranging from 13\% - 27\%. All the other variables in Table 13 maintained uncertainties at $6 \%$ or below. 


\section{Energy Balance Power}

Energy balance calculations were performed on both the water and air in order to quantify the heat transferred to each medium. These calculations were conducted for the system level as well as board level. The results with their uncertainty are shown in Table 14.

Table 14. Calculated energies transferred to water and air through the system

\begin{tabular}{|c|c|c|c|c|c|c|}
\hline Test & 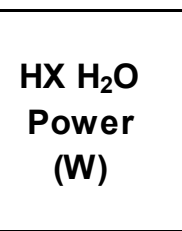 & $\begin{array}{c}\text { Board } \\
\mathrm{H}_{2} \mathrm{O} \\
\text { Power } \\
\text { (W) }\end{array}$ & $\begin{array}{l}\text { System Air } \\
\text { Power } \\
\text { (W) }\end{array}$ & $\begin{array}{l}\text { System } \\
\text { Pre-HX Air } \\
\text { Power } \\
\text { (W) }\end{array}$ & $\begin{array}{c}\text { Board Air } \\
\text { Power } \\
\text { (W) }\end{array}$ & $\begin{array}{c}\text { "A" } \\
\text { Junction } \\
\text { Max. } \\
\text { Temp. } \\
\left.\text { ( }{ }^{\circ} \mathrm{C}\right)\end{array}$ \\
\hline 1 & $2900 \pm 570$ & $330 \pm 50$ & 860 & 840 & $670 \pm 93$ & $91 \pm 1.0$ \\
\hline 2 & $3600 \pm 650$ & $330 \pm 50$ & $9500 \pm 830$ & $6400 \pm 810$ & $720 \pm 89$ & $94 \pm 1.0$ \\
\hline 3 & $3400 \pm 620$ & $350 \pm 51$ & $9200 \pm 710$ & $6500 \pm 670$ & $720 \pm 74$ & $95 \pm 1.0$ \\
\hline 4 & $3800 \pm 700$ & $300 \pm 47$ & $8900 \pm 640$ & $6800 \pm 570$ & $750 \pm 63$ & $105 \pm 1.0$ \\
\hline 5 & $3000 \pm 610$ & $310 \pm 48$ & $8900 \pm 880$ & $6400 \pm 870$ & $720 \pm 96$ & $93 \pm 1.0$ \\
\hline 6 & $2500 \pm 680$ & $270 \pm 51$ & $8000 \pm 880$ & $6500 \pm 870$ & $730 \pm 96$ & $99 \pm 1.0$ \\
\hline 7 & $2900 \pm 600$ & $310 \pm 48$ & $8800 \pm 840$ & $6600 \pm 820$ & $740 \pm 91$ & $93 \pm 1.0$ \\
\hline 8 & $3600 \pm 630$ & $370 \pm 54$ & $9700 \pm 890$ & $5500 \pm 860$ & $610 \pm 95$ & $102 \pm 1.0$ \\
\hline 9 & $3600 \pm 620$ & $380 \pm 54$ & $9600 \pm 850$ & $5500 \pm 820$ & $610 \pm 91$ & $104 \pm 1.0$ \\
\hline
\end{tabular}

The heat exchanger water power column represents the energy transferred from the water to the air through the heat exchanger. This power was calculated by Equation [ 3 ] shown below:

$$
q=\dot{\forall} \rho c_{p}\left(T_{o}-T_{i}\right)
$$

In Equation [ 3 ], $\left(T_{o}\right)$ and $\left(T_{i}\right)$ were Points 4 and 2, respectively, in Figure 27 and Table 5 for the

heat exchanger water power. Also, $(\dot{\forall})$ was the total water volumetric flow rate from

Flow Meter 1 and Flow Meter 2 in Figure 27 and Table 9. The density $(\rho)$ and specific heat $\left(c_{p}\right)$ 
were determined based on the average water temperature through the heat exchanger. The uncertainties with this calculated power ranged from $17 \%-20 \%$, which can primarily be contributed to the high uncertainty of the liquid flow rate measurements.

The board water power column represents the energy transferred from the Test Board cold plates to the water. This also represents the amount of energy all the cold plates were removing from the "X" complex chips. Equation [ 3 ] was used to calculate the board water power where $\left(T_{o}\right)$ and $\left(T_{i}\right)$ were Points 4 and 3, respectively, in Figure 27 and Table 5. There was no difference between Point 1 and Point 4 measured temperatures for all the tests; the results would be the same using either measurement point. The water volumetric flow rate $(\dot{\forall})$ through the Test board was measured by Flow Meter 2 in Figure 27 and Table 9. The density $(\rho)$ and specific heat $\left(c_{p}\right)$ were determined based on the average water temperature through the Test Board. The uncertainties for this power fluctuated between $14 \%-19 \%$, again primarily associated with the liquid flow rate large uncertainty.

The system air power column represents the total energy transferred to the air passing through the entire chassis, including the air passing through the heat exchanger. Equation [ 3 ] was again used for this calculation with $\left(T_{o}\right)$ and $\left(T_{i}\right)$ being Point 8 and Point 1 , respectively, in Figure 28 and Table 6 . The air volumetric flow rate $(\dot{\forall})$ through the chassis was the measured LFE value presented in Table 10 . The density $(\rho)$ was calculated based on the average air temperature using the ideal gas law equation, Equation [ 4 ]. 


$$
\begin{aligned}
\rho & =\frac{P}{R T} \\
R & =287 \frac{\mathrm{J}}{\mathrm{kg}-\mathrm{K}}
\end{aligned}
$$

The specific heat $\left(c_{p}\right)$ was assumed to be constant at $1.006 \mathrm{~kJ} / \mathrm{kg}-{ }^{\circ} \mathrm{C}$. The system air power uncertainties ranged from $7 \%-11 \%$.

The system pre-heat exchanger air column, in Table 14, represents the energy transferred to the air from the Test Board and the eight blank line cards with strip heaters. These calculations were performed in the same manner as the system air power mentioned earlier except for the $\left(T_{o}\right)$ value (i.e. system air volumetric flow rate $(\dot{\forall})$, density $(\rho)$, specific heat $\left(c_{p}\right),\left(T_{i}\right)=$ Point 1$)$. The $\left(T_{o}\right)$ value was the calculated average temperature between Point 3 , at the top of the Test Board, and Point 4, in front of HX1, in Figure 28 and Table 6. The non-uniform air temperature distribution before the heat exchangers was addressed by averaging two thermocouple temperatures in relatively the same location in the air stream path. The average temperature between Point 3 and Point 4 was used because the air was highly non-uniform before entering HX1. The temperature at Point 5, before HX2, was not used in the temperature averaging because its measurements were significantly higher than Point 4 suggesting it was in contact with the metal of HX2 or the metal of the blank line card strip heater not accurately measuring the air. More thermocouple readings, distributed across the same plane before the heat exchangers, should have been collected and averaged to obtain a more uniform air temperature to be used in the power calculation. Energy balance comparisons between the power transferred to the system pre-heat exchanger air and the supplied electrical power are discussed later in this section to help 
identify the uncertainty of this calculation. This method of calculating the power transferred to the system pre-heat exchanger air generated results with $8 \%-16 \%$ uncertainty.

The board level air power column, in Table 14, represents the energy transferred to the air from the Test Board alone. This calculation assumed the air flow through the chassis was evenly distributed across all nine line card slots, $1 / 9^{\text {th }}$ of the system air flow passing through each line card slot. The system pre-heat exchanger air power, described in the last paragraph, was divided by 9 to represent the energy transferred from one line card. The temperature $\left(T_{o}\right)$, was the average temperature between Point 3 and Point 4, and $\left(T_{i}\right)$ was the temperature at Point 1 , in Figure 28 and Table 6 . Energy balance comparisons between the power transferred to the board air before and the supplied electrical power to the board is discussed later in this section to help identify the uncertainty of this calculation. The board air power uncertainties ranged from $8 \%$ $16 \%$.

The "A" junction maximum temperature column is the measured temperature collected from sensor A6 in Figure 32 and presented in Table 8. Sample calculations for the energy balances shown in Table 14 can be found in Appendix A.

It is noticed from the calculated powers in Table 14 about $30 \%$ of the dissipated power was transferred to the water while the remaining $70 \%$ was transferred to the pre-heat exchanger air. This is true for the system level as well as the board level. Figure 37 shows the percentage of power transferred to each medium for different air flow rates while maintaining the same liquid flow rate. The trend in Figure 37 shows little change in power for the variations in air flow rate. 
This suggests the range of tested air flow rates had minimal impact on the heat transferred from the boards to the air.

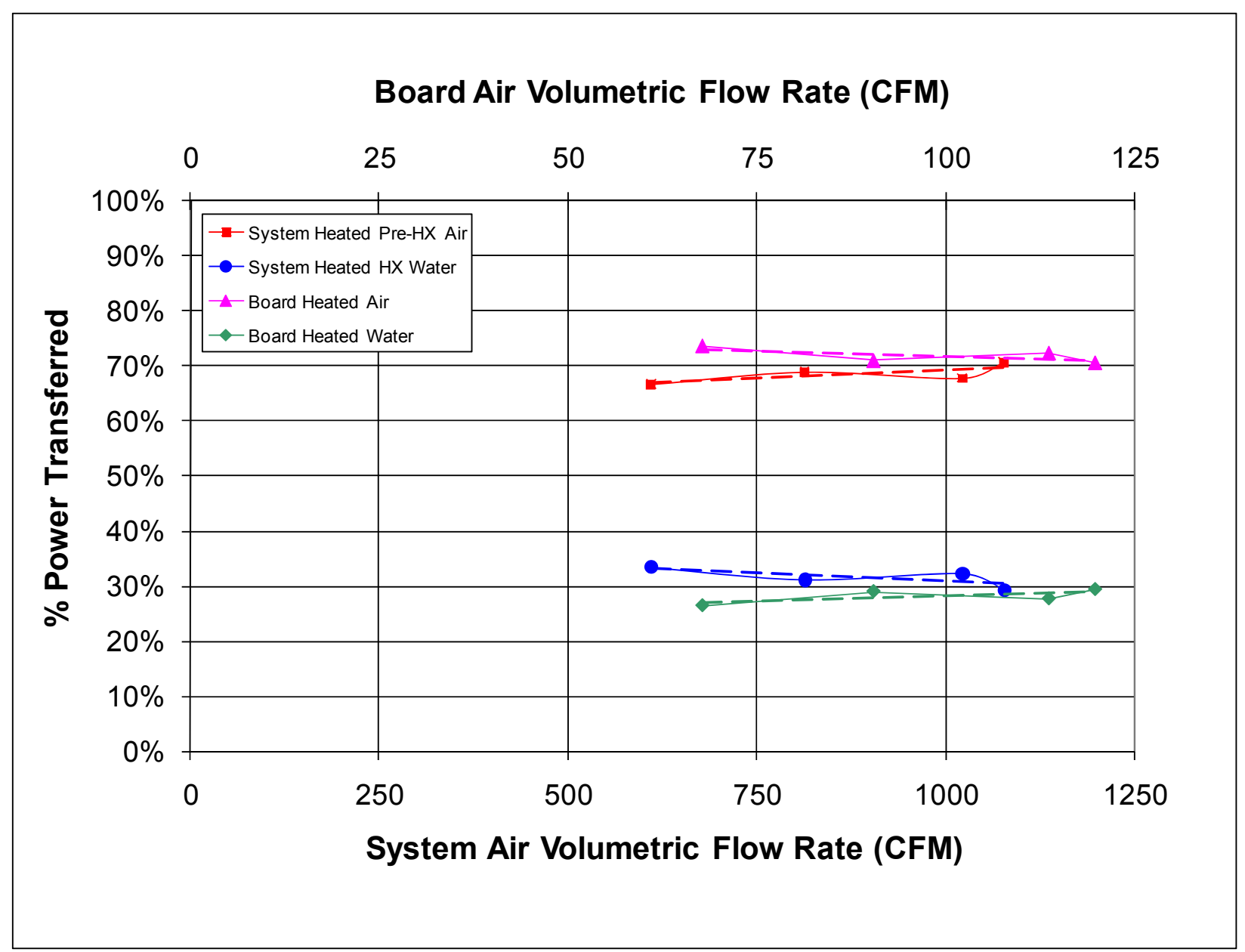

Figure 37. Overall energy percentage transferred to medium for different system level (bottom x-axis) and board level (top x-axis) air flow rates

Figure 38, on the next page, shows the percentage of power transferred to each medium for different liquid flow rates while maintaining the same air flow rate. The trend shows that as the liquid flow rate decreased the percentage of power transferred to the liquid also decreased, while for the air the percentage of power increased. This means the liquid flow rate had a greater 
impact on removing heat from the boards than the air flow rate seen in Figure 37. Also, the trend in Figure 38 suggests increasing the liquid flow rate would require less air flow to cool the boards and thus the fan speeds could be reduced. But a balance between air flow reduction and liquid flow increase would need to be reached because the system air does cool down the heated water through the liquid-to-air heat exchangers.

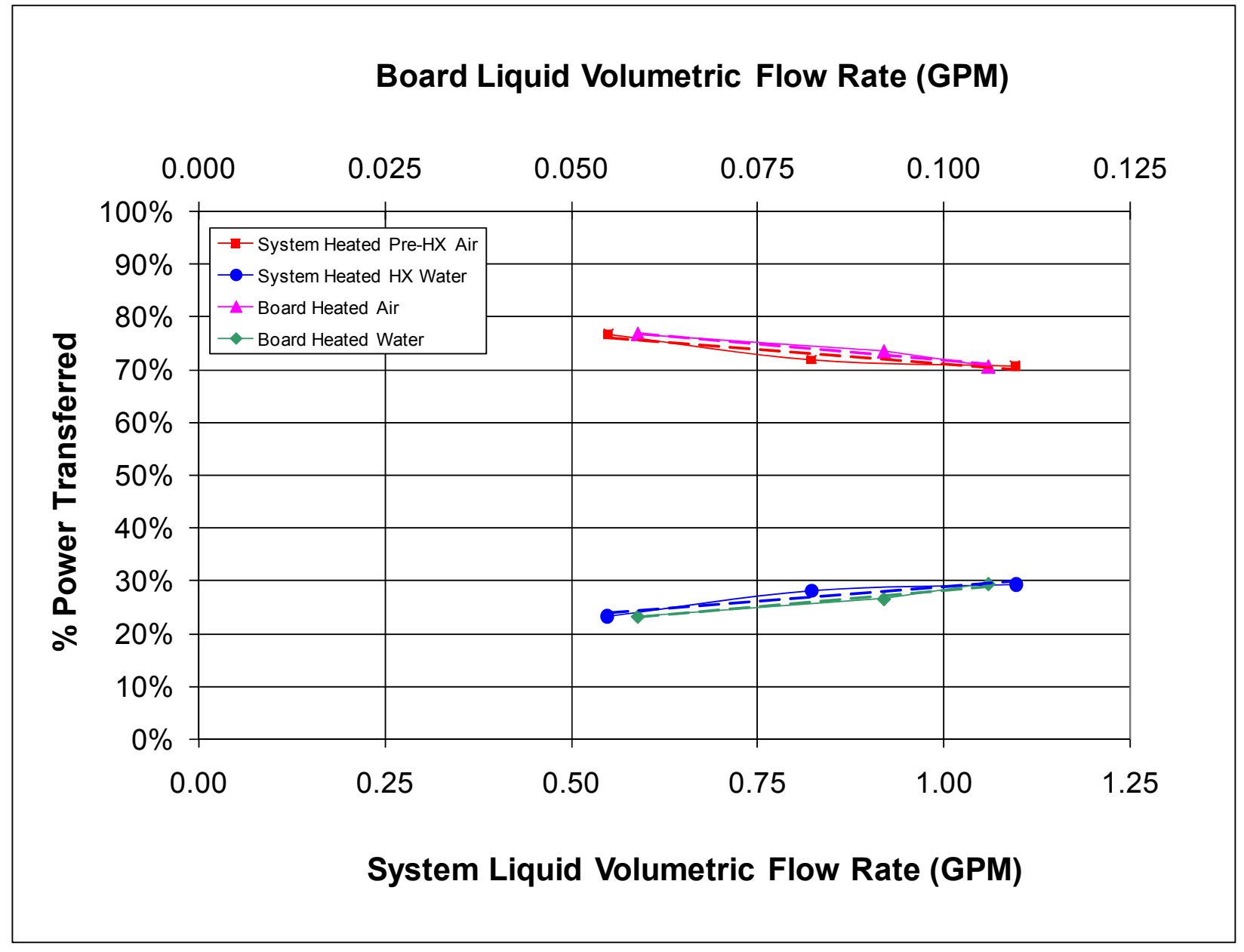

Figure 38. Overall energy percentage transferred to medium for different system level (bottom x-axis) and board level (top x-axis) liquid flow rates 
Figure 39 demonstrates the influence of the fan duty cycle and percentage of the liquid flow rate on the "A" Test Chip junction temperature. The system liquid flow rate did not significantly affect the "A" Test Chip junction temperature until it reached 50\% [2.08 lpm $(0.55$ gpm)]. The fan duty cycle noticeably affected the " $\mathrm{A}$ " Test Chip junction temperature when it reached $25 \%$, which was correlated to about $50 \%$ of the maximum rated air flow. The $25 \%$ duty cycle produced an "A" Test Chip junction temperature of $105^{\circ} \mathrm{C}$ under the lab ambient conditions.

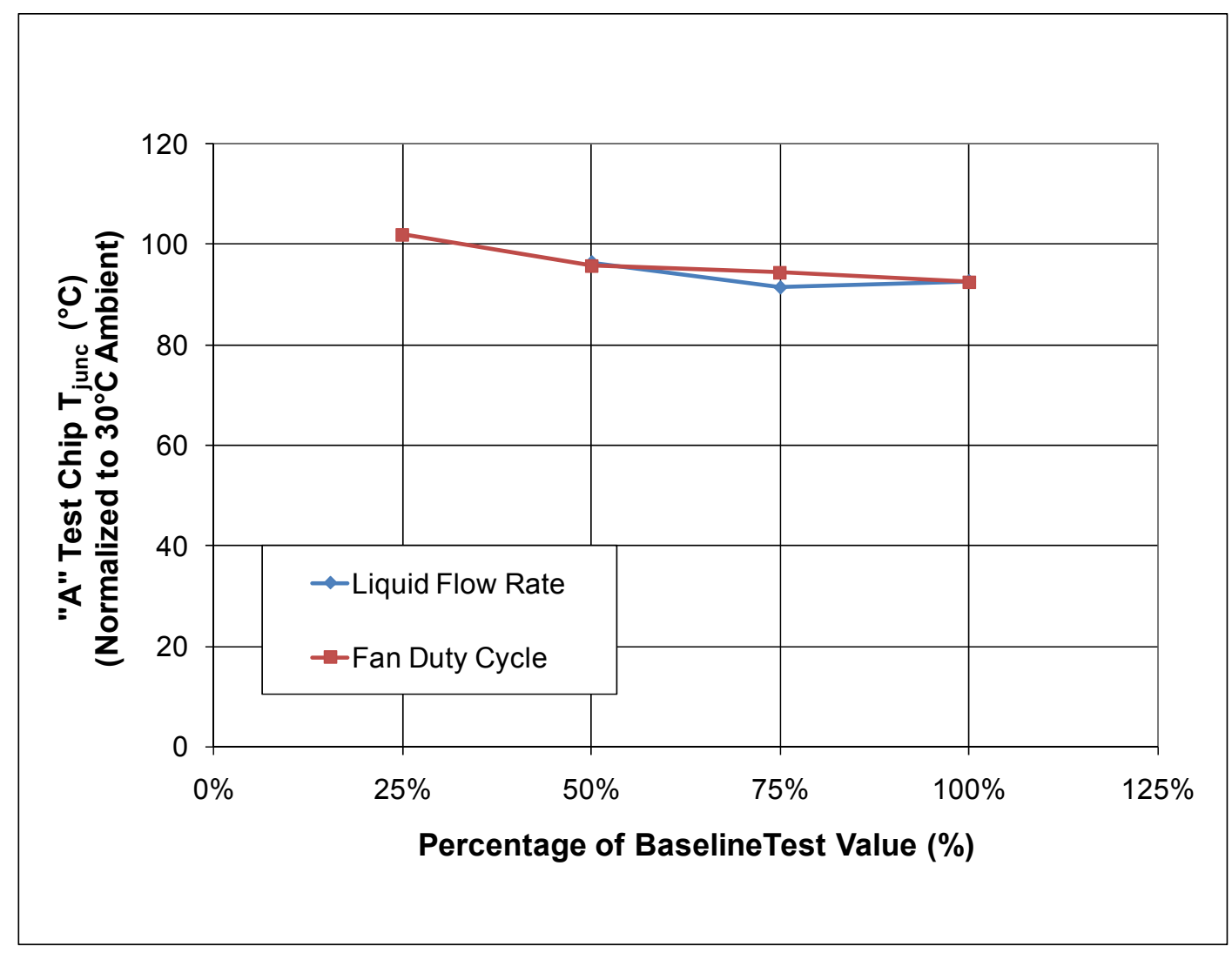

Figure 39. "A" test chip junction temperature as a function of fan duty cycle and percentage of liquid flow rate 
Figure 40 shows the influence the power transferred to the water had on the normalized "A" Test Chip junction temperature. The junction temperature was normalized to the two Cisco required ambient conditions: $50^{\circ} \mathrm{C}$ at $6,000 \mathrm{ft}$ and $40^{\circ} \mathrm{C}$ at $10,000 \mathrm{ft}$. The liquid flow rate was used as the primary axis because it is directly correlated to the power transferred to the water. It can be seen by reducing the power transferred to the water from about $30 \%$ [4.15 $1 \mathrm{pm}(1.10$ gpm) $]$ to $23 \%[2.08 \mathrm{lpm}(0.55 \mathrm{gpm})]$ the " $\mathrm{A}$ " Test Chip junction temperature increased by $5^{\circ} \mathrm{C}$, for both ambient conditions. This suggests that increasing the amount of power transferred to the water could help further reduce the junction temperature. Discussions regarding the temperature normalizations are provided in the next section titled "Temperature Corrections".

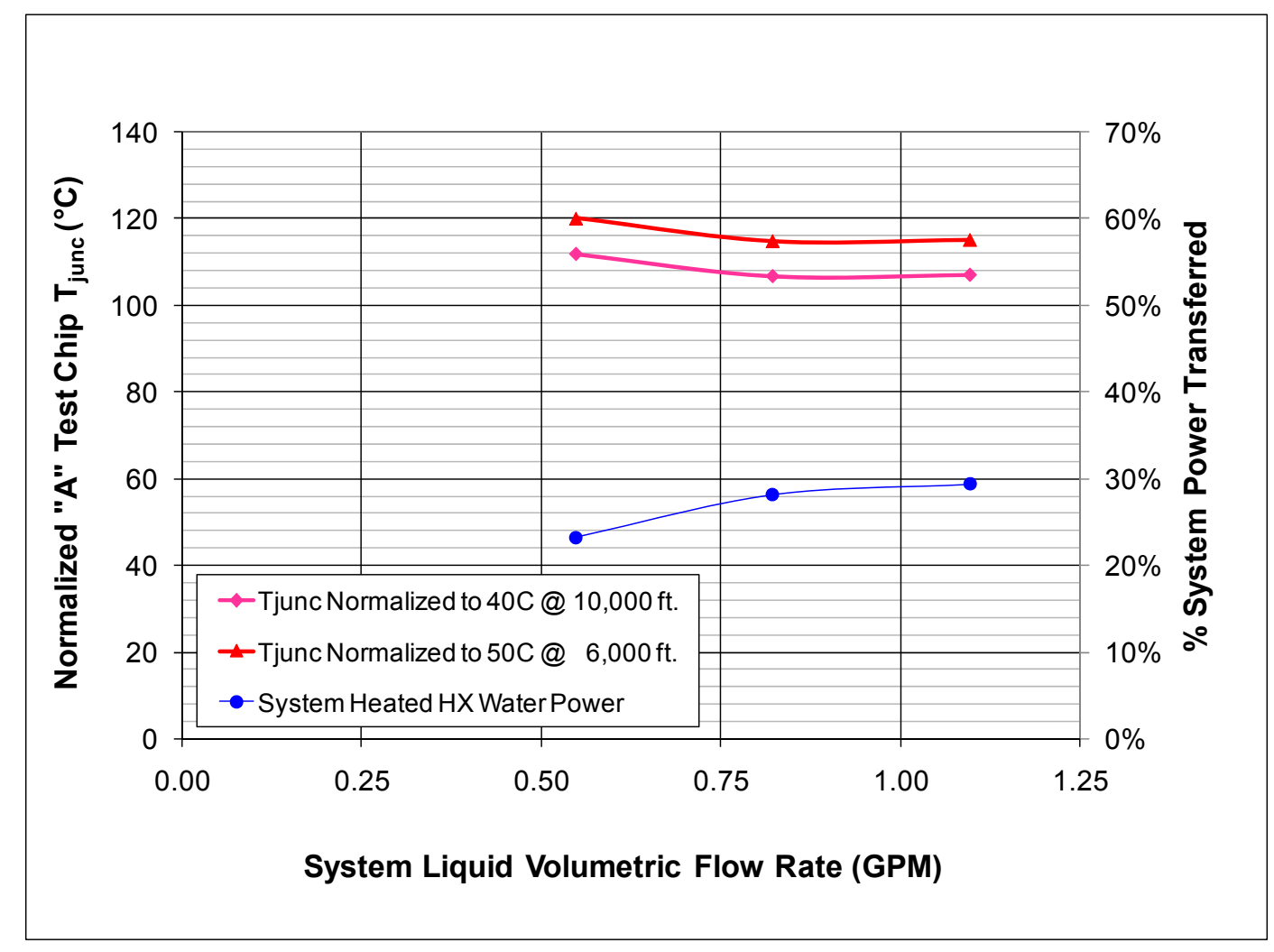

Figure 40. Influence of power transferred to water on nomalized Test Chip junction temperature. 
An energy balance of the combined measured electrical powers and estimated system fan powers were compared to the energy balance transferred to the system air. All the electrical powers and estimated system fan powers were summed together and compared to the calculated system air energy balance. The total electrical power was a summation of the circulation heater and strip heaters powers in Table 12 and the total board powers in Table 11. These values were more accurate than the total system power shown in Table 12 because they were measured at the heater supply terminals not the large power source terminals. This mitigated the power losses associated with the wires and power distribution. The power dissipated by the fans was estimated because the fans were powered by the chassis power supplies, not by an external power source; thus the system fan power data was not collected. Also, the influence of the system fans only affected the overall system exhaust air temperature after the heat exchangers because the system fans were located at the end of the air flow path, refer back to Figure 34. The air energy balance powers were calculated the same as the "System Air Power" results in Table 14. Table 15 shows the resulting differences between the total system electrical powers and system air energy balance powers.

It can be seen in Table 15 that the energy balance for air closely matches the measured electrical power input, with the greatest difference being $8 \%$. Taking more air measurements in order to get a uniform air temperature along with a more accurate power measurement from the PWM supply controllers would help reduce the power differences. 
Table 15. Electrical power, including estimated fan power, comparison to air energy balance

\begin{tabular}{|c|r|r|r|r|r|r|r|r|}
\hline Test & $\begin{array}{c}\text { Test } \\
\text { Board } \\
\text { Power } \\
(\mathbf{W})\end{array}$ & $\begin{array}{c}\text { Circulation } \\
\text { Heater } \\
\text { Power } \\
(\mathbf{W})\end{array}$ & $\begin{array}{c}\text { Strip } \\
\text { Heaters } \\
\text { Power } \\
\mathbf{( W )}\end{array}$ & $\begin{array}{c}\text { Estimated } \\
\text { System } \\
\text { Total Fan } \\
\text { Power } \\
\mathbf{( W )}\end{array}$ & $\begin{array}{c}\text { Total } \\
\text { Electrical } \\
\text { Power } \\
\mathbf{( W )}\end{array}$ & $\begin{array}{c}\text { Total } \\
\text { Power to } \\
\text { Air } \\
(\mathbf{W})\end{array}$ & $\begin{array}{c}\text { Difference } \\
\mathbf{( W )}\end{array}$ & $\begin{array}{c}\% \\
\text { Difference }\end{array}$ \\
\hline \hline $\mathbf{1}$ & 1060 & 2200 & 5000 & 940 & 9200 & 8500 & 700 & $8 \%$ \\
\hline $\mathbf{2}$ & 1060 & 2400 & 4900 & 730 & 9090 & 9500 & 410 & $4 \%$ \\
\hline $\mathbf{3}$ & 1050 & 2400 & 4900 & 550 & 8900 & 9200 & 300 & $3 \%$ \\
\hline $\mathbf{4}$ & 1050 & 2300 & 4900 & 350 & 8600 & 8900 & 300 & $3 \%$ \\
\hline $\mathbf{5}$ & 1050 & 2000 & 4700 & 920 & 8670 & 8900 & 230 & $3 \%$ \\
\hline $\mathbf{6}$ & 1060 & 1100 & 4700 & 930 & 7790 & 8000 & 210 & $3 \%$ \\
\hline $\mathbf{7}$ & 1060 & 1800 & 4800 & 710 & 8370 & 8800 & 430 & $5 \%$ \\
\hline $\mathbf{8}$ & 1100 & 3400 & 5000 & 930 & 10430 & 9700 & 730 & $8 \%$ \\
\hline $\mathbf{9}$ & 1110 & 3400 & 5000 & 700 & 10210 & 9600 & 610 & $6 \%$ \\
\hline
\end{tabular}

The estimation of the dissipated power from the fans was calculated by subtracting the system air flow power, Equation [ 5 ], from the total system fan power based on fan vendor specifications under nominal fan power for free air flow conditions, Equation [ 6 ].

$$
P_{\text {AirFlow }}=Q \times \Delta P
$$

$$
P_{\text {Fan }}=V \times I
$$

In Equation [ 5 ], $(Q)$ was the total system volumetric flow rate seen in Table 10 and $(\Delta P)$ was the total pressure increase in the system fans. $\Delta P$ was calculated by subtracting $\Delta P_{4}$ from $\Delta P_{3}$ from the pressure tap location $\# 4$ and \#3, respectively, from Figure 34. In Equation [ 6 ], $(V)$ was 
the supply voltage to the fans from the chassis power supplies $(48 \mathrm{~V})$ and $(I)$ the average current driving the fans based on the duty cycle.

It needs to be noted the system fans were loaded differently than the vendor's nominal free air condition power ratings. There were two fan trays each consisting of four parallel fans with the two fan trays placed in series inside the tested chassis. This made the fan power calculation a rough estimate but shows the fan powers did have an influence on the power transferred to the system air.

The fan efficiency was calculated to be around $22 \%$, at $100 \%$ duty cycle, based on the system flow rate and the nominal fan power of all 8 fans in the system. With this efficiency and the power rating of the fans (149 $\mathrm{W}$ each), the estimated temperature rise for the system exhaust air due to the fan powers is a little less than $2^{\circ} \mathrm{C}$, for the fans operating at $100 \%$ duty cycle. Table 16 shows this data as well as how much the fans contribute to the total system power. It can be seen that the fans, while operating at $100 \%$ duty cycle, can contribute to about $10 \%$ of the total power dissipated by the system. Reducing the duty cycle to $50 \%$ can reduce the percentage of the fan power to the system by about $4 \%-5 \%$ or about $200 \mathrm{~W}$. This would help lower system operating power consumption, as well as dissipation. A sample calculation of the dissipated fan power, fan efficiency, and the temperature rise can be found in Appendix A. 
Table 16. Fan power percentage of total system power

\begin{tabular}{|c|r|r|r|r|r|r|}
\hline Test & $\begin{array}{c}\text { Fan Duty } \\
\text { Cycle } \\
\mathbf{( \% )}\end{array}$ & $\begin{array}{c}\text { Estimated } \\
\text { System } \\
\text { Total Fan } \\
\text { Power } \\
(\mathbf{W})\end{array}$ & $\begin{array}{c}\text { System } \\
\text { Total } \\
\text { Power } \\
\mathbf{( W )}\end{array}$ & $\begin{array}{c}\text { Fan } \\
\text { Power } \% \\
\text { of Total } \\
\text { Power }\end{array}$ & $\begin{array}{c}\text { Fan } \\
\text { Efficiency } \\
(\mathbf{n})\end{array}$ & $\begin{array}{c}\text { Air Temp. } \\
\text { Rise from } \\
\text { Fans } \\
\left({ }^{\circ} \mathbf{C}\right)\end{array}$ \\
\hline \hline $\mathbf{1}$ & 100 & 940 & 9200 & $10 \%$ & $21.8 \%$ & 1.6 \\
\hline $\mathbf{2}$ & 75 & 730 & 9090 & $8 \%$ & $21.8 \%$ & 1.3 \\
\hline $\mathbf{3}$ & 50 & 550 & 8900 & $6 \%$ & $16.9 \%$ & 1.3 \\
\hline $\mathbf{4}$ & 25 & 350 & 8600 & $4 \%$ & $12.9 \%$ & 1.1 \\
\hline $\mathbf{5}$ & 100 & 920 & 8670 & $11 \%$ & $22.8 \%$ & 1.5 \\
\hline $\mathbf{6}$ & 100 & 930 & 7790 & $12 \%$ & $22.6 \%$ & 1.5 \\
\hline $\mathbf{7}$ & 75 & 710 & 8370 & $8 \%$ & $23.4 \%$ & 1.3 \\
\hline $\mathbf{8}$ & 100 & 930 & 10430 & $9 \%$ & $22.4 \%$ & 1.6 \\
\hline $\mathbf{9}$ & 100 & 700 & 10210 & $7 \%$ & $24.7 \%$ & 1.2 \\
\hline
\end{tabular}

The energy balance comparison between the system pre-heat exchanger air and the total electrical power supplied to the system is shown in Table 17. The "Power to Pre-HX Air" column has the same data presented in Table 14 as "System Pre-HX Air Power" calculated with the average temperature measurements between Point 3 and Point 4, in Figure 28 and Table 6. The "Power to System $\mathrm{HX}-\mathrm{H}_{2} \mathrm{O}$ " column has the same data presented in Table 14 as " $\mathrm{HX}-\mathrm{H}_{2} \mathrm{O}$ Power" calculated with the water temperature measurements at Point 2 and Point 4 in Figure 27 and Table 5. The "Total Power to Air" column has the summation of the pre-heat exchanger air power and the system heat exchanger water power representing the total power transferred to both mediums from the line cards. The "System Electrical Power" data has the summation of all the electrical power supplied to the system, but not including the estimated system fan power because the system fan power was not relevant in either of the two medium power calculations. Table 17 shows there was only $7 \%$ difference between the total power to air and system electrical power for the baseline test. Some of the other tests demonstrated larger differences but 
the system electrical power closely matched the energy balances calculated from the measured air and water temperatures and flow rates.

\section{Table 17. System power from pre-heat exchanger air and heat exchanger water compared to total power supplied to system}

\begin{tabular}{|c|r|r|r|r|r|r|}
\hline \multicolumn{8}{|c|}{ System } \\
\hline Test & $\begin{array}{c}\text { Power to } \\
\text { System } \\
\text { Pre-HX } \\
\text { Air } \mathbf{( W )}\end{array}$ & $\begin{array}{c}\text { Power to } \\
\text { System } \\
\mathbf{H X}-\mathbf{H}_{\mathbf{2}} \mathbf{O} \\
\mathbf{( W )}\end{array}$ & $\begin{array}{c}\text { Total } \\
\text { Power to } \\
\text { Air } \\
\mathbf{( W )}\end{array}$ & $\begin{array}{c}\text { System } \\
\text { Electrical } \\
\text { Power } \\
(\mathbf{W})\end{array}$ & $\begin{array}{c}\text { Difference } \\
(\mathbf{W})\end{array}$ & $\begin{array}{c}\text { \% } \\
\text { Difference }\end{array}$ \\
\hline \hline $\mathbf{1}$ & 6000 & 2900 & 8900 & 8300 & 600 & $7 \%$ \\
\hline $\mathbf{2}$ & 6400 & 3600 & 10000 & 8400 & 1600 & $16 \%$ \\
\hline $\mathbf{3}$ & 6500 & 3400 & 9900 & 8400 & 1500 & $15 \%$ \\
\hline $\mathbf{4}$ & 6800 & 3800 & 10600 & 8300 & 2300 & $22 \%$ \\
\hline $\mathbf{5}$ & 6400 & 3000 & 9400 & 7750 & 1650 & $18 \%$ \\
\hline $\mathbf{6}$ & 6500 & 2500 & 9000 & 6900 & 2100 & $23 \%$ \\
\hline $\mathbf{7}$ & 6600 & 2900 & 9500 & 7700 & 1800 & $19 \%$ \\
\hline $\mathbf{8}$ & 5500 & 3600 & 9100 & 9500 & 400 & $4 \%$ \\
\hline $\mathbf{9}$ & 5500 & 3600 & 9100 & 9510 & 410 & $5 \%$ \\
\hline
\end{tabular}

In Table 18 is data representing the power transferred to the air and water from the Test Board. The "Power to Board Air" column assumes the air flow was evenly distributed among all nine line card slots, thus is $1 / 9^{\text {th }}$ of the "Power to System Pre-HX Air" in Table 17. The "Power to Board $\mathrm{H}_{2} \mathrm{O}$ " is the same data presented in Table 14 as "Board $\mathrm{H}_{2} \mathrm{O}$ " calculated from the water temperatures at Point 3 and Point 4 in Figure 27 and Table 5. The "Total Power to Air and $\mathrm{H}_{2} \mathrm{O}$ " column has the summation of the Test Board air and water powers while "Board Electrical Power" has the same as the data presented in Table 13 as "Test Board Power", summing all the electrical power inputs to the Test Board. Table 18 shows good results between the energy balance calculations of the Test Board air and water power compared to the electrical inputs. 
There was some high uncertainty associated with the low liquid flow rates through the Test Board cold plates which also contributed to the difference between the calculated results powers.

Table 18. Board power from board pre-heat exchanger air and board water compared to total power supplied to Test Board

\begin{tabular}{|c|c|c|c|c|c|c|}
\hline \multicolumn{7}{|c|}{ Test Board } \\
\hline Test & $\begin{array}{c}\text { Power to } \\
\text { Board } \\
\text { Air } \\
\text { (W) }\end{array}$ & $\begin{array}{c}\text { Power to } \\
\text { Board } \\
\mathrm{H}_{2} \mathrm{O} \\
\text { (W) }\end{array}$ & \begin{tabular}{|c|} 
Total \\
Power to \\
Air and \\
$\mathrm{H}_{2} \mathrm{O}(W)$
\end{tabular} & \begin{tabular}{|c|} 
Board \\
Electrical \\
Power \\
(W)
\end{tabular} & $\begin{array}{c}\text { Difference } \\
\text { (W) }\end{array}$ & $\begin{array}{c}\% \\
\text { Difference }\end{array}$ \\
\hline$\overline{\overline{1}}$ & "670 & 330 & 1000 & 1059 & "59 & 6\% \\
\hline 2 & 720 & 330 & 1050 & 1056 & 6 & $1 \%$ \\
\hline 3 & 720 & 350 & 1070 & 1046 & 24 & $2 \%$ \\
\hline 4 & 750 & 300 & 1050 & 1051 & 1 & $0 \%$ \\
\hline 5 & 720 & 310 & 1030 & 1054 & 24 & $2 \%$ \\
\hline 6 & 730 & 270 & 1000 & 1059 & 59 & $6 \%$ \\
\hline 7 & 740 & 310 & 1050 & 1064 & 14 & $1 \%$ \\
\hline 8 & 610 & 370 & 980 & 1097 & 117 & $12 \%$ \\
\hline 9 & 610 & 380 & 990 & 1107 & 117 & $12 \%$ \\
\hline
\end{tabular}

\section{Temperature Correction}

The data shown in Table 14 along with the " $\mathrm{A}$ " Test Chip power measurements were used to calculate the thermal resistances between various components of the cold plate-chip stack up. Figure 41 shows the breakdown of the various components comprising the overall thermal resistance of the "A" Test Chip junction-to-air, $\Theta_{\mathrm{j}, \mathrm{a}}$. The case temperature, $\mathrm{T}_{\text {case, }}$, was not measured in these tests though it was calculated based on the "A" Test Chip packaging thermal resistance of junction-to-case, $\Theta_{\mathrm{j}, \mathrm{c}}$ and the assumption $100 \%$ of the supplied power transferred through the package case. The " $\mathrm{A}$ " Test Chip packaging had $\Theta_{\mathrm{j}, \mathrm{c}}=0.27^{\circ} \mathrm{C} / \mathrm{W}$, but the uncertainty was not provided so it was assumed to be $\pm 0.01{ }^{\circ} \mathrm{C} / \mathrm{W}$. This assumption was based on the resolution of the provided value. 


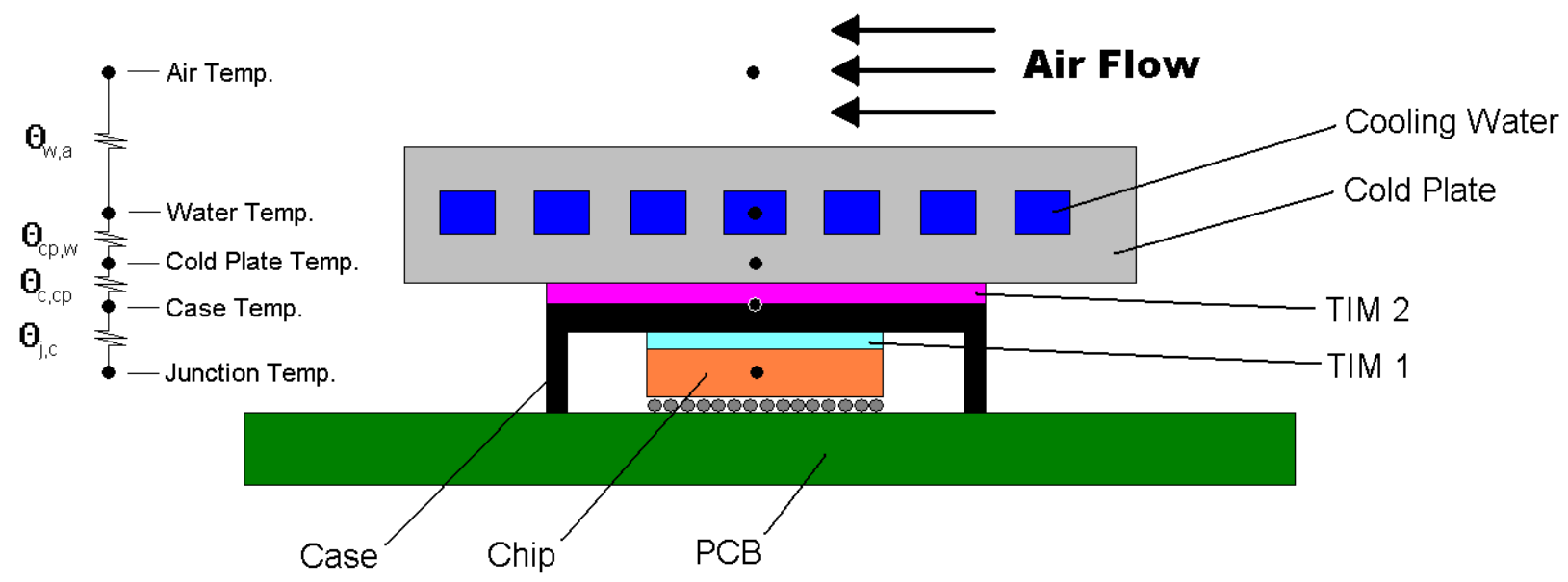

Figure 41. Thermal resistance stack up for chip-to-cold plate liquid performance

The thermal resistance of case-to-water, $\Theta_{\mathrm{c}, \mathrm{w}}$, was calculated with the predicted case temperature, $T_{\text {case }}$, and average water temperature, $T_{\mathrm{w}}$. This thermal resistance assumed $100 \%$ of the "A" Test Chip supplied power was transferred to the water; the calculated results are in Table 19. This thermal resistance was used to predict the "A" Test Chip junction temperature for the two ambient conditions required by Cisco. Equation [ 7 ] shows the equation used for calculating thermal resistance.

$$
\Theta_{c, w}=\frac{\Delta T}{q}=\frac{\left(T_{\text {case }}-T_{w}\right)}{q}
$$


Table 19. Thermal resistance values with case and average water temperatures

\begin{tabular}{|c|r|r|r|r|}
\hline Test & $\begin{array}{c}c \\
\begin{array}{c}\mathbf{\Theta}_{\mathrm{j}, \mathbf{c}} \\
\left({ }^{\circ} \mathbf{C} / \mathbf{W}\right) \\
\text { (Test Chip) }\end{array}\end{array}$ & $\begin{array}{c}\mathbf{T}_{\text {case }}\left({ }^{\circ} \mathbf{C}\right) \\
\text { (Test Chip) }\end{array}$ & $\mathbf{T}_{\mathbf{w}}\left({ }^{\circ} \mathbf{C}\right)$ & $\begin{array}{c}\boldsymbol{\Theta}_{\mathbf{c}, \mathbf{w}} \\
\left({ }^{\circ} \mathbf{C} / \mathbf{W}\right)\end{array}$ \\
\hline \hline $\mathbf{1}$ & 0.270 & $64 \pm 1.9$ & 47 & $0.170 \pm 0.024$ \\
\hline $\mathbf{2}$ & 0.270 & $67 \pm 1.9$ & 52 & $0.158 \pm 0.023$ \\
\hline $\mathbf{3}$ & 0.270 & $69 \pm 1.9$ & 55 & $0.146 \pm 0.023$ \\
\hline $\mathbf{4}$ & 0.270 & $79 \pm 1.8$ & 65 & $0.153 \pm 0.024$ \\
\hline $\mathbf{5}$ & 0.270 & $66 \pm 1.9$ & 51 & $0.146 \pm 0.023$ \\
\hline $\mathbf{6}$ & 0.270 & $72 \pm 1.9$ & 52 & $0.199 \pm 0.025$ \\
\hline $\mathbf{7}$ & 0.270 & $66 \pm 1.9$ & 53 & $0.129 \pm 0.023$ \\
\hline $\mathbf{8}$ & 0.270 & $67 \pm 2.4$ & 51 & $0.123 \pm 0.021$ \\
\hline $\mathbf{9}$ & 0.270 & $69 \pm 2.4$ & 51 & $0.134 \pm 0.022$ \\
\hline
\end{tabular}

The heat exchanger effectiveness was analyzed using the effectiveness-NTU method. The average temperature differences were calculated from the baseline test data (Test 1) and used with the air and water temperatures. The effectiveness, for the laboratory ambient conditions, was calculated to be around 0.803 suggesting a NTU value of 2.653 and a UA value of $0.761 \mathrm{~kW} / \mathrm{K}$ (Incropera and Dewitt, 2002). The NTU value was assumed to be constant for calculating the corrected water temperatures for the two Cisco ambient conditions. The effectiveness is influenced by the fluid properties so the heat exchanger would perform differently at different elevations and temperatures. A sample calculation of the heat exchanger effectiveness, NTU, and UA can be found in Appendix A.

The measured fluid temperatures were adjusted to represent ambient conditions of $40^{\circ} \mathrm{C}$ at $10,000 \mathrm{ft}$ and $50^{\circ} \mathrm{C}$ at $6,000 \mathrm{ft}$ These adjusted values were based on the predicted heat exchanger performance and inlet and outlet fluid temperatures under the two ambient conditions. Equation [ 8 ] is a modified form of Equation [ 3 ] and was used to estimate the chassis exhaust air, Point 8 (Figure 28), for each ambient condition. The heat transferred $(q)$ represents the 
energy transferred to the air. The air volumetric flow rate $(\dot{\forall})$ represents the measured values in Table 10. The density $(\rho)$, specific heat $\left(c_{p}\right)$ and inlet temperature $\left(T_{i}\right)$ are the ambient conditions the corrected temperature $\left(T_{o}\right)$ represents.

$$
T_{o}=\left(\frac{q}{\dot{\forall} \rho c_{p}}\right)+T_{i}
$$

The energy transferred to the pre-heat exchanger air was calculated with Equation [ 9 ].

$$
P_{\text {pre-HX }}=\left(P_{\text {TotalAir }}-P_{\text {HXwater }}\right)
$$

This equation subtracts the heat exchanger water power from the system air power; these two values came from Table 14. This method of determining the pre-heat exchanger air power was used as an alternative to the energy balance power calculated from the pre-heat exchanger air temperature (Equation [ 8 ] using Point 4 in Figure 28) because the air temperatures before the heat exchanger appeared to be more representative of localized air temperatures and not average air temperatures. The temperature rise from Point 4 to the exhaust air (Point 8) was only a few degrees and should have had a larger gradient. Also, the water temperatures did not fluctuate as much as the air temperatures suggesting the heat exchanger water power was more representative of the energy added to the air from the heat exchanger, even though the calculated uncertainty was higher than pre-heat exchanger air power shown in Table 14. 
The heat exchanger effectiveness was corrected to account for the air properties at the two ambient conditions. Equation [ 10 ], a form of the effectiveness equation which correlates to the different fluid temperatures, was used to predict the corrected water inlet and outlet temperatures (State 2 and State 4 in Figure 27, respectively) based on the corrected air temperatures. Table 20 summarizes all the powers used for correcting the air temperatures as well as the heat exchanger effectiveness for every test. Also, Table 20 presents the corrected effectiveness and water temperatures. Refer to Appendix A for a detailed sample calculation of the corrected water temperatures.

$$
\varepsilon=\frac{C_{h}\left(T_{h, i}-T_{h, o}\right)}{C_{\text {min }}\left(T_{h, i}-T_{c, i}\right)}=\frac{C_{c}\left(T_{c, o}-T_{c, i}\right)}{C_{\min }\left(T_{h, i}-T_{c, i}\right)}
$$

Table 20. Powers and corrected heat exchanger effectiveness with new water temperatures

\begin{tabular}{|c|c|c|c|c|c|c|c|c|c|c|c|}
\hline \multirow[b]{2}{*}{ Test } & \multirow[b]{2}{*}{$\begin{array}{c}\text { System } \\
\text { Air } \\
\text { Power } \\
\text { (W) }\end{array}$} & \multirow[b]{2}{*}{$\begin{array}{c}\text { HX } \\
\text { Water } \\
\text { Power } \\
\text { (W) }\end{array}$} & \multirow[b]{2}{*}{$\begin{array}{l}\text { Pre-HX } \\
\text { Air } \\
\text { Power } \\
\text { (W) }\end{array}$} & \multicolumn{4}{|c|}{$40^{\circ} \mathrm{C}$ at $10,000 \mathrm{ft}}$. & \multicolumn{4}{|c|}{$50^{\circ} \mathrm{C}$ at $6,000 \mathrm{ft}$. } \\
\hline & & & & $\varepsilon(-)$ & $\begin{array}{l}\text { HX Inlet } \\
\text { Water } \\
\text { Temp. } \\
\left({ }^{\circ} \mathrm{C}\right) \\
\text { (State 3) }\end{array}$ & $\begin{array}{c}\text { HX Outlet } \\
\text { Water } \\
\text { Temp. } \\
\left({ }^{\circ} \mathrm{C}\right) \\
\text { (State 4) }\end{array}$ & $\begin{array}{l}\text { Avg. } \\
\text { Water } \\
\text { Temp. } \\
\left({ }^{\circ} \mathrm{C}\right)\end{array}$ & $\varepsilon(-)$ & $\begin{array}{c}\text { HX Inlet } \\
\text { Water } \\
\text { Temp. } \\
\left({ }^{\circ} \mathrm{C}\right) \\
\text { (State 3) }\end{array}$ & $\mid \begin{array}{c}\text { HX Outlet } \\
\text { Water } \\
\text { Temp. } \\
\left({ }^{\circ} \mathrm{C}\right) \\
\text { (State 4) }\end{array}$ & $\begin{array}{l}\text { Avg. } \\
\text { Water } \\
\text { Temp. } \\
\left({ }^{\circ} \mathrm{C}\right)\end{array}$ \\
\hline 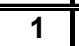 & 8450 & 2937 & 5513 & 0.741 & 68 & 58 & 63 & 0.765 & 76 & 66 & $\overline{711}$ \\
\hline 2 & 9461 & 3647 & 5814 & 0.731 & 73 & 60 & 67 & 0.756 & 81 & 68 & 74 \\
\hline 3 & 9191 & 3429 & 5762 & 0.678 & 77 & 65 & 71 & 0.708 & 84 & 72 & 78 \\
\hline 4 & 8908 & 3813 & 5096 & 0.623 & 86 & 72 & 79 & 0.657 & 93 & 78 & 85 \\
\hline 5 & 8874 & 3034 & 5840 & 0.797 & 72 & 58 & 65 & 0.814 & 80 & 66 & 73 \\
\hline 6 & 8021 & 2459 & 5562 & 0.845 & 74 & 57 & 66 & 0.856 & 82 & 65 & 74 \\
\hline 7 & 8840 & 2916 & 5924 & 0.788 & 73 & 59 & 66 & 0.807 & 81 & 67 & $\overline{74}$ \\
\hline 8 & 9661 & 3624 & 6037 & 0.746 & 72 & 59 & 66 & 0.769 & 80 & 67 & 73 \\
\hline 9 & 9575 & 3602 & 5973 & \begin{tabular}{l|l}
0.733 \\
\end{tabular} & 73 & 60 & 66 & 0.758 & 80 & 68 & 74 \\
\hline
\end{tabular}


The new case temperatures and junction temperatures were calculated with the corrected average water temperature, the case-water thermal resistance, $\Theta_{c, w}$, and measured power of the "A" Test Chip. The adjusted temperatures for the baseline test are in Table 21. For a detailed sample calculation on the corrected temperatures refer to Appendix A.

Table 21. Adjusted baseline (Test 1) temperatures to Cisco ambient requirements

\begin{tabular}{|c|c|c|c|c|c|c|c|c|}
\hline & $\begin{array}{l}\text { Air Inlet } \\
\text { Temp. } \\
\left({ }^{\circ} \mathrm{C}\right)\end{array}$ & $\begin{array}{c}\text { Pre-HX } \\
\text { Air } \\
\text { Temp. } \\
\left({ }^{\circ} \mathrm{C}\right)\end{array}$ & $\begin{array}{c}\text { Air } \\
\text { Exhaust } \\
\text { Temp. } \\
\left({ }^{\circ} \mathrm{C}\right)\end{array}$ & $\begin{array}{c}\mathrm{HX} \\
\text { Water } \\
\text { Outlet } \\
\text { Temp. } \\
\left({ }^{\circ} \mathrm{C}\right)\end{array}$ & $\begin{array}{c}\mathrm{HX} \\
\text { Water } \\
\text { Inlet } \\
\text { Temp. } \\
\left({ }^{\circ} \mathrm{C}\right)\end{array}$ & $\begin{array}{c}\text { Avg. } \\
\text { Water } \\
\text { Temp. } \\
\left({ }^{\circ} \mathrm{C}\right)\end{array}$ & $\begin{array}{c}\text { Cold } \\
\text { Plate } \\
\text { Temp. } \\
\left({ }^{\circ} \mathrm{C}\right)\end{array}$ & $\begin{array}{l}\text { "A" } \\
\text { Temp. } \\
\left({ }^{\circ} \mathrm{C}\right)\end{array}$ \\
\hline $\begin{array}{l}\text { Laboratory } \\
\left(29^{\circ} \mathrm{C}\right) \text { at sea } \\
\text { level }\end{array}$ & 29 & 41 & 43 & 52 & 42 & 47 & 61 & 91 \\
\hline $\begin{array}{l}40^{\circ} \mathrm{C} \text { at } \\
10,000 \mathrm{ft} .\end{array}$ & 40 & 54 & 61 & 68 & 58 & 63 & 77 & 107 \\
\hline $\begin{array}{l}50^{\circ} \mathrm{C} \text { at } \\
6,000 \mathrm{ft} .\end{array}$ & 50 & 62 & 69 & 76 & 66 & 71 & 85 & 115 \\
\hline
\end{tabular}

Table 21 shows that the " $\mathrm{A}$ " Test Chip junction temperature was above $105^{\circ} \mathrm{C}$ for both Cisco ambient conditions. This was representative of $101 \mathrm{~W}$ dissipated from the "A" Test Chip with a package junction-to-case thermal resistance, $\Theta_{\mathrm{j}, \mathrm{c}}$, of $0.27^{\circ} \mathrm{C} / \mathrm{W}$. In the true product application the "A" chip is expected to dissipate $90 \mathrm{~W}$ and have a package junction-to-case thermal resistance, $\Theta_{\mathrm{j}, \mathrm{c}}$, of $0.20^{\circ} \mathrm{C} / \mathrm{W}$. Lower " $\mathrm{A}$ ” chip junction temperatures were predicted using this design criteria in Equation [ 7 ] with the adjusted average water temperatures and the calculated case-to-water thermal resistance, $\Theta_{c, w}$, from the test data. Again this assumed 100\% of the chip power was transferred to the water. These temperatures, representative of the true product, are shown in Table 22 along with the testing adjusted temperatures and measured "A" Test Chip powers. 
Table 22. Corrected "A" case and junction temperatures for Cisco ambient conditions and true product design criteria

\begin{tabular}{|c|c|c|c|c|c|c|c|c|c|c|c|}
\hline \multirow{3}{*}{ Test } & \multirow{3}{*}{$\begin{array}{c}\text { "A" } \\
\text { Test } \\
\text { Chip } \\
\text { Power } \\
\text { (W) }\end{array}$} & \multirow{2}{*}{\multicolumn{2}{|c|}{$\begin{array}{c}\text { Laboratory } \\
\left(29^{\circ} \mathrm{C}\right) \text { at Sea } \\
\text { Level } \\
\text { (measured } \\
\text { data) }\end{array}$}} & \multicolumn{4}{|c|}{$40^{\circ} \mathrm{C}$ at $10,000 \mathrm{ft}}$. & \multicolumn{4}{|c|}{$50^{\circ} \mathrm{C}$ at $6,000 \mathrm{ft}$. } \\
\hline & & & & \multicolumn{2}{|c|}{$\begin{array}{c}\text { Testing } \\
\text { power } \sim 100 \mathrm{~W} \\
\Theta_{\mathrm{j}, \mathrm{c}}=0.27^{\circ} \mathrm{C} / \mathrm{W}\end{array}$} & \multicolumn{2}{|c|}{$\begin{array}{c}\text { True Product } \\
\text { power } 90 \mathrm{~W} \\
\Theta_{\mathrm{j}, \mathrm{c}}=0.20^{\circ} \mathrm{C} / \mathrm{W}\end{array}$} & \multicolumn{2}{|c|}{$\begin{array}{c}\text { Testing } \\
\text { power } \sim 100 \mathrm{~W} \\
\Theta_{\mathrm{j}, \mathrm{c}}=0.27^{\circ} \mathrm{C} / \mathrm{W}\end{array}$} & \multicolumn{2}{|c|}{$\begin{array}{c}\text { True Product } \\
\text { power } 90 \mathrm{~W} \\
\Theta_{\mathrm{j}, \mathrm{c}}=0.20^{\circ} \mathrm{C} / \mathrm{W}\end{array}$} \\
\hline & & $\begin{array}{l}\mathrm{T}_{\text {case }} \\
\left({ }^{\circ} \mathrm{C}\right)\end{array}$ & $\begin{array}{l}\mathrm{T}_{\text {junc }} \\
\left({ }^{\circ} \mathrm{C}\right)\end{array}$ & $\begin{array}{l}T_{\text {case }} \\
\left(^{\circ} \mathrm{C}\right)\end{array}$ & $\begin{array}{l}\mathrm{T}_{\text {junc }} \\
\left({ }^{\circ} \mathrm{C}\right)\end{array}$ & $\begin{array}{l}\mathrm{T}_{\text {case }} \\
\left({ }^{\circ} \mathrm{C}\right)\end{array}$ & $\begin{array}{l}\mathrm{T}_{\text {junc }} \\
\left({ }^{\circ} \mathrm{C}\right)\end{array}$ & $\begin{array}{l}\mathrm{T}_{\text {case }} \\
\left({ }^{\circ} \mathrm{C}\right)\end{array}$ & $\begin{array}{l}\mathrm{T}_{\text {junc }} \\
\left({ }^{\circ} \mathrm{C}\right)\end{array}$ & $\begin{array}{l}\mathrm{T}_{\text {case }} \\
\left({ }^{\circ} \mathrm{C}\right)\end{array}$ & $\begin{array}{l}T_{\text {junc }} \\
\left(^{\circ} \mathrm{C}\right)\end{array}$ \\
\hline$\overline{\overline{1}}$ & 101 & 64 & 91 & 80 & 107 & 78 & 96 & 88 & 115 & 86 & 104 \\
\hline 2 & 100 & 67 & 94 & 82 & 109 & 81 & 99 & 90 & 117 & 89 & 107 \\
\hline 3 & 99 & 69 & 95 & 86 & 112 & 84 & 102 & 93 & 119 & 91 & 109 \\
\hline 4 & 96 & 79 & 105 & 94 & 120 & 93 & 111 & 100 & 126 & 99 & 117 \\
\hline 5 & 100 & 66 & 93 & 80 & 107 & 78 & 96 & 88 & 115 & 86 & 104 \\
\hline 6 & 99 & 72 & 99 & 85 & 112 & 83 & 101 & 93 & 120 & 92 & 110 \\
\hline 7 & 100 & 66 & 93 & 79 & 106 & 78 & 96 & 87 & 114 & 85 & 103 \\
\hline 8 & 130 & 67 & 102 & 82 & 117 & ${ }^{*} 82$ & ${ }^{*} 108$ & 90 & 125 & ${ }^{*} 90$ & *116 \\
\hline 9 & 130 & 69 & 104 & 84 & 119 & *84 & *110 & 92 & 127 & ${ }^{*} 92$ & *118 \\
\hline
\end{tabular}

* True product case and junction temperatures calculated with measured power not expected $90 \mathrm{~W}$

The tests which reduced the water volumetric flow rate, Tests 5 through 7 , had an overall supplied system power significantly lower than the other tests. This is associated with the circulation heater power being reduced in order to match the circulation heater and Test Board water outlet temperatures. This reduction in system power skewed the corrected case and junction temperatures bringing them near or slightly below the baseline test (Test 1) corrected temperatures. Also, Tests 8 and 9 increased the "X" complex Test Chip power above the other tests as a way to determine the liquid cold plate thermal performance for a power beyond the chip's expected rated power. Tests 8 and 9 showed corrected temperatures for the true product package thermal resistance, $0.20^{\circ} \mathrm{C} / \mathrm{W}$, and the measured " $\mathrm{A}$ " Test Chip power.

The true product corrected values for the baseline test showed an estimated junction temperature of $104^{\circ} \mathrm{C}$ for $50^{\circ} \mathrm{C}$ at $6,000 \mathrm{ft}$. The $40^{\circ} \mathrm{C}$ at $10,000 \mathrm{ft}$ ambient condition had a 
corrected junction temperature of $96^{\circ} \mathrm{C}$, a $9^{\circ} \mathrm{C}$ margin. The ambient condition of $50^{\circ} \mathrm{C}$ at $6,000 \mathrm{ft}$. had adjusted temperature values above the $105^{\circ} \mathrm{C}$ for the remaining conducted tests. The $40^{\circ} \mathrm{C}$ at $10,000 \mathrm{ft}$ ambient condition could reduce the fan duty cycle to $50 \%$ (about $75 \%$ air flow reduction), while maintaining the same liquid flow rate, and still achieve a junction temperature $3^{\circ} \mathrm{C}$ below the maximum rating of $105^{\circ} \mathrm{C}$. The elevated "A" Test Chip power in Test 8 and Test 9 show the junction temperature was slightly above $105^{\circ} \mathrm{C}$ for the $40^{\circ} \mathrm{C}$ at $10,000 \mathrm{ft}$ ambient condition. This shows the hybrid cooling design has the potential of handling elevated powers demonstrated in the previous tests. The hybrid cooling design for $50^{\circ} \mathrm{C}$ at $6,000 \mathrm{ft}$ ambient condition was sufficient to provide a junction temperature below the maximum rating. There was only $1{ }^{\circ} \mathrm{C}$ margin for this ambient condition making it important to maintain sufficient air and liquid flow rates. 


\section{Chapter 6}

\section{$\underline{\text { Conclusion }}$}

The tests described in this document produced results for a router system generating approximately $8.3 \mathrm{~kW}$. As part of the $8.3 \mathrm{~kW}$, a mock test board produced $1.06 \mathrm{~kW}$ with an "X" complex Test Chip generating $0.144 \mathrm{~kW}$. The air flow rate was $0.508 \mathrm{~m}^{3} / \mathrm{s}(1077 \mathrm{cfm})$ $\left[0.057 \mathrm{~m}^{3} / \mathrm{s}(120 \mathrm{cfm}\right.$ per card $\left.)\right]$ while the liquid flow rate was $4.15 \mathrm{lpm}(1.1 \mathrm{gpm})$

[0.40 lpm $(0.106 \mathrm{gpm})$ through test board]. From the raw results this hybrid cooling design does not pass all the needed Cisco requirements, but the modified results, representing the true product " $\mathrm{A}$ " chip thermal characteristics, does demonstrate the design is capable of maintaining an " $\mathrm{A}$ " chip junction temperature below $105^{\circ} \mathrm{C}$ for both Cisco ambient conditions.

The modified results demonstrate a more accurate representation of the true product "A" chip thermal characteristics. The true product "A" chip is projected to have a thermal resistance from junction to case of $\Theta_{\mathrm{jc}}=0.20^{\circ} \mathrm{C} / \mathrm{W}$, which was not tested because the "A" Test Chip had a thermal resistance of $\Theta_{\mathrm{jc}}=0.27^{\circ} \mathrm{C} / \mathrm{W}$. Making these adjustments to the recorded temperature readings resulted in a junction temperature of $104^{\circ} \mathrm{C}$ under $50^{\circ} \mathrm{C}$ at $6,000 \mathrm{ft}$ ambient conditions. For $40^{\circ} \mathrm{C}$ at $10,000 \mathrm{ft}$ ambient conditions the junction temperature was $96^{\circ} \mathrm{C}$. These resulting junction temperatures fall below the required $105^{\circ} \mathrm{C}$ limit, concluding the hybrid cooling design can meet the thermal design constraints. 
The conclusions drawn from the modified results were based on the previously mentioned assumption that $100 \%$ of the " $\mathrm{A}$ " chip power was transferred to the liquid. In true application, a portion of the power would also be transferred to the PCB and air. The percentage of power dissipated to the water would be relatively large compared to the power transferred to the other mediums, suggesting there would be little temperature difference from what was calculated. Though, a more detailed analysis, such as Flotherm, should be performed to better predict the true characteristics.

As stated earlier the liquid system flow rate was below the original design of $5.30 \mathrm{lpm}$ (1.4 gpm). The prototype liquid system flow rate $4.16 \mathrm{lpm}(1.1 \mathrm{gpm})$ was about $79 \%$ of the designed $5.30 \mathrm{lpm}(1.4 \mathrm{gpm})$. The impact of lower flow rates on the hybrid design can be seen in Figure 39 and Figure 40. The liquid flow rate significantly affected the junction temperature when it dropped to $50 \%$ of the tested maximum flow rate. Increasing the power transferred to the water would further reduce the " $A$ " junction temperature. This power transfer increase would inevitably be the result of an increased liquid flow rate, but cold plates with higher heat transfer characteristics would also help. The liquid flow rate should be analyzed in more detail to determine the overall impact on the prototype thermal characteristics.

Further studies with Flotherm should be performed to verify the conclusion that the hybrid design meets all the requirements. This is due to the high uncertainties associated with the liquid flow rates and some electrical power measurements. It is also suggested that more tests be performed on the prototype at the desired ambient conditions. This will allow for more accurate measurements pertaining to the characteristics of the heat exchanger and cold plates under the 
Cisco standard ambient conditions. The modified temperatures for the Cisco standard ambient conditions assumed the quantity of power transferred to the air and water would be the same as the calculated air and water powers under the lab test conditions. In actuality, more heat would be transferred to air, and less to water, when the liquid temperature increases. From Figure 3, it was estimated there would be a $5 \%$ decrease in board power transferred to water for every $10^{\circ} \mathrm{C}$ increase in average water temperature. Also, Figure 40 suggests there could be as much as $5^{\circ} \mathrm{C}$ increase in " $\mathrm{A}$ " chip junction temperature with a $7 \%$ decrease in power transferred to water. The few data points and high uncertainties associated with those data points make it difficult to accurately predict the overall performance under different operating conditions. Though those trends suggest the hybrid design could have a lower performance at the elevated ambient temperature conditions than what was demonstrated in the results section. Testing the prototype under the desired ambient conditions would collect data accurately representing the design performance under those conditions and negate the assumptions used for the adjusted temperature calculations.

The thermal resistances calculated between case-to-water, $\Theta_{c, w}$, were influenced by the liquid flow rate, cold plate design and the mating surfaces of the cold plate and chip case. It is important to have a tight flatness tolerance for the cold plate mounting surface as well as using highly conductive thermal interface material (TIM). Also, the mounting pressure of the cold plate to the chips is critical to obtain the best performance of the TIM, while not applying too much pressure. Excessive pressure could cause the PCB to deflect which would result in uneven or partial chip contact to the cold plate, or worst, breakage of the chip. The cold plate design could be improved to provide a higher heat transfer rate to the water passing through it. This 
improvement would involve increasing the surface area which the water comes in contact with inside the cold plate. Increasing the number of channels in the cold plate and/or implementing grooves to the channels would increase this surface area. Following these suggestions would guarantee lower thermal resistance of case-to-water, $\Theta_{\mathrm{c}, \mathrm{w}}$, and provide higher margin for the chip junction temperature.

Some of the modified junction temperatures for the other tests were only a few degrees above the maximum rating of $105^{\circ} \mathrm{C}$ (refer to Table 22). Implementing the suggestions mentioned in the previous paragraph could reduce those temperatures below $105^{\circ} \mathrm{C}$. This would allow the system to operate the fans at a lower speed thus reducing the total system power consumption. The hybrid cooling design is more than capable of operating under the $40^{\circ} \mathrm{C}$ at $10,000 \mathrm{ft}$ ambient condition with $9^{\circ} \mathrm{C}$ margin. The hybrid design passes the $50^{\circ} \mathrm{C}$ at $6,000 \mathrm{ft}$ ambient condition, but only at nominal operating conditions (air flow, liquid flow, heat exchanger performance, etc.) and has very little margin, $1^{\circ} \mathrm{C}$. The variability associated with components and manufacturing could make it really hard to reproduce these conditions for every router. This suggests improvements would be needed in order to increase the margin for $50^{\circ} \mathrm{C}$ at $6,000 \mathrm{ft}$ ambient condition.

There are some features on this hybrid design which did not cause problems, but should be modified. The pumps, quick disconnects and tubing had a lower temperature rating than the maximum water temperature for the $50^{\circ} \mathrm{C}$ at $6,000 \mathrm{ft}$ ambient condition. There were rubber o-rings used with the pneumatic fittings on the cold plates which may have a lower temperature rating than what the cold plates may experience. The design of the cold plate could be improved 
and optimized for the router system. It was constructed primarily for manufacturability not optimized for heat transfer. A detailed design analysis could be performed to identify the most efficient design. The heat exchanger could be custom designed; the ones used in testing were 'Off-the-Shelf' heat exchangers. A custom heat exchanger would have better performance and require less modification to the chassis height.

From the modified results, the design met all the constraints and was a success. This hybrid cooling system can handle the projected heat load, but there are many other concerning issues before it can be shipped to customers. These issues address environmental impact of water inhibitors, material compatibility, leak detection, and shipping.

Untreated water can be very caustic to metals, especially aluminum. The corrosion associated with the water can cause undesirable fouling which changes the properties and characteristics of the liquid system. Most of the time, inhibitors are used in the water to prevent bacterial growth and reduce corrosion. These inhibitors have been known to have harmful impacts on the environment. The issue of having to dispose of the system water and its potential influence on the environment could create more problems in the future. There are more environmentally friendly inhibitors available; it is just a matter of investigating them and choosing the right ones.

Material compatibility is always a concern, but with the introduction of water, things become more complicated. Electrolysis can occur when two dissimilar metals are in contact with one another and running water. Water inhibitors can react with other materials in the system 
causing complications. Some plastics and rubbers used in gaskets and fittings may not create tight enough seals with one another. Material temperature ratings can also influence their characteristics. In fact, the pumps, fittings, and tubing should be replaced on the prototype if it were to run at the higher ambient temperatures, because their temperature ratings are below the expected water temperatures.

With water being involved with electronic systems, a leak could destroy everything. It is essential to prevent leaks and have a method to detect them. There are environmental measuring devices that can detect a single drop of water, but locations for placement need to be considered. With a pressurized system a pressure measuring device could be used. A reliable method of leak detection needs to be implemented with this design.

Having to ship, install, and repair these cooling systems will require purging and refilling. There needs to be a valve at the lowest possible location on the chassis and one on top. Also, a method of purging all the water out will be needed. Pumping could be an option, as well as just gravity, as a way of purging the system. The water should be readily available; meaning building water should be acceptable to replace the system water. The system water should also be able to be poured down drains, which brings back the environmental issue. Issues with manufacturing will arise with this hybrid design but these issues are a good starting point for the next design iteration. 
As long as electronic performance is dictated by temperature, there will always be a need to reject heat created by electrical components. There are going to be many more alternative cooling systems needed in the future as electronic technology keeps advancing. The hybrid liquid-air cooling system proved it can be the next generation router system cooling design used to help Cisco keep its technological advantage. 


\section{References}

Chan, A., and Wei, J., 2005, “Assessing Capabilities and Limitations of Air- and LiquidCooling for Low Profile Server," Proceedings of IPACK2005, ASME InterPACK, IPACK2005-73293, San Francisco, CA.

Chang, J., Prasher, R., Chau, D., Myers, A., Dirner, J., Prstic, S., and He, D., 2005, "Convective Performance of Package Based Single Phase Microchannel Heat Exchanger," Proceedings of IPACK2005, ASME InterPACK, IPACK2005-73126, San Francisco, CA.

Chu, R.C., Simmons, R.E., Ellsworth, M.J., Schmidt, R.R., and Cozzolino, V., 2004, "Review of Cooling Technologies for Computer Products," $\underline{\text { IEEE Transactions on Device }}$ and Materials Reliability, 4, No. 4, pp 568-585.

Dake, T.J., and Majdalani, J., 2003, “Design Optimization of a Router Board using Computational Fluid Dynamics," Proceedings of IPACK2003, ASME InterPACK, IPACK2003-35338, Maui, Hawaii.

Gao, M., and Cao, Y., 2003, "Flat and U-Shaped Heat Spreaders for High-Power Electronics," Heat Transfer Engineering, 24, No. 3, pp 57-65. 
Incropera, F.P., and Dewitt, D.P.. Introduction to Heat Transfer, $4^{\text {th }}$ edition. New York: John Wiley and Sons, 2002.

Kays, W.M., and London, A.L., Compact Heat Exchangers, $3^{\text {rd }}$ edition, McGraw-Hill, New York, 1984.

Kelkar, K.M., and Kang, S., 2005, “Computational Method for Characterization of a Microchannel Heat Sink involving Two-Phase Flow," Proceedings of IPACK2005, ASME InterPACK, IPACK2005-73119, San Francisco, CA.

Krishnan, S., Garimella, S.V., Chrysler, G.M., and Mahajan, R.V., 2005, “Towards a Thermal Moore's Law," Proceedings of IPACK2005, ASME InterPACK, IPACK200573409, San Francisco, CA.

Maddren, Jesse. "Next Generation Router System Cooling Design, Analysis and Testing: Phase 2 Study Report.” 13 July 2006. California Polytechnic State University, San Luis Obispo, CA.

Maddren, Jesse and Pascual, Chris. "Next Generation Router System Cooling Design, Analysis and Testing: Statement of Work." 8 April 2005. California Polytechnic State University, San Luis Obispo, CA. 
Pascual, Chris. "Next Generation Router System Cooling Design, Analysis and Testing: Phase 1 Study Report.” 20 December 2005. California Polytechnic State University, San Luis Obispo, CA.

Sauciuc, I., Prasher, R., Chang, J., Erturk, H., Chrysler, G., Chiu, C., and Mahajan, R., 2005, "Thermal Performance and Key Challenges for Future CPU Cooling Technologies," Proceedings of IPACK2005, ASME InterPACK, IPACK2005-73242, San Francisco, CA.

Wei, J., and Suzuki, M., 2005, "Thermal Management of Fujitsu High-End Unix Servers," Proceedings of IPACK2005, ASME InterPACK, IPACK2005-73313, San Francisco, CA.

Xu, G., Guenin, B., and Vogel, M., 2004, “Extension of Air Cooling for High Power Processors," Inter Society Conference on Thermal Phenomena, IEEE, pp 186-193.

Yeh, L.T., Chung, B.T.F., and Yeh, J., 2005, “A CFD Analysis of Telecommunications Racks Including Effects of Air Filter Locations," Proceedings of IPACK2005, ASME InterPACK, IPACK2005-73008, San Francisco, CA.

Zhang, H.Y., and Pinjala, D., 2005, “Flow Boiling Heat Transfer in Microchannel Heat Sinks of Different Flow Orientations," Proceedings of IPACK2005, ASME InterPACK, IPACK2005-73041, San Francisco, CA. 


\section{Appendix A}

Sample Calculations 


\section{Heat Exchanger Water Power Sample Calculation}

Measured Values: $\mathrm{T}_{\mathrm{i}}=41.58^{\circ} \mathrm{C}, \mathrm{T}_{\mathrm{o}}=51.86^{\circ} \mathrm{C}, \dot{\forall}_{\text {Total }}=0.106 \mathrm{gpm}+0.99 \mathrm{gpm}=1.096 \mathrm{gpm}$ Average Temperature Properties: $c_{p}=4.1814 \mathrm{~kJ} / \mathrm{kg}-\mathrm{K}, \rho=989 \mathrm{~kg} / \mathrm{m}^{3}$.

Energy Equation: $q=\dot{\forall}_{\text {Total }} \rho c_{p}\left(T_{o}-T_{i}\right)$

$$
\begin{aligned}
& q=\left(1.096 \mathrm{gpm} \times\left(6.309 \times 10^{-5} \frac{\mathrm{m}^{3} / \mathrm{s}}{\mathrm{gpm}}\right)\right) \times\left(989 \frac{\mathrm{kg}}{\mathrm{m}^{3}}\right) \times\left(4.181 \frac{\mathrm{kJ}}{\mathrm{kg} \cdot \mathrm{K}}\right) \\
& \times\left(1000 \frac{\mathrm{J}}{\mathrm{kJ}}\right) \times\left(51.86^{\circ} \mathrm{C}-41.58^{\circ} \mathrm{C}\right) \\
& q=2924 \mathrm{~W}
\end{aligned}
$$

Uncertainties: $u_{\dot{\forall}_{1}}= \pm 0.1 \mathrm{gpm}, u_{\dot{\forall}_{2}}= \pm 0.01 \mathrm{gpm}, u_{T_{o}}= \pm 1.0^{\circ} \mathrm{C}, u_{T_{i}}= \pm 1.0^{\circ} \mathrm{C}$

$$
\begin{aligned}
\text { Uncertainty Equation: } u_{q} & =\sqrt{\left(\frac{\partial q}{\partial \dot{\forall}_{1}} u_{\dot{\forall}_{1}}\right)^{2}+\left(\frac{\partial q}{\partial \dot{\forall}_{2}} u_{\dot{\forall}_{2}}\right)^{2}+\left(\frac{\partial q}{\partial T_{o}} u_{T_{o}}\right)^{2}+\left(\frac{\partial q}{\partial T_{i}} u_{T_{i}}\right)^{2}} \\
\frac{\partial q}{\partial \dot{\forall}_{1}} & =\rho c_{p}\left(T_{o}-T_{i}\right)=\frac{q}{\dot{\forall}_{\text {Total }}} \quad \frac{\partial q}{\partial T_{o}}=\dot{\forall}_{\text {Total }} \rho c_{p}=\frac{q}{\Delta T} \\
\frac{\partial q}{\partial \dot{\forall}_{2}} & =\rho c_{p}\left(T_{o}-T_{i}\right)=\frac{q}{\dot{\forall}_{\text {Total }}} \\
u_{q} & =\sqrt{\left(\frac{2924 \mathrm{~W}}{1.096 \mathrm{gpm}} \times 0.01 \mathrm{gpm}\right)^{2}+\left(\frac{2924 \mathrm{~W}}{10.28^{\circ} \mathrm{C}} \times 1.0^{\circ} \mathrm{C}\right)^{2}} \\
+\left(\frac{2924 \mathrm{~W}}{1.096 \mathrm{gpm}} \times 0.1 \mathrm{gpm}\right)^{2}+\left(\frac{2924 \mathrm{~W}}{10.28^{\circ} \mathrm{C}} \times 1.0^{\circ} \mathrm{C}\right)^{2} & \frac{q}{\Delta T} \\
u_{q} & = \pm 483 \mathrm{~W} \\
u_{q} & = \pm 17 \%
\end{aligned}
$$

Energy transferred to system water: $\mathbf{q}=\mathbf{2 9 0 0} \pm \mathbf{4 8 0} \mathrm{W}$ 


\section{Board Water Power Sample Calculation}

Measured Values: $\mathrm{T}_{\mathrm{i}}=41.51^{\circ} \mathrm{C}, \mathrm{T}_{\mathrm{o}}=53.38^{\circ} \mathrm{C}, \dot{\forall}=0.106 \mathrm{gpm}$

Average Temperature Properties: $c_{p}=4.1814 \mathrm{~kJ} / \mathrm{kg}-\mathrm{K}, \rho=989 \mathrm{~kg} / \mathrm{m}^{3}$.

Energy Equation: $q=\dot{\forall} \rho c_{p}\left(T_{o}-T_{i}\right)$

$$
\begin{aligned}
& q=\left(0.106 \mathrm{gpm} \times\left(6.309 \times 10^{-5} \frac{\mathrm{m}^{3} / \mathrm{s}}{\mathrm{gpm}}\right)\right) \times\left(989 \frac{\mathrm{kg}}{\mathrm{m}^{3}}\right) \times\left(4.181 \frac{\mathrm{kJ}}{\mathrm{kg} \cdot \mathrm{K}}\right) \\
& \times\left(1000 \frac{\mathrm{J}}{\mathrm{kJ}}\right) \times\left(53.38^{\circ} \mathrm{C}-41.51^{\circ} \mathrm{C}\right) \\
& q=328 \mathrm{~W}
\end{aligned}
$$

Uncertainties: $u_{\dot{\forall}}= \pm 0.01 \mathrm{gpm}, u_{T_{o}}= \pm 1.0^{\circ} \mathrm{C}, u_{T_{i}}= \pm 1.0^{\circ} \mathrm{C}$

Uncertainty Equation: $u_{q}=\sqrt{\left(\frac{\partial q}{\partial \dot{\forall}} u_{\dot{\forall}}\right)^{2}+\left(\frac{\partial q}{\partial T_{o}} u_{T_{o}}\right)^{2}+\left(\frac{\partial q}{\partial T_{i}} u_{T_{i}}\right)^{2}}$

$$
\begin{array}{cc}
\frac{\partial q}{\partial \dot{\forall}}=\rho c_{p}\left(T_{o}-T_{i}\right)=\frac{q}{\dot{\forall}} & \frac{\partial q}{\partial T_{o}}=\dot{\forall} \rho c_{p}=\frac{q}{\Delta T} \\
\frac{\partial q}{\partial T_{i}}=\dot{\forall} \rho c_{p}=\frac{q}{\Delta T} \\
u_{q}=\sqrt{\left(\frac{328 \mathrm{~W}}{0.106 g p m} \times 0.01 \mathrm{gpm}\right)^{2}+\left(\frac{328 \mathrm{~W}}{11.87^{\circ} \mathrm{C}} \times 1.0^{\circ} \mathrm{C}\right)^{2}+\left(\frac{328 \mathrm{~W}}{11.87^{\circ} \mathrm{C}} \times 1.0^{\circ} \mathrm{C}\right)^{2}} \\
u_{q}= \pm 50 \mathrm{~W} \\
u_{q}= \pm 15 \%
\end{array}
$$

Energy transferred to board water: $\mathbf{q}=\mathbf{3 3 0} \pm \mathbf{5 0} \mathrm{W}$ 


\section{$\underline{\text { Total Air Power Sample Calculation }}$}

Measured Values: $\mathrm{T}_{\mathrm{i}}=28.54^{\circ} \mathrm{C}$, (Temp. at exhaust $) \mathrm{T}_{\mathrm{o}}=43.04^{\circ} \mathrm{C}, \Delta \mathrm{P}=3.69 \mathrm{inH}_{2} \mathrm{O}$

Average Temperature Property: $\mathrm{c}_{\mathrm{p}}=1.006 \mathrm{~kJ} / \mathrm{kg}-\mathrm{K}$

Ideal Gas Law at $\mathrm{T}_{\mathrm{i}}$ condition: $\rho=1.142 \mathrm{~kg} / \mathrm{m}^{3}$

LFE Flow Rate Equation: $\dot{\forall}=(B \times \Delta P)+\left(C \times \Delta P^{2}\right)$

$$
\begin{aligned}
& \mathrm{B}=294.2444 \text { and } \mathrm{C}=-0.678646 \\
& \dot{\forall}=1035 \mathrm{cfm}
\end{aligned}
$$

Energy Equation: $q=\dot{\forall} \rho c_{p}\left(T_{o}-T_{i}\right)$

$$
\begin{aligned}
& q=\left(1035 c \mathrm{fm} \times\left(4.719 \times 10^{-4} \frac{\mathrm{m}^{3} / \mathrm{s}}{\mathrm{cfm}}\right)\right) \times\left(1.142 \frac{\mathrm{kg}}{\mathrm{m}^{3}}\right) \times\left(1.006 \frac{\mathrm{kJ}}{\mathrm{kg} \cdot \mathrm{K}}\right) \\
& \times\left(1000 \frac{\mathrm{J}}{\mathrm{kJ}}\right) \times\left(43.04^{\circ} \mathrm{C}-28.54^{\circ} \mathrm{C}\right) \\
& q=8138 \mathrm{~W}
\end{aligned}
$$

Uncertainties: $u_{\text {mano }}= \pm 0.1 \mathrm{inH}_{2} \mathrm{O}, u_{L F E}= \pm 0.86 \%$ per $1000 \mathrm{cfm}$,

$$
u_{T_{o}}= \pm 1.0^{\circ} \mathrm{C}, u_{T_{i}}= \pm 1.0^{\circ} \mathrm{C}
$$

LFE Uncertainty Equation:

$$
u_{\dot{\forall}_{L F E}}=\sqrt{\left(\frac{\partial \dot{\forall}_{L F E}}{\partial \Delta P} u_{\text {mano }}\right)^{2}+\left(0.0086 \times \dot{\forall}_{L F E}\right)^{2}}
$$




$$
\begin{aligned}
& \dot{\forall}=(B \times \Delta P)+\left(C \times \Delta P^{2}\right) \\
& \frac{\partial \dot{\forall}}{\partial \Delta P}=B+(2 \times C \times \Delta P)=294.2444+[2 \times(-0.678646) \times(3.69)] \\
& \frac{\partial \dot{\forall}}{\partial \Delta P}=294.2444+[2 \times(-0.678646) \times(3.69)] \\
& \frac{\partial \dot{\forall}}{\partial \Delta P}=289.236 \frac{c f m}{\mathrm{inH}_{2} \mathrm{O}} \\
& u_{\dot{\forall}_{L F E}}=\sqrt{\left(289.236 \frac{c f m}{i n H_{2} O} \times 0.1 \mathrm{inH}_{2} \mathrm{O}\right)^{2}+(0.0086 \times 1035 \mathrm{cfm})^{2}} \\
& u_{\dot{\forall}_{L F E}}= \pm 30 \mathrm{cfm}
\end{aligned}
$$

Total Uncertainty Equation: $u_{q}=\sqrt{\left(\frac{\partial q}{\partial \dot{\forall}_{L F E}} u_{\dot{\forall}_{L F E}}\right)^{2}+\left(\frac{\partial q}{\partial T_{o}} u_{T_{o}}\right)^{2}+\left(\frac{\partial q}{\partial T_{i}} u_{T_{i}}\right)^{2}}$

$$
\begin{array}{ll}
\frac{\partial q}{\partial \dot{\forall}_{L F E}}=\rho c_{p}\left(T_{o}-T_{i}\right)=\frac{q}{\dot{\forall}_{L F E}} & \frac{\partial q}{\partial T_{o}}=\dot{\forall}_{L F E} \rho c_{p}=\frac{q}{\Delta T} \\
\frac{\partial q}{\partial T_{i}}=\dot{\forall}_{L F E} \rho c_{p}=\frac{q}{\Delta T} \\
u_{q}=\sqrt{\left(\frac{8138 \mathrm{~W}}{1035 c f m} \times 30 \mathrm{cfm}\right)^{2}+\left(\frac{8138 \mathrm{~W}}{14.5^{\circ} \mathrm{C}} \times 1.0^{\circ} \mathrm{C}\right)^{2}+\left(\frac{8138 \mathrm{~W}}{14.5^{\circ} \mathrm{C}} \times 1.0^{\circ} \mathrm{C}\right)^{2}} \\
u_{q}= \pm 828 \mathrm{~W} \\
u_{q}= \pm 10 \%
\end{array}
$$

Energy transferred to system air: $\mathbf{q = 8 . 1} \pm \mathbf{0 . 8 3} \mathbf{~ k W}$ 


\section{Board Air Power Sample Calculation}

Measured Values: $\mathrm{T}_{\mathrm{i}}=28.54^{\circ} \mathrm{C}$, (Temp. before $\left.\mathrm{HX}\right) \mathrm{T}_{\mathrm{o}}=40.69^{\circ} \mathrm{C}, \Delta \mathrm{P}=3.69 \mathrm{inH}_{2} \mathrm{O}$

Average Temperature Property: $\mathrm{c}_{\mathrm{p}}=1.006 \mathrm{~kJ} / \mathrm{kg}-\mathrm{K}$

Ideal Gas Law at $\mathrm{T}_{\text {icondition: }} \rho=1.142 \mathrm{~kg} / \mathrm{m}^{3}$

LFE Flow Rate Equation: $\dot{\forall}=(B \times \Delta P)+\left(C \times \Delta P^{2}\right)$

$$
\begin{aligned}
& \mathrm{B}=294.2444 \text { and } \mathrm{C}=-0.678646 \\
& \dot{\forall}=1035 \mathrm{cfm}
\end{aligned}
$$

Energy Equation: $q=\dot{\forall} \rho c_{p}\left(T_{o}-T_{i}\right)$

$$
\begin{aligned}
& q=\left(1035 \mathrm{cfm} \times\left(4.719 \times 10^{-4} \frac{\mathrm{m}^{3} / \mathrm{s}}{\mathrm{cfm}}\right)\right) \times\left(1.142 \frac{\mathrm{kg}}{\mathrm{m}^{3}}\right) \times\left(1.006 \frac{\mathrm{kJ}}{\mathrm{kg} \cdot \mathrm{K}}\right) \\
& \times\left(1000 \frac{\mathrm{J}}{\mathrm{kJ}}\right) \times\left(40.69^{\circ} \mathrm{C}-28.54^{\circ} \mathrm{C}\right) \\
& q=6819 \mathrm{~W}
\end{aligned}
$$

Uncertainties: $u_{L F E}= \pm 30 \mathrm{cfm}, u_{T_{o}}= \pm 1.0^{\circ} \mathrm{C}, u_{T_{i}}= \pm 1.0^{\circ} \mathrm{C}$

Total Uncertainty Equation: $u_{q}=\sqrt{\left(\frac{\partial q}{\partial \dot{\forall}_{L F E}} u_{\dot{\forall}_{L F E}}\right)^{2}+\left(\frac{\partial q}{\partial T_{o}} u_{T_{o}}\right)^{2}+\left(\frac{\partial q}{\partial T_{i}} u_{T_{i}}\right)^{2}}$

$$
\begin{aligned}
\frac{\partial q}{\partial \dot{\forall}_{L F E}}=\rho c_{p}\left(T_{o}-T_{i}\right)=\frac{q}{\dot{\forall}_{L F E}} & \frac{\partial q}{\partial T_{o}}=\dot{\forall}_{L F E} \rho c_{p}=\frac{q}{\Delta T} \\
\frac{\partial q}{\partial T_{i}} & =\dot{\forall}_{L F E} \rho c_{p}=\frac{q}{\Delta T}
\end{aligned}
$$




$$
\begin{aligned}
& u_{q}=\sqrt{\left(\frac{6819 \mathrm{~W}}{1035 c f m} \times 30 c f m\right)^{2}+\left(\frac{6819 \mathrm{~W}}{12.2^{\circ} \mathrm{C}} \times 1.0^{\circ} \mathrm{C}\right)^{2}+\left(\frac{6819 \mathrm{~W}}{12.2^{\circ} \mathrm{C}} \times 1.0^{\circ} \mathrm{C}\right)^{2}} \\
& u_{q}= \pm 815 \mathrm{~W} \\
& u_{q}= \pm 12 \%
\end{aligned}
$$

Energy transferred to system air before heat exchanger: $\mathrm{q}=6.8 \pm 0.8 \mathrm{~kW}$

Energy transferred to single board $\left(1 / 9^{\text {th }}\right.$ system air $): \mathbf{q}=760 \pm 91 \mathrm{~W}$ 


\section{Board Electrical Power Sample Calculation}

Below in Table 9 are the calculated electrical powers and uncertainties for the terminal groups on the test board during the baseline test. Terminals $\# 5$ and $\# 7$ represent the "A" and "B" test chips, respectively. Terminals \#6 and \#12 represent the remaining three " $\mathrm{A}$ " and "B" heaters on the test board, respectively.

The voltages were measured with a digital volt-meter while the currents were measured with a digital clamp-meter. The clamp-meter had lower errors associated towards larger currents. The wires for each terminal/group were coiled several times generating a larger overall current in the clamp-meter. The clamp-meter current would be divided by the total number of coils, or loops, for each terminal/group to obtain the line current to the heaters. The current uncertainty would be applied to the clamp-meter reading and then divided by the number of coils/loops for each terminal/group. Each group had a different number of coils/loops depending on the wire length..

Uncertainties: $u_{\text {voltage }}= \pm 0.05 \mathrm{~V}, u_{\text {current }}= \pm 5 \%$ reading $+2.5 \mathrm{~A}$

Current Uncertainty Sample Calculation: Clamp-meter reading=18.6A, Coils/loops=7

$$
\begin{gathered}
u_{\text {clamp }}=(18.6 \mathrm{~A} \times 5 \%)+2.5 \mathrm{~A}=0.930 \mathrm{~A}+2.5 \mathrm{~A}= \pm 3.4 \mathrm{~A} \\
\text { LineCurrent }=\frac{18.6 \mathrm{~A}}{7 \text { coils }}=2.7 \mathrm{~A} \\
u_{\text {line }}=\frac{ \pm 3.4 \mathrm{~A}}{7 \text { coils }}= \pm 0.5 \mathrm{~A}
\end{gathered}
$$


Power Sample Calculation and Uncertainty:

$$
\begin{aligned}
& \text { Power }=V \times I=5.24 \mathrm{~V} \times 2.7 \mathrm{~A}=13.9 \mathrm{~W} \\
& u_{p}=\sqrt{\left(\frac{\partial P}{\partial V} \times u_{V}\right)^{2}+\left(\frac{\partial P}{\partial A} \times u_{A}\right)^{2}} \\
& u_{p}=\sqrt{\left(\frac{13.9 \mathrm{~W}}{5.24 \mathrm{~V}} \times 0.05 \mathrm{~V}\right)^{2}+\left(\frac{13.9 \mathrm{~W}}{2.7 \mathrm{~A}} \times 0.5 \mathrm{~A}\right)^{2}}= \pm 2.6 \mathrm{~A} \\
& \text { TotalPower }=\Sigma P_{i}=P_{5 V}+P_{10 V 1}+P_{10 V 2}+P_{10 V 3}+P_{15 V} \ldots=1053 \mathrm{~W} \\
& u_{p_{\text {TOTAL }}}=\sqrt{\sum u_{p_{i}}^{2}}=\sqrt{u_{p_{5 V}}^{2}+u_{p_{10 V 1}}^{2}+u_{p_{10 V 2}}^{2}+u_{p_{10 V 3}}^{2}+u_{p_{15 V}}^{2} \ldots} \\
& u_{p_{\text {TOTAL }}}= \pm 60 \mathrm{~W} \\
& u_{p_{\text {TOTAL }}}= \pm 5.7 \%
\end{aligned}
$$

\begin{tabular}{|c|c|c|c|c|c|c|c|c|c|}
\hline \multicolumn{10}{|c|}{ Test 2} \\
\hline $\begin{array}{c}\text { Terminal } / \\
\text { Group }\end{array}$ & $\begin{array}{l}\text { Voltage } \\
\text { (V) }\end{array}$ & $\begin{array}{l}u_{v} \\
(V)\end{array}$ & $\begin{array}{l}\text { Clamp-meter } \\
\text { Current (A) }\end{array}$ & $\begin{array}{c}\text { Clamp-meter } \\
\text { Uncertainty } \\
\mathrm{u}_{\text {clamp }}(\mathrm{A})\end{array}$ & $\begin{array}{c}\text { Number } \\
\text { of Coils } \\
(-)\end{array}$ & $\begin{array}{c}\text { Terminal } \\
\text { Current } \\
\text { (A) }\end{array}$ & $\begin{array}{c}\text { Terminal } \\
\text { Uncertainty } \\
\mathbf{u}_{\mathrm{A}}(\mathrm{A})\end{array}$ & $\begin{array}{l}\text { Calculated } \\
\text { Power (W) }\end{array}$ & $\begin{array}{l}u_{p} \\
(W)\end{array}$ \\
\hline$\overline{\# 2}$ & \begin{tabular}{l|l|}
15.48 \\
\end{tabular} & 0.05 & 23.4 & 3.7 & 4.0 & \begin{tabular}{l|l|}
5.9 \\
\end{tabular} & 0.9 & 90.6 & $\overline{14.2}$ \\
\hline$\# 3$ & 22.50 & 0.05 & 20.8 & 3.5 & 4.0 & 5.2 & 0.9 & 117.0 & 19.9 \\
\hline$\# 4$ & 22.50 & 0.05 & 18.8 & 3.4 & 3.0 & 6.3 & 1.1 & 141.0 & 25.8 \\
\hline$\# 5$ & 26.00 & 0.05 & \begin{tabular}{l|}
11.1 \\
\end{tabular} & 3.1 & 3.0 & 3.7 & 1.0 & 96.2 & 26.5 \\
\hline$\# 6$ & 14.33 & 0.05 & 38.6 & 4.4 & 2.0 & \begin{tabular}{l|}
19.3 \\
\end{tabular} & 2.2 & 276.6 & 31.8 \\
\hline \#7 & 17.75 & 0.05 & 9.5 & 3.0 & 4.0 & 2.4 & 0.7 & 42.2 & 13.2 \\
\hline \#8 & \begin{tabular}{l|l}
10.31 \\
\end{tabular} & 0.05 & 6.9 & 2.8 & 4.0 & 1.7 & 0.7 & 17.8 & 7.3 \\
\hline$\# 9$ & \begin{tabular}{l|}
10.31 \\
\end{tabular} & 0.05 & 5.8 & 2.8 & 4.0 & 1.5 & 0.7 & 14.9 & 7.2 \\
\hline$\# 10$ & 10.27 & 0.05 & 46.6 & 4.8 & 5.0 & 9.3 & 1.0 & $\begin{array}{l}95.7 \\
\end{array}$ & $\overline{9.9}$ \\
\hline \#11 & 5.24 & 0.05 & 18.6 & 3.4 & 7.0 & 2.7 & 0.5 & 13.9 & 2.6 \\
\hline \#12 & 10.35 & 0.05 & 56.9 & 5.3 & 4.0 & 14.2 & 1.3 & 147.2 & 13.8 \\
\hline \multicolumn{8}{|c|}{ Total } & 1053.1 & $\overline{59.6}$ \\
\hline
\end{tabular}

Table 23. Calculated board electrical power and uncertainty from measured

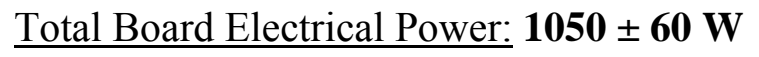




\section{"A" Test Chip Power Sample Calculations}

These calculations were performed on the power supplies for the "A" Test Chip.

Uncertainties: $u_{\text {voltage }}= \pm 5 \%$ reading +2 digits,$u_{\text {current }}= \pm 5 \%$ reading +2 digits

Voltage and Current Uncertainty Sample Calculations:

Voltage $=26.0 \mathrm{~V}$, Current $=2.27 \mathrm{~A}$

$$
\begin{aligned}
& u_{\text {voltage }}=(26.0 \mathrm{~V} \times 0.05)+0.2 \mathrm{~V}= \pm 1.5 \mathrm{~V} \\
& u_{\text {current }}=(2.27 \mathrm{~A} \times 0.05)+0.02 \mathrm{~A}= \pm 0.13 \mathrm{~A}
\end{aligned}
$$

The other voltage and current were $26.0 \mathrm{~V} \pm 1.5 \mathrm{~V}$ and $1.61 \mathrm{~A} \pm 0.10 \mathrm{~A}$

Power Uncertainty Sample Calculation:

Power $=(26.0 \mathrm{~V}) \mathrm{x}(2.27 \mathrm{~A})=59.0 \mathrm{~W}$

$$
\begin{aligned}
& u_{p}=\sqrt{\left(\frac{\partial P}{\partial V} u_{\text {voltage }}\right)^{2}+\left(\frac{\partial P}{\partial A} u_{\text {current }}\right)^{2}} \\
& u_{p}=\sqrt{\left(\frac{59.0 \mathrm{~W}}{26.0 \mathrm{~V}} \times 1.5 \mathrm{~V}\right)^{2}+\left(\frac{59.0 \mathrm{~W}}{2.27 \mathrm{~A}} \times 0.13 \mathrm{~A}\right)^{2}} \\
& u_{p}= \pm 4.8 \mathrm{~W}
\end{aligned}
$$

The other power uncertainty was $41.9 \mathrm{~W} \pm 3.6 \mathrm{~W}$

"A" Test Chip Power Uncertainty Sample Calculation:

"A" Power $=59.0 \mathrm{~W}+41.9 \mathrm{~W}=101 \mathrm{~W}$

$$
\begin{aligned}
& u_{" A^{\prime \prime}}=\sqrt{(4.8 W)^{2}+(3.6 W)^{2}} \\
& u_{" A^{\prime \prime}}= \pm 6.0 W \\
& u_{" A^{\prime \prime}}= \pm 5.9 \%
\end{aligned}
$$

Total "A" Test Chip Power: $101 \mathrm{~W} \pm \mathbf{6 . 0} \mathrm{W}$ 


\section{Fan Dissipated Power Estimation}

These calculations were performed to estimate the heat dissipated by the system fans.

Measured Values: $\mathrm{Q}=1077$ CFM, $\mathrm{P}_{4}=0.93 \mathrm{inH}_{2} \mathrm{O}, \mathrm{P}_{3}=-1.33 \mathrm{inH}_{2} \mathrm{O}$

Average Temperature Property: $\mathrm{c}_{\mathrm{p}}=1006 \mathrm{~J} / \mathrm{kg}^{\circ}{ }^{\circ} \mathrm{C}$

Ideal Gas Law: $\rho=1.142 \mathrm{~kg} / \mathrm{m}^{3}$

Air Flow Power Equation:

$$
\begin{aligned}
& P_{\text {AirFlow }}=Q \times \Delta P \\
& P_{\text {AirFlow }}=\left[1077 \mathrm{ft}^{3} / \mathrm{min}\left(\frac{0.3048 \mathrm{~m}}{1 \mathrm{ft}}\right)^{3}\left(\frac{1 \mathrm{~min}}{60 \mathrm{sec}}\right)\right] \times\left[0.93 \mathrm{inH}_{2} \mathrm{O}-\left(-1.33 \mathrm{inH}_{2} \mathrm{O}\right)\right] \\
& P_{\text {AirFlow }}=261 \mathrm{~W}
\end{aligned}
$$

Fan power varies depending on the operating duty cycle. The vendor specifications sheet only provided power ratings for three duty cycle operating conditions: $100 \%, 66 \%$, and $33 \%$.

Vendor Nominal Free Air Condition Fan Data: $\quad \mathrm{V}_{1}=48 \mathrm{~V}, \quad \mathrm{I}_{1}=3.10 \mathrm{~A}, \quad$ Duty $=100 \%$

$$
\begin{array}{lll}
\mathrm{V}_{2}=48 \mathrm{~V}, & \mathrm{I}_{2}=2.20 \mathrm{~A}, & \text { Duty }=66 \% \\
\mathrm{~V}_{3}=48 \mathrm{~V}, & \mathrm{I}_{3}=1.25 \mathrm{~A}, & \text { Duty }=33 \%
\end{array}
$$

This data was plotted and a linear fit curve was generated and the equation was used to estimate the four operating duty cycles through the testing: $100 \%, 75 \%, 50 \%$, and $25 \%$. Figure 42 shows the plot of the fan vendor nominal power rating based on the fan operating duty cycle. Also, 
shown in the Figure 42 is the linear curve fit equation used to calculate the fan power for all the four operating duty cycles in the testing.

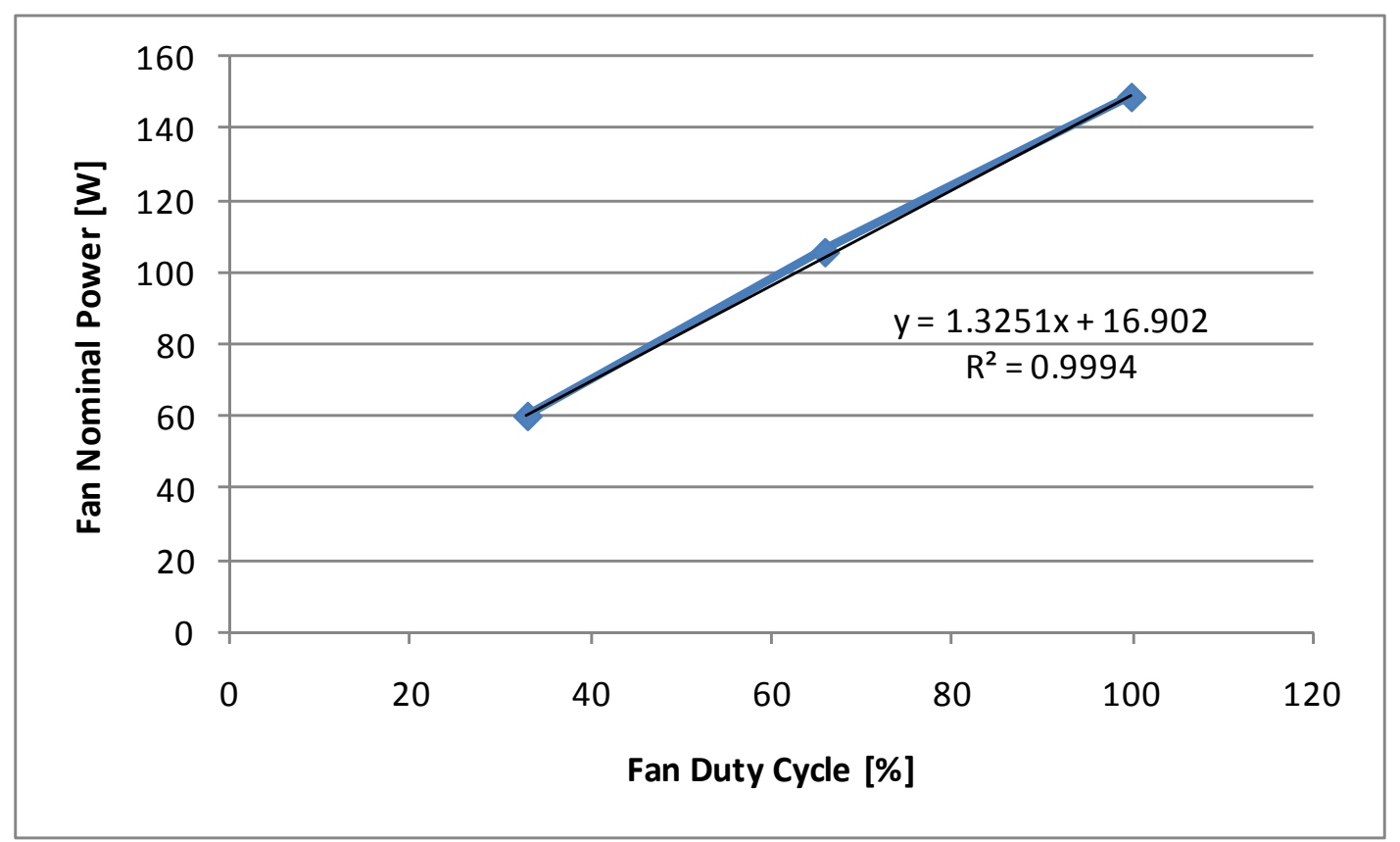

Figure 42: Fan nominal power based on operating duty cycle

System Fans Total Nominal Power Equation:

$$
\begin{gathered}
P_{\text {Fan }}=1.3251 \times(\text { DutyCycle } \%)+16.902 \\
P_{\text {Fan }}=1.3251 \times(100)+16.902 \\
P_{\text {Fan }}=149 \mathrm{~W} \\
P_{\text {SystemFans }}=8 \times P_{\text {Fan }}=8 \times 149 \mathrm{~W} \\
P_{\text {SystemFans }}=1190 \mathrm{~W}
\end{gathered}
$$

System Fans Efficiency Equation:

$$
\begin{aligned}
& \eta=\frac{P_{\text {AirFlow }}}{P_{\text {SystemFans }}} \times 100=\frac{261 \mathrm{~W}}{1190 \mathrm{~W}} \\
& \eta=21.9 \%
\end{aligned}
$$


Air Temperature Rise Contributed by System Fans Sample Calculations:

$$
\begin{aligned}
\Delta T & =\frac{q}{Q \rho c_{p}}=\frac{P_{\text {SystemFans }}-P_{\text {AirFlow }}}{Q \rho c_{p}} \\
\Delta T & =\frac{1190.4 \mathrm{~W}-260.8 \mathrm{~W}}{\left[1077 \mathrm{ft}^{3} / \mathrm{min}\left(\frac{0.3048 \mathrm{~m}}{1 \mathrm{ft}}\right)^{3}\left(\frac{1 \mathrm{~min}}{60 \mathrm{sec}}\right)\right] \times 1.142 \mathrm{~kg} / \mathrm{m}^{3} \times 1006 \mathrm{~J} / \mathrm{kg}-{ }^{\circ} \mathrm{C}} \\
\Delta T & =1.59^{\circ} \mathrm{C}
\end{aligned}
$$

\begin{tabular}{|c|c|c|c|c|c|c|c|c|c|}
\hline \multirow[t]{2}{*}{ Test \# } & $\begin{array}{l}\text { PWM } \\
\text { Duty } \\
\text { Cycle }\end{array}$ & $\begin{array}{c}\text { LFE Vol. } \\
\text { Flow Rate } \\
\text { (CFM) }\end{array}$ & $\mathbf{P}_{3}$ & $\mathbf{P}_{4}$ & $\begin{array}{c}\text { Air Flow } \\
\text { Power }\end{array}$ & $\begin{array}{c}\text { Nominal } \\
\text { Electrical } \\
\text { Power }\end{array}$ & \multirow[t]{2}{*}{$\begin{array}{c}\text { Efficiency } \\
\text { (n) }\end{array}$} & $\begin{array}{l}\text { Dissipated } \\
\text { Heat to air }\end{array}$ & $\begin{array}{c}\text { Air } \\
\text { Temp. } \\
\text { Rise from } \\
\text { Fans }\end{array}$ \\
\hline & [\%] & [CFM] & {$\left[\mathrm{inH}_{2} \mathrm{O}\right]$} & {$\left[\mathrm{inH}_{2} \mathrm{O}\right]$} & {$[W]$} & [W] & & [W] & {$\left[{ }^{\circ} \mathrm{C}\right]$} \\
\hline 1 & 100 & 1077 & -1.13 & 0.93 & 261 & 1195 & $21.8 \%$ & 935 & 1.6 \\
\hline 2 & 75 & 1022 & -0.94 & 0.75 & 203 & 930 & $21.8 \%$ & 727 & 1.3 \\
\hline 3 & 50 & 813 & -0.68 & 0.50 & 113 & 665 & $16.9 \%$ & 553 & 1.3 \\
\hline 4 & 25 & 609 & -0.43 & 0.29 & 52 & 400 & $12.9 \%$ & 349 & 1.1 \\
\hline 5 & 100 & 1108 & -1.20 & 0.89 & 272 & 1195 & $22.8 \%$ & 923 & 1.5 \\
\hline 6 & 100 & 1108 & -1.20 & 0.87 & 270 & 1195 & $22.6 \%$ & 926 & 1.5 \\
\hline 7 & 75 & 1045 & -1.02 & 0.75 & 217 & 930 & $23.4 \%$ & 713 & 1.3 \\
\hline 8 & 100 & 1103 & -1.19 & 0.88 & 268 & 1195 & $22.4 \%$ & 927 & 1.6 \\
\hline 9 & 75 & 1045 & -1.06 & 0.81 & 230 & 930 & $24.7 \%$ & 701 & 1.2 \\
\hline
\end{tabular}

Table 24: Summary of the fan power, efficiencies and air temperature rise for all conducted tests 


\section{$\underline{\text { Heat Exchanger Performance Sample Calculations }}$}

The NTU method was used to determine the heat exchanger performance for the baseline test data. The effectiveness was determined using the equation below from Incropera and Dewitt (2002).

$$
\varepsilon=\frac{q}{q_{\max }}=\frac{C_{h}\left(T_{h, i}-T_{h, o}\right)}{C_{\min }\left(T_{h, i}-T_{c, i}\right)}
$$

subscript $_{h}=$ hot fluid(water), subscript $_{c}=$ cold fluid(air)

subscript $_{, i}=$ inlet, subscript $_{, o}=$ outlet,

$\mathrm{C}$, is the heat transfer coefficient for the fluid. The subscript ${ }_{\min }$ represents the smaller of the two fluid heat transfer coefficients. The water heat transfer coefficient is calculated with this equation:

$$
C_{\text {water }}=\dot{\forall}_{\text {water }} \rho_{\text {water }} c_{p_{\text {water }}}
$$

The same is true for the air heat transfer coefficient. Below are the calculations for the baseline test data. The densities and specific heats were calculated using average temperatures of the fluids.

$$
\begin{aligned}
& C_{\text {water }}=\left(1.10 \mathrm{gpm} \times\left(6.309 \times 10^{-5} \frac{\mathrm{m}^{3} / \mathrm{s}}{\mathrm{gpm}}\right)\right) \times\left(990 \frac{\mathrm{kg}}{\mathrm{m}^{3}}\right) \times\left(4.180 \frac{\mathrm{kJ}}{\mathrm{kg} \cdot{ }^{\circ} \mathrm{C}}\right)=0.287 \frac{\mathrm{kW}}{{ }^{\circ} \mathrm{C}} \\
& C_{\text {air }}=\left(1035 \mathrm{cfm} \times\left(4.719 \times 10^{-4} \frac{\mathrm{m}^{3} / \mathrm{s}}{\mathrm{gpm}}\right)\right) \times\left(1.163 \frac{\mathrm{kg}}{\mathrm{m}^{3}}\right) \times\left(1.006 \frac{\mathrm{kJ}}{\mathrm{kg} \cdot{ }^{\circ} \mathrm{C}}\right)=0.571 \frac{\mathrm{kW}}{{ }^{\circ} \mathrm{C}}
\end{aligned}
$$

$\mathrm{C}_{\text {water }}$ is $\mathrm{C}_{\min }$ since it is the smaller of the two heat transfer coefficients. The effectiveness calculation is shown on the next page. 
$\mathrm{q}=2924 \mathrm{~W}$ (heat exchanger water power)

$\mathrm{T}_{\mathrm{h}, \mathrm{i}}=53.38^{\circ} \mathrm{C}$ (test board water outlet temperature)

$\mathrm{T}_{\mathrm{c}, \mathrm{i}}=40.69^{\circ} \mathrm{C}$ (air temperature after test board/before heat exchanger)

$$
\varepsilon=\frac{2.9 k W}{\left(0.287 \frac{k W}{{ }^{\circ} \mathrm{C}}\right) \times\left(53.38^{\circ} \mathrm{C}-40.69^{\circ} \mathrm{C}\right)}=0.803
$$

Using Eq. [11.33] for single pass, cross flow heat exchanger with both fluids unmixed, from Incropera and Dewitt (2002), the NTU and overall heat transfer coefficient, UA, was calculated.

$$
\begin{aligned}
& \varepsilon=1-\exp \left[\left(\frac{1}{C_{r}}\right)(N T U)^{0.22}\left\{\exp \left[-C_{r}(N T U)^{0.78}\right]-1\right\}\right] \\
& C_{r}=\frac{C_{\min }}{C_{\max }}=\frac{0.287 \frac{\mathrm{kW}}{{ }^{\circ} \mathrm{C}}}{0.571 \frac{\mathrm{kW}}{{ }^{\circ} \mathrm{C}}}=0.503 \\
& N T U \equiv \frac{U_{h} A_{h}}{C_{\min }}=2.653 \\
& U_{h} A_{h}=\left(0.287 \frac{\mathrm{kW}}{{ }^{\circ} \mathrm{C}}\right) \times(2.653)=0.761 \frac{\mathrm{kW}}{{ }^{\circ} \mathrm{C}}
\end{aligned}
$$




\section{Corrected Fluid Temperature Sample Calculations}

The two standard operating conditions are: $40^{\circ} \mathrm{C}$ at 10,000 feet and $50^{\circ} \mathrm{C}$ at 6,000 feet

Eq. [4] was manipulated to generate the exhaust air temperature at each condition.

$$
T_{o}=\left(\frac{q}{\dot{\forall} \rho c_{p}}\right)+T_{i}
$$

The same volumetric flow rate $(\dot{\forall})$, measured by the LFE, and calculated total air power (q) were used. The density $(\rho)$, specific heat $\left(c_{p}\right)$, and inlet temperature $\left(T_{i}\right)$ were all adjusted based on the operating condition.

\section{Properties:}

$40^{\circ} \mathrm{C}$ at 10,000 feet:

$$
\rho=0.772 \mathrm{~kg} / \mathrm{m}^{3}, \mathrm{c}_{\mathrm{p}}=1.006 \mathrm{~kJ} / \mathrm{kg}-\mathrm{K}, \dot{\forall}=1035 \mathrm{cfm}\left(0.4975 \mathrm{~m}^{3} / \mathrm{s}\right), \mathrm{T}_{\mathrm{i}}=40^{\circ} \mathrm{C}
$$

$50^{\circ} \mathrm{C}$ at 6,000 feet:

$\rho=0.871 \mathrm{~kg} / \mathrm{m}^{3}, \mathrm{c}_{\mathrm{p}}=1.007 \mathrm{~kJ} / \mathrm{kg}-\mathrm{K}, \dot{\forall}=1035 \mathrm{cfm}\left(0.4975 \mathrm{~m}^{3} / \mathrm{s}\right), \mathrm{T}_{\mathrm{i}}=50^{\circ} \mathrm{C}$

$\underline{\text { Calculations: }}$

$$
\begin{aligned}
& T_{o}=\left(\frac{8138 \mathrm{~W} \times\left(\frac{1 \mathrm{~kW}}{1000 \mathrm{~W}}\right)}{\left(0.4975 \frac{\mathrm{m}^{3}}{\mathrm{~s}}\right) \times\left(0.772 \frac{\mathrm{kg}}{\mathrm{m}^{3}}\right) \times\left(1.006 \frac{\mathrm{kJ}}{\mathrm{kg} \cdot \mathrm{K}}\right)}\right)+40^{\circ} \mathrm{C}=61.1^{\circ} \mathrm{C} \\
& T_{o}=\left(\frac{8138 \mathrm{~W} \times\left(\frac{1 \mathrm{~kW}}{1000 \mathrm{~W}}\right)}{\left(0.4975 \frac{\mathrm{m}^{3}}{\mathrm{~s}}\right) \times\left(0.871 \frac{\mathrm{kg}}{\mathrm{m}^{3}}\right) \times\left(1.007 \frac{\mathrm{kJ}}{\mathrm{kg} \cdot \mathrm{K}}\right)}\right)+50^{\circ} \mathrm{C}=68.6^{\circ} \mathrm{C}
\end{aligned}
$$

The $50^{\circ} \mathrm{C}$ at 6,000 feet condition is shown in the next calculations. 
The power dissipated to the air before the heat exchanger was calculated by subtracting the heat exchanger water power from the total air power.

$$
P_{\text {pre-hx }}=\left(P_{\text {Totallir }}-P_{\text {HXwater }}\right)=(8138 \mathrm{~W}-2924 \mathrm{~W})=5214 \mathrm{~W}
$$

This power was used in the previous equation to calculate the temperature of the air before the heat exchanger.

$$
T_{o}=\left(\frac{5214 \mathrm{~W} \times\left(\frac{1 \mathrm{~kW}}{1000 \mathrm{~W}}\right)}{\left(0.4975 \frac{\mathrm{m}^{3}}{\mathrm{~s}}\right) \times\left(0.871 \frac{\mathrm{kg}}{\mathrm{m}^{3}}\right) \times\left(1.007 \frac{\mathrm{kJ}}{\mathrm{kg} \cdot \mathrm{K}}\right)}\right)+50^{\circ} \mathrm{C}=61.9^{\circ} \mathrm{C}
$$

The amount of energy transferred to the heat exchanger water was assumed constant in these calculations. The average water temperature was assumed to be $70^{\circ} \mathrm{C}$ for the water properties. The new heat transfer coefficients for the water and air were calculated in order to apply the heat exchanger characteristics to the new conditions.

$$
\begin{aligned}
& C_{\text {water }}=\left(1.10 \mathrm{gpm} \times\left(6.309 \times 10^{-5} \frac{\mathrm{m}^{3} / \mathrm{s}}{\mathrm{gpm}}\right)\right) \times\left(978 \frac{\mathrm{kg}}{\mathrm{m}^{3}}\right) \times\left(4.189 \frac{\mathrm{kJ}}{\mathrm{kg} \cdot{ }^{\circ} \mathrm{C}}\right)=0.284 \frac{\mathrm{kW}}{{ }^{\circ} \mathrm{C}} \\
& C_{\text {air }}=\left(1035 \mathrm{cfm} \times\left(4.719 \times 10^{-4} \frac{\mathrm{m}^{3} / \mathrm{s}}{\mathrm{gpm}}\right)\right) \times\left(0.871 \frac{\mathrm{kg}}{\mathrm{m}^{3}}\right) \times\left(1.007 \frac{\mathrm{kJ}}{\mathrm{kg} \cdot{ }^{\circ} \mathrm{C}}\right)=0.428 \frac{\mathrm{kW}}{{ }^{\circ} \mathrm{C}} \\
& C_{r}=\frac{0.284 \frac{\mathrm{kW}}{{ }^{\circ} \mathrm{C}}}{0.428 \frac{\mathrm{kW}}{{ }^{\circ} \mathrm{C}}}=0.664
\end{aligned}
$$

Using Eq. [11.33] from Incropera and Dewitt (2002) with the same NTU value calculated from the baseline test data and the new $\mathrm{C}_{\mathrm{r}}$ value the new heat exchanger effectiveness was calculated.

$$
\varepsilon=1-\exp \left[\left(\frac{1}{0.664}\right)(2.653)^{0.22}\left\{\exp \left[-0.664(2.653)^{0.78}\right]-1\right\}\right]=0.757
$$


The other form of the effectiveness equation was manipulated to calculate the heat exchanger inlet temperature.

$$
\begin{aligned}
& \mathcal{E}=\frac{C_{h}\left(T_{h, i}-T_{h, o}\right)}{C_{\min }\left(T_{h, i}-T_{c, i}\right)}=\frac{C_{c}\left(T_{c, o}-T_{c, i}\right)}{C_{\min }\left(T_{h, i}-T_{c, i}\right)} \\
& T_{h, i}=\frac{C_{c}\left(T_{c, o}-T_{c, i}\right)}{\varepsilon C_{\min }}+T_{c, i} \\
& T_{h, i}=\frac{\left(0.428 \frac{\mathrm{kW}}{{ }^{\circ} \mathrm{C}}\right) \times\left(68.6^{\circ} \mathrm{C}-61.9^{\circ} \mathrm{C}\right)}{(0.757) \times\left(0.284 \frac{\mathrm{kW}}{{ }^{\circ} \mathrm{C}}\right)}+61.9^{\circ} \mathrm{C}=75.2^{\circ} \mathrm{C}
\end{aligned}
$$

The heat exchanger water outlet temperature was calculated by manipulating the effectiveness equation above.

$$
\begin{aligned}
& \varepsilon=\frac{C_{h}\left(T_{h, i}-T_{h, o}\right)}{C_{\text {min }}\left(T_{h, i}-T_{c, i}\right)}=\frac{C_{c}\left(T_{c, o}-T_{c, i}\right)}{C_{\text {min }}\left(T_{h, i}-T_{c, i}\right)} \\
& T_{h, o}=T_{h, i}-\left(\frac{\varepsilon C_{\text {min }}\left(T_{h, i}-T_{c, i}\right)}{C_{h}}\right) \\
& T_{h, o}=\left(75.2^{\circ} \mathrm{C}-\left[(0.757) \times\left(75.2^{\circ} \mathrm{C}-61.9^{\circ} \mathrm{C}\right)\right]\right)=65.1^{\circ} \mathrm{C}
\end{aligned}
$$

The average water temperature becomes $70.2^{\circ} \mathrm{C}$ from the new inlet and outlet water temperatures for the $50^{\circ} \mathrm{C}$ at 6,000 feet condition. 


\section{Corrected Junction Temperature Sample Calculations}

Thermal resistance was calculated with this equation:

$$
\Theta_{2-1}=\frac{\Delta T}{q}=\frac{\left(T_{2}-T_{1}\right)}{q}
$$

The thermal resistance between the " $\mathrm{A}$ " test chip junction and the cold plate temperatures was calculated assuming all the "A" test chip power was dissipated to the cold plate. The same was true for the thermal resistance between the cold plate and average water temperatures.

$$
\begin{aligned}
& \text { (j)-junction, (cp)-cold plate, (w)-water, (c)-case } \\
& \Theta_{j c p}=\frac{\left(T_{j}-T_{c p}\right)}{q}=\frac{\left(91.0^{\circ} \mathrm{C}-60.6^{\circ} \mathrm{C}\right)}{90 \mathrm{~W}}=0.338 \frac{{ }^{\circ} \mathrm{C}}{\mathrm{W}} \\
& \Theta_{j w}=\frac{\left(T_{j}-T_{w}\right)}{q}=\frac{\left(91.0^{\circ} \mathrm{C}-47.4^{\circ} \mathrm{C}\right)}{90 \mathrm{~W}}=0.484 \frac{{ }^{\circ} \mathrm{C}}{\mathrm{W}} \\
& \Theta_{c p w}=\frac{\left(T_{c p}-T_{w}\right)}{q}=\frac{\left(60.6^{\circ} \mathrm{C}-47.4^{\circ} \mathrm{C}\right)}{90 \mathrm{~W}}=0.147 \frac{{ }^{\circ} \mathrm{C}}{\mathrm{W}}
\end{aligned}
$$

The case, or lid, temperature was calculated from the test chip junction-to-case thermal resistance and assuming all the "A" test chip power was dissipated to the cold plate.

$$
\begin{aligned}
& T_{\text {case }}=T_{j u n c}-\left(\Theta_{j c} q\right) \\
& T_{\text {case }}=91.0^{\circ} \mathrm{C}-\left(0.27 \frac{{ }^{\circ} \mathrm{C}}{\mathrm{W}}\right) \times(90 \mathrm{~W})=66.7^{\circ} \mathrm{C}
\end{aligned}
$$

With the case/lid temperature the thermal resistance was measured between the case and water temperatures.

$$
\Theta_{c w}=\frac{\left(T_{c}-T_{w}\right)}{q}=\frac{\left(66.7^{\circ} \mathrm{C}-47.4^{\circ} \mathrm{C}\right)}{90 \mathrm{~W}}=0.214 \frac{{ }^{\circ} \mathrm{C}}{\mathrm{W}}
$$

The new case temperature was calculated with the calculated $\Theta_{\mathrm{cw}}$ and the new calculated average water temperature, $70^{\circ} \mathrm{C}$. 


$$
\begin{aligned}
& T_{\text {case }}=\left(\Theta_{c w} q\right)+T_{w} \\
& T_{\text {case }}=\left(0.214 \frac{{ }^{\circ} \mathrm{C}}{\mathrm{W}}\right) \times(90 \mathrm{~W})+70^{\circ} \mathrm{C}=89.3^{\circ} \mathrm{C}
\end{aligned}
$$

The new junction temperature was calculated using the new $T_{\text {case }}$ and the $\Theta_{\mathrm{jc}}$ for the " $\mathrm{A}$ " test chip.

$$
\begin{aligned}
& T_{\text {junc }}=\left(\Theta_{j c} q\right)+T_{\text {case }} \\
& T_{\text {junc }}=\left(0.27 \frac{{ }^{\circ} \mathrm{C}}{\mathrm{W}}\right) \times(90 \mathrm{~W})+89.3^{\circ} \mathrm{C}=113.6^{\circ} \mathrm{C}
\end{aligned}
$$

With the more accurate power readings from the smaller power supplies the power dissipation would increase to $101 \mathrm{~W}$ for the thermal resistance calculations from the baseline test data, thus reducing the resistances. The expected power generated by the "A" chips is $90 \mathrm{~W}$, not $101 \mathrm{~W}$. Also the expected junction-to-case thermal resistance is $0.20^{\circ} \mathrm{C} / \mathrm{W}$, not $0.27^{\circ} \mathrm{C} / \mathrm{W}$. The calculations applying the $101 \mathrm{~W}$, calculated thermal resistances, and the $0.20^{\circ} \mathrm{C} / \mathrm{W}$ junction-tocase thermal resistance is shown below.

$$
\begin{aligned}
& T_{\text {case }}=91{ }^{\circ} \mathrm{C}-\left(0.27 \frac{{ }^{\circ} \mathrm{C}}{\mathrm{W}}\right) \times(101 \mathrm{~W})=63.7^{\circ} \mathrm{C} \\
& \Theta_{c w}=\frac{\left(63.7^{\circ} \mathrm{C}-47.4^{\circ} \mathrm{C}\right)}{101 \mathrm{~W}}=0.161 \frac{{ }^{\circ} \mathrm{C}}{\mathrm{W}} \\
& T_{\text {NewCase }}=\left(0.161 \frac{{ }^{\circ} \mathrm{C}}{\mathrm{W}}\right) \times(90 \mathrm{~W})+70^{\circ} \mathrm{C}=84.5^{\circ} \mathrm{C} \\
& T_{\text {NewJunc }}=\left(0.2 \frac{{ }^{\circ} \mathrm{C}}{\mathrm{W}}\right) \times(90 \mathrm{~W})+84.5^{\circ} \mathrm{C}=102.5^{\circ} \mathrm{C}
\end{aligned}
$$




\section{Laminar Flow Element Mass and Flow Rate Sample Calculations}

Measured Values: $\mathrm{T}_{\mathrm{i}}=26.2^{\circ} \mathrm{C}$ (Cabinet inlet air temp.), $\mathrm{P}_{\mathrm{atm}}=29.91 \mathrm{inHg}, \Delta \mathrm{P}=3.69 \mathrm{inH}_{2} \mathrm{O}$

Ideal Gas Law at $\mathrm{T}_{\mathrm{i}}$ condition: $\rho=1.179 \mathrm{~kg} / \mathrm{m}^{3}$

Actual Flow Rate Equation: $Q_{a c t}=\left[B\left(\Delta P_{\text {corr }}\right)+C\left(\Delta P_{c o r r}\right)^{2}\right] \times\left(\frac{\mu_{a i r, s t d}}{\mu_{a i r}}\right)$

Micropoise equation (from LFE manual): $\mu_{\text {air }}=\frac{14.58\left(\frac{459.67+\left[{ }^{\circ} F\right]}{1.8}\right)^{3 / 2}}{110.4+\left(\frac{459.67+\left[{ }^{\circ} F\right]}{1.8}\right)}$

$\left[{ }^{\circ} \mathrm{F}\right]=$ Measured temperature in Fahrenheit

$$
\left[{ }^{\circ} \mathrm{F}\right]=\left(\frac{9}{5}\right)\left[{ }^{\circ} \mathrm{C}\right]+32=79.2^{\circ} \mathrm{F}
$$

$$
\begin{aligned}
& \mu_{\text {air }}=\frac{14.58\left(\frac{459.67+\left[79.2^{\circ} \mathrm{F}\right]}{1.8}\right)^{3 / 2}}{110.4+\left(\frac{459.67+\left[79.2^{\circ} \mathrm{F}\right]}{1.8}\right)}=184.3 \\
& \mu_{\text {air }}=184.3
\end{aligned}
$$

*Assumes dry air and does not correct for volume change due to temperature

**Standard air temperature is $70^{\circ} \mathrm{F}$

$\underline{\Delta \mathrm{P}} \underline{\text { correction equation: }} \Delta P_{\text {corr }}=\Delta P\left(\frac{\rho_{\mathrm{H}_{2} \mathrm{O} @ 20^{\circ} \mathrm{C}}}{\rho_{\mathrm{H}_{2} \mathrm{O} @ 4^{\circ} \mathrm{C}}}\right)=\Delta P\left(\frac{62.316^{l b_{f}} / f t^{3}}{62.426^{l b_{f} / f t^{3}}}\right)$

*Values are the environmental conditions the LFE calibration tests were performed 


$$
\Delta P_{\text {corr }}=\left(3.69 \mathrm{inH}_{2} \mathrm{O}\right) \times\left(\frac{62.316^{l b_{f}} / f t^{3}}{62.426^{l b_{f}} / f t^{3}}\right)=3.64 \text { inH }_{2} \mathrm{O}
$$

$$
\Delta \mathrm{P}_{\text {corr }}=3.64 \mathrm{inH}_{2} \mathrm{O}
$$

$$
\begin{gathered}
\text { Actual Flow Rate equation: } Q_{\text {act }}=\left[B\left(\Delta P_{\text {corr }}\right)+C\left(\Delta P_{\text {corr }}\right)^{2}\right] \times\left(\frac{\mu_{\text {air }, \text { std }}}{\mu_{\text {air }}}\right) \\
\mathrm{B}=294.2444 \quad \mathrm{C}=-0.678646
\end{gathered}
$$

* $\mathrm{B}$ and $\mathrm{C}$ are calibration constants

$$
\begin{aligned}
& Q_{a c t}=\left[(294.2444) \times(3.64)+(-0.678646) \times(3.64)^{2}\right] \times\left(\frac{181.87}{184.30}\right) \\
& Q_{a c t}=1048 \mathrm{cfm}
\end{aligned}
$$




\section{Appendix B}

\section{$\underline{\text { Test Board Specifications }}$}


Table 25. Test board heater specifications

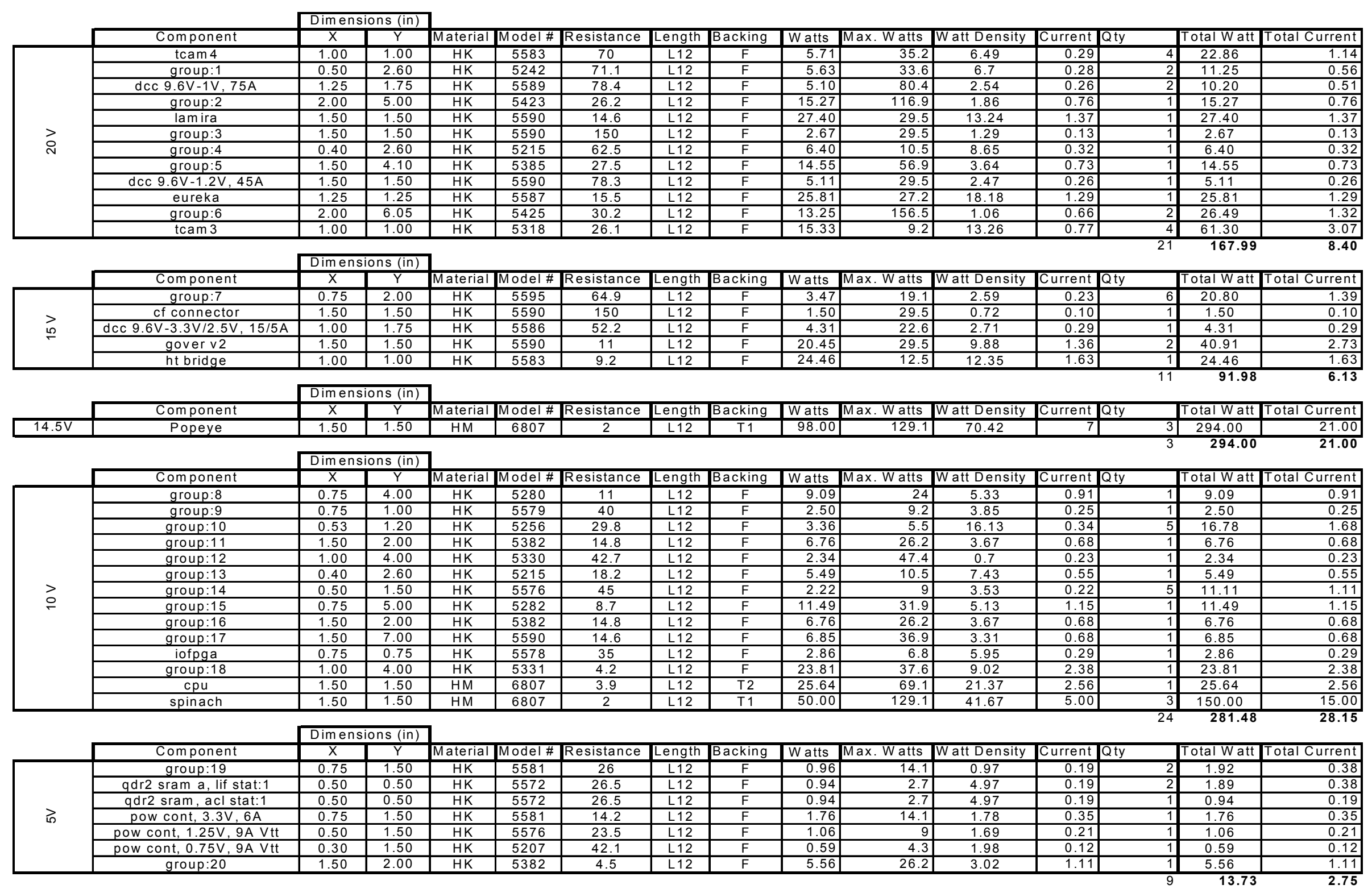


Table 26. Heater groups with measured resistances and calculated powers

\begin{tabular}{|c|c|c|c|c|c|c|c|}
\hline Group Tag & Tag Number & Voltage & Group & $\begin{array}{c}\text { Resistance } \\
(\Omega)\end{array}$ & Power (W) & $\begin{array}{l}\text { Current } \\
\text { (A) }\end{array}$ & \\
\hline \multirow{9}{*}{ く } & 1 & 5 & 19 & 25.9 & 0.97 & 0.19 & \\
\hline & 25 & 5 & 19 & 25.7 & 0.97 & 0.19 & \\
\hline & 29 & 5 & 20 & 4.5 & 5.56 & 1.11 & \\
\hline & 44 & 5 & pow cont $1.25 \mathrm{~V} 9 \mathrm{~A}$ & 23.7 & 1.05 & 0.21 & \\
\hline & $\mathrm{D}$ & 5 & pow cont 3.3V $6 \mathrm{~A}$ & 14.4 & 1.74 & 0.35 & \\
\hline & $\mathrm{F}$ & 5 & pow cont $0.75 \mathrm{~V} 9 \mathrm{~A}$ & 40.0 & 0.63 & 0.13 & \\
\hline & $\bar{G}$ & 5 & qdr2 sram & 25.2 & 0.99 & 0.20 & \\
\hline & $\mathrm{H}$ & 5 & qdr2 sram & 25.7 & 0.97 & 0.19 & \multirow{2}{*}{$\begin{array}{c}\text { Measured Resistance After } \\
\text { Assembly }\end{array}$} \\
\hline & $\bar{M}$ & 5 & qdr2 sram & 25.5 & 0.98 & 0.20 & \\
\hline & & 5 & Total & 1.8 & 13.85 & 2.77 & 1.8 \\
\hline
\end{tabular}

\begin{tabular}{|c|c|c|c|c|c|c|c|}
\hline Group Tag & Tag Number & Voltage & Group & $\begin{array}{c}\text { Resistance } \\
(\Omega)\end{array}$ & Power (W) & $\begin{array}{l}\text { Current } \\
\text { (A) }\end{array}$ & \\
\hline \multirow{5}{*}{ 흠 } & 36 & 10 & 14 & 49.1 & 2.04 & 0.20 & \\
\hline & 38 & 10 & 14 & 48.8 & 2.05 & 0.20 & \\
\hline & $\mathrm{N}$ & 10 & 13 & 17.4 & 5.75 & 0.57 & \\
\hline & $E$ & 10 & 10 & 30.4 & 3.29 & 0.33 & \multirow{2}{*}{\begin{tabular}{|} 
Measured Resistance After \\
Assembly
\end{tabular}} \\
\hline & $\mathrm{K}$ & 10 & 14 & 48.7 & 2.05 & 0.21 & \\
\hline & & 10 & Total & 6.6 & 15.18 & 1.52 & 6.6 \\
\hline
\end{tabular}

\begin{tabular}{|c|c|c|c|c|c|c|c|}
\hline Group Tag & Tag Number & Voltage & Group & $\begin{array}{c}\text { Resistance } \\
(\Omega)\end{array}$ & Power (W) & $\begin{array}{l}\text { Current } \\
\text { (A) }\end{array}$ & \\
\hline \multirow{5}{*}{ 음 } & 3 & 10 & 10 & 32.1 & 3.12 & 0.31 & \\
\hline & 4 & 10 & 11 & 14.5 & 6.90 & 0.69 & \\
\hline & 9 & 10 & 10 & 31.0 & 3.23 & 0.32 & \\
\hline & 11 & 10 & 10 & 31.0 & 3.23 & 0.32 & \multirow{2}{*}{$\begin{array}{c}\text { Measured Resistance After } \\
\text { Assembly }\end{array}$} \\
\hline & 30 & 10 & 14 & 49.1 & 2.04 & 0.20 & \\
\hline & & 10 & Total & 5.4 & 18.50 & 1.85 & 5.4 \\
\hline
\end{tabular}

\begin{tabular}{|c|c|c|c|c|c|c|c|}
\hline Group Tag & Tag Number & Voltage & Group & $\begin{array}{c}\text { Resistance } \\
(\Omega)\end{array}$ & Power (W) & $\begin{array}{l}\text { Current } \\
\text { (A) }\end{array}$ & \\
\hline \multirow{11}{*}{ ?ำ } & 5 & 10 & 12 & 43.4 & 2.30 & 0.23 & \\
\hline & 13 & 10 & 9 & 43.2 & 2.31 & 0.23 & \\
\hline & 16 & 10 & 10 & 32.1 & 3.12 & 0.31 & \\
\hline & 17 & 10 & 8 & 11.0 & 9.09 & 0.91 & \\
\hline & 20 & 10 & 18 & 4.1 & 24.39 & 2.44 & \\
\hline & 23 & 10 & 17 & 13.9 & 7.19 & 0.72 & \\
\hline & 24 & 10 & iofgpa & 38.0 & 2.63 & 0.26 & \\
\hline & 27 & 10 & 14 & 49.1 & 2.04 & 0.20 & \\
\hline & 31 & 10 & 11 & 14.6 & 6.85 & 0.68 & \\
\hline & 35 & 10 & 15 & 9.2 & 10.87 & 1.09 & \multirow{2}{*}{$\begin{array}{c}\text { Measured Resistance After } \\
\text { Assembly }\end{array}$} \\
\hline & $\bar{U}$ & 10 & $\mathrm{cpu}$ & 3.8 & 26.32 & 2.63 & \\
\hline & & 10 & Total & 1.0 & 97.11 & 9.71 & 1.0 \\
\hline
\end{tabular}

\begin{tabular}{|c|c|c|c|c|c|c|c|}
\hline Group Tag & Tag Number & Voltage & Group & $\begin{array}{c}\text { Resistance } \\
(\Omega)\end{array}$ & Power (W) & $\begin{array}{l}\text { Current } \\
\text { (A) }\end{array}$ & \\
\hline \multirow{11}{*}{$\frac{\pi}{30}$} & 2 & 15 & 7 & 66.4 & 3.39 & 0.23 & \\
\hline & 7 & 15 & 7 & 65.7 & 3.42 & 0.23 & \\
\hline & 10 & 15 & 7 & 65.1 & 3.46 & 0.23 & \\
\hline & 14 & 15 & 7 & 65.7 & 3.42 & 0.23 & \\
\hline & 18 & 15 & 7 & 64.2 & 3.50 & 0.23 & \\
\hline & HT & 15 & ht bridge & 9.9 & 22.73 & 1.52 & \\
\hline & 26 & 15 & cf connector & 156.3 & 1.44 & 0.10 & \\
\hline & 28 & 15 & groverV2 & 10.1 & 22.28 & 1.49 & \\
\hline & 34 & 15 & 7 & 64.7 & 3.48 & 0.23 & \\
\hline & 37 & 15 & groverV2 & 10.4 & 21.63 & 1.44 & \multirow{2}{*}{$\begin{array}{c}\text { Measured Resistance After } \\
\text { Assembly }\end{array}$} \\
\hline & 40 & 15 & dcc 9.6V-3.3V 15/5A & 52.9 & 4.25 & 0.28 & \\
\hline & & 15 & Total & 2.4 & 93.01 & 6.20 & 2.4 \\
\hline
\end{tabular}


Table 26 (cont.). Heater groups with measured resistances and calculated powers

\begin{tabular}{|c|c|c|c|c|c|c|c|}
\hline Group Tag & Tag Number & Voltage & Group & $\begin{array}{c}\text { Resistance } \\
(\Omega)\end{array}$ & Power (W) & $\begin{array}{l}\text { Current } \\
\text { (A) }\end{array}$ & \\
\hline \multirow{11}{*}{ 方 } & 6 & 20 & dcc 9.6V-1V 75A & 72.1 & 5.55 & 0.28 & \\
\hline & 32 & 20 & dcc $9.6 \mathrm{~V}-1.2 \mathrm{~V} 45 \mathrm{~A}$ & 78.8 & 5.08 & 0.25 & \\
\hline & 33 & 20 & dcc 9.6V-1V 75A & 73.3 & 5.46 & 0.27 & \\
\hline & 39 & 20 & 6 & 31.6 & 12.66 & 0.63 & \\
\hline & 41 & 20 & 1 & $\overline{72.2}$ & 5.54 & 0.28 & \\
\hline & 42 & 20 & tcam4 & 71.8 & 5.57 & 0.28 & \\
\hline & A & 20 & lamira & 13.5 & 29.63 & 1.48 & \\
\hline & $\mathrm{R}$ & 20 & 3 & 156.8 & 2.55 & 0.13 & \\
\hline & $\mathrm{J}$ & 20 & eureka & 17.1 & 23.39 & 1.17 & \\
\hline & $\bar{Y}$ & 20 & tcam3 & 27.3 & 14.65 & 0.73 & \multirow{2}{*}{$\begin{array}{c}\text { Measured Resistance After } \\
\text { Assembly }\end{array}$} \\
\hline & Z & 20 & tcam3 & 27.4 & 14.60 & 0.73 & \\
\hline & & 20 & Total & 3.2 & 124.67 & 6.23 & $\overline{3.2}$ \\
\hline
\end{tabular}

\begin{tabular}{|c|c|c|c|c|c|c|c|}
\hline Group Tag & Tag Number & Voltage & Group & $\begin{array}{c}\text { Resistance } \\
(\Omega)\end{array}$ & Power (W) & $\begin{array}{l}\text { Current } \\
\text { (A) }\end{array}$ & \\
\hline \multirow{10}{*}{$\stackrel{\text { D }}{\text { ¿ }}$} & 8 & 20 & tcam4 & 71.0 & 5.63 & 0.28 & \\
\hline & 15 & 20 & tcam4 & 72.7 & 5.50 & 0.28 & \\
\hline & 12 & 20 & 1 & 72.5 & 5.52 & 0.28 & \\
\hline & 19 & 20 & tcam4 & 70.8 & 5.65 & 0.28 & \\
\hline & 21 & 20 & 2 & 28.5 & 14.04 & 0.70 & \\
\hline & 22 & 20 & 6 & 31.8 & 12.58 & 0.63 & \\
\hline & 43 & 20 & 5 & 27.1 & 14.76 & 0.74 & \\
\hline & 45 & 20 & 4 & 60.8 & 6.58 & 0.33 & \\
\hline & $\bar{W}$ & 20 & tcam3 & 27.6 & 14.49 & 0.72 & \multirow{2}{*}{$\begin{array}{c}\text { Measured Resistance After } \\
\text { Assembly }\end{array}$} \\
\hline & $\bar{x}$ & 20 & tcam3 & 28.6 & 13.99 & 0.70 & \\
\hline & & 20 & Total & 4.1 & 98.73 & 4.94 & 4.0 \\
\hline
\end{tabular}

\begin{tabular}{|c|c|c|c|c|c|c|c|}
\hline Group Tag & Tag Number & Voltage & Group & \begin{tabular}{|c|} 
Resistance \\
$(\Omega)$ \\
\end{tabular} & Power (W) & $\begin{array}{l}\text { Current } \\
\text { (A) }\end{array}$ & \\
\hline \multirow{3}{*}{0} & Q1 & 14.5 & popeye & 2.2 & 95.57 & 6.59 & \\
\hline & Q2 & 14.5 & popeye & 2.1 & 100.12 & 6.90 & \multirow{2}{*}{$\begin{array}{c}\text { Measured Resistance After } \\
\text { Assembly } \\
\end{array}$} \\
\hline & Q3 & 14.5 & popeye & 2.2 & 95.57 & 6.59 & \\
\hline & & 14.5 & Total & 0.7 & 291.26 & 20.09 & 0.7 \\
\hline
\end{tabular}

\begin{tabular}{|c|c|c|c|c|c|c|c|}
\hline Group Tag & Tag Number & Voltage & Group & $\begin{array}{c}\text { Resistance } \\
(\Omega)\end{array}$ & Power (W) & $\begin{array}{l}\text { Current } \\
\text { (A) }\end{array}$ & \\
\hline \multirow{3}{*}{$\infty$} & S1 & 10 & spinach & 2.1 & 47.62 & 4.76 & \\
\hline & S2 & 10 & spinach & 2.2 & 45.45 & 4.55 & \multirow{2}{*}{$\begin{array}{c}\text { Measured Resistance After } \\
\text { Assembly }\end{array}$} \\
\hline & S3 & 10 & spinach & 2.2 & 45.45 & 4.55 & \\
\hline & & 10 & Total & 0.7 & 138.53 & 13.85 & 0.7 \\
\hline
\end{tabular}


Table 26 (cont.). Heater groups with measured resistances and calculated powers

\begin{tabular}{|c|c|c|c|c|c|c|c|}
\hline Group Tag & Tag Number & Voltage & Group & $\begin{array}{c}\text { Resistance } \\
(\Omega)\end{array}$ & Power (W) & $\begin{array}{l}\text { Current } \\
\text { (A) }\end{array}$ & \\
\hline \multirow{3}{*}{$\sum^{M}$} & $\mathrm{M} 3 \mathrm{P}$ & 17 & Popeye Test Chip & 31.9 & 9.06 & 0.53 & \\
\hline & M4P & 17 & Popeye Test Chip & 42.4 & 6.82 & 0.40 & \multirow{2}{*}{$\begin{array}{c}\text { Measured Resistance After } \\
\text { Assembly }\end{array}$} \\
\hline & M5P & 17 & Popeye Test Chip & 150.3 & 1.92 & 0.11 & \\
\hline & & 17 & Total & $\overline{16.2}$ & 17.80 & $\overline{1.05}$ & $\overline{17.0}$ \\
\hline Group Tag & Tag Number & Voltage & Group & $\begin{array}{c}\text { Resistance } \\
(\Omega)\end{array}$ & Power (W) & $\begin{array}{l}\text { Current } \\
\text { (A) }\end{array}$ & \\
\hline \multirow{4}{*}{$\sum^{+}$} & M1P & 17 & Popeye Test Chip & 31.9 & 9.06 & 0.53 & \\
\hline & M2P & 17 & Popeye Test Chip & 42.5 & 6.80 & 0.40 & \\
\hline & $\mathrm{M} 6 \mathrm{P}$ & 17 & Popeye Test Chip & 42.4 & 6.82 & 0.40 & \multirow{2}{*}{$\begin{array}{l}\text { Measured Resistance After } \\
\text { Assembly }\end{array}$} \\
\hline & \multirow[t]{2}{*}{ M7P } & 17 & Popeye Test Chip & 31.9 & 9.06 & 0.53 & \\
\hline & & 17 & Total & 9.1 & 31.74 & 1.87 & 9.2 \\
\hline & & & & & & & $\begin{array}{l}\text { Measured Resistance After } \\
\text { Assembly }\end{array}$ \\
\hline & & & Cumlative & 5.8 & 49.53 & 2.91 & 6.0 \\
\hline Group Tag & Tag Number & Voltage & Group & \begin{tabular}{|c} 
Resistance \\
$(\Omega)$
\end{tabular} & Power (W) & $\begin{array}{l}\text { Current } \\
\text { (A) }\end{array}$ & \\
\hline \multirow{3}{*}{$\underline{m}$} & M3S & 23 & Spinach Test Chip & 31.7 & 16.69 & 0.73 & \\
\hline & M4S & 23 & Spinach Test Chip & 42.3 & 12.51 & 0.54 & \multirow{2}{*}{$\begin{array}{l}\text { Measured Resistance After } \\
\text { Assembly }\end{array}$} \\
\hline & M5S & 23 & Spinach Test Chip & 42.3 & 12.51 & 0.54 & \\
\hline & & 23 & Total & 12.7 & 41.70 & 1.81 & 12.8 \\
\hline Group Tag & Tag Number & Voltage & Group & $\begin{array}{c}\text { Resistance } \\
(\Omega)\end{array}$ & Power (W) & $\begin{array}{l}\text { Current } \\
\text { (A) }\end{array}$ & \\
\hline \multirow{4}{*}{ ষ } & M1S & 23 & Spinach Test Chip & 31.9 & 16.58 & 0.72 & \\
\hline & M2S & 23 & Spinach Test Chip & 42.4 & 12.48 & 0.54 & \\
\hline & M6S & 23 & Spinach Test Chip & 42.2 & 12.54 & 0.55 & \multirow{2}{*}{$\begin{array}{c}\text { Measured Resistance After } \\
\text { Assembly }\end{array}$} \\
\hline & \multirow[t]{2}{*}{ M7S } & 23 & Spinach Test Chip & 31.7 & 16.69 & 0.73 & \\
\hline & & 23 & Total & 9.1 & 58.28 & 2.53 & 9.2 \\
\hline & & & & & & & $\begin{array}{l}\text { Measured Resistance After } \\
\text { Assembly }\end{array}$ \\
\hline & & & Cumlative & 5.3 & 99.98 & 4.35 & 5.4 \\
\hline
\end{tabular}

\begin{tabular}{|l|l|}
\hline Test Board Power & 1040.36 \\
\hline
\end{tabular} 


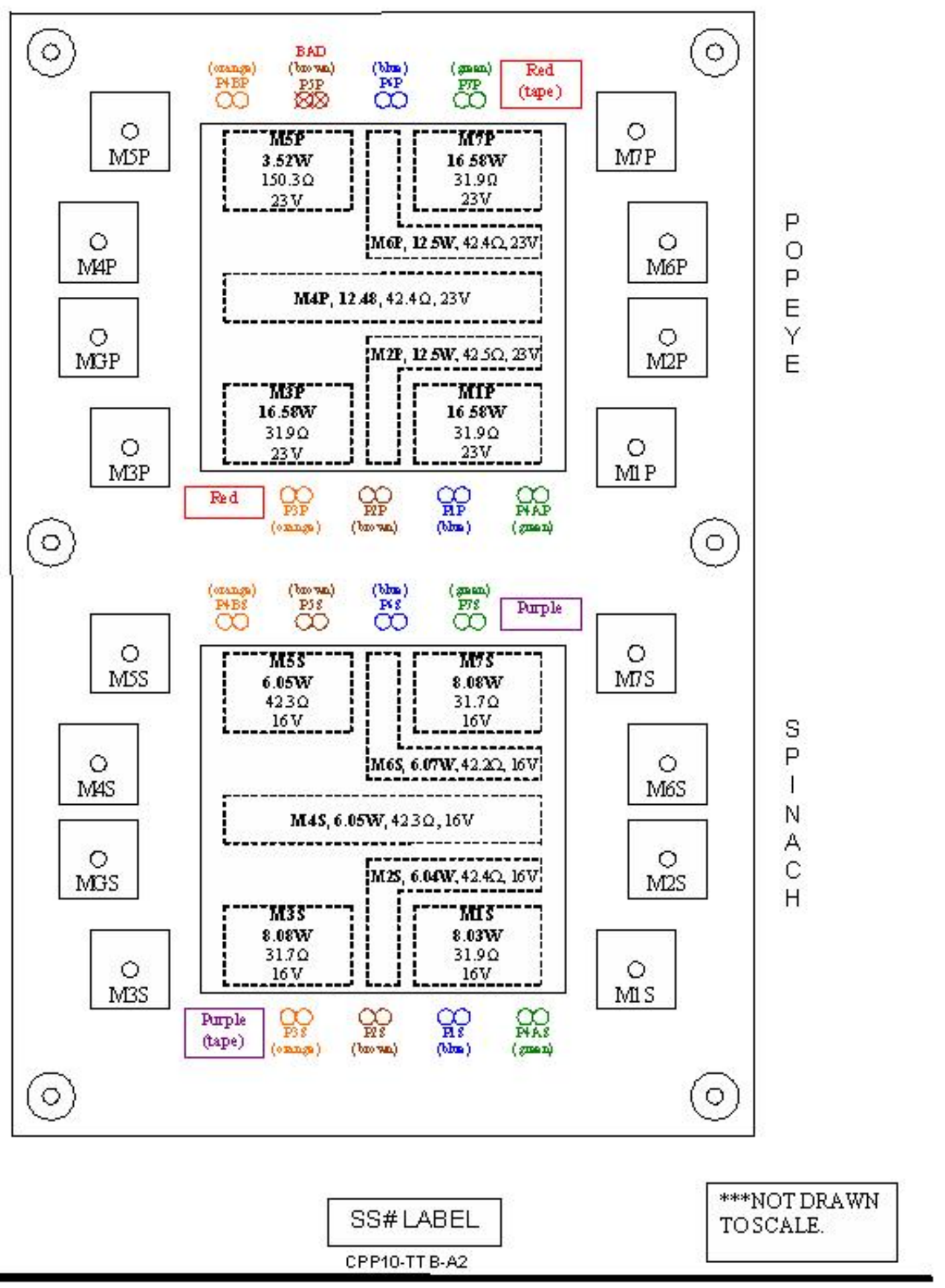

Figure 43. " $X$ " complex Test Chip layout with measured resistances and expected powers 


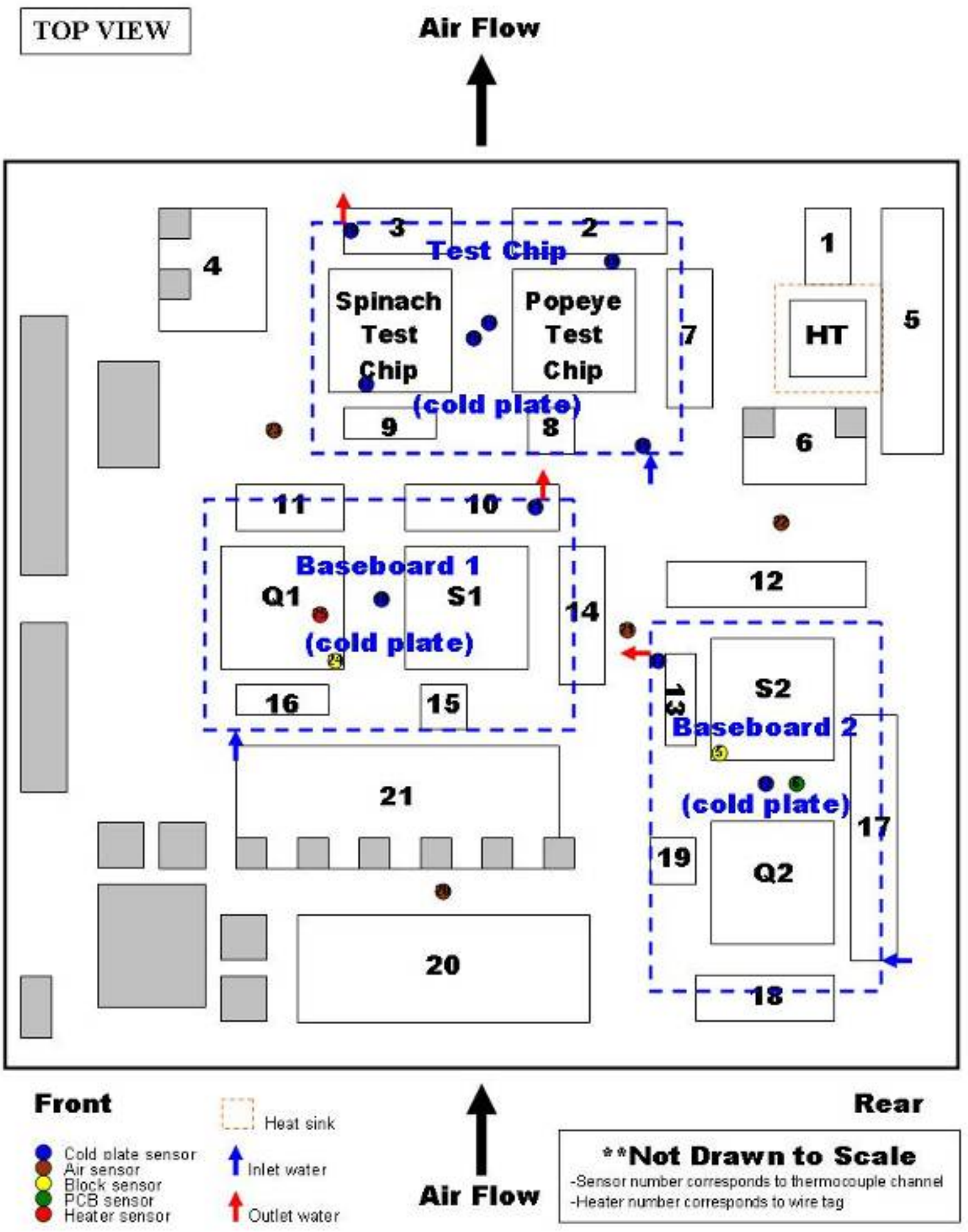

Figure 44. Mainboard heater, block, and thermocouple layout 


\section{TOP VIEW}

Earl 8 Daughter Card

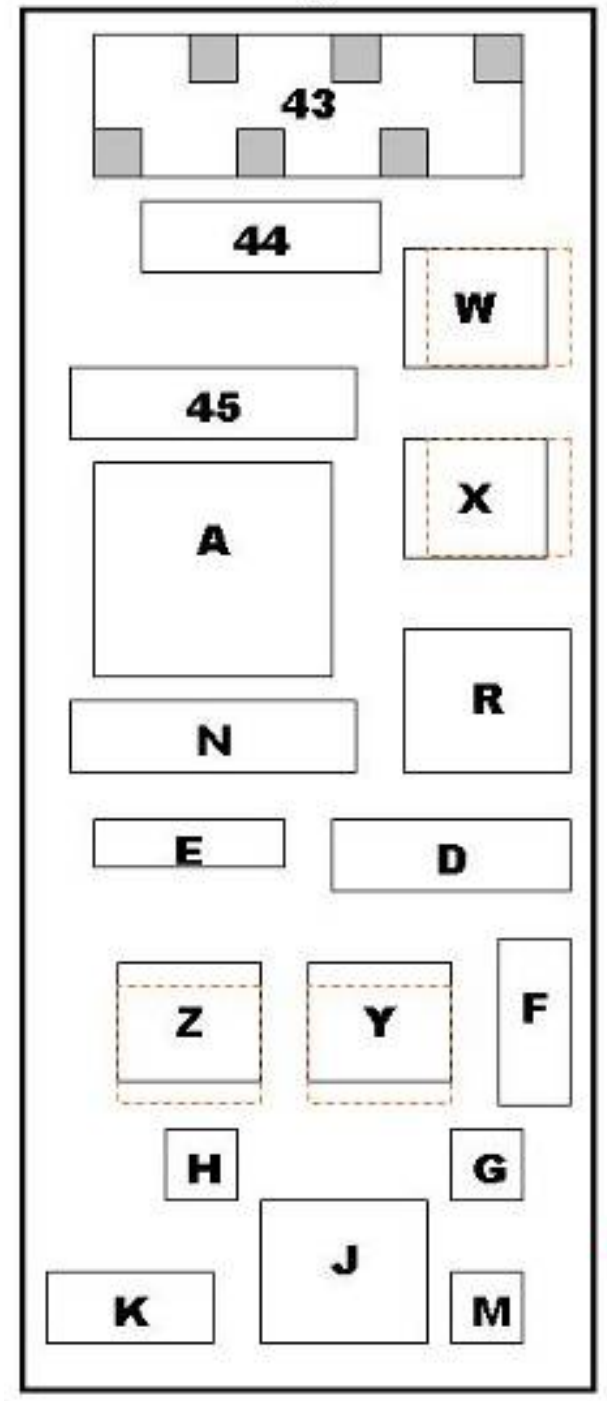

Front

Cold olate sensor

Air sensor

Block senso

PCB sensor

Heater sensor

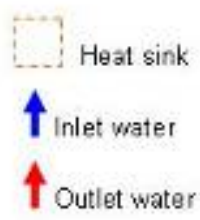

\section{Air Flow}

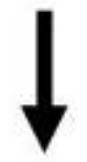

Link Daughter Card

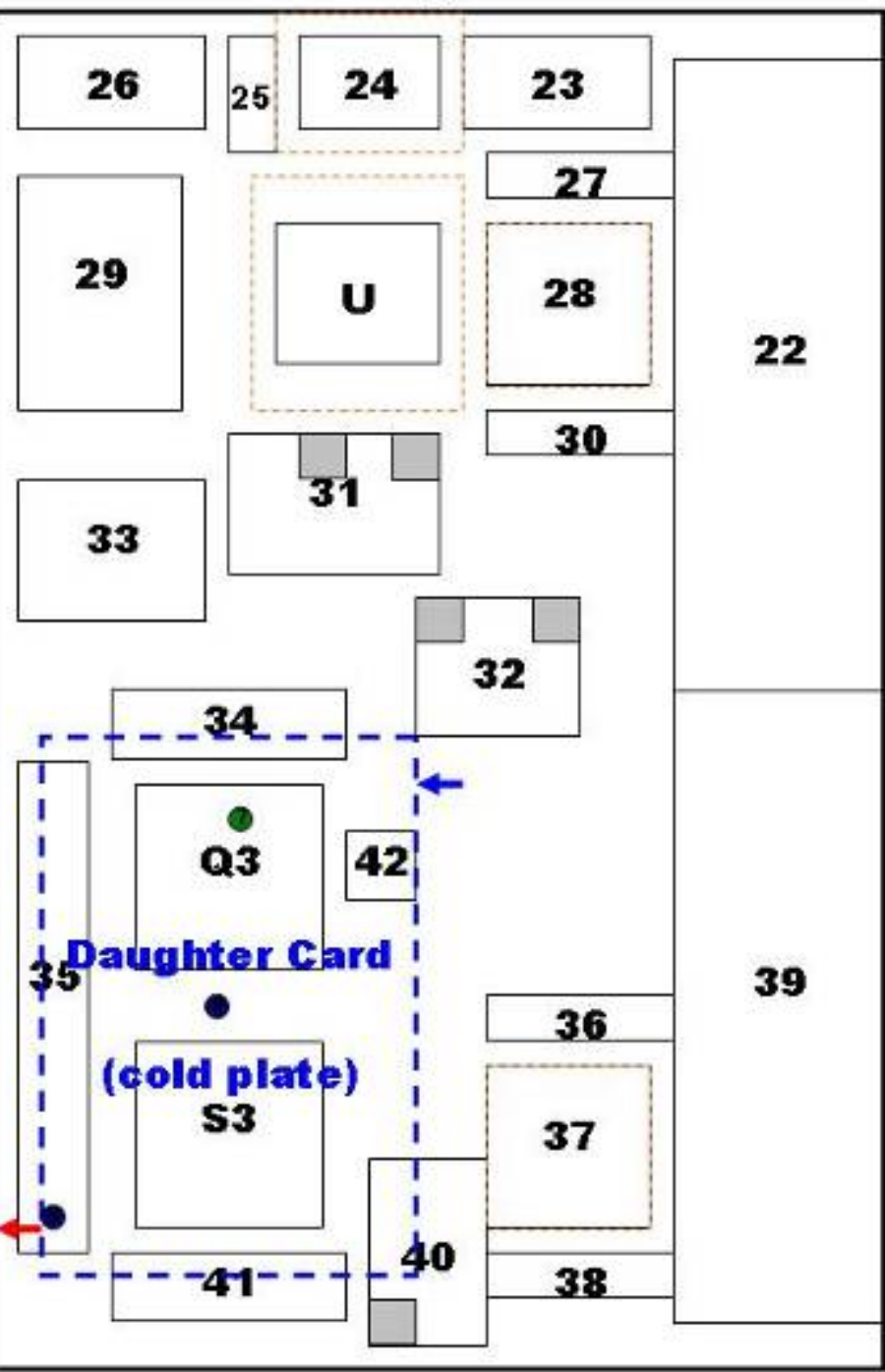

Rear

-Sensor number corresponds to thermocouple channel - Heater number corresponds to wire tag

Figure 45. Daughter cards heater, block, and thermocouple layouts 


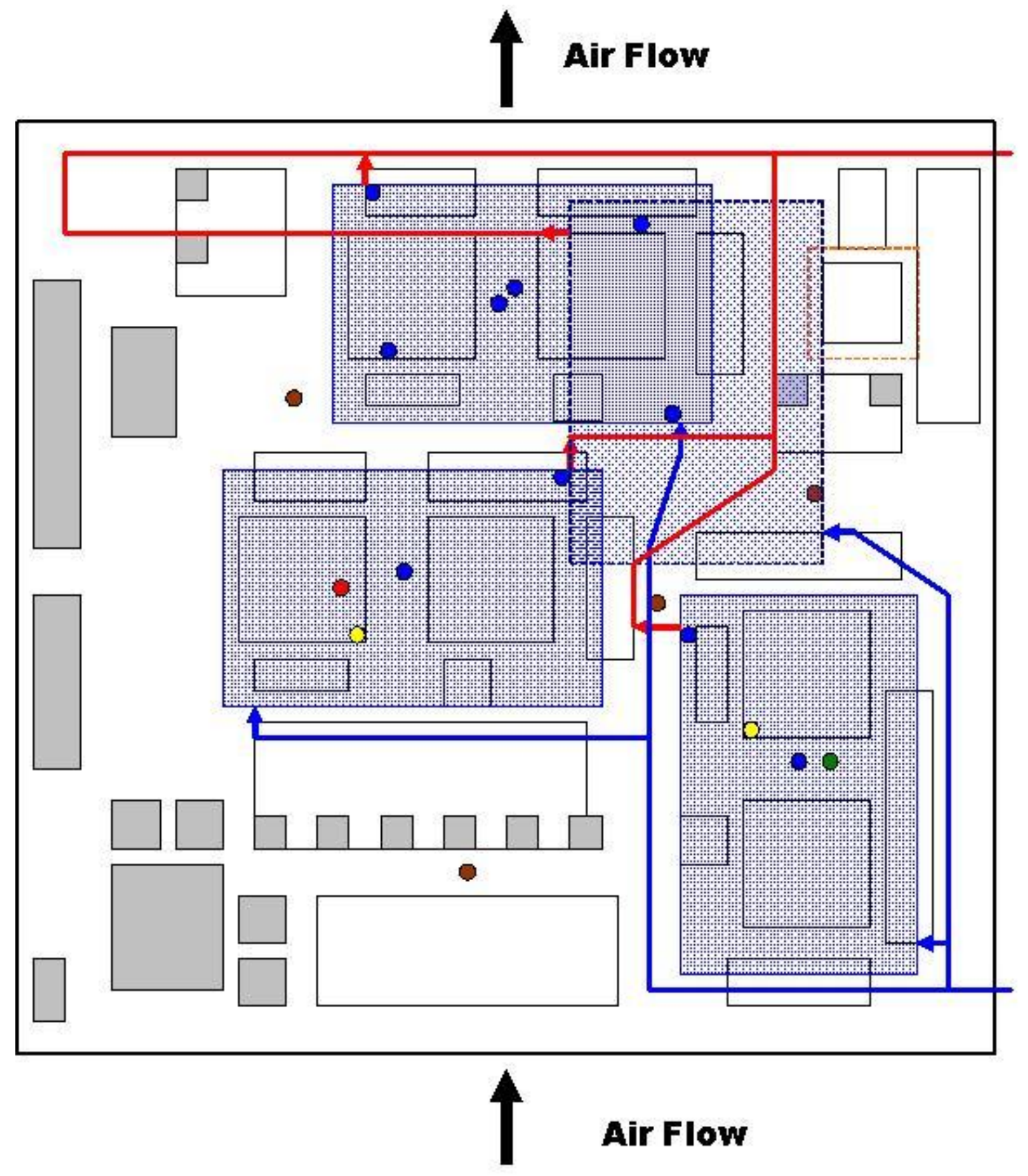

Figure 46. Test board liquid flow schematic 


\section{Appendix C}

\section{Equipment Specifications}




\section{Cold Plate Specifications}

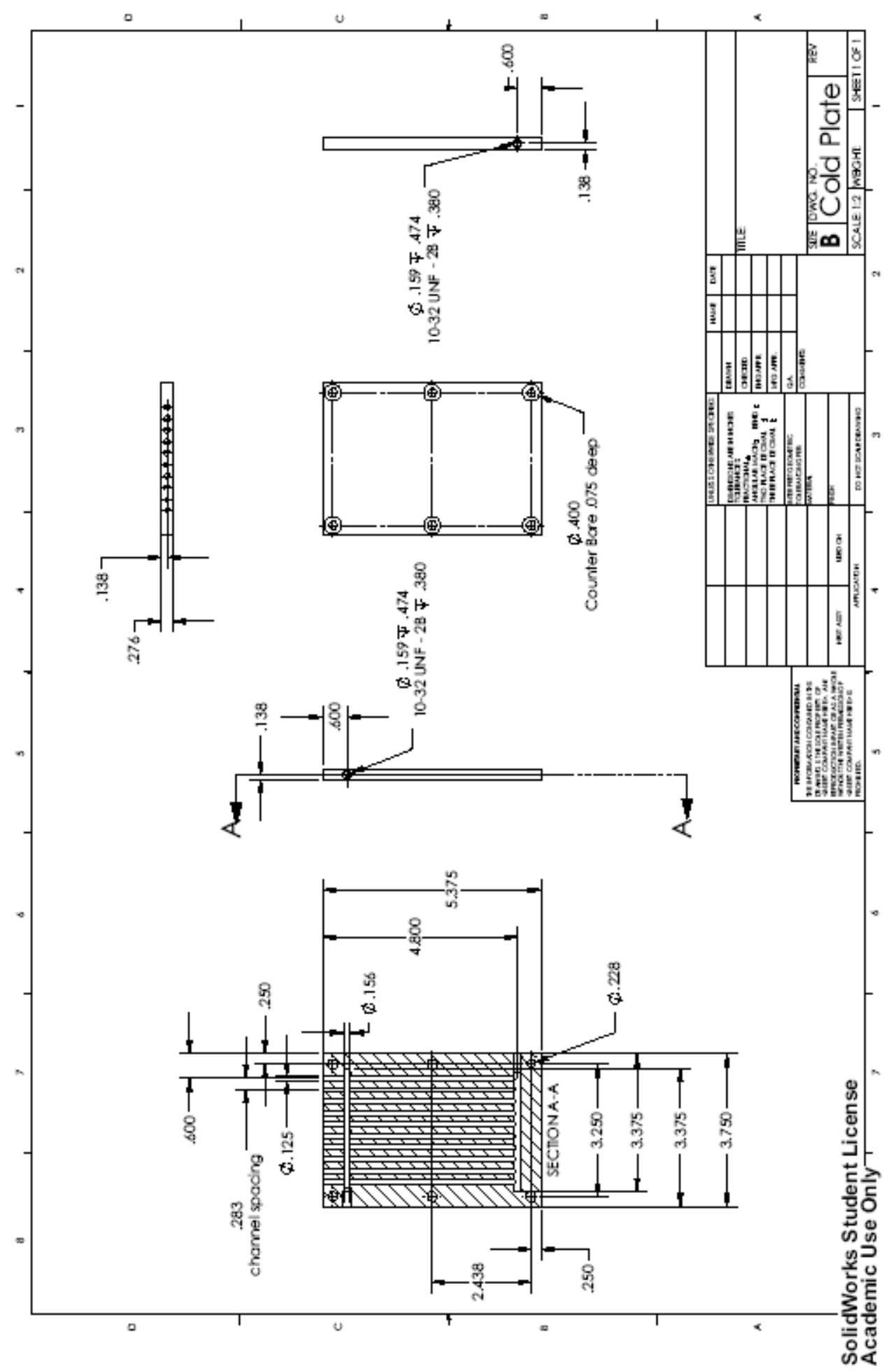




\section{Disc Springs}

This product matches all of your selections.

$\begin{array}{ll}\text { Part Number: } 9712 \mathrm{~K} 53 & \text { Belleville Disc Springs } \\ \text { Minimum Inside Diameter } & \text { Steel } \\ \text { Maximum Outside Diameter } & .125^{\prime \prime} \\ & .250^{\prime \prime} \\ \text { Thickness } & .0090^{\prime \prime} \\ \text { Overall Height } & .017^{\prime \prime} \\ \text { Load } & 12 \mathrm{lbs} . \\ \text { Deflection at Load } & .004^{\prime \prime} \\ \text { Flat Load } & 16 \mathrm{lbs} . \\ \text { Specifications Met } & \text { Not Rated } \\ & \end{array}$


$\underline{\text { Pneumatic Fittings }}$

\begin{tabular}{|l|l|}
\hline Manufacturer: & www.clippard.com \\
\hline Size: & for 1/8" ID tubing \\
\hline Thread: & $\# 10-32$ \\
\hline Tube sealing: & single barbed \\
\hline Material: & Steel \\
\hline Surface sealing: & rubber O-ring \\
\hline
\end{tabular}

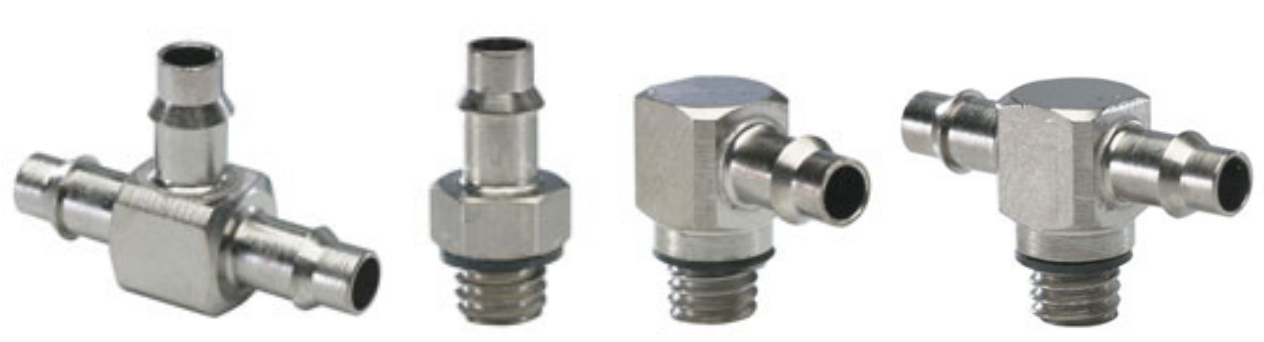

Figure 47. Pneumatic fittings used on cold plates 


\section{Pump Specifications}

\section{Model: DDC2 12 Volt}

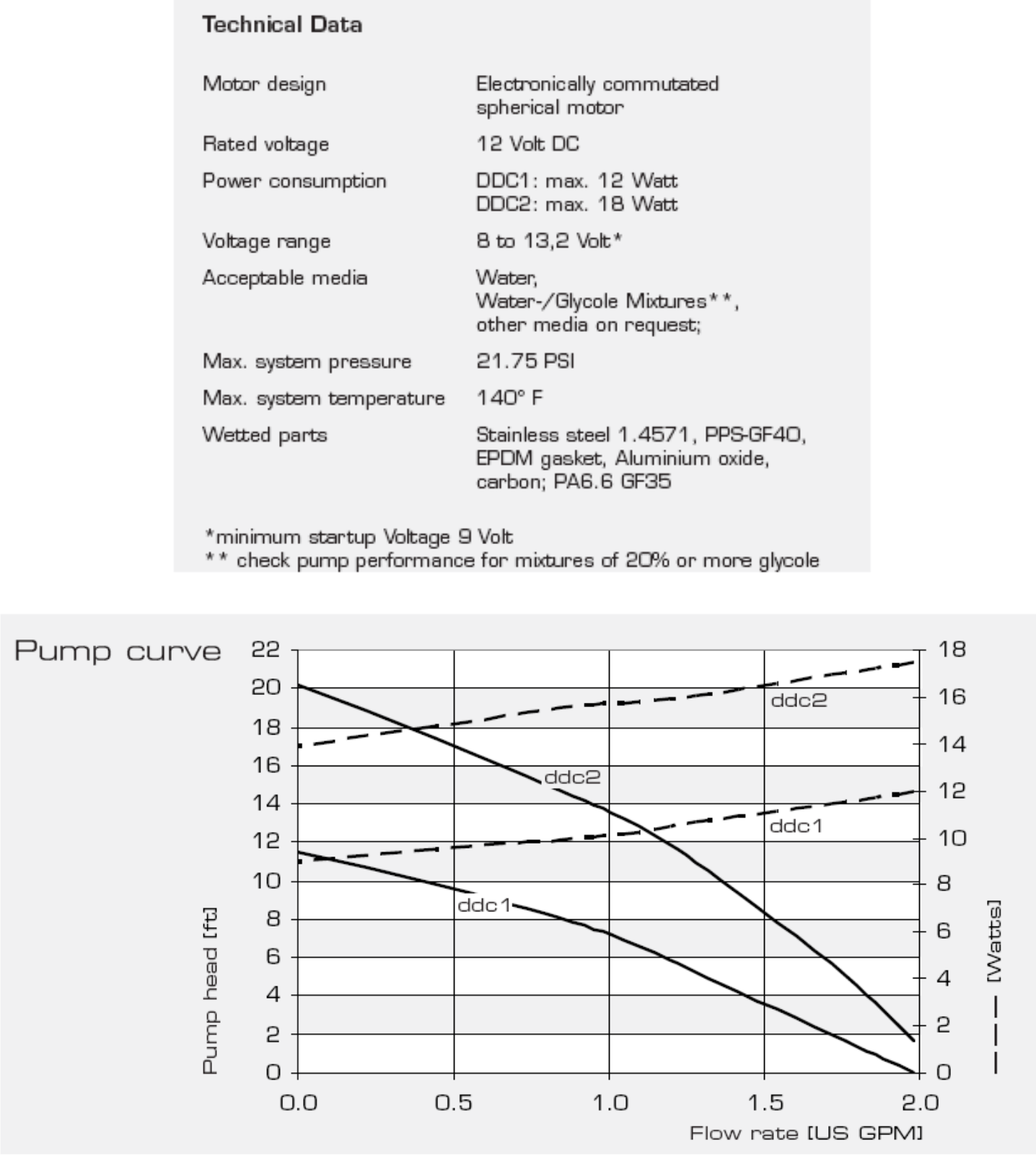



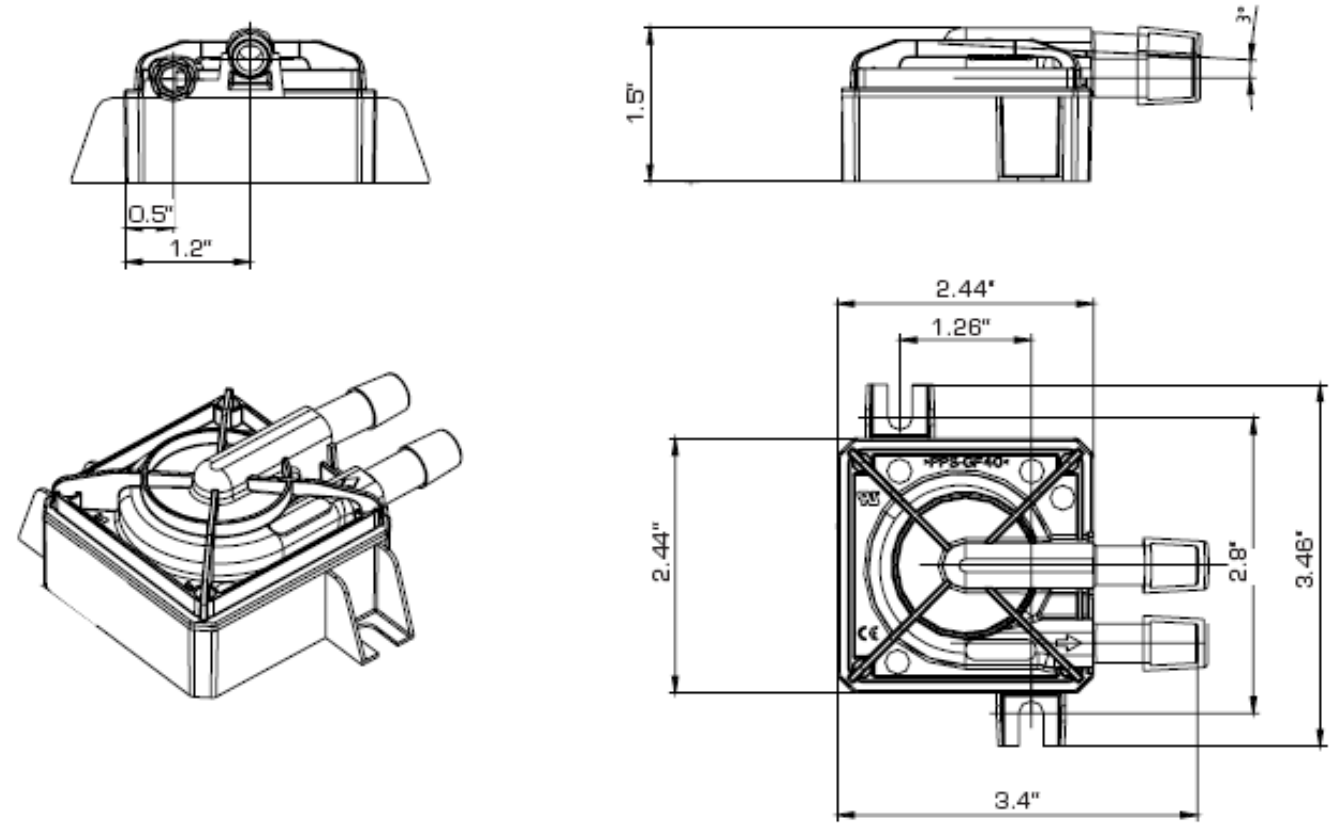
$\underline{\text { Heat Exchanger Specifications }}$

Model: ES0714G

\begin{tabular}{|c|c|c|c|c|}
\hline Core Number & ES0505G & ES0510G & ES0707G & ES0714G \\
\hline Fluid path & \multicolumn{4}{|c|}{ aluminum } \\
\hline Fin material & \multicolumn{4}{|c|}{ aluminum } \\
\hline Dry weight & $\begin{array}{c}2.0 \\
0.91\end{array}$ & $\begin{array}{l}2.85 \\
1.30 \\
\end{array}$ & $\begin{array}{l}2.85 \\
1.30 \\
\end{array}$ & $\begin{array}{l}5.53 \\
2.51 \\
\end{array}$ \\
\hline Fluid volume & $\begin{array}{c}14 \\
229 \\
\end{array}$ & $\begin{array}{c}17 \\
278 \\
\end{array}$ & $\begin{array}{c}24 \\
393 \\
\end{array}$ & $\begin{array}{c}31 \\
508 \\
\end{array}$ \\
\hline Fittings (see page 88) & \multicolumn{4}{|c|}{$3 / 8-18$ NPT } \\
\hline Max. operating temp. & \multicolumn{4}{|c|}{$400^{\circ} \mathrm{F} / 200^{\circ} \mathrm{C}$} \\
\hline
\end{tabular}

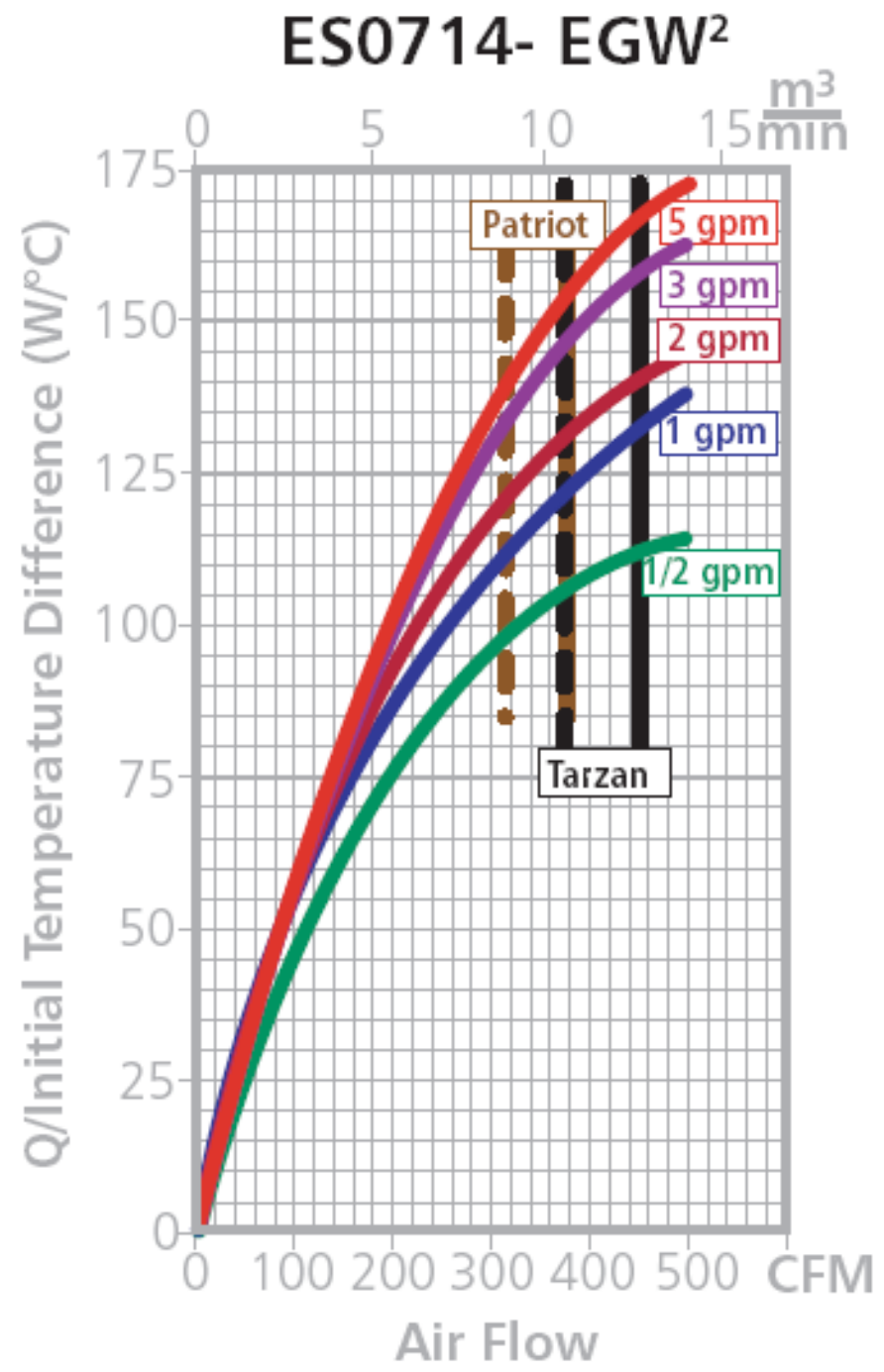




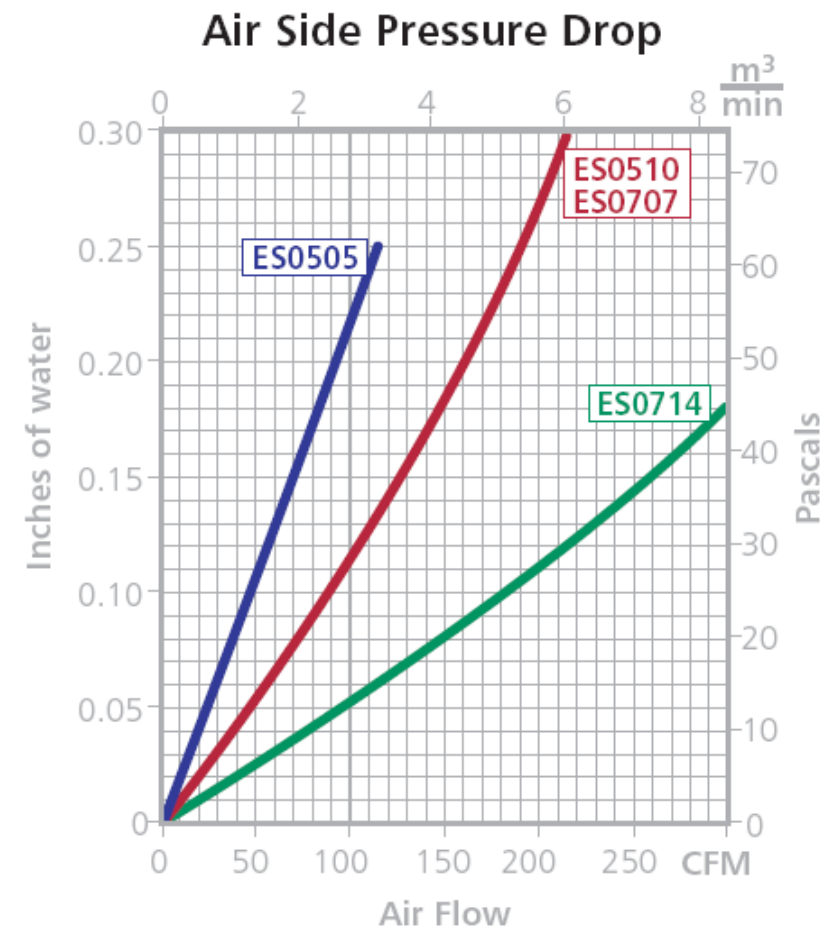

\section{Liquid Side Pressure Drop - EGW}

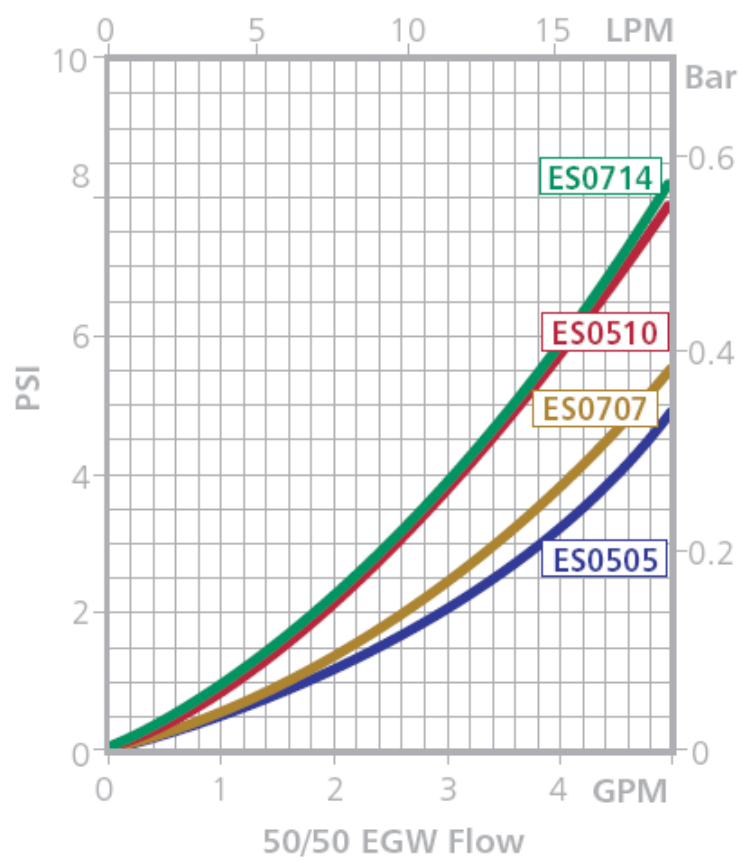




\section{Quick Disconnect Specifications}

\section{Polypropylene Quick-Disconnect Tube Couplings}

- Max. Pressure:

Type 301 Stainless Steel Thumb Latch: 120

- Temperature Range: $32^{\circ}$ to $160^{\circ} \mathrm{F}$

- Use with air, water, steam, alcohol, ammonia, ethanol, and methanol

- Color: Type 301 Stainless Steel Thumb Latch: Almond (opaque): Polypropylene Thumb Latch: Light gray (opaque)

- Material Meets: Not rated

- Vacuum:20" $\mathrm{Hg} @ 70^{\circ} \mathrm{F}$

- Tubing: Use polyethylene, nylon, and polyurethane with a durom-

- Tubing: Use polyethylene, nylon, and polyure
eter of 40A-80A with barbed fittings

- Clamps: Recommended with barbed fittings (see pages 238-247)

Polypropylene material provides greater resistance to acids than ac etal. O-ring is EPDM and pipe connections are NPT. Suitable for chemical sterilization. Connected plug and socket swivel for adjustment purposes. For a complete coupling, order a socket and a plug with the same coupler size. Straight-through components don't have a valve to stop flow when couplings are disconnected. Couplings with shut-off valves stop flow when separated

Panel-mount sockets, also known as bulkhead couplings, require a $1 / 2^{\prime \prime}$ dia. hole to mount the $1 / 8^{\prime \prime}$ coupler size, an $11 / 16^{\prime \prime}$ dia. hole to mount the $1 / 4^{\prime \prime}$ coupler size, and a $13 / 16^{\prime \prime}$ dia. hole to mount the $3 / 8^{\prime \prime}$ size.

For NSF certified polypropylene thumb latch couplings, see series $5385 \mathrm{~K}$ on page 178 .

Model: 51545K25

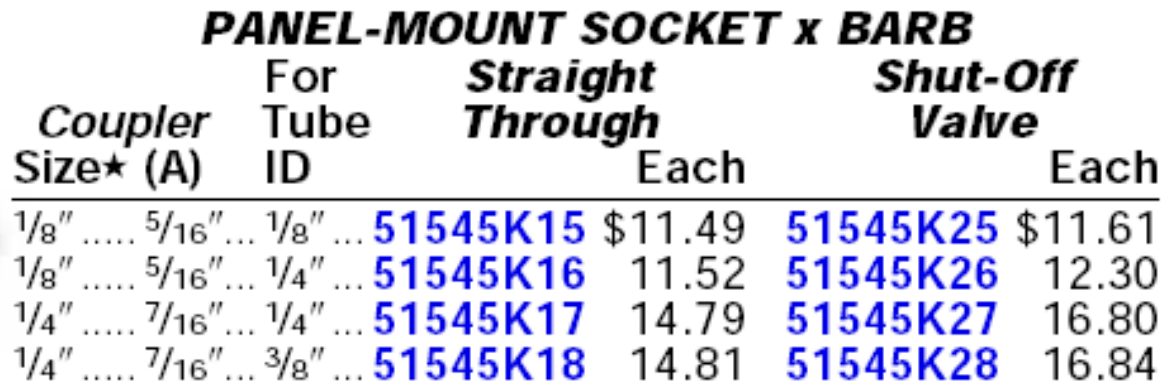

Model: 51545K77

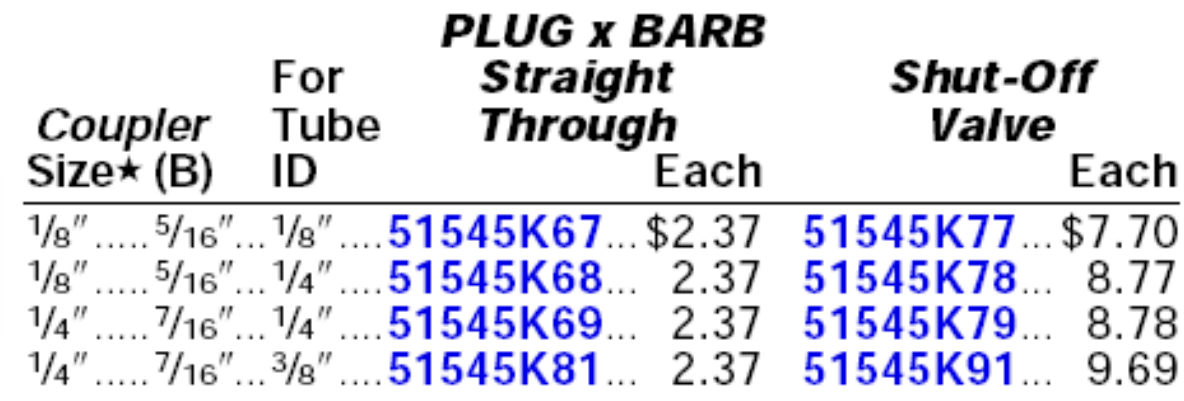




\section{$\underline{\text { Tubing and Fittings Specifications }}$}

\section{3-A Sanitary Clear PVC Tubing \\ - Very flexible \\ - Temperature Range: $-10^{\circ}$ to $+175^{\circ} \mathrm{F}$ \\ - Tensile Strength: $2200 \mathrm{psi}$ \\ - Use barbed fittings \\ (see pages 137-144) \\ With a nonabsorbing surface that resists bacterial growth, this PVC tubing facilitates thorough cleansing, won't impart taste, and meets 3-A sanitary requirements. It is clear, so you can easily monitor the flow of your line. Use with dairy as well as water and food and beverage. Material is FDA CFR21 175.300 and USDA compliant; it is also NSF 51 certified. This tubing can be cleaned with alkaline-based cleaners and sanitizers; it can be sterilized with steam (autoclaving), gas, and chemicals. Not rated for vacuum.}

roorders Please specify length from the available lengths listed.

Max.

Bend psi@ Available ID OD Wall Radius $73^{\circ} \mathrm{F}$ Lengths, $\mathrm{ft}$.

Per Ft.

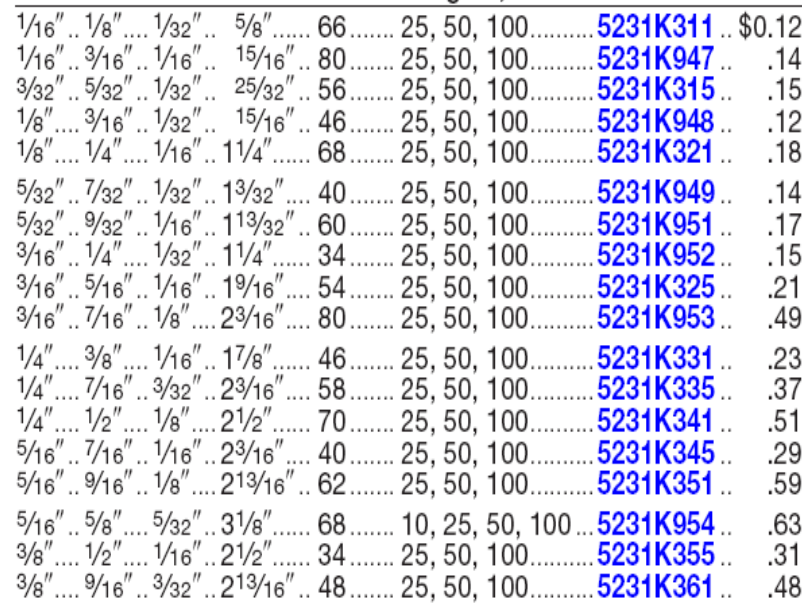

Max.

Bend psi @ Available ID OD Wall Radius $73^{\circ} \mathrm{F}$ Lengths, $\mathrm{ft}$.

Per Ft. $3 / 8^{\prime \prime} \ldots . .5 / 8^{\prime \prime} \ldots . .1 / 8^{\prime \prime} \ldots 3^{1} 18^{\prime \prime} \ldots .58 \ldots . .10,25,50,100 \ldots 5231 K 365 \ldots \$ 0.69$

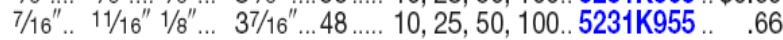
$1 / 2 " \ldots . .5 / 8^{\prime \prime} \ldots .1 / 16^{\prime \prime} \quad 31 / 8^{\prime \prime} \ldots .28 \ldots . .25,50,100 \ldots \ldots .5231 K 371 \ldots . .47$ $1 / 2^{\prime \prime} \ldots . .111 / 16^{\prime \prime} 3 / 32^{\prime \prime} \quad 37 / 16^{\prime \prime} \ldots 38 \ldots . . .10,25,50,100 \ldots 5231 \mathrm{~K} 451 \ldots . .67$ $1 / 2^{\prime \prime} \ldots . .3 / 4^{\prime \prime} \ldots .1 / 8^{\prime \prime} \ldots 3.3 / 4^{\prime \prime} \ldots . .44 \ldots . .10,25,50,100 \ldots 5231 \mathrm{~K} 375 \ldots . .81$ $5 / 8^{\prime \prime} \ldots . .7 / 8^{\prime \prime} \ldots 1 / 8^{\prime \prime} \ldots \quad 43 / 8^{\prime \prime} \ldots 38 \ldots . .10,25,50,100 \ldots 5231 \mathrm{~K} 381 \ldots .91$ $11 / 16^{\prime \prime} 15 / 16^{\prime \prime} 1 / 8^{\prime \prime} \ldots 411 / 16^{\prime \prime} 38 \ldots . .10,25,50 \ldots \ldots \ldots . .5231 \mathrm{~K} 944 \ldots 1.03$ $3 / 4^{\prime \prime} \ldots 1^{\prime \prime} \ldots \ldots 1 / 8^{\prime \prime} \ldots 5^{\prime \prime} \ldots \ldots . \ldots 34 \ldots . .10,25,50 \ldots \ldots \ldots . .5231 \mathrm{~K} 385 \ldots 1.05$ $7 / 8^{\prime \prime} \ldots 118^{\prime \prime} \ldots .1 / 8^{\prime \prime} \ldots 55 / 8^{\prime \prime} \ldots . .30 \ldots . .10,25,50 \ldots \ldots \ldots .5231 \mathrm{~K} 945 \ldots 1.21$ $1^{\prime \prime} \ldots \ldots . .11^{\prime \prime} 4^{\prime \prime} \ldots .1 / 8^{\prime \prime} \ldots 6^{1} 4^{\prime \prime} \ldots .28 \ldots . .10,25,50 \ldots \ldots \ldots .5231 \mathrm{~K} 391 \ldots 1.36$ $1^{\prime \prime} \ldots . \ldots . .13 / 8^{\prime \prime} \ldots . .3 / 16^{\prime \prime} \quad 67 / 8^{\prime \prime} \ldots 38 \ldots . .5,10,25,50 \ldots . . .5231 \mathrm{~K} 395 \ldots 2.12$ $1^{\prime \prime} \ldots \ldots \ldots 11 / 2^{\prime \prime} \ldots . .1 / 4^{\prime \prime} \ldots \quad 71 / 2^{\prime \prime} \ldots . .44 \ldots . .5,10,25,50 \ldots \ldots .5231 \mathrm{~K} 946 \ldots 2.75$

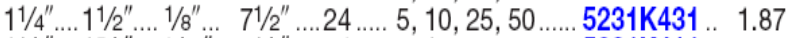
$11 / 4^{\prime \prime} \ldots . \ldots 15 / 8^{\prime \prime \ldots . . .3 / 166^{\prime \prime}} 81 / 8^{\prime \prime} \ldots . . .34 \ldots . . .5,10,25,50 \ldots . . .5231 \mathrm{~K} 411 \ldots 2.60$ $11 / 2^{\prime \prime} \ldots . .17 / 8^{\prime \prime} \ldots . .3 / 16^{\prime \prime} \quad 93 / 8^{\prime \prime} \ldots .28 \ldots . .2,5,10,25,50 \ldots 5231 \mathrm{~K} 435 \ldots 3.32$ $11^{1} 2^{\prime \prime} \ldots 2^{\prime \prime} \ldots \ldots .1 / 4^{\prime \prime} \ldots 10^{\prime \prime} \ldots \ldots . .36 \ldots . .2,5,10,25,50 \ldots 5231 \mathrm{~K} 415 \ldots 3.97$ $2^{\prime \prime} \ldots \ldots . .2^{1} 12^{\prime \prime} \ldots .1 / 4^{\prime \prime} \ldots 12^{1} 2^{\prime \prime} \ldots . .28 \ldots . .2,5,10,25,50 \ldots 5231 K 421 \ldots 6.89$ 


\section{Nylon Single-Barbed Tube Fittings}

- Max. Pressure: 150 psi @ 72’ F unless noted

- Temperature Range: $-60^{3}$ to $+175^{\circ} \mathrm{F}$

- Use with air, water, hydraulic fluids, and chemicals

Not recommended for use with phenols, acids, and oxidizers

- Color: Semiclear (translucont) whito; opaque black

- Material Meets: Semiclear (translucent) white: NSF-61 (drinking water)

- Tubing: Use with PVC and polyurethane tubing vith a durometer of $75 \mathrm{~A}-90 \mathrm{~A}$

- Clamps: Recommended (see pages 238-247)

Tube-to-Pipe Adapters
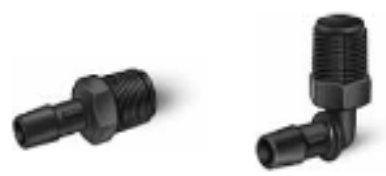

For

Tube Pipe

Barbed $\boldsymbol{x}$ Male Pipe

Per Pkg.

$90^{*}$ Elbows, Barbed $x$

Per Pkg.

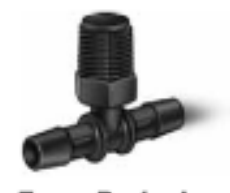

Tees, Barbed $x$

Male Pipe $x$

Barbed

Per Pkg.

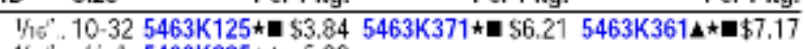

$1 / 16^{\prime \prime}, 1 / 16^{*} .5463 \mathrm{~K} 295 \star^{*} 5.8 \mathrm{~s}$

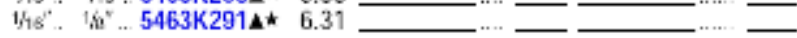

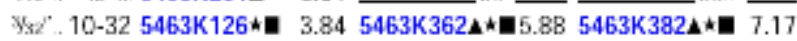

$3 z_{32}{ }^{\prime}, 1 \mathrm{~g}^{*} \ldots 5463 \mathrm{~K} 294 \star \ldots 6.52$

$1,8^{\prime} \ldots 10-325463 K 127 \star \square 3.84 \overline{5463 K 373 * \square \overline{6.67}} \overline{5463 K 363 \star} * \overline{7.81}$

$1,6{ }^{\star} \ldots{ }^{1 / 66^{*}} .5463 \mathrm{~K} 297 \star \ldots 6.10$

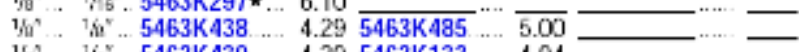

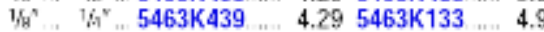

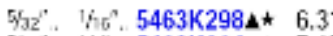

$5 / 32^{*}, 1 \mathrm{~g}^{*}+5463 \mathrm{~K} 364 \mathrm{~A}^{*} 7.17$

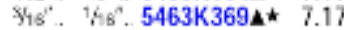

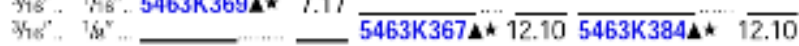

$1 / 4^{\prime}-1 \mathrm{~g}^{\mathrm{v}} \quad 5463 \mathrm{~K} 442 \quad 4.295463 \mathrm{~K} 487 \quad 5.005463 \mathrm{~K} 532 \quad 5.00$

$1 / 4^{4} \ldots 1 / 4^{v} \ldots 5463 \mathrm{~K} 445 \ldots . .24 .295463 \mathrm{~K} 489 \ldots . .5 .005463 \mathrm{~K} 534 \ldots \ldots .5 .00$

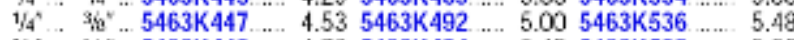

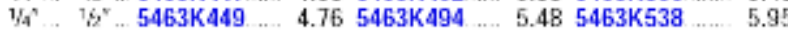

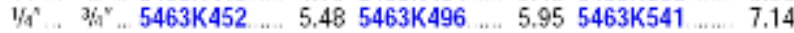

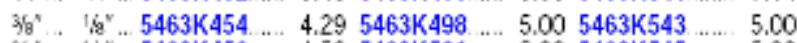

$56{ }^{*} \ldots 1 / 4{ }^{*} \ldots 5463 \mathrm{~K} 456 \ldots . . .4 .535463 \mathrm{~K} 501 \ldots . .5 .005463 \mathrm{~K} 545 \ldots . .5 .00$

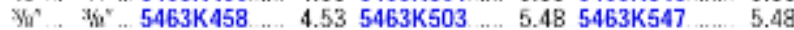

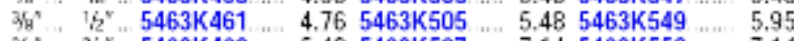

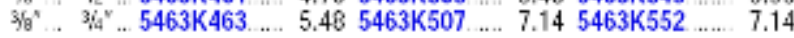

$1 / 2^{*} \ldots 1 / 4^{*} \ldots 5463 K 465 \ldots . .5435463 K 509 \ldots .5 .005463 K 554 \ldots \ldots .5 .48$

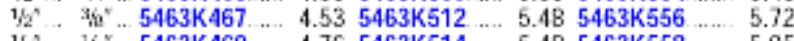

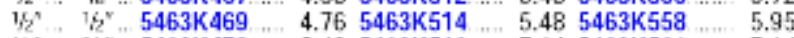

$1 / 2^{n} \ldots 34^{2} \ldots 5463 K 472 \ldots .4 .48 \quad 5463 K 516 \ldots .7 .145463 K 561 \ldots .7 .14$

$5 / 8^{*} \ldots 1 / 2^{2} \ldots 5463 \mathrm{~K} 474 \ldots . . .465463 \mathrm{~K} 518 \ldots .6 .19$

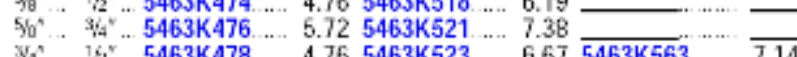

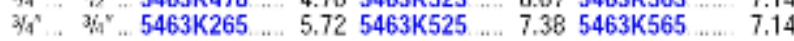

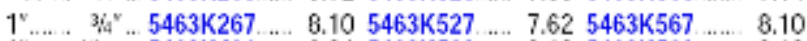

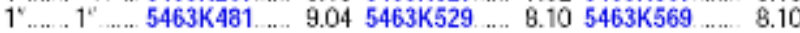

* Orrered in opaque black only. - Pipe connections are UNF straight screw thread. Max. pressure is 125 psi $\oplus 72^{\circ} \mathrm{F}$.
Single-barbed fittings minimize leaks by having a smoother sealing surface than multi-barbed fittings. They're made of nylon for durability and impact and abrasion resistance. Sterilization: Steam (autoclave). Not rated for vacuum. Pipe connections are NPT unless noted. Package quantity is 10 roOrdera Please specify semiclear (translucent) white or opaque black (except where noted).

Tube-to-Tube

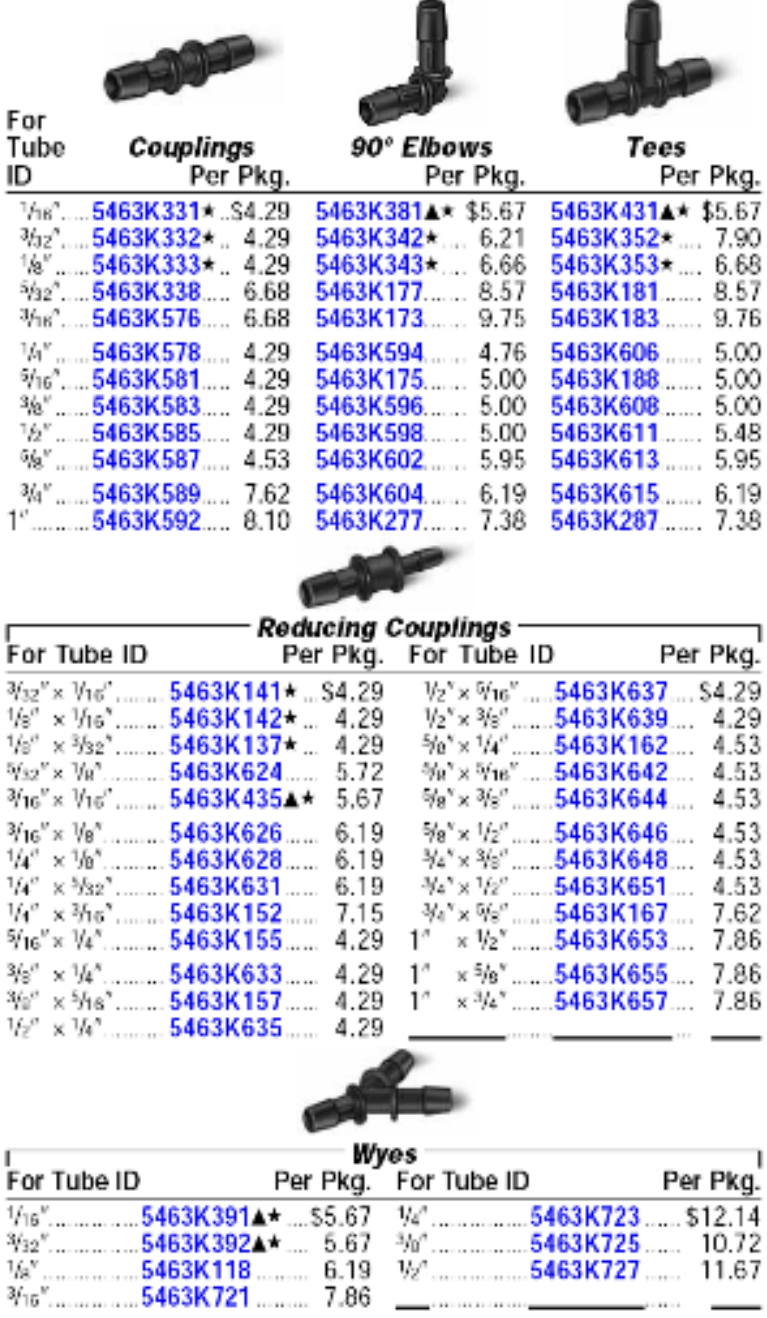




\section{$\underline{\text { Circulation Heater Specifications }}$}

\section{Model: CBEC23J10-X-X}

\begin{tabular}{|c|c|}
\hline Element Type & $11 / 4$ inches NPT Screw Plug-WATROD Element \\
\hline Heater Type & Watrod \\
\hline Heater Diameter- in & 1.25 \\
\hline $\begin{array}{l}\text { Watt Density W/in. }{ }^{2} \\
\left(\mathrm{~W} / \mathrm{cm}^{2}\right)\end{array}$ & $60(9.3)$ \\
\hline Power (kW) & 5 \\
\hline Volts & 240 \\
\hline Est. Net Wt. - Ibs (kg) & $29(14)$ \\
\hline Dimension A- in (mm) & $325 / 8(829)$ \\
\hline Dimension B- in (mm) & $23(584)$ \\
\hline Dimension C- in (mm) & $3(76)$ \\
\hline Phase & 1-Phase \\
\hline Terminal Enclosure Type & $\begin{array}{l}S=\text { General purpose with thermostat (NEMA 1) } \\
W=\text { Moisture resistant (NEMA 4) } \\
E=\text { Explosion resistant (NEMA 7) } \\
\text { E } W=\text { Explosion/moisture resistant (NEMA 7/4) }\end{array}$ \\
\hline Thermostat or Thermocouple & $\begin{array}{l}1 \text { = On-off Temp Control Single Pole Single Throw (SPST) } \\
2 \text { = On-off Temp Control Single Pole Single Throw (SPST) } \\
\text { 2A = On-off Temp Control Single Pole Single Throw (SPST) } \\
3 \text { = On-off Temp Control Single Pole Single Throw (SPST) } \\
\text { 3A = On-off Temp Control Single Pole Single Throw (SPST) } \\
10=\text { On-off Temp Control Single Pole Single Throw (SPST) } \\
12 \text { A = On-off Temp Control Single Pole Single Throw (SPST) } \\
4=\text { On-off Temp Control Double Pole Single Throw (DPST) } \\
5 \text { = On-off Temp Control Double Pole Single Throw (DPST) } \\
5 \text { A = On-off Temp Control Double Pole Single Throw (DPST) } \\
7 \text { = On-off Temp Control Double Pole Single Throw (DPST) } \\
7 \text { A = On-off Temp Control Double Pole Single Throw (DPST) } \\
8=\text { On-off with manual Reset (DPST) } \\
9=\text { On-off with manual Reset (DPST) } \\
11=\text { On-off with manual Reset (SPST) }\end{array}$ \\
\hline Tank Material & Steel \\
\hline Sheath Material & 2-Copper \\
\hline Sheath Temperature & $350(175) \circ \mathrm{F}$ \\
\hline
\end{tabular}


$\underline{\text { Strip Heater Specifications }}$

\section{Moisture-Resistant Strip Heaters}

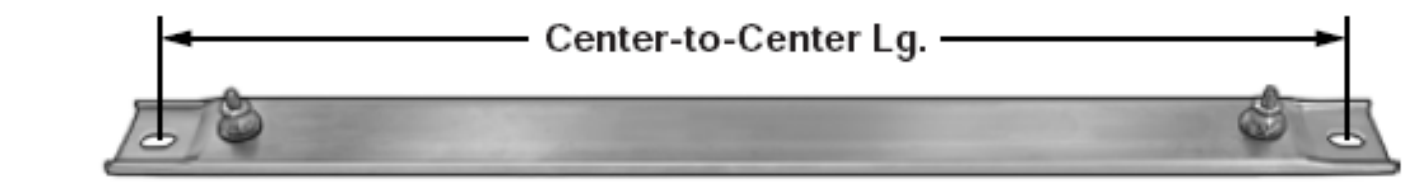

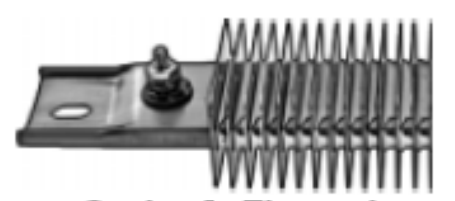

Style A Finned

Style A Channel

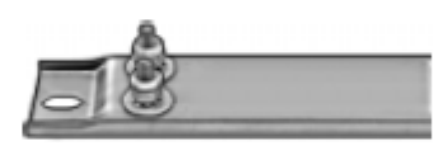

Style B Channel

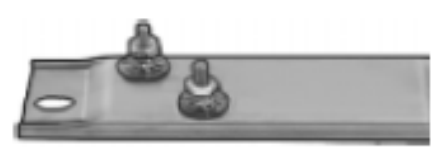

Style C Channel

Ceramic insulation encased in a seamless Type 304 stainless steel sheath gives these heaters moisture resistance and high heat output. Maximum heat output is $1200^{\circ} \mathrm{F}$. All are single phase. Size is $11 / 2^{\prime \prime}$ Wd. $\times 5 / 16^{\prime \prime}$ Thick. Heaters have two $1 / 2^{\prime \prime} \mathrm{Lg} . \times 5 / 16^{\prime \prime}$ Wd. mounting slots and two $5 / 8^{\prime \prime}$ high stainless steel stud and nut terminals with 10-32 threads. Choose from three different terminal configurations. Note: Heaters should be used with a temperature controller (see 7981K on page 544).

\section{Finned Strip Heaters}

The fins provide a large surface area for excellent heat dissipation in forced-air heating equipment. Mount in ducts and at the bottom of cabinet-type ovens for air heating and food warming. Fins are nickelplated steel and $2^{\prime \prime} \mathrm{Wd} . \times 13 / 8^{\prime \prime} \mathrm{Ht}$. UL recognized. To Ordera Please specify terminal configuration style $(A, B$, or $C)$ shown above.

\begin{tabular}{|c|c|c|c|c|c|c|c|c|}
\hline lat & $\begin{array}{l}\text { Г Wat } \\
\text { Style }\end{array}$ & $\begin{array}{l}\text { tts/sq } \\
\text { Style } \\
\text { B }\end{array}$ & $\begin{array}{l}\text { in. } 7 \\
\text { Style } \\
\text { C }\end{array}$ & Amps & O'all & Fin & $\begin{array}{l}\text { Ctr.- } \\
\text { to- } \\
\text { Ctr. La }\end{array}$ & Each \\
\hline
\end{tabular}

240 VAC

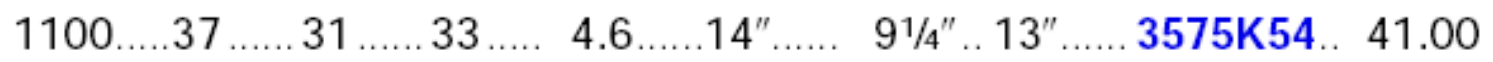

- For Style B, fin length is approx. ${ }^{3 / 4^{\prime \prime}}$ longer. 


\section{$\underline{\text { SCR Specifications }}$}

Model \# SCR19Z-24-040

\section{Specifications}

Supply Voltage: 24 to $600 \mathrm{Vac}$

Frequency: 50 to $60 \mathrm{~Hz}$

Current Rating: 40, 60, and $80 \mathrm{~A}$

Control Signal Isolation:

2500 Vac

Transient Voltage Protection:

MOV and RC suppression

Ambient Temperature Range:

0 to $50^{\circ} \mathrm{C}\left(32\right.$ to $\left.122^{\circ} \mathrm{F}\right)$ for listed

current rating

Load: Resistive, 3-phase, 3 wire

Delta or Ungrounded Wye SCR19Z/

SCR19P -1 phase, 1 line control

SCR39Z -3 phase, 2 lines controlled

SCR39P -3 phase, 3 lines controlled

Diagnostic Indicators:

Shorted or open SCR reversed

signal input (mA/V)

\begin{tabular}{|c|c|c|c|c|c|c|c|}
\hline Model No. & Price & Model No. & Price & Model No. & Price & $\begin{array}{c}\text { Wt. } \\
\text { kg (lib.) }\end{array}$ & $\begin{array}{l}\text { Current } \\
\text { (amps) }\end{array}$ \\
\hline \multicolumn{2}{|c|}{120 V Single Phase } & \multicolumn{2}{|c|}{240 V Single Phase } & \multicolumn{2}{|l|}{480 Single Phase } & & \\
\hline SCR19Z-12-040 & $\$ 249$ & SCR19Z-24-040 & $\$ 249$ & SCR19Z-48-040 & $\$ 266$ & $1.4(3)$ & 40 \\
\hline
\end{tabular}




\section{Zero Voltage}
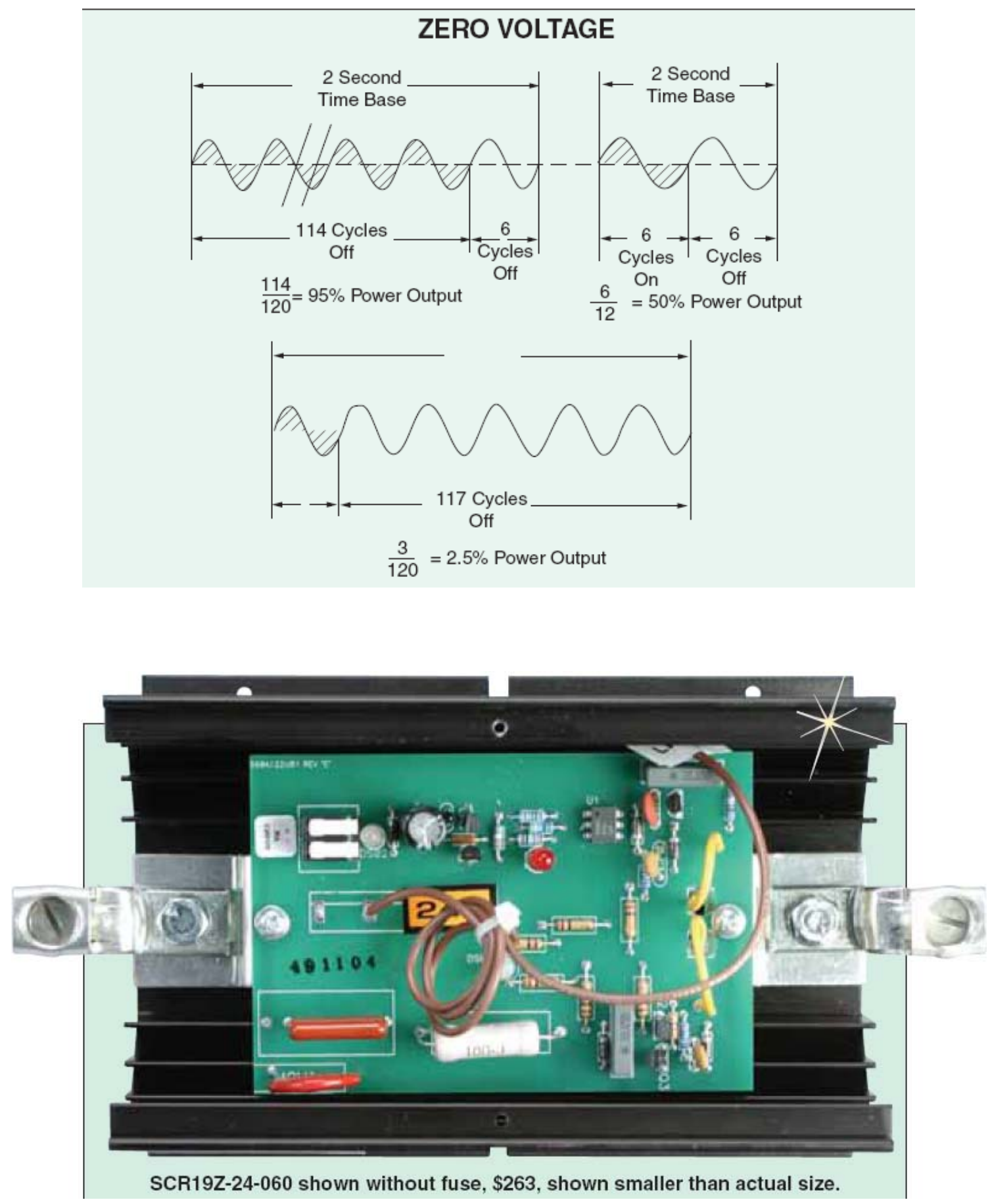


\section{Laminar Flow Element Specifications}

\begin{tabular}{|c|c|c|c|}
\hline Model Number \& Description & Pipe Size & $\begin{array}{c}\text { NPT tapered } \\
\text { thread }\end{array}$ \\
\hline \hline & $\begin{array}{l}\text { 50MC2 Aluminum housing for } \\
\text { low pressure applications. Inlet } \\
\text { and outlet are for hose type } \\
\text { connections. Differential pressure } \\
\text { connections 1/4" hose barb. }\end{array}$ & $\begin{array}{l}\text { 2 T.D. } \\
\text { 6 T.D. }\end{array}$ & 50MC2-2 \\
80MC2-4 & 50MC2-6 \\
\hline
\end{tabular}

\begin{tabular}{|c|c|c|c|c|c|c|c|}
\hline \multicolumn{2}{|c|}{$\begin{array}{l}\text { Nominal Air Flow Range } \\
\left(29.92^{\prime \prime} \mathrm{Hg} \text {. Abs. \& } 70^{\circ} \mathrm{F}\right)\end{array}$} & \multirow{2}{*}{$\begin{array}{l}\text { Max. DP } \\
\text { In. } \mathrm{H}_{2} \mathrm{O}\end{array}$} & \multirow[b]{2}{*}{ Pipe Size } & \multicolumn{3}{|c|}{$\begin{array}{c}\text { Nominal Air Flow Range } \\
\left.760 \mathrm{MM} \mathrm{Hg} \text {. Abs. \& } 21.1^{\circ} \mathrm{C}\right)\end{array}$} & \multirow{2}{*}{$\begin{array}{l}\text { Max DP } \\
\mathrm{MM} \mathrm{H}_{2} \mathrm{O}\end{array}$} \\
\hline SCFM* & PPM & & & CC/MIN* & LPM $^{*}$ & $\mathrm{Kg} / \mathrm{M}$ & \\
\hline 2250 & 168 & $8^{\prime \prime}$ & 8"ID. & $6.37 \times 10^{7}$ & 63700 & 76.3 & 203.2 \\
\hline
\end{tabular}




\section{Power Supply Specifications}

\section{Model: HP 6012b}

\section{Power Supplies}

Single-Output Autoranging: $200 \mathrm{~W}$ to $1000 \mathrm{~W}$

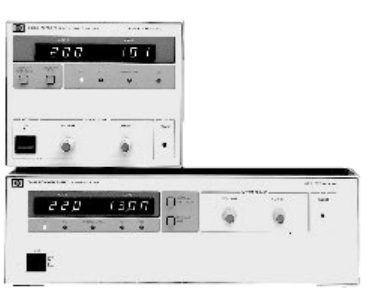

Above:HP 6023A, HP 6028A

Below:HP 6010A, 6011A, 6012A and 6015A

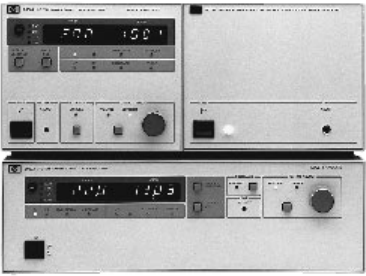

Above:HP 6033A and HP 6031A(0ption 001 on right) Below:HP 6030A, 6031A, 6032A, and 6035A

Abbreviated Specifications and Characteristics

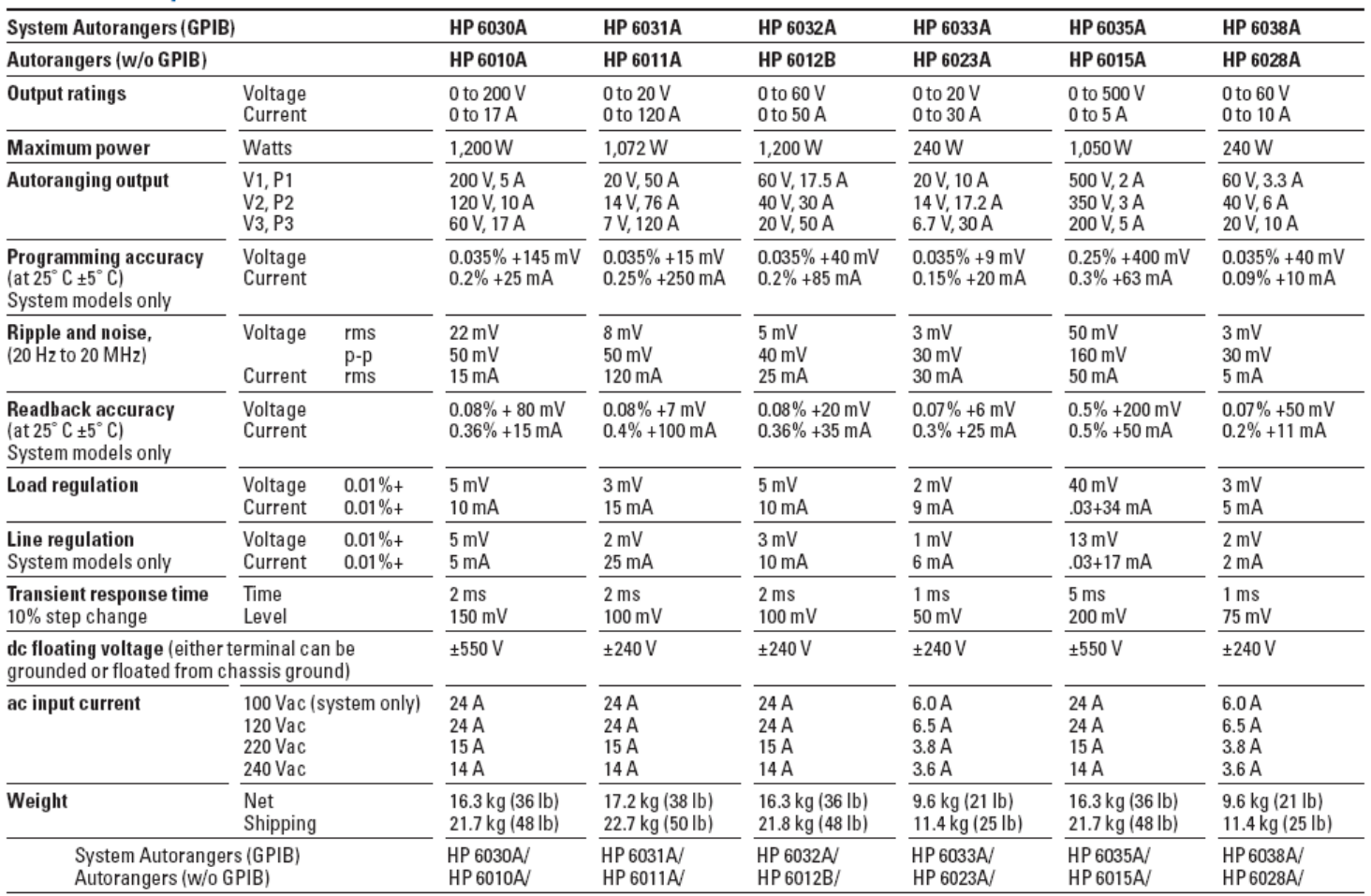

Remote Sensing: Up to $2 \mathrm{~V}$ drop in each lead. Voltage regulation degrades for greater than $0.5 \mathrm{~V}$ drop.

Regulatory Compliance: Listed to UL-1244; certified to CSA 556B; complies with EN 61010-1, carries the CE mark

RFI Suppression: Complies with CISPR-11, Group 1, Class A Inductive Load: HP 6023A, 6028A are stable in CC mode for loads up to 1 H. HP 6010A-6012B, 6015A are stable in CC mode for loads up to $100 \mathrm{mH}$. Size:

HP 6030A-32A, 6035A: $425.5 \mathrm{~mm} \mathrm{~W} \times 132.6 \mathrm{~mm} \mathrm{H} \times 503.7 \mathrm{~mm}$ D (16.75 in $\times 5.25$ in $\times 19.83$ in)

HP 6033A, 6038A, 6023A, 6028A: $212.3 \mathrm{~mm} \mathrm{~W}$ x $177.0 \mathrm{~mm} \mathrm{H}$ x $516.4 \mathrm{~mm}$ D ( 8.36 in $\times 6.97$ in $\times 17.87$ in).

HP 6010A-12B, 6015A: $425.5 \mathrm{~mm}$ W x $132.6 \mathrm{~mm} \mathrm{H}$ x $516.4 \mathrm{~mm}$ D $(16.75$ in $\times 5.25$ in $\times 20.33$ in).
Opt 002 Provides extra programming and monitoring capabilities (HP 6010A-12B, 6023A, 6028A only) Opt 10087 to $106 \mathrm{Vac}, 48$ to $63 \mathrm{~Hz}$ (power supply output is derated to $75 \%$ ) HP $6030 \mathrm{~A}-33 \mathrm{~A}, 6035 \mathrm{~A}, 6038 \mathrm{~A}$ only Opt 220191 to $233 \mathrm{Vac}, 48$ to $63 \mathrm{~Hz}$ Opt 240209 to $250 \mathrm{Vac}, 48$ to $63 \mathrm{~Hz}$

Opt 800 Rackmount Kit for Two Half-rack Units Side by Side. HP p/n 5061-9694 and 5062-3978 Opt 908 Rackmount Kit for a Single Half-rack Unit HP Models 6023A, 6028A, 6033A and 6038A (with blank filler panel); HP p/n 5062-3960 HP Models 6010A-12B, 6015A, 6030A-32A and 6035A; $\mathrm{HP}$ p/n 5062-3977

Opt 909 Rackmount Kit with Handles. For HP 6010A-12B. 


\section{Model: GPS-Series (Digital)}

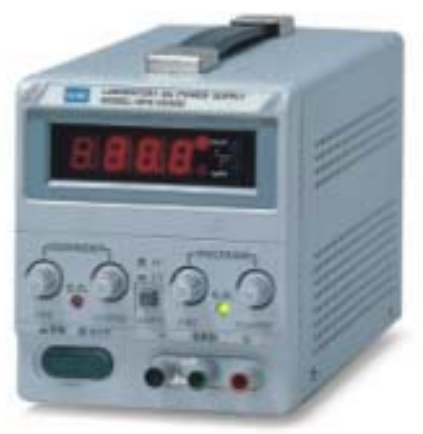

GPS-SERIES

(DIGITAL TYPE)

* Light and Compact Design

* $0.01 \%$ High Regulation

* Constant Voltage and Constant Current Operation

* Series or Parallel Operation Function
* Remote Control by External Voltage

* Internal Select for Continuous or Dynamic Load

* Low Ripple and Noise

* Overload and Reverse Polarity protection

\begin{tabular}{|c|c|c|}
\hline \multicolumn{3}{|c|}{ SPECIFICATIONS } \\
\hline $\begin{array}{l}\text { CONSTANT } \\
\text { VOLTAGE } \\
\text { OPERATION }\end{array}$ & $\begin{array}{l}\text { Regulation } \\
\text { Ripple \& Noise } \\
\text { Recovery Time } \\
\text { Temp. Coefficient } \\
\text { Output Range }\end{array}$ & $\begin{array}{l}\text { Line regulation } \leq 0.01 \%+3 \mathrm{mV} \\
\text { Load regulation } \leq 0.01 \%+3 \mathrm{mV} \text { (rating current } \leq 3 \mathrm{~A}) \\
\leq \leq 0.01 \%+5 \mathrm{mV} \text { (rating current }>3 \mathrm{~A}) \\
\leq 0.5 \mathrm{mVrms} 5 \mathrm{~Hz} \sim 1 \mathrm{MHz} \text { (rating current } \leq 3 \mathrm{~A}) \\
\leq 1 \mathrm{mVrms} 5 \mathrm{~Hz} \sim 1 \mathrm{MHz} \text { (rating current }>3 \mathrm{~A}) \\
\leq 100 \mu \mathrm{S}(50 \% \text { Load change, Minimum load } 0.5 \mathrm{~A}) \\
\leq 300 \mathrm{ppm} /{ }^{\circ} \mathrm{C} \\
0 \text { to rating voltage continuously adjustable }\end{array}$ \\
\hline $\begin{array}{l}\text { CONSTANT } \\
\text { CURRENT } \\
\text { OPERATION }\end{array}$ & $\begin{array}{l}\text { Regulation } \\
\text { Ripple Current } \\
\text { Output Range }\end{array}$ & $\begin{array}{l}\text { Line regulation } \leq 0.2 \%+3 \mathrm{~mA} \\
\text { Load regulation } \leq 0.2 \%+3 \mathrm{~mA} \\
\leq 3 \mathrm{mArms} \\
0 \text { to rating current continuously adjustable ( } \mathrm{Hi} / \text { Lo range switchable ) }\end{array}$ \\
\hline METER & Analog & $\begin{array}{l}\text { V-meter and I-meter each one } \\
2.5 \text { class } \\
\text { Dimensions } 50 \times 50 \mathrm{~mm} \\
31 / 2 \text { digits } 0.5^{\prime \prime} \text { LED display } \\
31 / 2 \text { digits } 0.39^{\prime \prime} \text { LED display (for GPS-3030DD) } \\
\text { Accuracy }+(0.5 \% \text { of rdg + } 2 \text { digits ) }\end{array}$ \\
\hline INSULATION & $\begin{array}{l}\text { Chassis and Terminal } \\
\text { Chassis and AC Cord }\end{array}$ & $\begin{array}{l}20 \mathrm{M} \Omega \text { or above }(\text { DC } 500 \mathrm{~V}) \\
30 \mathrm{M} \Omega \text { or above }(\text { DC } 500 \mathrm{~V})\end{array}$ \\
\hline POWER SOURCE & & $\mathrm{AC} 100 \mathrm{~V} / 120 \mathrm{~V} / 220 \mathrm{~V} / 240 \mathrm{~V} \pm 10 \%, 50 / 60 \mathrm{~Hz}$ \\
\hline ACCESSORIES & & $\begin{array}{l}\text { Power cord } \times 1 \text {, Instruction manual x } 1 \\
\text { Test lead GTL-105 x } 1(\leq 3 \mathrm{~A}) \text { or GTL-104 } \times 1(\leq 10 \mathrm{~A})\end{array}$ \\
\hline DIMENSIONS & & $128(\mathrm{~W}) \times 145(\mathrm{H}) \times 285(\mathrm{D}) \mathrm{mm}$ \\
\hline
\end{tabular}

\begin{tabular}{|c|c|c|c|c|}
\hline & Model & Output Volts(V) & Output Amps(A) & Weight (kg) \\
\hline \multirow{4}{*}{ Analog } & GPS-1830 & $0 \sim 18$ & $0 \sim 3$ & $\mathbf{4}$ \\
\cline { 2 - 5 } & GPS-1850 & $0 \sim 18$ & $0 \sim 5$ & 5.5 \\
\cline { 2 - 5 } & GPS-3030 & $0 \sim 30$ & $0 \sim 3$ & $\mathbf{5}$ \\
\cline { 2 - 5 } & GPS-6010 & $0 \sim 60$ & $0 \sim 1$ & 4 \\
\hline \multirow{4}{*}{ Digital } & GPS-1830D & $0 \sim 18$ & $0 \sim 3$ & $\mathbf{5}$ \\
\cline { 2 - 5 } & GPS-1850D & $0 \sim 18$ & $0 \sim 5$ & $\mathbf{5}$ \\
\cline { 2 - 5 } & GPS-3030D & $0 \sim 30$ & $0 \sim 3$ & $\mathbf{5}$ \\
\cline { 2 - 5 } & GPS-3030DD & $0 \sim 30$ & $0 \sim 3$ & \\
\hline
\end{tabular}


Flow Meter Specifications

Model: 2300ABR

\section{SPECIFICATIONS}

Accuracy: $\pm 2 \%$ full scale

Repeatability: $\pm 1 \%$

Dimensions: $48 \times 43 \mathrm{~mm}$

$\left(1.9 \times 1.7^{\prime \prime}\right)$ for $116^{\circ} \mathrm{C}\left(240^{\circ} \mathrm{F}\right)$ units

Length: $121 \mathrm{~mm}\left(4.75^{\prime \prime}\right)$ for $116^{\circ} \mathrm{C}$ $\left(240^{\circ} \mathrm{F}\right)$ units; $168 \mathrm{~mm}\left(6.6^{\prime \prime}\right)$ for $204^{\circ} \mathrm{C}\left(400^{\circ} \mathrm{F}\right)$ units

Max. Pressure: 241.3 bar (3500 psig) Max. Temperature:

$116^{\circ} \mathrm{C}\left(240^{\circ} \mathrm{F}\right)$ std.; $204^{\circ} \mathrm{C}\left(400^{\circ} \mathrm{F}\right)$ at $124 \mathrm{bar}$ (1800 psig) max., opt.

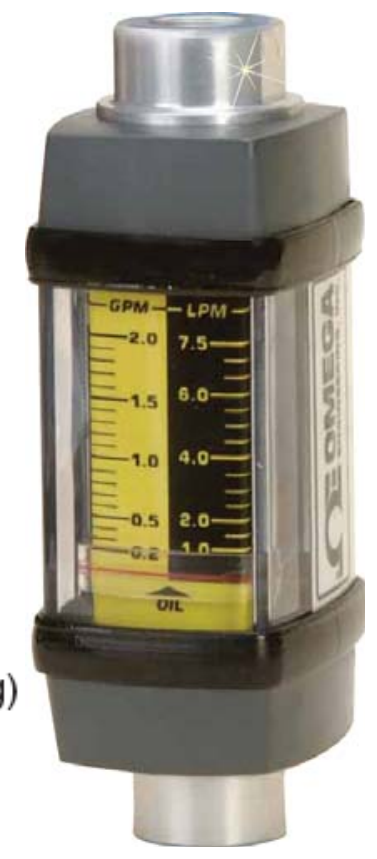

\section{FL-2100A}

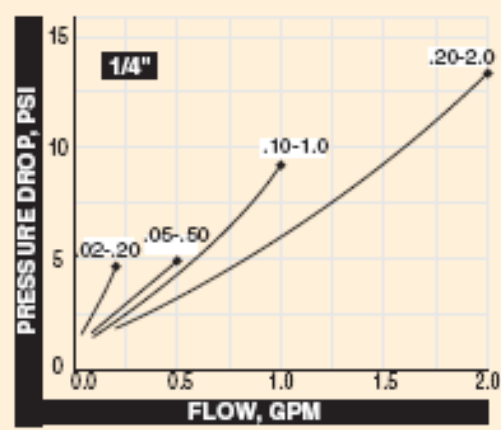

Note: Calibrated with 140 SUS (32 cSt) Hydraulic Oil

\section{FL-2300AB}

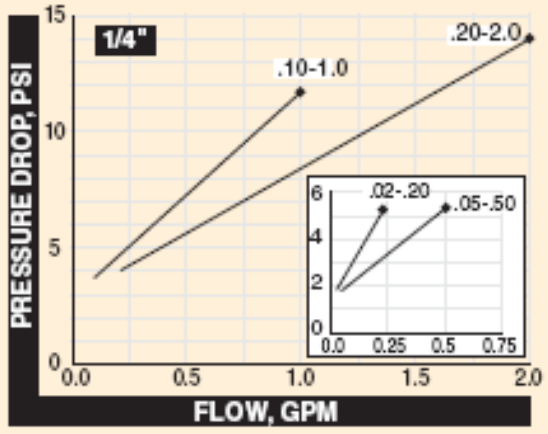

Note: Calibrated with Water

Pressure Drop: Approximate pressure losses in flowmeters using oil at normal temperatures. Add $10 \%$ to pressure for equal water flows.

\begin{tabular}{|l|r|c|c|} 
Model No. & Price & $\begin{array}{c}\text { Flow Range } \\
\text { (GPM) }\end{array}$ & $\begin{array}{c}\text { Medium/Specific } \\
\text { Gravity }\end{array}$ \\
\hline FL-2300ABR & 172 & 0.05 to 0.5 & Water/1.0
\end{tabular}


Model: 6302ABR

\section{SPECIFICATIONS}

Accuracy: $\pm 2 \%$ Full Scale

Repeatability: $\pm 1 \%$

Connection: $1 / 2$ " FNPT

Dimensions: $60.96 \times 53.34 \mathrm{~mm}$

$\left(2.4 \times 2.1^{\prime \prime}\right)$ for $116^{\circ} \mathrm{C}\left(240^{\circ} \mathrm{F}\right)$ units Length: $168 \mathrm{~mm}$ (6.6") for all units

Max. Pressure: 241.3 bar (3500 psig)

Max. Temp: $116^{\circ} \mathrm{C}\left(240^{\circ} \mathrm{F}\right)$

standard, $204^{\circ} \mathrm{C}\left(400^{\circ} \mathrm{F}\right)$ optional

Shipping Weight:

Oil: $0.57 \mathrm{~kg}(1.25 \mathrm{lb})$

Water: $1.18 \mathrm{~kg}(2.60 \mathrm{lb})$

Wetted Parts: 302 SS (oil units) or 302 SS spring (water units), $V$ iton $^{\oplus}$ O-rings, polyphenylene sulfide/ceramic magnetic. Oil units have aluminum body, water units have brass body.
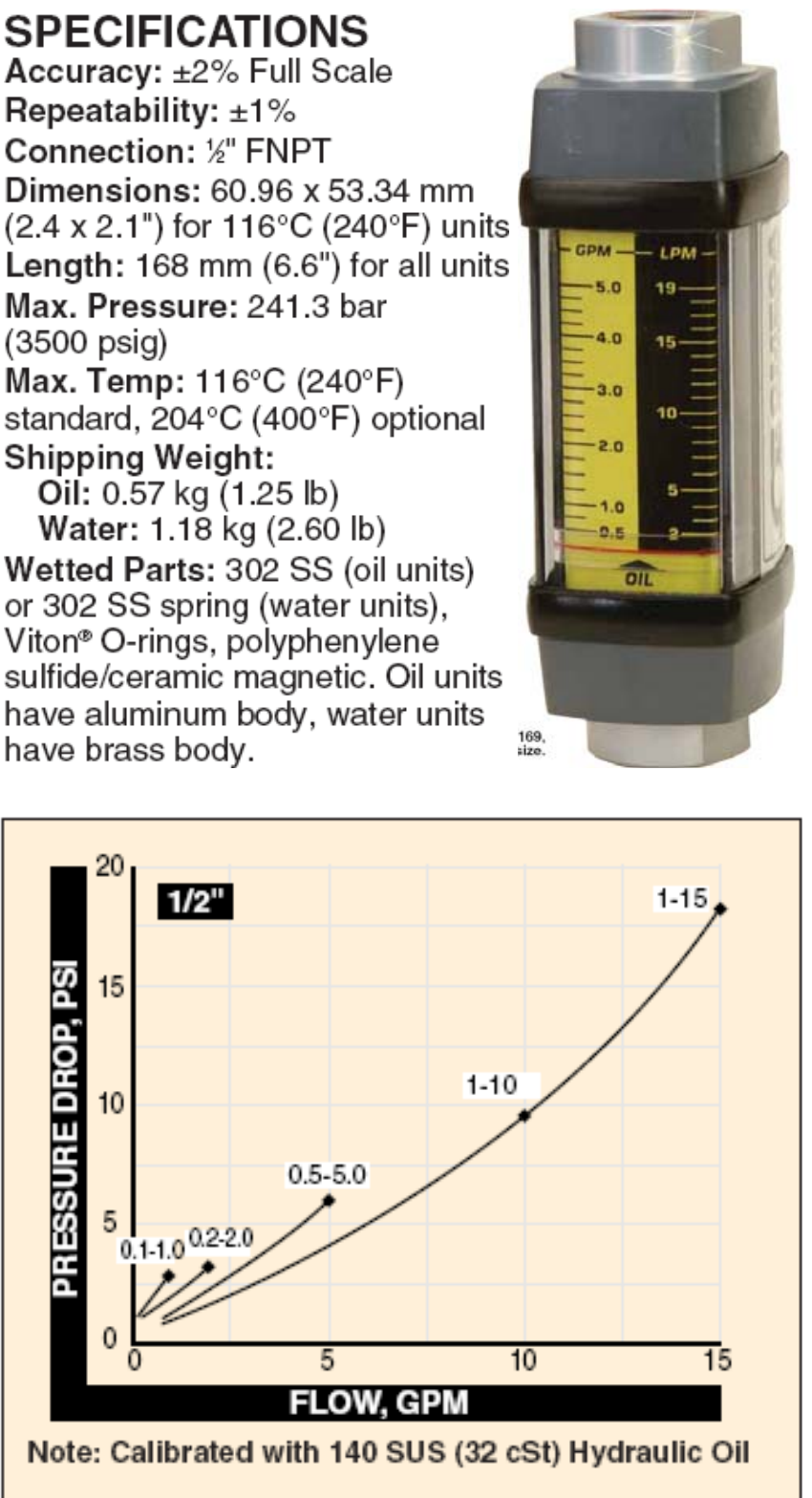

Pressure Drop: Approximate pressure losses in meters using oil at low and normal temperatures. Add $10 \%$ to pressure for equal water flows.

\begin{tabular}{|l|r|c|c|} 
Model No. & Price & Flow Range (GPM) & Medium/Specific Gravity \\
\hline FL-6302ABR & 201 & 0.2 to 2.0 & Water/1.0
\end{tabular}




\section{Appendix D}

Raw Data 
Table 27. Data acquisition thermocouple temperature readings during testing with calculated

properties for system water and air

\begin{tabular}{|c|c|c|c|c|c|c|c|c|c|}
\hline Measurement & \multicolumn{9}{|c|}{ Test } \\
\hline Test Number & 1 & 2 & 3 & 4 & 5 & 6 & 7 & 8 & 9 \\
\hline Fan and Liquid Flow Adjustments & $\begin{array}{l}100 \% \\
\text { Duty }\end{array}$ & $75 \%$ Duty & $\mathbf{5 0} \%$ Duty & $25 \%$ Duty & $\begin{array}{c}75 \% \\
\text { Liquid } \\
100 \% \text { Fan }\end{array}$ & $\begin{array}{c}50 \% \\
\text { Liquid } \\
100 \% \text { Fan }\end{array}$ & $\begin{array}{c}75 \% \\
\text { Liquid } \\
75 \% \text { Fan }\end{array}$ & $\begin{array}{l}100 \% \\
\text { Duty }\end{array}$ & $75 \%$ Duty \\
\hline Total Liquid Flow Rate [gpm] & 1.09 & 1.09 & 1.10 & 1.02 & 0.82 & 0.55 & 0.82 & 1.10 & 1.11 \\
\hline Fan Speed [rpm] & 7260 & 6630 & 5400 & 4170 & 7200 & 7200 & 6570 & 7230 & 6990 \\
\hline \multicolumn{10}{|l|}{\begin{tabular}{|l} 
Water Temepratures \\
\end{tabular}} \\
\hline HX outlet_water $\left[{ }^{\circ} \mathrm{C}\right]$ & 41.58 & 45.32 & 48.52 & 57.43 & 44.18 & 43.79 & 46.47 & 44.35 & 44.92 \\
\hline Circ Heater outlet_water $\left[{ }^{\circ} \mathrm{C}\right]$ & 51.86 & 58.08 & 60.49 & 71.88 & 58.34 & 60.97 & 60.11 & 57.00 & 57.35 \\
\hline Test board outlet_water [ $\left.{ }^{\circ} \mathrm{C}\right]$ & 53.38 & 57.07 & 60.70 & 70.00 & 57.19 & 61.54 & 59.81 & 56.24 & 56.85 \\
\hline Test board inlet_water [ $\left.{ }^{\circ} \mathrm{C}\right]$ & 41.51 & 45.26 & 48.43 & 57.33 & 44.18 & 43.76 & 46.42 & 44.28 & 44.86 \\
\hline Average Temperature $\left[{ }^{\circ} \mathrm{C}\right]$ & 46.72 & 51.70 & 54.50 & 64.66 & 51.26 & 52.38 & 53.29 & 50.67 & 51.13 \\
\hline Specific Heat $[\mathrm{kJ} / \mathrm{kg}-\mathrm{K}]$ & 4.1814 & 4.1820 & 4.1834 & 4.1887 & 4.1819 & 4.1823 & 4.1827 & 4.1819 & 4.1819 \\
\hline Density $[\mathrm{kg} / \mathrm{m} 3]$ & 989.03 & 987.16 & 985.66 & 980.13 & 987.32 & 986.81 & 986.32 & 987.54 & 987.37 \\
\hline Board Volumetric Flow Rate $[\mathrm{m} 3 / \mathrm{s}]$ & $6.69 \mathrm{E}-06$ & $6.69 \mathrm{E}-06$ & $6.81 \mathrm{E}-06$ & $5.83 \mathrm{E}-06$ & $5.83 \mathrm{E}-06$ & $3.75 \mathrm{E}-06$ & 5.67E-06 & $7.5 \mathrm{E}-06$ & $7.66 \mathrm{E}-06$ \\
\hline Circulation Heater Volumetric Flow Rate [m3/s] & $6.21 \mathrm{E}-05$ & $6.23 \mathrm{E}-05$ & $6.25 \mathrm{E}-05$ & $5.83 \mathrm{E}-05$ & $4.58 \mathrm{E}-05$ & $3.1 \mathrm{E}-05$ & $4.58 \mathrm{E}-05$ & $6.16 \mathrm{E}-05$ & $6.25 \mathrm{E}-05$ \\
\hline Total Volumetric Flow Rate $[\mathrm{m} 3 / \mathrm{s}]$ & $6.88 \mathrm{E}-05$ & $6.9 \mathrm{E}-05$ & $6.93 \mathrm{E}-05$ & $6.41 \mathrm{E}-05$ & $5.17 \mathrm{E}-05$ & $3.47 \mathrm{E}-05$ & $5.15 \mathrm{E}-05$ & $6.91 \mathrm{E}-05$ & $7.01 \mathrm{E}-05$ \\
\hline Total Mass Flow Rate $[\mathrm{kg} / \mathrm{s}]$ & 0.068076 & 0.068134 & 0.068341 & 0.062851 & 0.051011 & 0.034292 & 0.050795 & 0.06826 & 0.069233 \\
\hline \multicolumn{10}{|l|}{ Spcecial Temperatures } \\
\hline Q1 heater $\left[{ }^{\circ} \mathrm{C}\right]$ & 568.97 & 569.83 & 573.13 & 565.51 & 567.85 & 569.00 & 570.83 & 573.35 & 573.64 \\
\hline Q1 block $\left[{ }^{\circ} \mathrm{C}\right]$ & 61.61 & 65.32 & 69.64 & 79.98 & 65.16 & 69.45 & 67.65 & 64.19 & 65.04 \\
\hline $\mathrm{S} 2$ block $\left[{ }^{\circ} \mathrm{C}\right]$ & 53.98 & 57.75 & 61.80 & 73.18 & 57.71 & 63.24 & 60.60 & 57.27 & 58.24 \\
\hline PCB BB2 $\left[{ }^{\circ} \mathrm{C}\right]$ & 64.47 & 68.45 & 73.47 & 85.60 & 68.24 & 72.02 & 71.63 & 67.75 & 68.77 \\
\hline \multicolumn{10}{|l|}{ Cold Plate Temperatures } \\
\hline $\mathrm{cpDC}$ bottom $\left[{ }^{\circ} \mathrm{C}\right]$ & 69.97 & 72.94 & 69.40 & 74.44 & 74.13 & 73.82 & 77.30 & 62.32 & 64.01 \\
\hline $\operatorname{cpDC}$ outlet $\left[{ }^{\circ} \mathrm{C}\right]$ & 64.45 & 67.88 & 71.17 & 78.13 & 67.90 & 72.45 & 71.39 & 64.71 & 65.54 \\
\hline cpBB1 bottom $\left[{ }^{\circ} \mathrm{C}\right]$ & 58.22 & 59.12 & 67.12 & 79.88 & 60.68 & 62.89 & 68.41 & 59.97 & 60.71 \\
\hline cpBB1 outlet $\left[{ }^{\circ} \mathrm{C}\right]$ & 57.88 & 59.13 & 65.21 & 75.54 & 60.93 & 66.65 & 64.07 & 59.43 & 60.29 \\
\hline cpBB2 bottom $\left[{ }^{\circ} \mathrm{C}\right]$ & 47.90 & 50.75 & 53.99 & 63.88 & 50.70 & 59.74 & 53.78 & 53.54 & 54.52 \\
\hline cpBB2 outlet $\left[{ }^{\circ} \mathrm{C}\right]$ & 53.82 & 57.84 & 62.02 & 72.57 & 57.70 & 64.02 & 60.54 & 57.43 & 58.41 \\
\hline cpTC bottom $\left[{ }^{\circ} \mathrm{C}\right]$ & 60.57 & 63.93 & 64.79 & 75.43 & 62.14 & 67.93 & 62.59 & 63.08 & 64.48 \\
\hline cpTC outlet $\left[{ }^{\circ} \mathrm{C}\right]$ & 56.68 & 60.02 & 63.41 & 73.27 & 59.88 & 64.63 & 62.16 & 60.64 & 61.95 \\
\hline \multicolumn{10}{|l|}{ Air Temperatures } \\
\hline Cabinet in & 28.54 & 29.88 & 29.61 & 33.32 & 31.61 & 32.43 & 33.10 & 29.96 & 29.84 \\
\hline Fan outlet_air $\left[{ }^{\circ} \mathrm{C}\right]$ & 43.04 & 47.00 & 50.50 & 60.34 & 46.40 & 45.80 & 48.73 & 46.15 & 46.77 \\
\hline Test board mid_air [ [ $\mathrm{C}]$ & 36.34 & 38.86 & 40.79 & 45.33 & 40.05 & 41.10 & 42.13 & 39.57 & 39.31 \\
\hline Test board end_air $\left[{ }^{\circ} \mathrm{C}\right]$ & 37.00 & 39.35 & 42.00 & 51.27 & 40.15 & 40.71 & 42.66 & 36.16 & 36.45 \\
\hline Test board outlet_air [ $\left.{ }^{\circ} \mathrm{C}\right]$ & 40.69 & 43.73 & 46.86 & 56.36 & 44.53 & 45.94 & 46.97 & 42.21 & 42.76 \\
\hline $\mathrm{HX}$ outlet_air_test board $\left[{ }^{\circ} \mathrm{C}\right]$ & 45.92 & 50.41 & 54.73 & 64.78 & 49.49 & 49.61 & 52.33 & 49.24 & 50.00 \\
\hline Dummy board outlet_air [ $\left.{ }^{\circ} \mathrm{C}\right]$ & 56.67 & 61.43 & 70.02 & 88.29 & 60.66 & 61.18 & 64.62 & 59.38 & 60.97 \\
\hline HX outlet_air_strip heaters $\left[{ }^{\circ} \mathrm{C}\right]$ & 48.98 & 53.36 & 57.30 & 67.63 & 52.93 & 53.19 & 55.50 & 52.27 & 53.03 \\
\hline Average Temperature $\left[{ }^{\circ} \mathrm{C}\right]$ & 35.79 & 38.44 & 40.05 & 46.83 & 39.00 & 39.12 & 40.92 & 38.05 & 38.31 \\
\hline Specific Heat $[\mathrm{kJ} / \mathrm{kg}-\mathrm{K}]$ & 1.006 & 1.006 & 1.006 & 1.006 & 1.006 & 1.006 & 1.006 & 1.006 & 1.006 \\
\hline Density $[\mathrm{kg} / \mathrm{m} 3]$ & 1.1421 & 1.1324 & 1.1266 & 1.1046 & 1.1304 & 1.1299 & 1.1235 & 1.1357 & 1.1348 \\
\hline Volumetric Flow Rate $[\mathrm{m} 3 / \mathrm{s}]$ & 0.4886 & 0.4606 & 0.3650 & 0.2691 & 0.4990 & 0.4989 & 0.4682 & 0.4976 & 0.4712 \\
\hline Mass Flow Rate $[\mathrm{kg} / \mathrm{s}]$ & 0.5580 & 0.5216 & 0.4112 & 0.2973 & 0.5641 & 0.5637 & 0.5260 & 0.5651 & 0.5347 \\
\hline \multicolumn{10}{|l|}{ Test Chip Temperatures } \\
\hline $\mathrm{P} 1 \mathrm{P}\left[{ }^{\circ} \mathrm{C}\right]$ & 65.71 & 69.10 & 69.97 & 80.55 & 67.35 & 72.63 & 68.07 & 69.76 & 70.91 \\
\hline $\mathrm{P} 2 \mathrm{P}\left[{ }^{\circ} \mathrm{C}\right]$ & 66.80 & 70.21 & 71.02 & 81.55 & 68.37 & 73.66 & 68.96 & 71.08 & 72.25 \\
\hline $\mathrm{P} 3 \mathrm{P}\left[{ }^{\circ} \mathrm{C}\right]$ & 66.33 & 69.70 & 70.74 & 81.07 & 68.03 & 73.25 & 68.51 & 70.20 & 71.47 \\
\hline $\mathrm{P} 6 \mathrm{P}\left[{ }^{\circ} \mathrm{C}\right]$ & 65.93 & 69.33 & 70.22 & 80.68 & 67.55 & 72.77 & 68.05 & 70.00 & 71.21 \\
\hline $\mathrm{P} 2 \mathrm{~S}\left[{ }^{\circ} \mathrm{C}\right]$ & 91.01 & 94.22 & 95.36 & 105.25 & 92.88 & 98.73 & 93.40 & 102.00 & 103.61 \\
\hline P4AS [ $\left.{ }^{\circ} \mathrm{C}\right]$ & 84.52 & 87.78 & 88.96 & 98.93 & 86.49 & 92.28 & 87.49 & 93.89 & 95.24 \\
\hline $\mathrm{P} 6 \mathrm{~S}\left[{ }^{\circ} \mathrm{C}\right]$ & 91.12 & 94.32 & 95.47 & 105.24 & 92.97 & 98.74 & 93.33 & 102.01 & 103.65 \\
\hline $\mathrm{P} 7 \mathrm{~S}\left[{ }^{\circ} \mathrm{C}\right]$ & 89.89 & 93.13 & 93.95 & 101.62 & 91.53 & 97.48 & 91.99 & 100.55 & 101.62 \\
\hline
\end{tabular}


Table 28. Circulation heater power measurements for various PWM input control currents

\begin{tabular}{|c|c|c|c|}
\hline $\begin{array}{c}\text { PWM } \\
\text { Control } \\
\text { Current } \\
\text { (mA) }\end{array}$ & $\begin{array}{c}\text { Avg. } \\
\text { Voltage } \\
\text { (V) }\end{array}$ & $\begin{array}{c}\text { Avg. } \\
\text { Current } \\
\text { (A) }\end{array}$ & $\begin{array}{c}\text { Power } \\
\text { (W) }\end{array}$ \\
\hline $\mathbf{4 . 9 9}$ & 14 & 3.3 & $\mathbf{4 6}$ \\
\hline $\mathbf{8 . 0 2}$ & 55 & 4.0 & $\mathbf{2 2 0}$ \\
\hline $\mathbf{1 2 . 0 1}$ & 88 & 7.3 & $\mathbf{6 4 2}$ \\
\hline $\mathbf{1 6 . 0 0}$ & 131 & 11.4 & $\mathbf{1 4 9 3}$ \\
\hline $\mathbf{1 8 . 2 1}$ & 158 & 13.8 & $\mathbf{2 1 8 0}$ \\
\hline $\mathbf{2 0 . 0 0}$ & 197.9 & 17.4 & $\mathbf{3 4 4 3}$ \\
\hline
\end{tabular}

${ }^{* *}$ REMAINED STEADY AT MAX PMW

CONTROL CURRENT

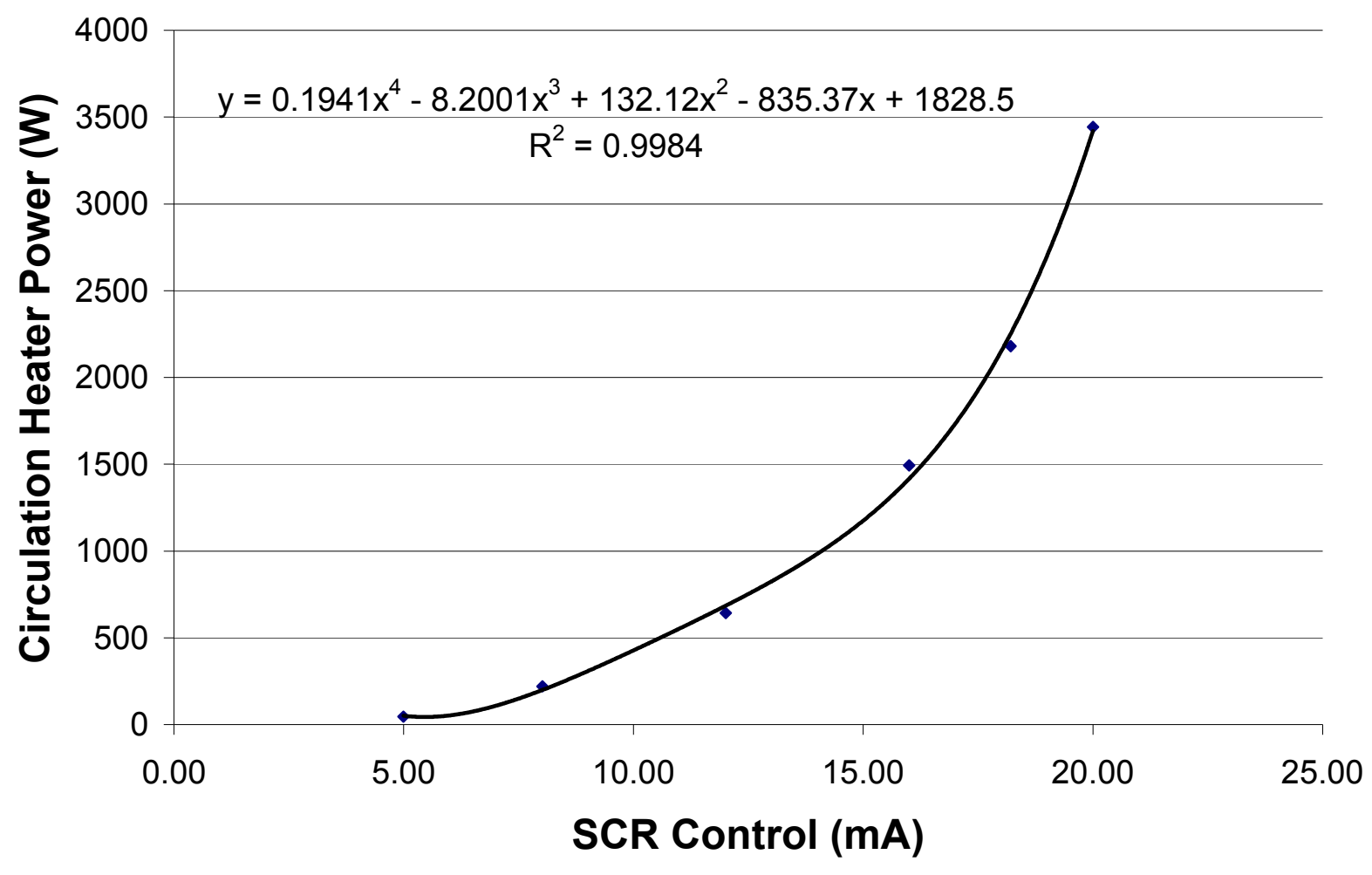

- Circulation Heater Power — Poly. (Circulation Heater Power)

Figure 48. Circulation heater power for different PWM control currents 
Table 29. Test Chip cold plate thermocouple preliminary test data

\begin{tabular}{|c|c|c|c|c|c|c|c|}
\hline Date & $3 / 1 / 2007$ & $3 / 2 / 2007$ & $3 / 3 / 2007$ & $3 / 4 / 2007$ & $3 / 5 / 2007$ & $3 / 6 / 2007$ & $3 / 7 / 2007$ \\
\hline Time & 4:30pm & 4:40pm & 4:50pm & 5:00pm & 5:30pm & 6:00pm & $6: 25 \mathrm{pm}$ \\
\hline Test Conditions & Fans Blower Pumps & Strip Heaters 16mA & Girc. Heater 17.3mA & Testboard 15V \&7.5V & Testboard20V\&10V & Testboard22V\& $10.33 \mathrm{~V}$ & $50 \%$ Duty Same Testboard \\
\hline HXoutlet water (Mean) & 24.61 & 30.68 & 35.97 & 38.03 & 38.92 & 40.03 & 43.54 \\
\hline Grc Heater outlet water & 24.37 & 30.37 & 4251 & 45.01 & 45.75 & 47.11 & 50.36 \\
\hline Test board outlet water & 24.34 & 29.20 & 33.75 & 4297 & 48.83 & 51.80 & 55.83 \\
\hline Test Board inlet water & 24.59 & 30.21 & 35.86 & 37.94 & 38.82 & 39.97 & 43.39 \\
\hline S2Blodk(Mean) & 24.58 & 28.42 & 3210 & 4270 & 50.44 & 54.66 & 57.25 \\
\hline Q1 Heater (Mean) & 24.51 & 28.61 & 3256 & 218.93 & 289.55 & 421.72 & 425.79 \\
\hline Cabinet inlet air (Mean) & 24.98 & 26.11 & 27.69 & 28.49 & 28.99 & 29.70 & 29.14 \\
\hline opDCbottom(Mean) & 24.50 & 28.45 & 3273 & 5205 & 65.54 & 67.38 & 73.65 \\
\hline cpDC outlet (Mean) & 24.54 & 28.49 & 3227 & 49.47 & 60.83 & 63.22 & 69.81 \\
\hline cpBB1 bottom(Mean) & 24.43 & 28.84 & 3299 & 44.44 & 52.84 & 56.73 & 64.56 \\
\hline cpBB1 autlet (Mean) & 23.02 & 28.11 & 31.20 & 41.88 & 54.73 & 49.89 & 60.63 \\
\hline cpBB2 bottom (Mean) & 22.61 & 26.37 & 30.83 & 4208 & 51.50 & 57.01 & 57.13 \\
\hline cpBB2 autlet (Mean) & 22.48 & 28.81 & 3277 & 40.75 & 51.63 & 55.03 & 57.17 \\
\hline cpTCcenter (Mean) & 24.46 & 29.45 & 34.11 & 44.71 & 51.62 & 55.45 & 59.01 \\
\hline cpTC inlet (Mean) & 24.47 & 29.38 & 33.94 & 39.86 & 43.49 & 45.66 & 49.25 \\
\hline cpTCleft comer (Mean) & 24.54 & 29.72 & 34.47 & 41.54 & 45.89 & 48.50 & 51.60 \\
\hline cpTCright comer & 24.44 & 29.07 & 33.43 & 43.94 & 50.88 & 54.53 & 58.56 \\
\hline cpTC bottom(Mean) & 24.23 & 29.23 & 33.85 & 44.33 & 51.20 & 54.98 & 58.40 \\
\hline cpTCoutlet (Mean) & 24.32 & 29.01 & 33.38 & 4229 & 48.08 & 51.46 & 55.04 \\
\hline Dummy Board outlet air & 24.71 & 43.35 & 45.81 & 47.15 & 47.46 & 48.63 & 56.71 \\
\hline HXoutlet air test board & 24.55 & 31.51 & 37.07 & 40.09 & 41.57 & 43.04 & 47.49 \\
\hline Fan outlet air (Mean) & 25.67 & 32.26 & 37.78 & 39.84 & 40.57 & 41.82 & 45.00 \\
\hline Air Flow end (Mean) & 24.41 & 25.83 & 27.55 & 34.29 & 38.87 & 41.91 & 45.85 \\
\hline Q1 Block (Mean) & 24.37 & 28.34 & 3213 & 46.61 & 56.13 & 60.35 & 65.32 \\
\hline P1P(Mean) & 24.94 & 30.09 & 34.85 & 5218 & 63.78 & 69.54 & 72.71 \\
\hline P2P(Mean) & 25.03 & 30.24 & 35.06 & 53.40 & 65.78 & 71.93 & 75.00 \\
\hline P3P(Mean) & 25.03 & 30.19 & 34.97 & 5234 & 63.99 & 69.77 & 72.85 \\
\hline P4AP (Mean) & 25.14 & 30.33 & 35.13 & 51.37 & 62.18 & 67.60 & 70.77 \\
\hline P1S(Mean) & 25.01 & 29.89 & 34.49 & 49.74 & 60.14 & 65.51 & 69.20 \\
\hline P2S(Mean) & 25.17 & 30.10 & 34.74 & 51.13 & 62.41 & 68.16 & 71.80 \\
\hline P3S(Mean) & 24.92 & 29.82 & 34.45 & 49.56 & 59.87 & 65.18 & 68.78 \\
\hline P4AS (Mean) & 24.97 & 29.88 & 34.50 & 49.86 & 60.31 & 65.67 & 69.38 \\
\hline
\end{tabular}


Table 30. Test Chip temperature sensor preliminary data

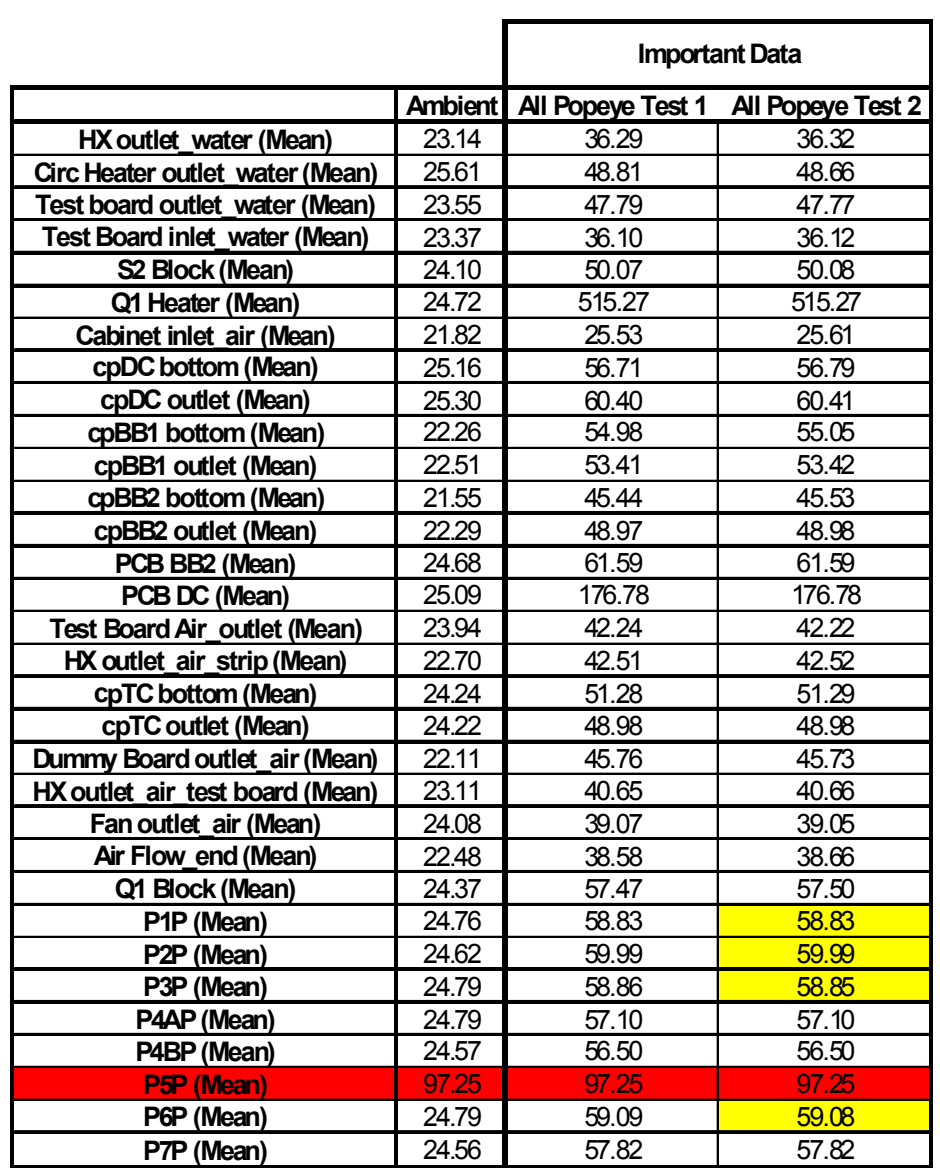

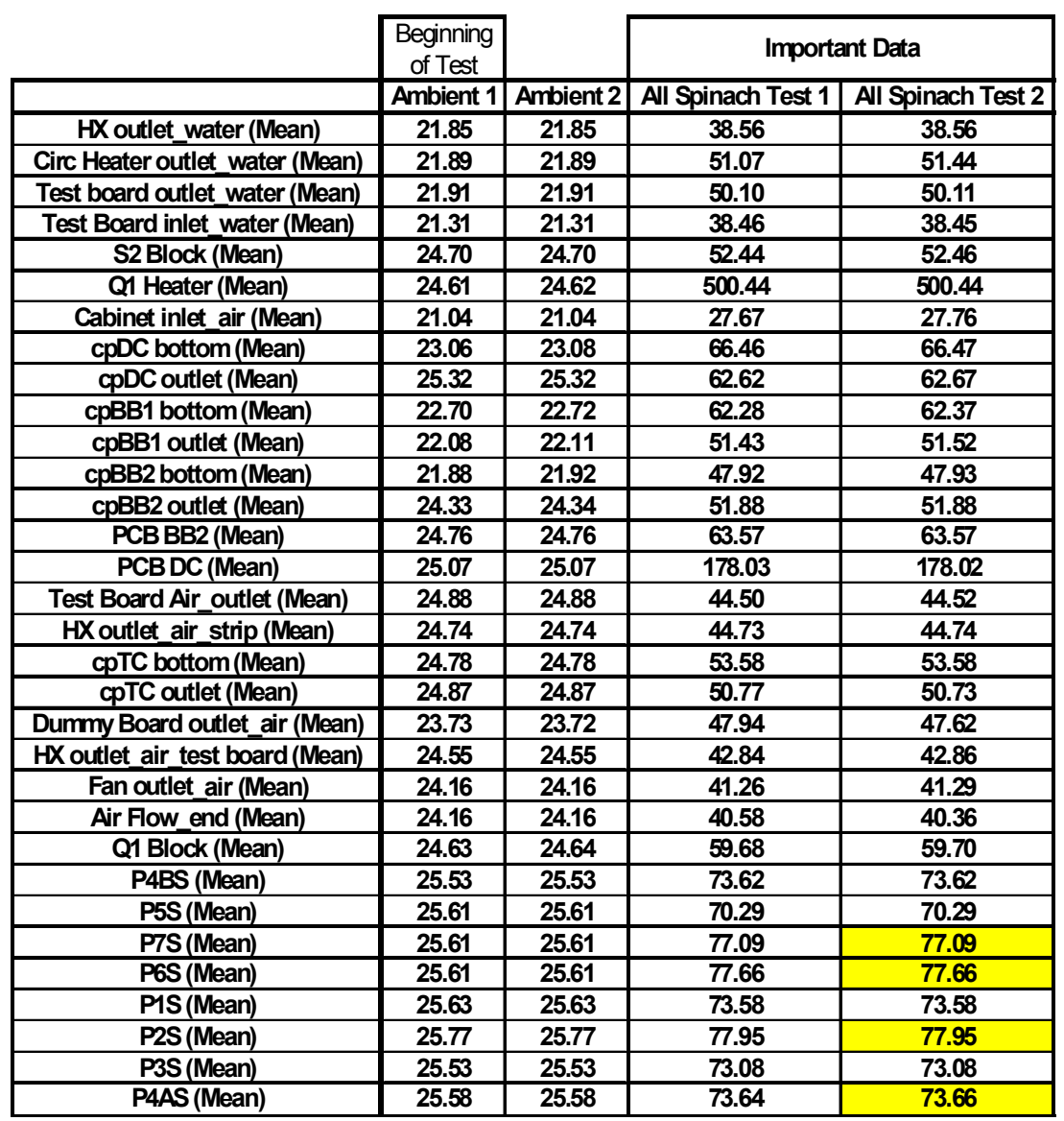




\begin{tabular}{|c|c|c|}
\hline Date & March 10th & 2007 \\
\hline Start Time & $2: 15$ & $\mathrm{pm}$ \\
\hline Ambient Temp. & 26.20 & ${ }^{\circ} \mathrm{C}$ \\
\hline Barometer Pressure & 29.91 & $\mathrm{inHg}$ \\
\hline \multicolumn{2}{|c|}{ Comments: Fans running at $100 \%$ duty cycle }
\end{tabular}

\begin{tabular}{|c|c|c|c|c|c|c|c|}
\hline Device & Voltage & & Current & & Power & & \\
\hline Top Power Supply Display & 23.00 & [V] & 40.80 & {$[\mathrm{~A}]$} & 938.40 & {$[\mathrm{~W}]$} & \\
\hline Top Power Supply Rear & 23.00 & [V] & & & & & \\
\hline Bottom Power Supply Display & 10.65 & {$[\mathrm{~V}]$} & 30.60 & {$[\mathrm{~A}]$} & 325.89 & {$[\mathrm{~W}]$} & \\
\hline Bottom Power Supply Rear & 10.65 & [V] & & & & & \\
\hline N4 & 26.00 & {$[\mathrm{~V}]$} & 2.27 & {$[\mathrm{~A}]$} & 59.02 & & \\
\hline N3 & 26.00 & [V] & 1.61 & {$[\mathrm{~A}]$} & 41.86 & & Power Comparison \\
\hline Ciculation Heater & 114.00 & {$[\mathrm{~V}]$} & 12.30 & {$[\mathrm{~A}]$} & 2229.86 & {$[\mathrm{~W}]$} & 3323.67 \\
\hline Strip Heaters & 198.10 & [V] & 25.30 & {$[\mathrm{~A}]$} & 5011.93 & {$[\mathrm{~W}]$} & 6656.00 \\
\hline
\end{tabular}

\begin{tabular}{|c|c|c|}
\hline Device & Reading & Units \\
\hline Low Flow Meter & 0.106 & {$[\mathrm{gpm}]$} \\
\hline High Flow Meter & 0.99 & {$[\mathrm{gpm}]$} \\
\hline LFE Manometer & 3.69 & {$\left[\mathrm{inH}_{2} \mathrm{O}\right]$} \\
\hline Cabinet Inlet & 0.31 & {$\left[\mathrm{inH}_{2} \mathrm{O}\right]$} \\
\hline Before HX & 0.57 & {$\left[\mathrm{inH}_{2} \mathrm{O}\right]$} \\
\hline After HX & 1.13 & {$\left[\mathrm{inH}_{2} \mathrm{O}\right]$} \\
\hline After Fans & 0.93 & {$\left[\mathrm{inH}_{2} \mathrm{O}\right]$} \\
\hline Circulation Heater & 18.16 & {$[\mathrm{~mA}]$} \\
\hline Strip Heaters & 20.00 & {$[\mathrm{~mA}]$} \\
\hline Fan Speed & 242.00 & {$[\mathrm{~Hz}]$} \\
\hline
\end{tabular}

0.35

\begin{tabular}{|c|c|c|c|c|c|c|c|c|c|}
\hline Terminal Blocks & Voltage & & Current (Black) & & & Power (black) & & Total Power & \\
\hline Main Bus & 22.60 & {$[\mathrm{~V}]$} & & & & & & & \\
\hline Popeye Test (N3\&N4) & 26.00 & {$[\mathrm{~V}]$} & 10.40 & {$[\mathrm{~A}]$} & 3 & 90.13 & {$[\mathrm{~W}]$} & \multirow{6}{*}{753.66} & \multirow{6}{*}{ 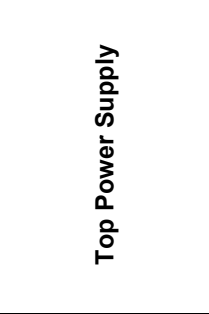 } \\
\hline $20 \mathrm{~V} 1$ (Top) & 22.50 & {$[\mathrm{~V}]$} & 18.20 & {$[\mathrm{~A}]$} & 3 & 136.50 & {$[\mathrm{~W}]$} & & \\
\hline 20V2 (Bottom) & 22.50 & {$[\mathrm{~V}]$} & 20.20 & {$[\mathrm{~A}]$} & 4 & 113.63 & {$[\mathrm{~W}]$} & & \\
\hline Popeye Heater (Q) & 14.36 & [V] & 38.80 & {$[\mathrm{~A}]$} & 2 & 278.58 & {$[\mathrm{~W}]$} & & \\
\hline Spinach Test (M3\&M4) & 17.71 & {$[\mathrm{~V}]$} & 9.70 & {$[\mathrm{~A}]$} & 4 & 42.95 & {$[\mathrm{~W}]$} & & \\
\hline $15 \mathrm{~V}$ & 15.44 & {$[\mathrm{~V}]$} & 23.80 & {$[\mathrm{~A}]$} & 4 & 91.87 & {$[\mathrm{~W}]$} & & \\
\hline Spinach Heater/Main Bus (S) & 10.35 & {$[\mathrm{~V}]$} & 57.90 & {$[\mathrm{~A}]$} & 4 & 149.82 & {$[\mathrm{~W}]$} & \multirow{5}{*}{294.57} & \multirow{5}{*}{ 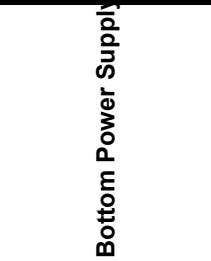 } \\
\hline 10V1 (Top) & 10.32 & {$[\mathrm{~V}]$} & 6.20 & {$[\mathrm{~A}]$} & 4 & 16.00 & {$[\mathrm{~W}]$} & & \\
\hline 10V2 (Top) & 10.32 & [V] & 7.40 & {$[\mathrm{~A}]$} & 4 & 19.09 & {$[\mathrm{~W}]$} & & \\
\hline 10V3 (Bottom) & 10.27 & {$[\mathrm{~V}]$} & 46.30 & {$[\mathrm{~A}]$} & 5 & 95.10 & {$[\mathrm{~W}]$} & & \\
\hline \multirow[t]{2}{*}{$5 \mathrm{~V}$} & 5.23 & {$[\mathrm{~V}]$} & 19.50 & {$[\mathrm{~A}]$} & 7 & 14.57 & {$[\mathrm{~W}]$} & & \\
\hline & & & & & & & & 1048.23 & Test Board Total \\
\hline
\end{tabular}




\begin{tabular}{|c|c|c|}
\hline Date & March 10th & 2007 \\
\hline Start Time & $2: 45$ & $\mathrm{pm}$ \\
\hline Ambient Temp. & 28.80 & ${ }^{\circ} \mathrm{C}$ \\
\hline Barometer Pressure & 29.91 & $\mathrm{inHg}$ \\
\hline
\end{tabular}

\begin{tabular}{|c|c|c|c|c|c|c|c|}
\hline Device & Voltage & & Current & & Power & & \\
\hline Top Power Supply Display & 23.00 & [V] & 40.80 & {$[\mathrm{~A}]$} & 938.40 & {$[\mathrm{~W}]$} & \\
\hline Top Power Supply Rear & 23.00 & [V] & & & & & \\
\hline Bottom Power Supply Display & 10.66 & {$[\mathrm{~V}]$} & 30.60 & {$[\mathrm{~A}]$} & 326.20 & {$[\mathrm{~W}]$} & \\
\hline Bottom Power Supply Rear & 10.66 & [V] & & & & & \\
\hline N4 & 26.00 & {$[\mathrm{~V}]$} & 2.24 & {$[\mathrm{~A}]$} & 58.24 & & \\
\hline N3 & 26.00 & [V] & 1.59 & {$[\mathrm{~A}]$} & 41.34 & & Power Comparison \\
\hline Ciculation Heater & 114.00 & {$[\mathrm{~V}]$} & 15.90 & {$[\mathrm{~A}]$} & 2353.98 & {$[\mathrm{~W}]$} & 3380.00 \\
\hline Strip Heaters & 198.00 & [V] & 24.60 & {$[\mathrm{~A}]$} & 4870.80 & {$[\mathrm{~W}]$} & 6656.00 \\
\hline
\end{tabular}

\begin{tabular}{|c|c|c|}
\hline Device & Reading & Units \\
\hline Low Flow Meter & 0.106 & [gpm] \\
\hline High Flow Meter & 0.99 & {$[\mathrm{gpm}]$} \\
\hline LFE Manometer & 3.50 & {$\left[\mathrm{inH}_{2} \mathrm{O}\right]$} \\
\hline Cabinet Inlet & 0.28 & {$\left[\mathrm{inH}_{2} \mathrm{O}\right]$} \\
\hline Before HX & 0.51 & {$\left[\mathrm{inH}_{2} \mathrm{O}\right]$} \\
\hline After $\mathrm{HX}$ & 0.94 & {$\left[\mathrm{inH}_{2} \mathrm{O}\right]$} \\
\hline After Fans & 0.75 & {$\left[\mathrm{inH}_{2} \mathrm{O}\right]$} \\
\hline Circulation Heater & 18.40 & {$[\mathrm{~mA}]$} \\
\hline Strip Heaters & 20.00 & {$[\mathrm{~mA}]$} \\
\hline Fan Speed & 221.00 & {$[\mathrm{~Hz}]$} \\
\hline
\end{tabular}

0.31

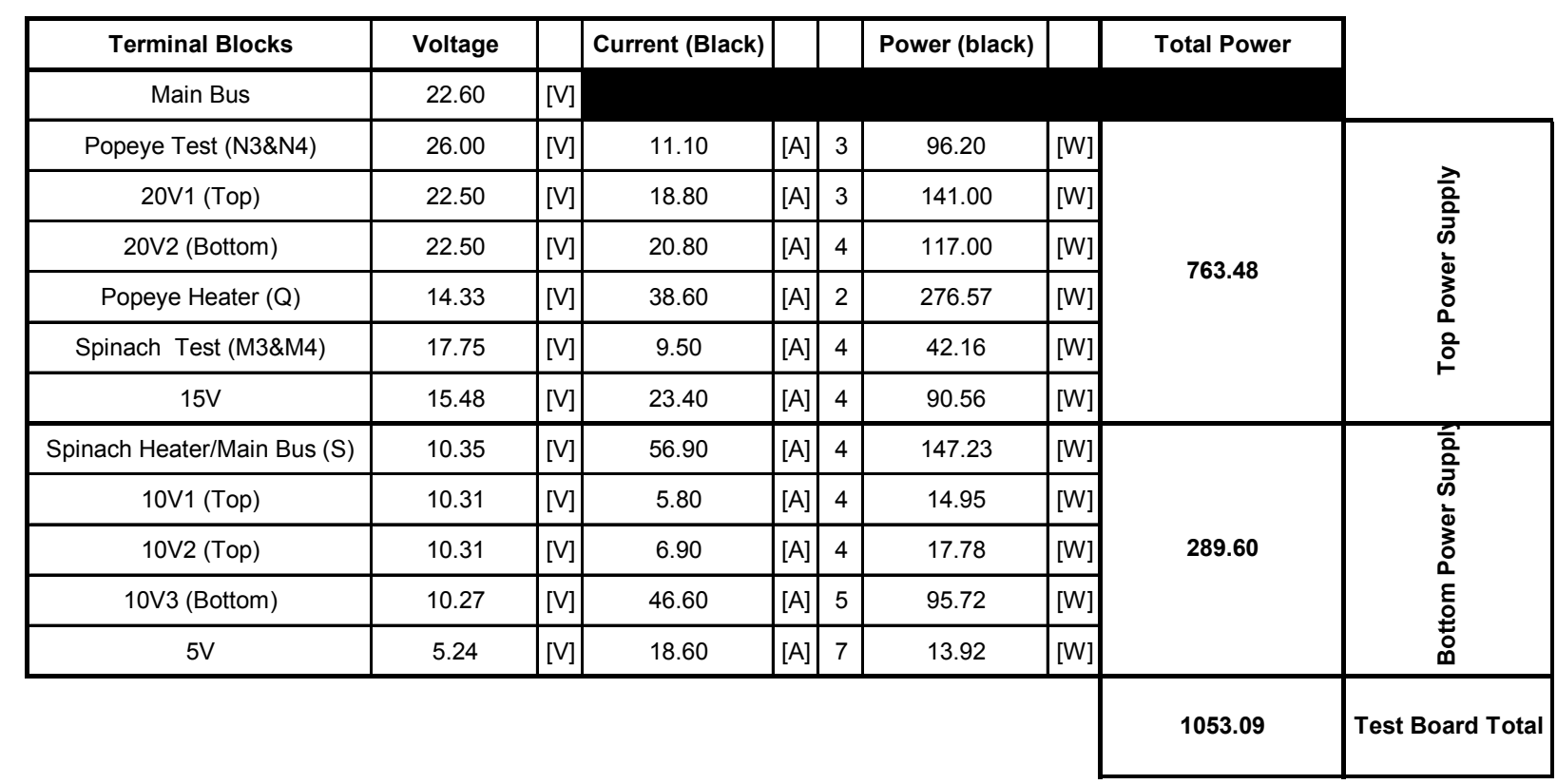




\begin{tabular}{|c|c|c|}
\hline Date & March 10th & 2007 \\
\hline Start Time & $3: 00$ & $\mathrm{pm}$ \\
\hline Ambient Temp. & 30.00 & ${ }^{\circ} \mathrm{C}$ \\
\hline Barometer Pressure & 29.91 & $\mathrm{inHg}$ \\
\hline
\end{tabular}

\begin{tabular}{|c|c|c|c|c|c|c|c|}
\hline Device & Voltage & & Current & & Power & & \\
\hline Top Power Supply Display & 23.00 & [V] & 40.80 & {$[\mathrm{~A}]$} & 938.40 & {$[\mathrm{~W}]$} & \\
\hline Top Power Supply Rear & 23.00 & [V] & & & & & \\
\hline Bottom Power Supply Display & 10.66 & {$[\mathrm{~V}]$} & 30.60 & {$[\mathrm{~A}]$} & 326.20 & {$[\mathrm{~W}]$} & \\
\hline Bottom Power Supply Rear & 10.66 & [V] & & & & & \\
\hline N4 & 26.00 & {$[\mathrm{~V}]$} & 2.22 & {$[\mathrm{~A}]$} & 57.72 & & \\
\hline N3 & 26.00 & [V] & 1.57 & {$[\mathrm{~A}]$} & 40.82 & & Power Comparison \\
\hline Ciculation Heater & 114.00 & {$[\mathrm{~V}]$} & 16.00 & {$[\mathrm{~A}]$} & 2364.70 & {$[\mathrm{~W}]$} & 3384.70 \\
\hline Strip Heaters & 197.90 & [V] & 24.60 & {$[\mathrm{~A}]$} & 4868.34 & {$[\mathrm{~W}]$} & 6656.00 \\
\hline
\end{tabular}

\begin{tabular}{|c|c|c|}
\hline Device & Reading & Units \\
\hline Low Flow Meter & 0.108 & {$[\mathrm{gpm}]$} \\
\hline High Flow Meter & 0.99 & {$[\mathrm{gpm}]$} \\
\hline LFE Manometer & 2.78 & {$\left[\mathrm{inH}_{2} \mathrm{O}\right]$} \\
\hline Cabinet Inlet & 0.16 & {$\left[\mathrm{inH}_{2} \mathrm{O}\right]$} \\
\hline Before HX & 0.32 & {$\left[\mathrm{inH}_{2} \mathrm{O}\right]$} \\
\hline After HX & 0.68 & {$\left[\mathrm{inH}_{2} \mathrm{O}\right]$} \\
\hline After Fans & 0.50 & {$\left[\mathrm{inH}_{2} \mathrm{O}\right]$} \\
\hline Circulation Heater & 18.42 & {$[\mathrm{~mA}]$} \\
\hline Strip Heaters & 20.00 & {$[\mathrm{~mA}]$} \\
\hline Fan Speed & 180.00 & {$[\mathrm{~Hz}]$} \\
\hline
\end{tabular}

0.19

\begin{tabular}{|c|c|c|c|c|c|c|c|c|c|}
\hline Terminal Blocks & Voltage & & Current (Black) & & & Power (black) & & Total Power & \\
\hline Main Bus & 22.60 & [V] & & & & & & & \\
\hline Popeye Test (N3\&N4) & 25.90 & {$[\mathrm{~V}]$} & 10.80 & {$[A]$} & 3 & 93.24 & {$[\mathrm{~W}]$} & \multirow{6}{*}{751.29} & \multirow{6}{*}{$\begin{array}{l}\text { a } \\
\overline{0} \\
\overline{3} \\
0 \\
\frac{0}{0} \\
\vdots \\
0 \\
0 \\
\circ \\
\circ\end{array}$} \\
\hline $20 \mathrm{~V} 1$ (Top) & 22.50 & {$[\mathrm{~V}]$} & 18.40 & {$[A]$} & 3 & 138.00 & {$[W]$} & & \\
\hline 20V2 (Bottom) & 22.50 & [V] & 20.50 & {$[A]$} & 4 & 115.31 & {$[\mathrm{~W}]$} & & \\
\hline Popeye Heater (Q) & 14.39 & {$[\mathrm{~V}]$} & 38.20 & {$[A]$} & 2 & 274.85 & {$[\mathrm{~W}]$} & & \\
\hline Spinach Test (M3\&M4) & 17.80 & {$[\mathrm{~V}]$} & 9.20 & {$[A]$} & 4 & 40.94 & {$[\mathrm{~W}]$} & & \\
\hline $15 \mathrm{~V}$ & 15.47 & {$[\mathrm{~V}]$} & 23.00 & {$[\mathrm{~A}]$} & 4 & 88.95 & {$[\mathrm{~W}]$} & & \\
\hline Spinach Heater/Main Bus (S) & 10.34 & [V] & 57.50 & {$[\mathrm{~A}]$} & 4 & 148.64 & {$[\mathrm{~W}]$} & \multirow{5}{*}{289.74} & \multirow{5}{*}{ 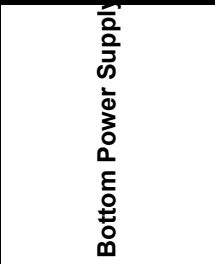 } \\
\hline 10V1 (Top) & 10.32 & [V] & 5.70 & {$[A]$} & 4 & 14.71 & {$[\mathrm{~W}]$} & & \\
\hline 10V2 (Top) & 10.32 & {$[\mathrm{~V}]$} & 6.80 & {$[A]$} & 4 & 17.54 & {$[W]$} & & \\
\hline 10V3 (Bottom) & 10.27 & [V] & 46.30 & {$[\mathrm{~A}]$} & 5 & 95.10 & {$[\mathrm{~W}]$} & & \\
\hline \multirow[t]{2}{*}{$5 \mathrm{~V}$} & 5.23 & {$[\mathrm{~V}]$} & 18.40 & {$[\mathrm{~A}]$} & 7 & 13.75 & {$[\mathrm{~W}]$} & & \\
\hline & & & & & & & & 1041.03 & Test Board Total \\
\hline
\end{tabular}




\begin{tabular}{|c|c|c|}
\hline Date & March 12th & 2007 \\
\hline Start Time & $2: 05$ & $\mathrm{pm}$ \\
\hline Ambient Temp. & 33.00 & ${ }^{\circ} \mathrm{C}$ \\
\hline Barometer Pressure & 29.96 & inHg \\
\hline
\end{tabular}

Comments: Fans running at $25 \%$ duty cycle $100 \%$

power and $100 \%$ liquid flow rate

\begin{tabular}{|c|c|c|c|c|c|c|c|}
\hline Device & Voltage & & Current & & Power & & \\
\hline Top Power Supply Display & 23.00 & {$[\mathrm{~V}]$} & 40.50 & {$[\mathrm{~A}]$} & 931.50 & {$[\mathrm{~W}]$} & \\
\hline Top Power Supply Rear & 23.00 & [V] & & & & & \\
\hline Bottom Power Supply Display & 10.66 & {$[\mathrm{~V}]$} & 30.50 & {$[\mathrm{~A}]$} & 325.13 & {$[\mathrm{~W}]$} & \\
\hline Bottom Power Supply Rear & 10.66 & [V] & & & & & \\
\hline N4 & 26.00 & {$[\mathrm{~V}]$} & 2.16 & {$[\mathrm{~A}]$} & 56.16 & & \\
\hline N3 & 26.00 & [V] & 1.53 & {$[\mathrm{~A}]$} & 39.78 & & Power Comparison \\
\hline Ciculation Heater & 113.40 & {$[\mathrm{~V}]$} & 16.00 & {$[\mathrm{~A}]$} & 2275.44 & {$[\mathrm{~W}]$} & 3344.80 \\
\hline Strip Heaters & 197.30 & [V] & 25.00 & {$[\mathrm{~A}]$} & 4932.50 & {$[\mathrm{~W}]$} & 6656.00 \\
\hline
\end{tabular}

\begin{tabular}{|c|c|c|}
\hline Device & Reading & Units \\
\hline Low Flow Meter & 0.092 & {$[\mathrm{gpm}]$} \\
\hline High Flow Meter & 0.92 & {$[\mathrm{gpm}]$} \\
\hline LFE Manometer & 2.08 & {$\left[\mathrm{inH}_{2} \mathrm{O}\right]$} \\
\hline Cabinet Inlet & 0.10 & {$\left[\mathrm{inH}_{2} \mathrm{O}\right]$} \\
\hline Before HX & 0.20 & {$\left[\mathrm{inH}_{2} \mathrm{O}\right]$} \\
\hline After HX & 0.43 & {$\left[\mathrm{inH}_{2} \mathrm{O}\right]$} \\
\hline After Fans & 0.29 & {$\left[\mathrm{inH}_{2} \mathrm{O}\right]$} \\
\hline Circulation Heater & 18.25 & {$[\mathrm{~mA}]$} \\
\hline Strip Heaters & 20.00 & {$[\mathrm{~mA}]$} \\
\hline Fan Speed & 139.00 & {$[\mathrm{~Hz}]$} \\
\hline
\end{tabular}

0.11

\begin{tabular}{|c|c|c|c|c|c|c|c|c|c|}
\hline Terminal Blocks & Voltage & & Current (Black) & & & Power (black) & & Total Power & \\
\hline Main Bus & 22.60 & [V] & & & & & & & \\
\hline Popeye Test (N3\&N4) & 26.00 & {$[\mathrm{~V}]$} & 10.50 & {$[A]$} & 3 & 91.00 & {$[\mathrm{~W}]$} & \multirow{6}{*}{755.89} & \multirow{6}{*}{$\begin{array}{l}\text { a } \\
\overline{0} \\
\overline{3} \\
0 \\
\frac{0}{0} \\
\vdots \\
0 \\
0 \\
\circ \\
\circ\end{array}$} \\
\hline $20 \mathrm{~V} 1$ (Top) & 22.50 & {$[\mathrm{~V}]$} & 18.20 & {$[A]$} & 3 & 136.50 & {$[W]$} & & \\
\hline 20V2 (Bottom) & 22.50 & [V] & 20.50 & {$[A]$} & 4 & 115.31 & {$[\mathrm{~W}]$} & & \\
\hline Popeye Heater (Q) & 14.34 & {$[\mathrm{~V}]$} & 38.70 & {$[A]$} & 2 & 277.48 & {$[\mathrm{~W}]$} & & \\
\hline Spinach Test (M3\&M4) & 17.90 & {$[\mathrm{~V}]$} & 9.60 & {$[A]$} & 4 & 42.96 & {$[\mathrm{~W}]$} & & \\
\hline $15 \mathrm{~V}$ & 15.44 & {$[\mathrm{~V}]$} & 24.00 & {$[\mathrm{~A}]$} & 4 & 92.64 & {$[\mathrm{~W}]$} & & \\
\hline Spinach Heater/Main Bus (S) & 10.33 & [V] & 57.50 & {$[\mathrm{~A}]$} & 4 & 148.49 & {$[\mathrm{~W}]$} & \multirow{5}{*}{290.45} & \multirow{5}{*}{ 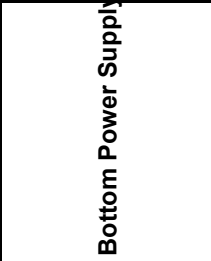 } \\
\hline 10V1 (Top) & 10.31 & [V] & 5.70 & {$[A]$} & 4 & 14.69 & {$[\mathrm{~W}]$} & & \\
\hline 10V2 (Top) & 10.31 & {$[\mathrm{~V}]$} & 6.90 & {$[A]$} & 4 & 17.78 & {$[W]$} & & \\
\hline 10V3 (Bottom) & 10.27 & [V] & 46.50 & {$[\mathrm{~A}]$} & 5 & 95.51 & {$[\mathrm{~W}]$} & & \\
\hline \multirow[t]{2}{*}{$5 \mathrm{~V}$} & 5.23 & {$[\mathrm{~V}]$} & 18.70 & {$[\mathrm{~A}]$} & 7 & 13.97 & {$[\mathrm{~W}]$} & & \\
\hline & & & & & & & & 1046.34 & Test Board Total \\
\hline
\end{tabular}




\begin{tabular}{|c|c|c|}
\hline Date & March 11th & 2007 \\
\hline Start Time & $3: 45$ & $\mathrm{pm}$ \\
\hline Ambient Temp. & 26.10 & ${ }^{\circ} \mathrm{C}$ \\
\hline Barometer Pressure & 29.91 & $\mathrm{inHg}$ \\
\hline
\end{tabular}

\begin{tabular}{|c|c|c|c|c|c|c|c|}
\hline Device & Voltage & & Current & & Power & & \\
\hline Top Power Supply Display & 23.00 & [V] & 40.80 & {$[\mathrm{~A}]$} & 938.40 & {$[\mathrm{~W}]$} & \\
\hline Top Power Supply Rear & 23.00 & [V] & & & & & \\
\hline Bottom Power Supply Display & 10.66 & {$[\mathrm{~V}]$} & 30.60 & {$[\mathrm{~A}]$} & 326.20 & {$[\mathrm{~W}]$} & \\
\hline Bottom Power Supply Rear & 10.66 & [V] & & & & & \\
\hline N4 & 26.00 & {$[\mathrm{~V}]$} & 2.26 & {$[\mathrm{~A}]$} & 58.76 & & \\
\hline N3 & 26.00 & [V] & 1.60 & {$[\mathrm{~A}]$} & 41.60 & & Power Comparison \\
\hline Ciculation Heater & 114.00 & {$[\mathrm{~V}]$} & 12.30 & {$[\mathrm{~A}]$} & 1957.73 & {$[\mathrm{~W}]$} & 3185.18 \\
\hline Strip Heaters & 197.80 & [V] & 23.90 & {$[\mathrm{~A}]$} & 4727.42 & {$[\mathrm{~W}]$} & 6656.00 \\
\hline
\end{tabular}

Comments: $75 \%$ Liquid Flow Rate with 100\% Fan Duty

Cycle and $100 \%$ Supplied Power

\begin{tabular}{|c|c|c|c|c|c|c|c|c|c|}
\hline Terminal Blocks & Voltage & & Current (Black) & & & Power (black) & & Total Power & \\
\hline Main Bus & 22.60 & {$[\mathrm{~V}]$} & & & & & & & \\
\hline Popeye Test (N3\&N4) & 26.00 & {$[\mathrm{~V}]$} & 11.10 & {$[\mathrm{~A}]$} & 3 & 96.20 & {$[\mathrm{~W}]$} & \multirow{6}{*}{761.92} & \multirow{6}{*}{ 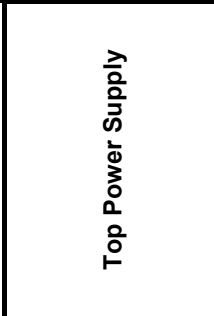 } \\
\hline $20 \mathrm{~V} 1$ (Top) & 22.50 & [V] & 18.70 & {$[\mathrm{~A}]$} & 3 & 140.25 & {$[\mathrm{~W}]$} & & \\
\hline 20V2 (Bottom) & 22.50 & [V] & 21.00 & {$[\mathrm{~A}]$} & 4 & 118.13 & \multirow{2}{*}{$\frac{w]}{w]}$} & & \\
\hline Popeye Heater (Q) & 14.38 & [V] & 38.10 & {$[\mathrm{~A}]$} & 2 & 273.94 & & & \\
\hline Spinach Test (M3\&M4) & 17.74 & {$[\mathrm{~V}]$} & 9.60 & {$[\mathrm{~A}]$} & 4 & 42.58 & {$[\mathrm{~W}]$} & & \\
\hline $15 \mathrm{~V}$ & 15.46 & {$[\mathrm{~V}]$} & 23.50 & {$[\mathrm{~A}]$} & 4 & 90.83 & {$[\mathrm{~W}]$} & & \\
\hline Spinach Heater/Main Bus (S) & 10.35 & {$[\mathrm{~V}]$} & 56.90 & {$[\mathrm{~A}]$} & 4 & 147.23 & {$[\mathrm{~W}]$} & \multirow{5}{*}{287.52} & \multirow{5}{*}{ 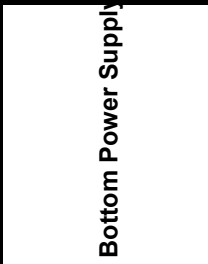 } \\
\hline 10V1 (Top) & 10.31 & [V] & 5.90 & {$[\mathrm{~A}]$} & 4 & 15.21 & {$[\mathrm{~W}]$} & & \\
\hline 10V2 (Top) & 10.32 & {$[\mathrm{~V}]$} & 6.90 & {$[\mathrm{~A}]$} & 4 & 17.80 & {$[\mathrm{~W}]$} & & \\
\hline 10V3 (Bottom) & 10.27 & [V] & 45.50 & {$[\mathrm{~A}]$} & 5 & 93.46 & {$[\mathrm{~W}]$} & & \\
\hline \multirow[t]{2}{*}{$5 \mathrm{~V}$} & 5.23 & {$[\mathrm{~V}]$} & 18.50 & {$[\mathrm{~A}]$} & 7 & 13.82 & {$[\mathrm{~W}]$} & & \\
\hline & & & & & & & & 1049.43 & Test Board Total \\
\hline
\end{tabular}

\begin{tabular}{|c|c|c|}
\hline Device & Reading & Units \\
\hline Low Flow Meter & 0.092 & {$[\mathrm{gpm}]$} \\
\hline High Flow Meter & 0.73 & {$[\mathrm{gpm}]$} \\
\hline LFE Manometer & 3.80 & {$\left[\mathrm{inH}_{2} \mathrm{O}\right]$} \\
\hline Cabinet Inlet & 0.38 & {$\left[\mathrm{inH}_{2} \mathrm{O}\right]$} \\
\hline Before HX & 0.64 & {$\left[\mathrm{inH}_{2} \mathrm{O}\right]$} \\
\hline After HX & 1.20 & {$\left[\mathrm{inH}_{2} \mathrm{O}\right]$} \\
\hline After Fans & 0.89 & {$\left[\mathrm{inH}_{2} \mathrm{O}\right]$} \\
\hline Circulation Heater & 17.57 & {$[\mathrm{~mA}]$} \\
\hline Strip Heaters & 20.00 & {$[\mathrm{~mA}]$} \\
\hline Fan Speed & 240.00 & {$[\mathrm{~Hz}]$} \\
\hline
\end{tabular}

0.37 


\begin{tabular}{|c|c|c|}
\hline Date & March 11th & 2007 \\
\hline Start Time & $4: 20$ & $\mathrm{pm}$ \\
\hline Ambient Temp. & 32.00 & ${ }^{\circ} \mathrm{C}$ \\
\hline Barometer Pressure & 29.91 & $\mathrm{inHg}$ \\
\hline
\end{tabular}

Comments: $50 \%$ Liquid Flow Rate and 100\% Fan Duty

Cycle with $100 \%$ Supplied Power

\begin{tabular}{|c|c|c|c|c|c|c|c|}
\hline Device & Voltage & & Current & & Power & & \\
\hline Top Power Supply Display & 23.00 & {$[\mathrm{~V}]$} & 40.80 & {$[\mathrm{~A}]$} & 938.40 & {$[\mathrm{~W}]$} & \\
\hline Top Power Supply Rear & 23.00 & [V] & & & & & \\
\hline Bottom Power Supply Display & 10.66 & {$[\mathrm{~V}]$} & 30.60 & {$[\mathrm{~A}]$} & 326.20 & {$[\mathrm{~W}]$} & \\
\hline Bottom Power Supply Rear & 10.66 & [V] & & & & & \\
\hline N4 & 26.00 & {$[\mathrm{~V}]$} & 2.22 & {$[A]$} & 57.72 & & \\
\hline N3 & 26.00 & {$[\mathrm{~V}]$} & 1.58 & {$[\mathrm{~A}]$} & 41.08 & & Power Comparison \\
\hline Ciculation Heater & 115.00 & {$[\mathrm{~V}]$} & 10.10 & {$[\mathrm{~A}]$} & 1124.07 & {$[\mathrm{~W}]$} & 2523.27 \\
\hline Strip Heaters & 197.50 & {$[\mathrm{~V}]$} & 23.90 & {$[\mathrm{~A}]$} & 4720.25 & {$[\mathrm{~W}]$} & 6656.00 \\
\hline
\end{tabular}

\begin{tabular}{|c|c|c|}
\hline Device & Reading & Units \\
\hline Low Flow Meter & 0.059 & {$[\mathrm{gpm}]$} \\
\hline High Flow Meter & 0.49 & {$[\mathrm{gpm}]$} \\
\hline LFE Manometer & 3.80 & {$\left[\mathrm{inH}_{2} \mathrm{O}\right]$} \\
\hline Cabinet Inlet & 0.39 & {$\left[\mathrm{inH}_{2} \mathrm{O}\right]$} \\
\hline Before HX & 0.66 & {$\left[\mathrm{inH}_{2} \mathrm{O}\right]$} \\
\hline After HX & 1.20 & {$\left[\mathrm{inH}_{2} \mathrm{O}\right]$} \\
\hline After Fans & 0.87 & {$\left[\mathrm{inH}_{2} \mathrm{O}\right]$} \\
\hline Circulation Heater & 14.75 & {$[\mathrm{~mA}]$} \\
\hline Strip Heaters & 20.00 & {$[\mathrm{~mA}]$} \\
\hline Fan Speed & 240.00 & {$[\mathrm{~Hz}]$} \\
\hline
\end{tabular}

\begin{tabular}{|c|c|c|c|c|c|c|c|c|c|}
\hline Terminal Blocks & Voltage & & Current (Black) & & & Power (black) & & Total Power & \\
\hline Main Bus & 22.60 & {$[\mathrm{~V}]$} & & & & & & & \\
\hline Popeye Test (N3\&N4) & 26.00 & {$[\mathrm{~V}]$} & 10.90 & {$[\mathrm{~A}]$} & 3 & 94.47 & {$[\mathrm{~W}]$} & \multirow{6}{*}{763.92} & \multirow{6}{*}{ 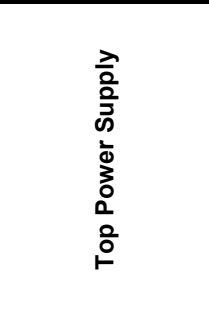 } \\
\hline $20 \mathrm{~V} 1$ (Top) & 22.50 & {$[\mathrm{~V}]$} & 18.60 & {$[\mathrm{~A}]$} & 3 & 139.50 & {$[\mathrm{~W}]$} & & \\
\hline 20V2 (Bottom) & 22.50 & {$[\mathrm{~V}]$} & 20.90 & {$[\mathrm{~A}]$} & 4 & 117.56 & {$[\mathrm{~W}]$} & & \\
\hline Popeye Heater (Q) & 14.37 & {$[\mathrm{~V}]$} & 38.70 & {$[\mathrm{~A}]$} & 2 & 278.06 & {$[\mathrm{~W}]$} & & \\
\hline Spinach Test (M3\&M4) & 17.78 & {$[\mathrm{~V}]$} & 9.70 & {$[\mathrm{~A}]$} & 4 & 43.12 & {$[\mathrm{~W}]$} & & \\
\hline $15 \mathrm{~V}$ & 15.46 & {$[\mathrm{~V}]$} & 23.60 & {$[\mathrm{~A}]$} & 4 & 91.21 & {$[\mathrm{~W}]$} & & \\
\hline Spinach Heater/Main Bus (S) & 10.35 & {$[\mathrm{~V}]$} & 57.20 & {$[\mathrm{~A}]$} & 4 & 148.01 & {$[\mathrm{~W}]$} & \multirow{5}{*}{290.85} & \multirow{5}{*}{$\begin{array}{l}\overline{\bar{\alpha}} \\
\frac{2}{3} \\
0 \\
\frac{0}{0} \\
3 \\
0 \\
0 \\
\varepsilon \\
0 \\
0 \\
0 \\
0\end{array}$} \\
\hline 10V1 (Top) & 10.32 & {$[\mathrm{~V}]$} & 6.00 & {$[\mathrm{~A}]$} & 4 & 15.48 & {$[\mathrm{~W}]$} & & \\
\hline 10V2 (Top) & 10.31 & {$[\mathrm{~V}]$} & 7.20 & {$[\mathrm{~A}]$} & 4 & 18.56 & {$[\mathrm{~W}]$} & & \\
\hline 10V3 (Bottom) & 10.27 & {$[\mathrm{~V}]$} & 46.10 & {$[\mathrm{~A}]$} & 5 & 94.69 & {$[\mathrm{~W}]$} & & \\
\hline \multirow[t]{2}{*}{$5 \mathrm{~V}$} & 5.23 & {$[\mathrm{~V}]$} & 18.90 & {$[\mathrm{~A}]$} & 7 & 14.12 & {$[\mathrm{~W}]$} & & \\
\hline & & & & & & & & 1054.77 & Test Board Total \\
\hline
\end{tabular}




\begin{tabular}{|c|c|c|}
\hline Date & March 11th & 2007 \\
\hline Start Time & $6: 35$ & $\mathrm{pm}$ \\
\hline Ambient Temp. & 31.50 & ${ }^{\circ} \mathrm{C}$ \\
\hline Barometer Pressure & 29.91 & $\mathrm{inHg}$ \\
\hline
\end{tabular}

Comments: $75 \%$ Liquid Flow Rate and 75\% Fan Duty Cycle with 100\% Supplied Power.

\begin{tabular}{|c|c|c|}
\hline Device & Reading & Units \\
\hline Low Flow Meter & 0.090 & {$[\mathrm{gpm}]$} \\
\hline High Flow Meter & 0.73 & {$[\mathrm{gpm}]$} \\
\hline LFE Manometer & 3.58 & {$\left[\mathrm{inH}_{2} \mathrm{O}\right]$} \\
\hline Cabinet Inlet & 0.31 & {$\left[\mathrm{inH}_{2} \mathrm{O}\right]$} \\
\hline Before HX & 0.52 & {$\left[\mathrm{inH}_{2} \mathrm{O}\right]$} \\
\hline After HX & 1.02 & {$\left[\mathrm{inH}_{2} \mathrm{O}\right]$} \\
\hline After Fans & 0.75 & {$\left[\mathrm{inH}_{2} \mathrm{O}\right]$} \\
\hline Circulation Heater & 17.26 & {$[\mathrm{~mA}]$} \\
\hline Strip Heaters & 20.00 & {$[\mathrm{~mA}]$} \\
\hline Fan Speed & 219.00 & {$[\mathrm{~Hz}]$} \\
\hline
\end{tabular}

0.31

\begin{tabular}{|c|c|c|c|c|c|c|c|c|}
\hline Device & Voltage & & Current & & \multicolumn{2}{|c|}{ Power } & \\
\hline Top Power Supply Display & 23.00 & {$[\mathrm{~V}]$} & 41.10 & {$[\mathrm{~A}]$} & \multicolumn{2}{|c|}{945.30} & {$[\mathrm{~W}]$} \\
\hline Top Power Supply Rear & 23.00 & {$[\mathrm{~V}]$} & \multicolumn{3}{|c|}{} \\
\hline Bottom Power Supply Display & 10.65 & {$[\mathrm{~V}]$} & 30.50 & {$[\mathrm{~A}]$} & & 324.83 & {$[\mathrm{~W}]$} & \\
\hline Bottom Power Supply Rear & 10.65 & {$[\mathrm{~V}]$} & & & & \\
\hline N4 & 26.00 & {$[\mathrm{~V}]$} & 2.26 & {$[\mathrm{~A}]$} & 58.76 & & \\
\hline N3 & 26.00 & {$[\mathrm{~V}]$} & 1.60 & {$[\mathrm{~A}]$} & 41.60 & & Power Comparison \\
\hline Ciculation Heater & 114.00 & {$[\mathrm{~V}]$} & 12.60 & {$[\mathrm{~A}]$} & 1831.76 & {$[\mathrm{~W}]$} & 3112.42 \\
\hline Strip Heaters & 197.70 & {$[\mathrm{~V}]$} & 24.30 & {$[\mathrm{~A}]$} & 4804.11 & {$[\mathrm{~W}]$} & 6656.00 \\
\hline
\end{tabular}

\begin{tabular}{|c|c|c|c|c|c|c|c|c|c|}
\hline Terminal Blocks & Voltage & & Current (Black) & & & Power (black) & & Total Power & \\
\hline Main Bus & 22.70 & [V] & & & & & & & \\
\hline Popeye Test (N3\&N4) & 26.00 & {$[\mathrm{~V}]$} & 11.20 & {$[A]$} & 3 & 97.07 & {$[\mathrm{~W}]$} & \multirow{6}{*}{771.75} & \multirow{6}{*}{$\begin{array}{l}\text { a } \\
\overline{0} \\
\overline{3} \\
0 \\
\frac{0}{0} \\
\vdots \\
0 \\
0 \\
\circ \\
\circ\end{array}$} \\
\hline $20 \mathrm{~V} 1$ (Top) & 22.50 & {$[\mathrm{~V}]$} & 18.80 & {$[A]$} & 3 & 141.00 & {$[W]$} & & \\
\hline 20V2 (Bottom) & 22.50 & [V] & 20.90 & {$[A]$} & 4 & 117.56 & {$[\mathrm{~W}]$} & & \\
\hline Popeye Heater (Q) & 14.42 & {$[\mathrm{~V}]$} & 38.80 & {$[A]$} & 2 & 279.75 & {$[\mathrm{~W}]$} & & \\
\hline Spinach Test (M3\&M4) & 17.79 & {$[\mathrm{~V}]$} & 9.80 & {$[A]$} & 4 & 43.59 & {$[\mathrm{~W}]$} & & \\
\hline $15 \mathrm{~V}$ & 15.53 & {$[\mathrm{~V}]$} & 23.90 & {$[\mathrm{~A}]$} & 4 & 92.79 & {$[\mathrm{~W}]$} & & \\
\hline Spinach Heater/Main Bus (S) & 10.34 & [V] & 57.30 & {$[\mathrm{~A}]$} & 4 & 148.12 & {$[\mathrm{~W}]$} & \multirow{5}{*}{288.63} & \multirow{5}{*}{ 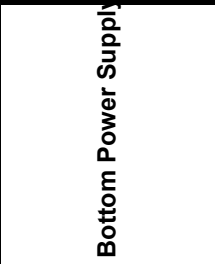 } \\
\hline 10V1 (Top) & 10.30 & [V] & 5.80 & {$[A]$} & 4 & 14.94 & {$[\mathrm{~W}]$} & & \\
\hline 10V2 (Top) & 10.30 & {$[\mathrm{~V}]$} & 6.90 & {$[A]$} & 4 & 17.77 & {$[W]$} & & \\
\hline 10V3 (Bottom) & 10.26 & [V] & 45.80 & {$[\mathrm{~A}]$} & 5 & 93.98 & {$[\mathrm{~W}]$} & & \\
\hline \multirow[t]{2}{*}{$5 \mathrm{~V}$} & 5.23 & {$[\mathrm{~V}]$} & 18.50 & {$[\mathrm{~A}]$} & 7 & 13.82 & {$[\mathrm{~W}]$} & & \\
\hline & & & & & & & & 1060.38 & Test Board Total \\
\hline
\end{tabular}




\begin{tabular}{|c|c|c|}
\hline Date & March 13th & 2007 \\
\hline Start Time & $7: 25$ & $\mathrm{pm}$ \\
\hline Ambient Temp. & 29.60 & ${ }^{\circ} \mathrm{C}$ \\
\hline Barometer Pressure & 29.96 & $\mathrm{inHg}$ \\
\hline
\end{tabular}

Comments: Test Chip at $125 \%$ Power with Ciculation Heater and Strip Heaters at $100 \%$ power. $100 \%$ Fan Duty cycle and 100\% Liquid Flow rater.

\begin{tabular}{|c|c|c|}
\hline Device & Reading & Units \\
\hline Low Flow Meter & 0.119 & {$[\mathrm{gpm}]$} \\
\hline High Flow Meter & 0.98 & {$[\mathrm{gpm}]$} \\
\hline LFE Manometer & 3.78 & {$\left[\mathrm{inH}_{2} \mathrm{O}\right]$} \\
\hline Cabinet Inlet & 0.38 & {$\left[\mathrm{inH}_{2} \mathrm{O}\right]$} \\
\hline Before HX & 0.63 & {$\left[\mathrm{inH}_{2} \mathrm{O}\right]$} \\
\hline After HX & 1.19 & {$\left[\mathrm{inH}_{2} \mathrm{O}\right]$} \\
\hline After Fans & 0.88 & {$\left[\mathrm{inH}_{2} \mathrm{O}\right]$} \\
\hline Circulation Heater & 20.00 & {$[\mathrm{~mA}]$} \\
\hline Strip Heaters & 20.00 & {$[\mathrm{~mA}]$} \\
\hline Fan Speed & 241.00 & {$[\mathrm{~Hz}]$} \\
\hline
\end{tabular}

0.35

\begin{tabular}{|c|c|c|c|c|c|c|c|c|}
\hline Device & Voltage & & Current & & \multicolumn{2}{|c|}{ Power } & \\
\hline Top Power Supply Display & 23.00 & {$[\mathrm{~V}]$} & 41.10 & {$[\mathrm{~A}]$} & \multicolumn{2}{|l|}{945.30} & {$[\mathrm{~W}]$} \\
\hline Top Power Supply Rear & 22.90 & {$[\mathrm{~V}]$} & \multicolumn{5}{|l|}{} \\
\hline Bottom Power Supply Display & 10.66 & {$[\mathrm{~V}]$} & 30.60 & {$[\mathrm{~A}]$} & & 326.20 & {$[\mathrm{~W}]$} \\
\hline Bottom Power Supply Rear & 10.66 & {$[\mathrm{~V}]$} & \multicolumn{5}{|l|}{} \\
\hline N4 & 30.10 & {$[\mathrm{~V}]$} & 2.54 & {$[\mathrm{~A}]$} & 76.45 & & \\
\hline N3 & 30.00 & {$[\mathrm{~V}]$} & 1.80 & {$[\mathrm{~A}]$} & 54.00 & & Power Comparison \\
\hline Ciculation Heater & 114.00 & {$[\mathrm{~V}]$} & 15.20 & {$[\mathrm{~A}]$} & 3424.30 & {$[\mathrm{~W}]$} & 3755.56 \\
\hline Strip Heaters & 197.80 & {$[\mathrm{~V}]$} & 25.30 & {$[\mathrm{~A}]$} & 5004.34 & {$[\mathrm{~W}]$} & 6656.00 \\
\hline
\end{tabular}

\begin{tabular}{|c|c|c|c|c|c|c|c|c|c|}
\hline Terminal Blocks & Voltage & & Current (Black) & & & Power (black) & & Total Power & \\
\hline Main Bus & 22.60 & {$[\mathrm{~V}]$} & & & & & & & \\
\hline Popeye Test (N3\&N4) & 30.10 & {$[\mathrm{~V}]$} & 12.30 & {$[A]$} & 3 & 123.41 & {$[\mathrm{~W}]$} & \multirow{6}{*}{801.19} & \multirow{6}{*}{ 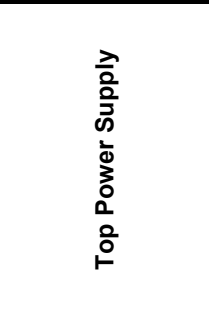 } \\
\hline $20 \mathrm{~V} 1$ (Top) & 22.50 & {$[\mathrm{~V}]$} & 18.60 & {$[A]$} & 3 & 139.50 & {$[\mathrm{~W}]$} & & \\
\hline 20V2 (Bottom) & 22.50 & {$[\mathrm{~V}]$} & 20.80 & {$[\mathrm{~A}]$} & 4 & 117.00 & \multirow{2}{*}{$\frac{w]}{w]}$} & & \\
\hline Popeye Heater (Q) & 14.32 & {$[\mathrm{~V}]$} & 38.70 & {$[\mathrm{~A}]$} & 2 & 277.09 & & & \\
\hline Spinach Test (M3\&M4) & 19.50 & {$[\mathrm{~V}]$} & 10.50 & {$[\mathrm{~A}]$} & 4 & 51.19 & {$[\mathrm{~W}]$} & & \\
\hline $15 \mathrm{~V}$ & 15.50 & {$[\mathrm{~V}]$} & 24.00 & {$[\mathrm{~A}]$} & 4 & 93.00 & {$[\mathrm{~W}]$} & & \\
\hline Spinach Heater/Main Bus (S) & 10.35 & {$[\mathrm{~V}]$} & 57.50 & {$[\mathrm{~A}]$} & 4 & 148.78 & {$[\mathrm{~W}]$} & \multirow{5}{*}{289.09} & \multirow{5}{*}{ 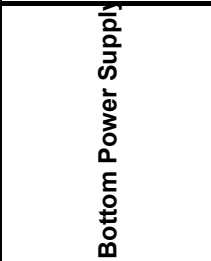 } \\
\hline 10V1 (Top) & 10.32 & {$[\mathrm{~V}]$} & 5.50 & {$[\mathrm{~A}]$} & 4 & 14.19 & {$[W]$} & & \\
\hline 10V2 (Top) & 10.31 & {$[\mathrm{~V}]$} & 6.60 & {$[\mathrm{~A}]$} & 4 & 17.01 & {$[W]$} & & \\
\hline 10V3 (Bottom) & 10.27 & {$[\mathrm{~V}]$} & 46.50 & {$[\mathrm{~A}]$} & 5 & 95.51 & {$[\mathrm{~W}]$} & & \\
\hline \multirow[t]{2}{*}{$5 \mathrm{~V}$} & 5.23 & {$[\mathrm{~V}]$} & 18.20 & {$[\mathrm{~A}]$} & 7 & 13.60 & {$[\mathrm{~W}]$} & & \\
\hline & & & & & & & & 1090.28 & Test Board Total \\
\hline
\end{tabular}




\begin{tabular}{|c|c|c|}
\hline Date & March 13th & 2007 \\
\hline Start Time & $7: 45$ & $\mathrm{pm}$ \\
\hline Ambient Temp. & 29.60 & ${ }^{\circ} \mathrm{C}$ \\
\hline Barometer Pressure & 29.96 & $\mathrm{inHg}$ \\
\hline
\end{tabular}

Comments: Test Chip at $125 \%$ Power with Ciculation

Heater and Strip Heaters at 100\% power. 75\% Fan Duty cycle and $100 \%$ Liquid Flow rater.

\begin{tabular}{|c|c|c|}
\hline Device & Reading & Units \\
\hline Low Flow Meter & 0.121 & {$[\mathrm{gpm}]$} \\
\hline High Flow Meter & 0.99 & {$[\mathrm{gpm}]$} \\
\hline LFE Manometer & 3.58 & {$\left[\mathrm{inH}_{2} \mathrm{O}\right]$} \\
\hline Cabinet Inlet & 0.31 & {$\left[\mathrm{inH}_{2} \mathrm{O}\right]$} \\
\hline Before HX & 0.54 & {$\left[\mathrm{inH}_{2} \mathrm{O}\right]$} \\
\hline After HX & 1.06 & {$\left[\mathrm{inH}_{2} \mathrm{O}\right]$} \\
\hline After Fans & 0.81 & {$\left[\mathrm{inH}_{2} \mathrm{O}\right]$} \\
\hline Circulation Heater & 20.00 & {$[\mathrm{~mA}]$} \\
\hline Strip Heaters & 20.00 & {$[\mathrm{~mA}]$} \\
\hline Fan Speed & 233.00 & {$[\mathrm{~Hz}]$} \\
\hline
\end{tabular}

0.32

\begin{tabular}{|c|c|c|c|c|c|c|c|c|}
\hline Device & Voltage & & Current & & \multicolumn{2}{|c|}{ Power } & \\
\hline Top Power Supply Display & 22.90 & {$[\mathrm{~V}]$} & 41.00 & {$[\mathrm{~A}]$} & 938.90 & {$[\mathrm{~W}]$} & \\
\hline Top Power Supply Rear & 22.90 & {$[\mathrm{~V}]$} & \multicolumn{5}{|l|}{} \\
\hline Bottom Power Supply Display & 10.66 & {$[\mathrm{~V}]$} & 30.60 & {$[\mathrm{~A}]$} & & 326.20 & {$[\mathrm{~W}]$} & \\
\hline Bottom Power Supply Rear & 10.66 & {$[\mathrm{~V}]$} & \multicolumn{5}{|l|}{} \\
\hline N4 & 30.10 & {$[\mathrm{~V}]$} & 2.53 & {$[\mathrm{~A}]$} & & 76.15 & & \\
\hline N3 & 30.00 & {$[\mathrm{~V}]$} & 1.79 & {$[\mathrm{~A}]$} & 53.70 & & Power Comparison \\
\hline Ciculation Heater & 114.00 & {$[\mathrm{~V}]$} & 15.40 & {$[\mathrm{~A}]$} & & 3424.30 & {$[\mathrm{~W}]$} & 3755.56 \\
\hline Strip Heaters & 197.80 & {$[\mathrm{~V}]$} & 25.50 & {$[\mathrm{~A}]$} & & 5043.90 & {$[\mathrm{~W}]$} & 6656.00 \\
\hline
\end{tabular}

\begin{tabular}{|c|c|c|c|c|c|c|c|c|c|}
\hline Terminal Blocks & Voltage & & Current (Black) & & & Power (black) & & Total Power & \\
\hline Main Bus & 22.50 & [V] & & & & & & & \\
\hline Popeye Test (N3\&N4) & 30.10 & [V] & 12.80 & {$[\mathrm{~A}]$} & 3 & 128.43 & {$[\mathrm{~W}]$} & \multirow{6}{*}{813.37} & \multirow{6}{*}{ 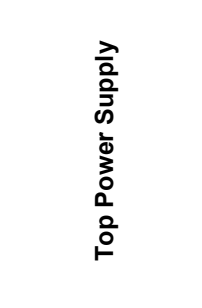 } \\
\hline $20 \mathrm{~V} 1$ (Top) & 22.40 & [V] & 18.90 & {$[\mathrm{~A}]$} & 3 & 141.12 & {$[\mathrm{~W}]$} & & \\
\hline 20V2 (Bottom) & 22.50 & [V] & 21.10 & {$[\mathrm{~A}]$} & 4 & 118.69 & \multirow{2}{*}{$\frac{[W]}{[W]}$} & & \\
\hline Popeye Heater (Q) & 14.33 & {$[\mathrm{~V}]$} & 38.90 & {$[\mathrm{~A}]$} & 2 & 278.72 & & & \\
\hline Spinach Test (M3\&M4) & 19.52 & [V] & 10.80 & {$[\mathrm{~A}]$} & 4 & 52.70 & {$[W]$} & & \\
\hline $15 \mathrm{~V}$ & 15.49 & {$[\mathrm{~V}]$} & 24.20 & {$[\mathrm{~A}]$} & 4 & 93.71 & {$[\mathrm{~W}]$} & & \\
\hline Spinach Heater/Main Bus (S) & 10.35 & {$[\mathrm{~V}]$} & 57.70 & {$[\mathrm{~A}]$} & 4 & 149.30 & {$[\mathrm{~W}]$} & \multirow{5}{*}{292.04} & \multirow{5}{*}{ 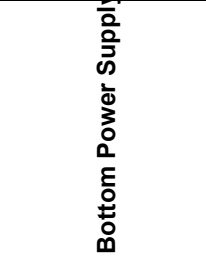 } \\
\hline 10V1 (Top) & 10.32 & {$[\mathrm{~V}]$} & 7.00 & {$[\mathrm{~A}]$} & 4 & 18.06 & {$[\mathrm{~W}]$} & & \\
\hline 10V2 (Top) & 10.32 & {$[\mathrm{~V}]$} & 5.60 & {$[\mathrm{~A}]$} & 4 & 14.45 & {$[\mathrm{~W}]$} & & \\
\hline 10V3 (Bottom) & 10.27 & {$[\mathrm{~V}]$} & 46.90 & {$[\mathrm{~A}]$} & 5 & 96.33 & {$[\mathrm{~W}]$} & & \\
\hline \multirow[t]{2}{*}{$5 \mathrm{~V}$} & 5.23 & [V] & 18.60 & {$[\mathrm{~A}]$} & 7 & 13.90 & {$[\mathrm{~W}]$} & & \\
\hline & & & & & & & & 1105.41 & Test Board Total \\
\hline
\end{tabular}


